\title{
Toward a Definition of High Expectations: Interpretive Case Studies of Selected Secondary Schools in West Virginia
}

David S. Tupper

West Virginia University

Follow this and additional works at: https://researchrepository.wvu.edu/etd

\section{Recommended Citation}

Tupper, David S., "Toward a Definition of High Expectations: Interpretive Case Studies of Selected Secondary Schools in West Virginia" (2011). Graduate Theses, Dissertations, and Problem Reports. 3550. https://researchrepository.wvu.edu/etd/3550

This Dissertation is protected by copyright and/or related rights. It has been brought to you by the The Research Repository @ WVU with permission from the rights-holder(s). You are free to use this Dissertation in any way that is permitted by the copyright and related rights legislation that applies to your use. For other uses you must obtain permission from the rights-holder(s) directly, unless additional rights are indicated by a Creative Commons license in the record and/ or on the work itself. This Dissertation has been accepted for inclusion in WVU Graduate Theses, Dissertations, and Problem Reports collection by an authorized administrator of The Research Repository @ WVU.

For more information, please contact researchrepository@mail.wvu.edu. 
Toward a Definition of High Expectations: Interpretive Case Studies of Selected Secondary Schools in West Virginia

David S. Tupper

\author{
Dissertation submitted to the \\ College of Human Resources \& Education \\ at West Virginia University \\ in partial fulfillment of the requirements \\ for the degree of
}

Doctor of Education

in

Educational Leadership Studies

\author{
Helen Hazi, Ph. D., Chair \\ Paul Chapman, Ph. D. \\ Martha Dean, Ed. D. \\ Adriane Williams, Ph. D. \\ Neal Shambaugh, Ph. D. \\ Department of Educational Leadership Studies
}

\title{
Morgantown, WV \\ 2011
}

Key Words: Teacher Expectancy, High Expectations, Effective Schools, School Effectiveness Research, Principal Leadership,

Qualitative Research

Copyright 2011 David S. Tupper 


\section{Abstract \\ Toward a Definition of High Expectations: Interpretive Case Studies \\ Of Selected Secondary Schools In West Virginia}

\section{David S. Tupper}

The purpose of this study was to examine the curricular, instructional and administrative practices that teachers and principals used in establishing high expectations from interpretive case studies of selected West Virginia secondary schools. A qualitative research design was used to focus on the specific practices that teachers and principals used at the three sites. The three sites were chosen using purposeful sampling with a unique attribute. The unique attribute was that each school had to have met adequate yearly progress (AYP) for four consecutive years. Data collection included interviews where a semi-structured interview format was used. Included in the data collection were classroom observations, school observations, document collection and field notes. It was the teachers and principals in each building who created the practices of high expectations unique to their values and beliefs. Each building was a microcosm of the community the teachers and principals were members of. Therefore, one unified definition cannot exist because of the lack of unified communities throughout West Virginia. However, this research found the existence of seven commonalities in schools that promoted a culture of high academic achievement and hence high expectations in selected West Virginia secondary schools. The commonalities found in this research were: (1) master schedule, (2) strong professional learning community, (3) course curriculum aligned to the state assessment tool, (4) teachers teaching the prescribed curriculum, (5) strong offering of advanced placement courses, (6) strong parental involvement/support, and (7) time where extra help/extra time is provided. 


\section{Acknowledgement}

I would like to start by thanking my parents, Clare and Barbara, because without them this whole thing would not have been possible. Their steadfast belief in me and unwavering support I will never forget. I hope that they are looking down from heaven at this very moment so that they, too, can see that I made it.

A special thank you goes to my Chairperson, Dr. Helen M. Hazi, for her support and guidance. Through the years, she often said that she did not know if she should be a cheerleader or kick me in the butt. I am glad she did both and knew when to distinguish which type of action to take.

Next, I would like to thank the teachers, staff and principals at the three schools for allowing me to be a part of their life for one full week. Being a part of the school culture for a week was what allowed this research to be full of rich data.

Finally, thank you to my children, Sarah, Anna, Eva, and Sophia, for putting everything on hold for the past five years. I know I was difficult to live with, but we got through it. Now maybe I will be able to stay awake through the evening news. Last but definitely not lease, to my wife, Barbara, for her perseverance as a single parent the past five years. Your patience and unconditional love has been greatly appreciated. I love you. 


\section{Table of Contents}

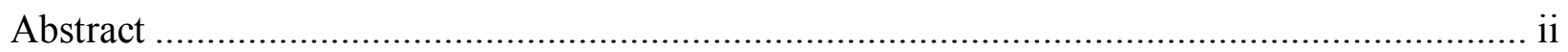

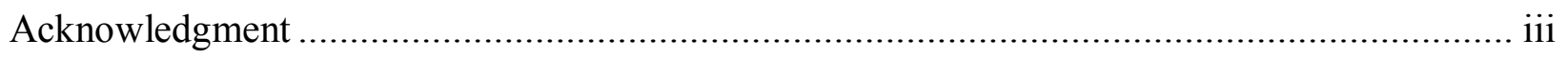

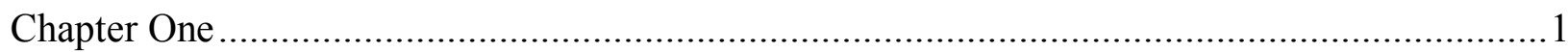

Introduction to The Study ............................................................................... 1

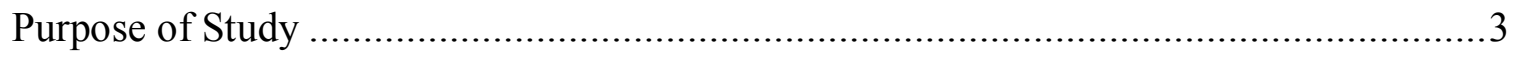

Research Questions .....................................................................................

Description of the Study ................................................................................

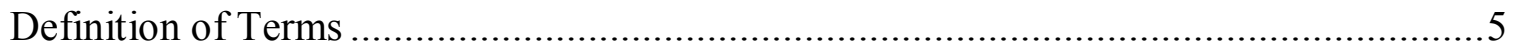

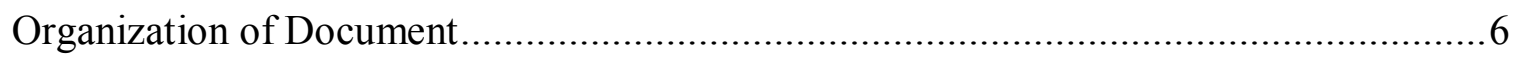

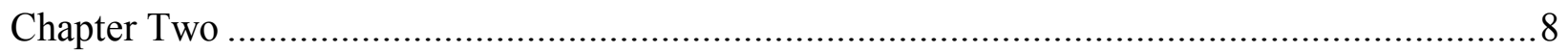

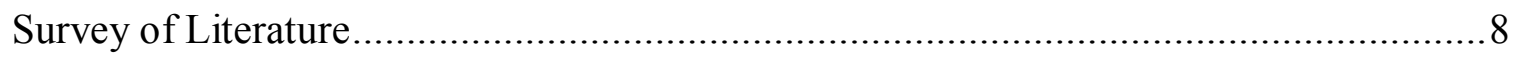

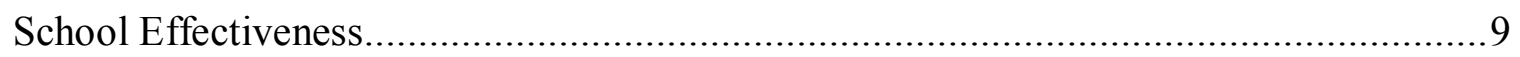

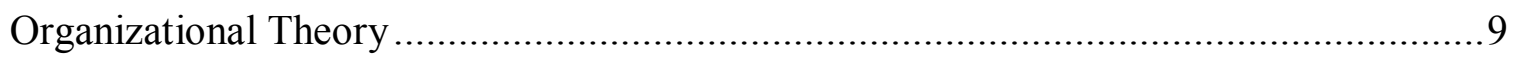

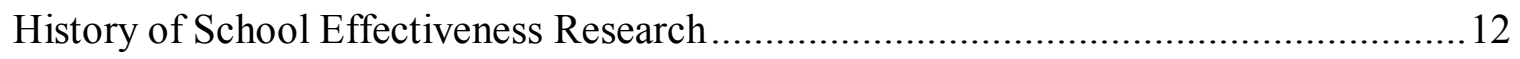

The Work of Ron Edmonds .......................................................................... 18

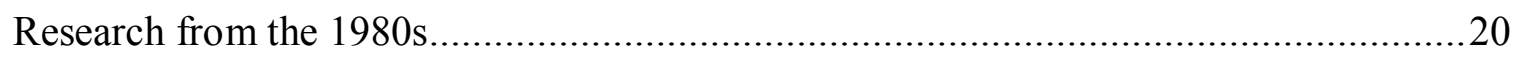

Critiques of Effective Schools Research ..........................................................22

History of Effective School Research in West Virginia ........................................25

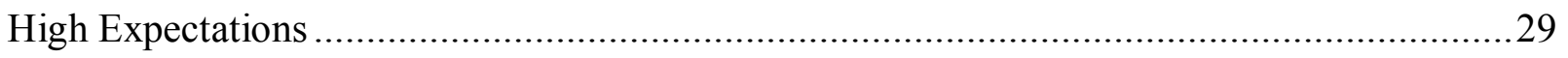

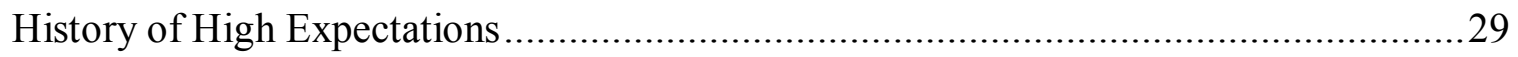

National Board Certified Teacher ...................................................................... 36

Principals and High Expectations...................................................................... 38 


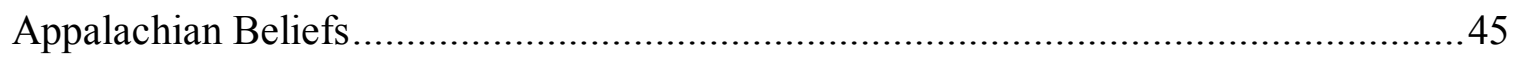

Defining High Expectations in West Virginia ............................................................48

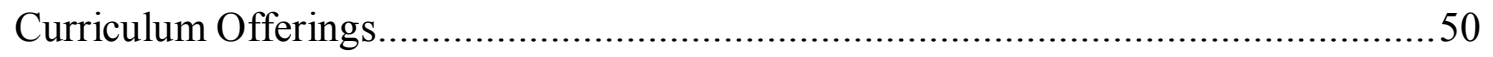

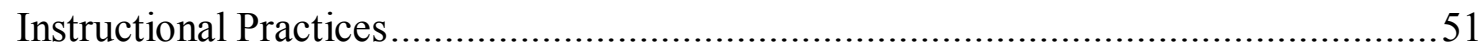

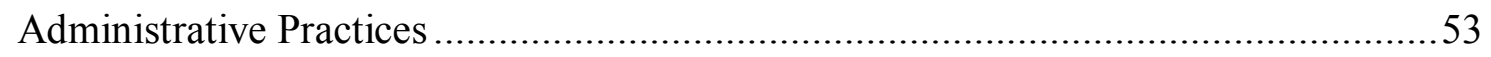

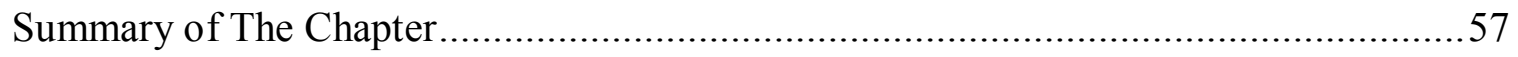

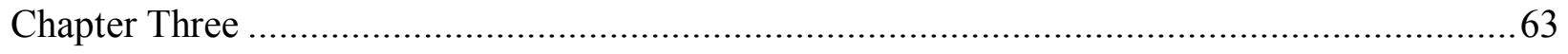

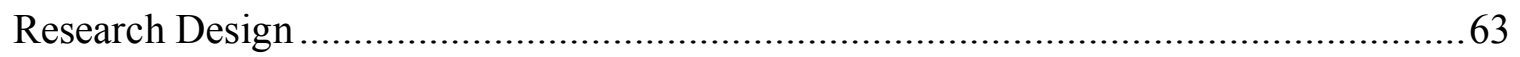

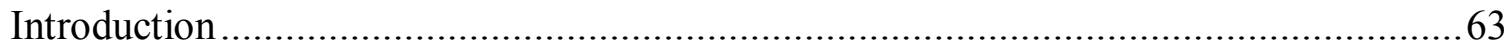

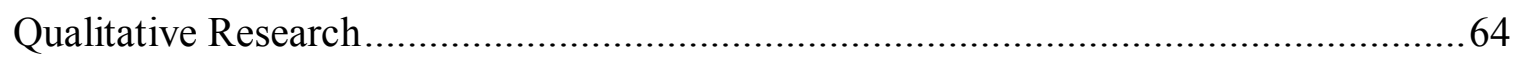

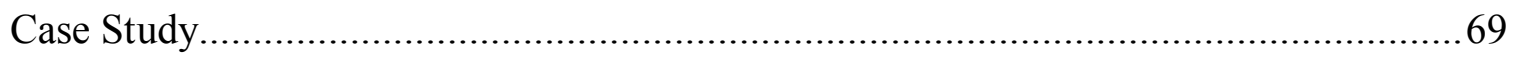

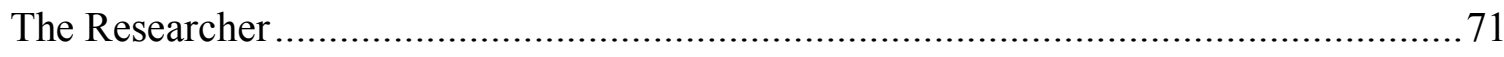

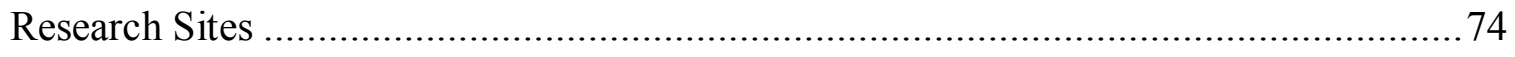

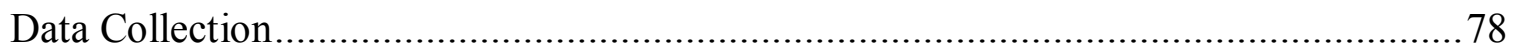

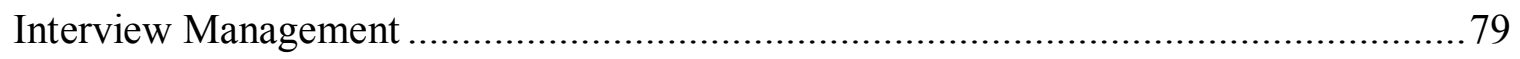

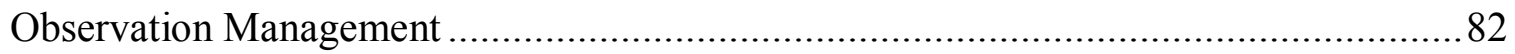

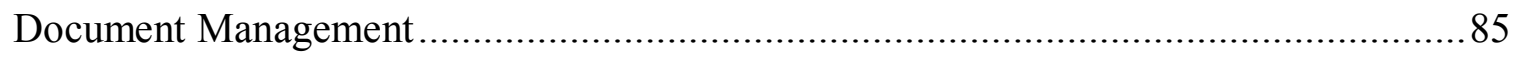

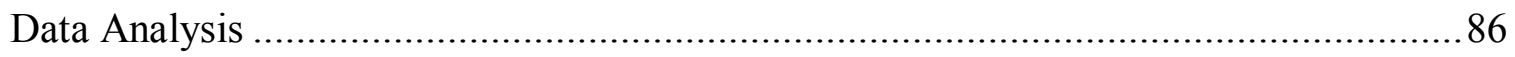

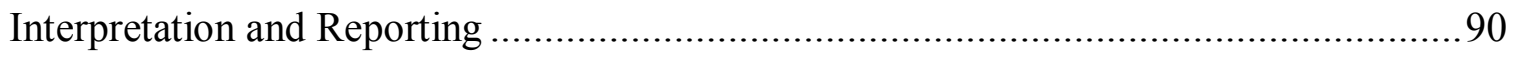

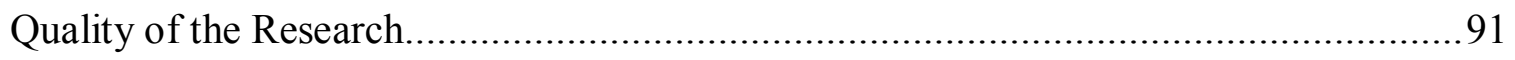

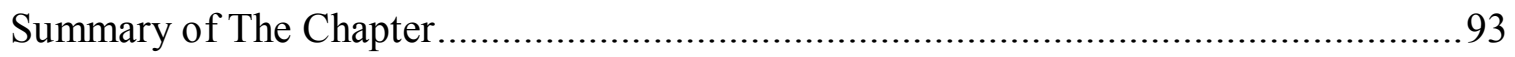

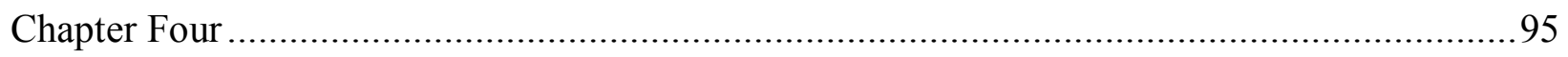

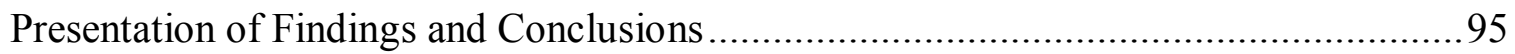




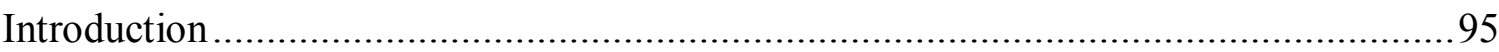

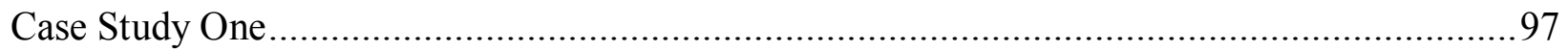

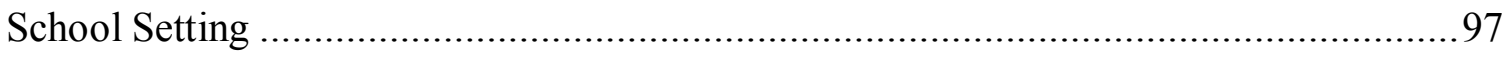

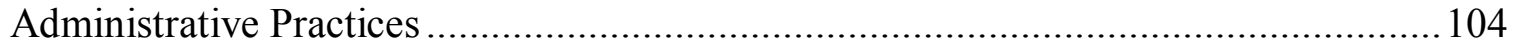

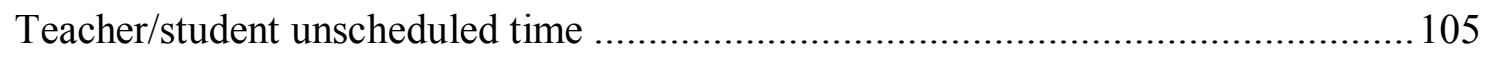

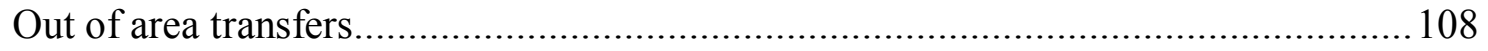

Principal use of behavioral data ........................................................................... 109

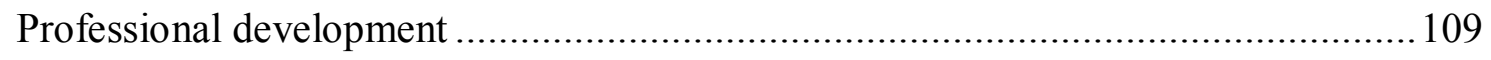

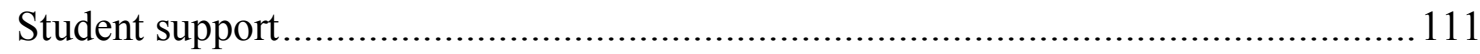

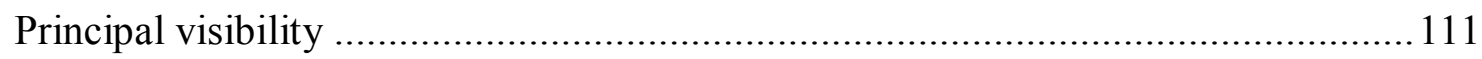

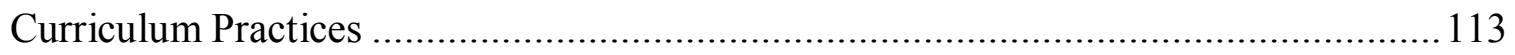

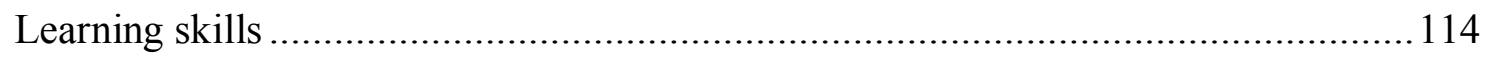

Advanced placement courses ............................................................................114

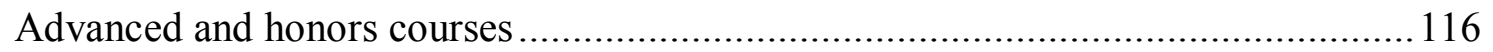

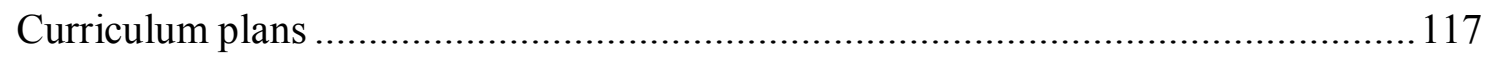

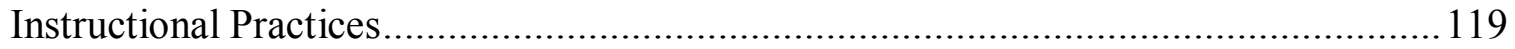

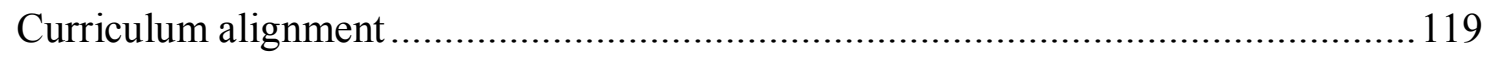

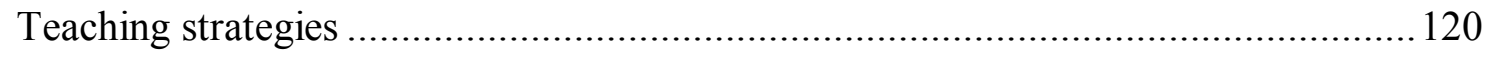

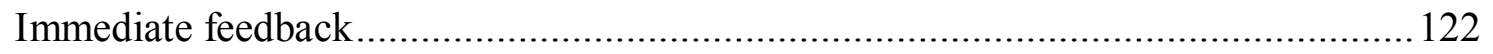

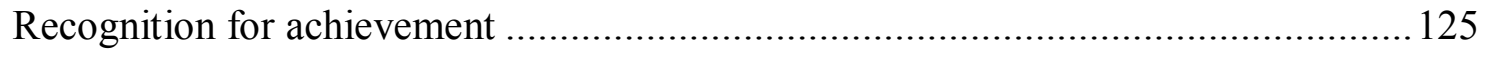

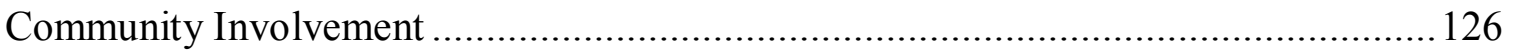

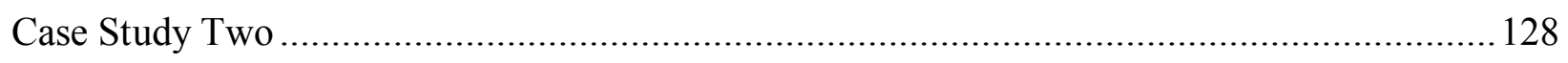

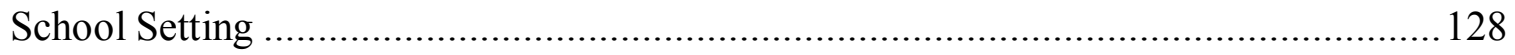




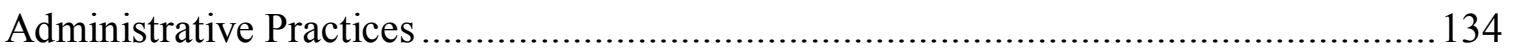

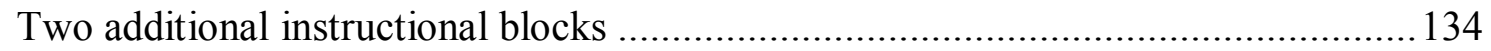

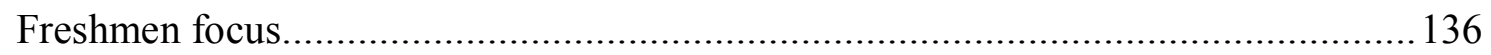

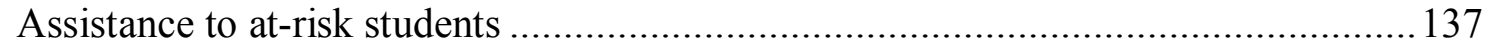

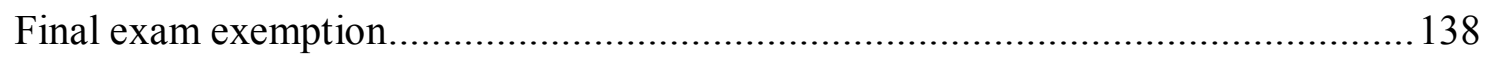

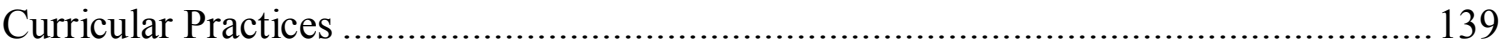

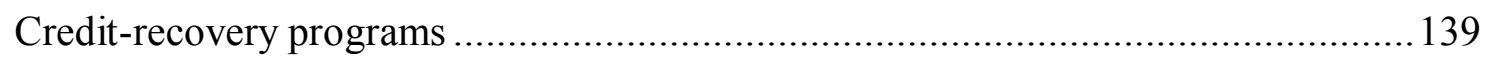

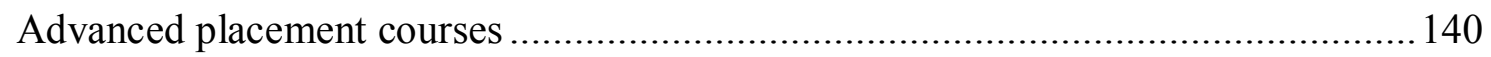

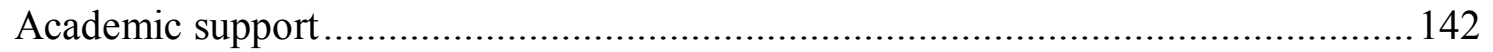

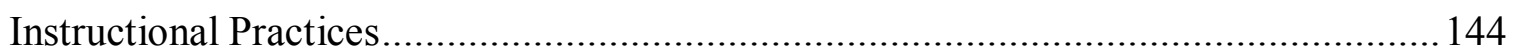

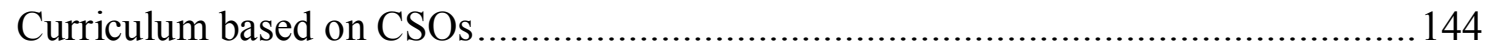

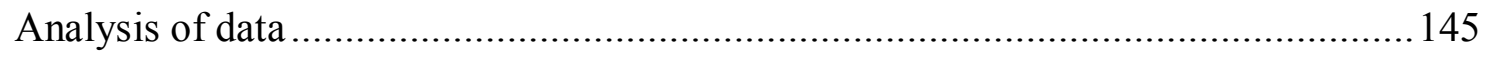

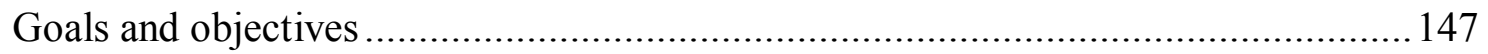

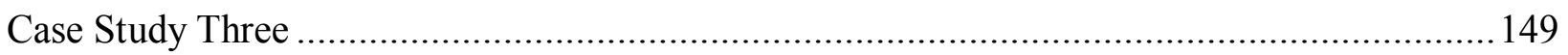

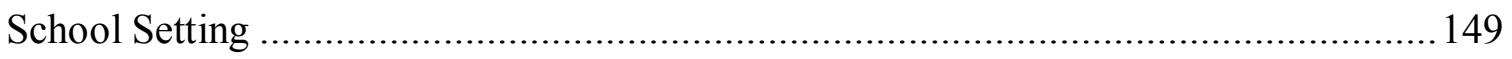

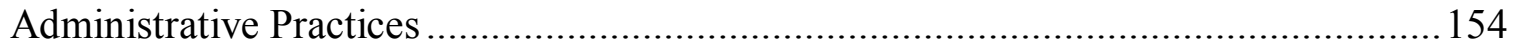

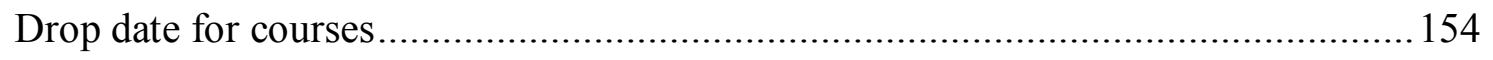

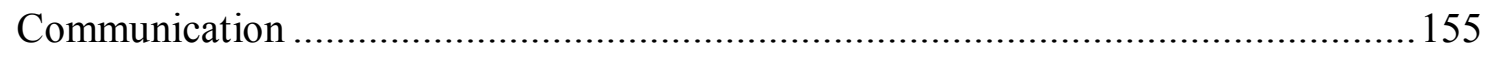

Community organization involvement ……......................................................... 156

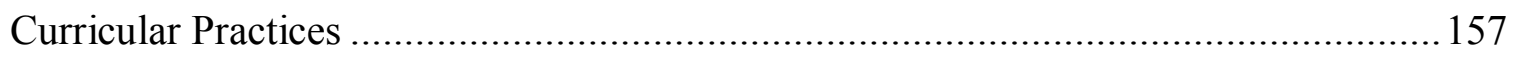

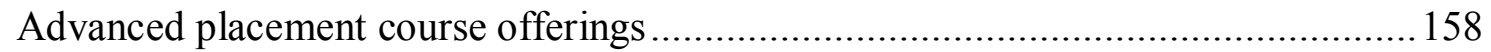

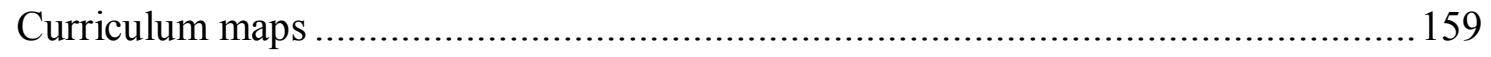

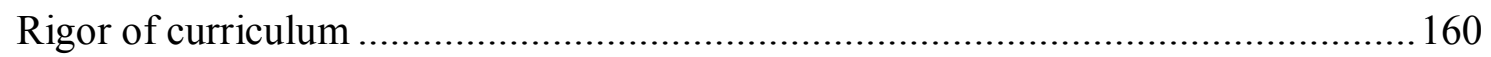




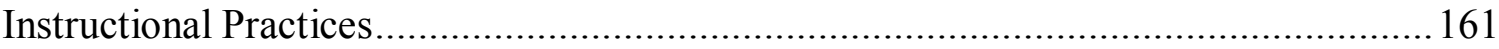

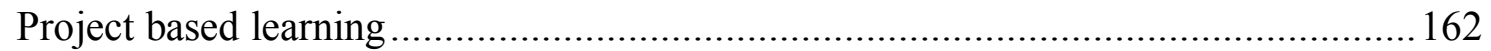

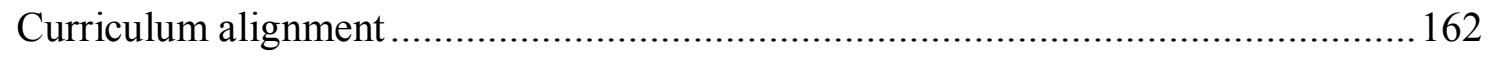

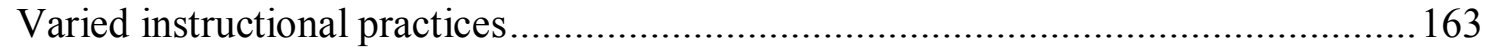

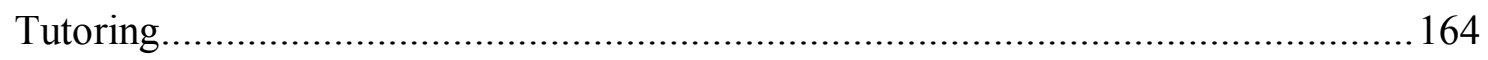

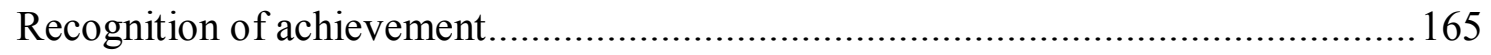

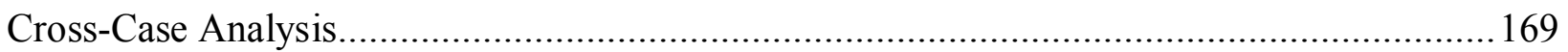

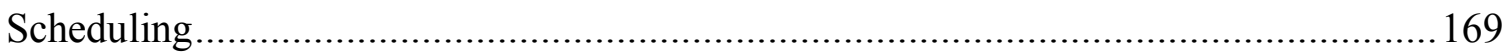

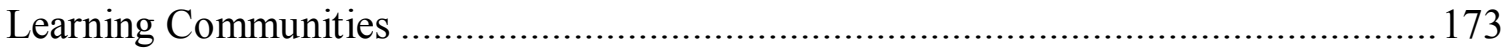

Advanced Placement Course Offerings ..................................................................... 176

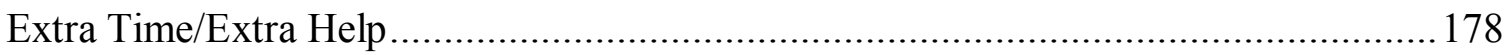

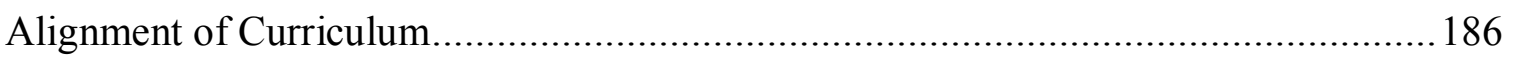

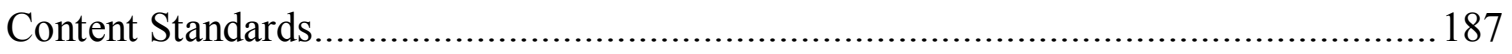

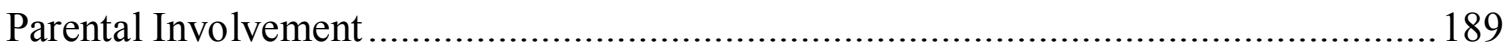

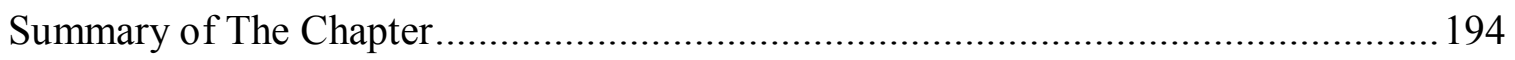

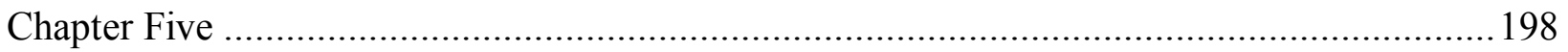

Conclusion, Discussion, and Recommendation for Future Research..............................198

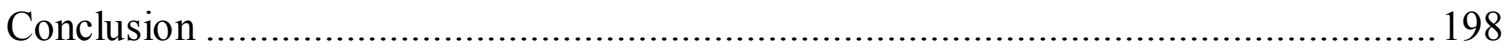

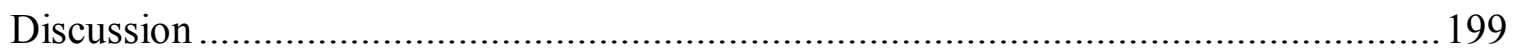

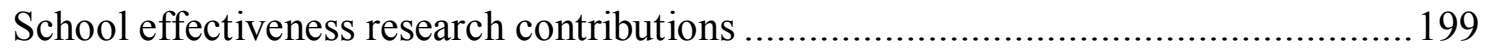

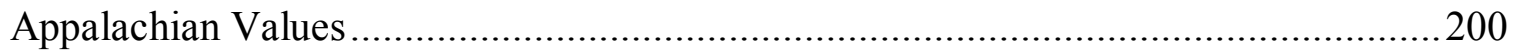

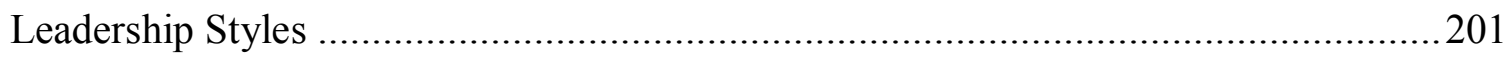

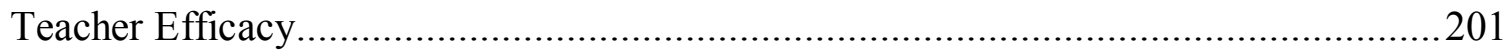


High Expectations With No Evidence ............................................................... 202

Improving Low Performing Schools .......................................................... 202

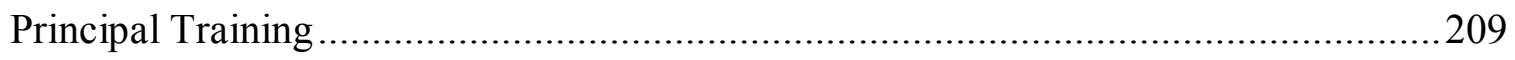

Missing Elements in The Proposed Definition ........................................................ 211

Different Practices Occurred at Each Site ......................................................... 212

Value of Qualitative Inquiry in Studying Schools ............................................213

Recommendation For Future Research ............................................................ 213

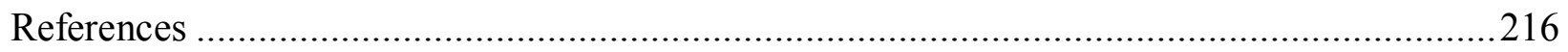

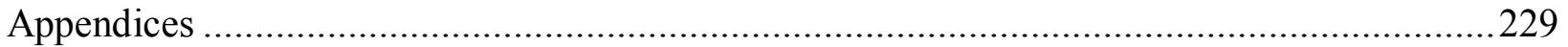

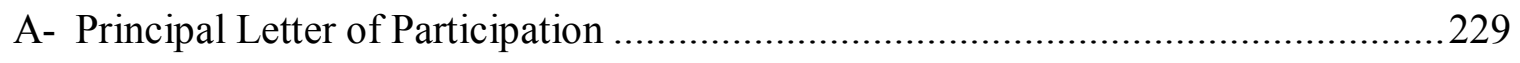

B- Central Office Letter of Participation ...............................................................2231

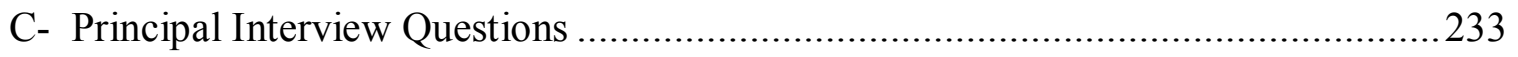

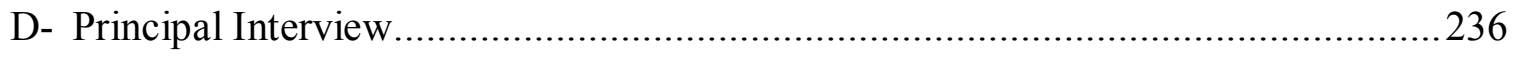

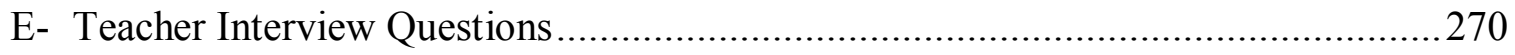

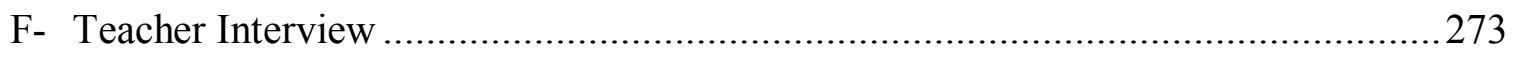

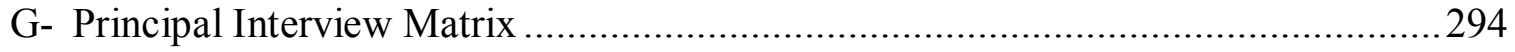

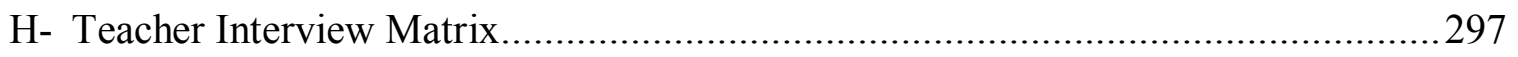

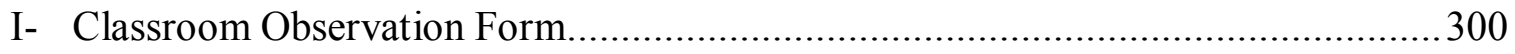




\section{List of Tables}

List of Tables $\mathrm{X}$

1. National Board Standards Compared to The Effective School Correlates .................38

2. Elements of High Expectations Definition Linked to Policy or Scholar Reference ...61

3. Grade Configuration of West Virginia Secondary Schools that made AYP for Four

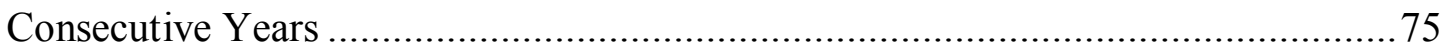

4. Cherry High School Teacher Education Levels Compared to State Levels ...............99

5. Cherry High School Percent of Students at or Above Proficiency in Mathematics and

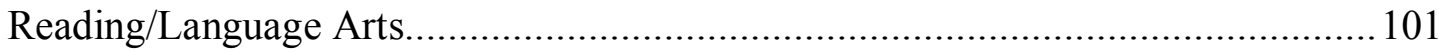

6. Cherry High School ACT Scores Compared to State and National Averages for 2008 and 2009 .102

7. Cherry High School SAT Average Scores Compared to State Average Scores ........ 102

8. Apple High School Teacher Education Levels Compared to State Levels. 129

9. Apple High School Percent of Students at or Above Proficiency in Mathematics and Reading/Language Arts.

10. Apple High School ACT Scores Compared to State and National Averages for 2008 and 2009 132

11. Apple High School SAT Average Scores Compared to State Average Scores 133

12. Percent of Apple High School AP Students Scoring 3 or Better on one AP Exam .. 141

13. Orange High School Teacher Educational Levels Compared to State Levels. 150

14. Orange High School Percent of Students at or Above Proficiency in Mathematics and Reading/Language Arts. 151 
15. Orange High School ACT Scores Compared to State and National Averages for 2008

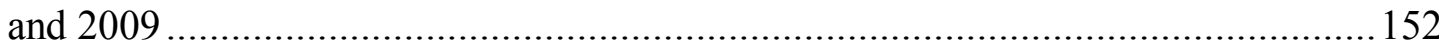

16. Orange High School SAT Average Scores Compared to State Average Scores ...... 153

17. Summary of Commonalities Between the Three Schools .................................... 196 


\section{Chapter One}

\section{Introduction To The Study}

Two major educational reports: Equality of Educational Opportunity (Coleman, J. S., Campbell, E., Hobson, C., McPartland, J., Mood, A., Weinfeld, R. and York, R., 1966) and Inequality: A Reassessment of the Effect of the Family and Schooling in America (Jencks, C. S.,

Smith, M., Ackland, H., Bane, M. J., Cohen, D., Ginter, H., Heyns, B. and Michelson, S., 1972), brought a national question to the research community: Do Schools Matter? The effective schools movement, which began in the mid-1960s, sought to find characteristics that existed across school contexts that had exceptionally high student achievement gains. It was not just a student's social economic background that determined high achievement, but factors such as teacher-student relationships and other micro-detailed classroom-level factors, too.

Murnane (1981) found that "physical facilities, class size, curricular and instructional strategies were seen as secondary resources that affected student learning through their influence on the behavior of teachers and students" (p. 45). Some scholars believed (e.g., Dusek, 1975; Good \& Brophy, 2003; Rist, 1970) that through positive teacher-student interactions, a school could increase its output as measured by student achievement. Although classroom-level factors could explain a considerable proportion of the variance in school performance, school effectiveness research (SER) paid little attention to the characteristics of classroom life.

What the effective schools research found was that effective schools had certain salient characteristics. One of those characteristics was that high expectations existed. Being that those were only characteristics, the fledgling question among the research community was to find out what constituted high expectations. Stemming from the work of Brophy and Good (1974) was that teacher-student relationships were characteristic for high expectations. What Brophy and 
Good (1974) found was that teachers believed brighter students were those who were pleasant and cooperative, and it was those students teachers rewarded with a more positive classroom environment.

From the teacher expectancy research of Rosenthal and Jacobson (1968) evolved the belief that if a teacher held high expectations for all students, then the student's intellectual growth was greater. Within the public schools that created a problem because, teachers knew the level of student performance based upon the previous year's standardized test score. If a student scored poorly, then that student was labeled as a low-expectancy student. Thus, high expectations for all students was important because our nation holds schools accountable for what children learn each day, month and year they attend school.

The words high-expectancy and high expectations became synonymous through the research of Edmonds (1979). It was Edmonds' (1979) initial research with low SES, urban elementary students that found when high expectations existed from both the principal and teacher, student achievement for all students increased. Edmonds (1979) believed that if all students, low-expectancy or high-expectancy, were held to high expectations, then student achievement for all would improve.

The concept of high expectations was then an important, but unexamined, element throughout the evolution of the effective schools movement. Since the 1960s, the School Effectiveness Research (SER) had relied on quantitative research methods. Those methods had been met with harsh criticism from scholars working outside of the effectiveness tradition (Angus, 1993; Slee \& Weiner, 2001; Thrupp, 2001). In an effort to thwart the criticism, studies by Thrupp (2001) and by Scheerens and Bosker (1997) argued that qualitative studies were 
needed to examine the processes that occurred within schools. It would be important to find those practices that teachers and principals use in establishing high expectations.

Within West Virginia the phrase high expectations is associated with the Office of Educational Performance Audits. In 2006-2007 the Office of Educational Performance Audits performed a school audit in 39 West Virginia public elementary, middle, high and vocational schools in 18 counties. Fifteen of those 39 schools (38 percent) were identified as low performing schools because they failed to meet Adequate Yearly Progress. Furthermore, nine of the 15 schools (60 percent) were cited for not meeting OEPA's standard on high expectations (OEPA, 2007).

This study's intent was to develop an understanding of what curriculum, instructional and administrative practices teachers and principals used to establish high expectations. The literature review will point out that no tangible definition of high expectations exists for secondary schools. Giving practitioners concrete, tangible ways of promoting high expectations in secondary schools will assist all West Virginia schools in meeting that standard.

\section{Purpose of the study}

The purpose of this study was to examine the curricular, instructional and administrative practices that teachers and principals used in establishing high expectations in selected secondary schools in West Virginia.

\section{Research Questions}

1.) What instructional practices and curriculum methods do teachers use to communicate high expectations to the students?

2.) What do principals perceive to be high expectations in these classrooms? 
3.) What are the administrative and curriculum practices that principals use to promote high expectations within the school?

\section{Description of the study}

This study was a qualitative case study where data was collected from at least three secondary schools located in West Virginia chosen purposefully using the following criteria: 1 . sites had met AYP for four consecutive years; 2 . sites contained at least one teacher who was Nationally Board Certified; 3 . location of sites were convient, 4. sites participated voluntarily. The researcher used semi-structured, open-ended questions to interview the principal and teachers at each site. In addition, the researcher observed classrooms, meetings and the daily school events. Finally, documents were collected at each site and included: minutes of meeting (i.e., faculty senate, curriculum, local school improvement, and department), teacher lesson plans, student work, student handbook, teacher handbook, course syllabi, school newsletter, state testing data, and the master schedule.

To further assist in the development of interview questions, a pilot study was completed using teachers and a principal from another site. During the pilot study, the interview questions for both principal and teacher were found to be sufficient in gathering the data.

Data obtained from the interviews, observations and document collection from each site were stored as a case file and first written as a case for the three schools. Through the data analysis, a cross-case analysis was performed. As data was collected and analyzed, the themes that emerged lead to the discovery of what practices produced high expectations in selected West Virginia secondary schools.

The country no longer is satisfied with maintaining the status quo within the educational community. Citizens around the country and in West Virginia are clamoring for better results as 
children compete for jobs and admission to colleges and Universities. If public education is to survive in the age of accountability, then the need to change the paradigm so that all students can achieve is now here. It was through high expectations that the literature review and the research believed that all students can and do achieve.

\section{Definition of terms}

Advanced Placement (AP): The West Virginia Department of Education (2008) defined as "courses provided by The College Board which are advanced in terms of content and performance expectations for the age/grade level of students and provide credit toward graduation and possible college credit or advanced standing upon passing an examination through The College Board" (p. 53).

Case Study: “An exploration of a bounded system or a case (or multiple cases) over time through detailed, in-depth data collection involving multiple sources of information rich in context" (Creswell 1998, p. 61).

Coding: A process used to produce a framework for organizing and describing what has been collected during fieldwork (Patton, 2002).

Content Standard: The West Virginia Department of Education (2008) defined as “a broad description of knowledge and skills that students are expected to acquire in a content area" (p. 54).

Effective School: Lezotte (2001) defined as "a school that is successful in educating all students regardless of their socioeconomic status or family background" (p. 1). This research proposal defines an effective school as one that made AYP for four consecutive years.

High Expectancy Student: A student that teachers believe has the most learning potential (Hall \& Merkel, 1985). 
Honors Courses: The West Virginia Department of Education (2008) defined as "courses that expand the approved academic content standards and objectives in a given program of study and may include, but are not limited to, research and in-depth studies, mentorships, internships, content-focused seminars and extended instruction in a content area” (p. 58).

Interview: A conversation between two or more people where the interviewer poses questions that may be structured, semi-structured, open, or probing in order to obtain information about interviewees' understanding about a selected topic (Patton, 2002).

Low SES: Children who qualify for free and reduced lunch. Free lunch is defined by the National School Lunch Program (2011) as "families with income at or below 130 percent of the poverty level. Reduced lunch is defined as families with income between $130-185$ percent of the poverty level."

Observation: "Collecting data from observing phenomena of interest” (Merriam 1988, p. 87).

Self-Fulfilling Prophecy: Merton (as cited in Good \& Brophy, 2003) defined as "when an original erroneous expectation leads to behavior that causes the expectation to become true" (p. 68).

Triangulation: The use of multiple methods of collecting data (Denzin, as cited in Merriam, 1988).

\section{Organization of the study}

Chapter one includes the introduction and significance of the study. Chapter two presents the review of the literature on effective schools, teacher efficacy, high expectations, and how National Board Certification blends into the Effective Schools research. Chapter three explains 
the design and procedure of the study. Chapter four reports the findings. Chapter five provides the conclusion, and recommendations for further research. 


\section{Chapter Two}

\section{Survey of Literature}

Student achievement has become increasingly important due to demands placed on public schools through the No Child Left Behind Act of 2001 (2002). Prior to the No Child Left Behind Act of 2001 (2002), teachers and schools were not held accountable for student achievement. The result of this Federal legislation was that student achievement was disaggregated into the following cells or groups: total achievement, ethnicity, economic status and special needs. As a consequence of the breakdown of data, schools across the nation had looked at ways to increase student achievement for all students. Effective schools research had identified schools characterized by high achievement as those that contained five common characteristic or correlates (Lezotte, 2001).

This chapter consists of two sections, school effectiveness and high expectations that lead to the development of a framework for a definition for high expectations in West Virginia. The school effectiveness section includes: organizational theory related to leadership theory, school effectiveness history, the work of Ron Edmunds, research on effective schools from the 1980s, critiques of the research and the history of effective schools in West Virginia. The high expectations section includes the following topics: the history of high expectations, National Board Certification, teacher expectations, principals and high expectations and the Appalachian beliefs related to educational values. The chapter ends by developing a framework for a definition of high expectations in West Virginia that includes three elements: curriculum offerings, instructional practices, and administrative practices. This framework provided the foundation for the research design through the development of interview questions, observation checks and document collection. Those items were used to interpret and explain the curricular, 
instructional and administrative practices that teachers and principals used in the establishment of high expectations.

\section{School Effectiveness}

Organizational theory. The purpose of this chapter is to lay the foundation as to why the researcher was interested in defining high expectations. A part of this foundation was connecting the practicality of making a connection of high expectations to leadership theory. That connection was found in the following definition of an organization: "a social unit with some particular purpose” (Shafritz, Ott, \& Jang, 2005, p. 1). Schools are considered organizations because each one has a purpose identified through its mission and vision with an overall theme of preparing children to enter the work force of the $21^{\text {st }}$ Century.

Principals, superintendents and other school leaders are a part of preparing children. To prepare children the school leader has to look at how the organization can be framed to efficiently accomplish this challenge. During the post war revolution Chester I. Barnard wrote a book The Functions of the Executive that focused on framing organizations in a sociological way where the behavior of the organization was at the center. In an attempt to create a theory of behavior, Barnard's work looked at how leaders in organizations enlisted others to help accomplish tasks that individuals could not accomplish alone (Shafritz et al., 2005). Barnard (as cited in Shafritz et al., 2005) believed that "cooperation holds an organization together" (p. 89).

Miskel and Hoy (2005) believed that Barnard's work of the 1930s stressed the importance of work-group norms and other interactions that occurred in the workplace as it pertained to the functions of the informal organization. It was this informal organization that made up the organizational culture. Schein (as cited in Bolman \& Deal, 2003) offered a formal definition of culture as: 
A pattern of shared basic assumptions that a group learned as it solved its problems of external adaptation and integration that has worked well enough to be considered valid and therefore to be taught to new members as the correct way to perceive, think, and feel in relation to those problems. (p. 243)

In addition, Bolman and Deal (2003) believed that the culture of an organization was the glue holding it together and uniting workers around shared values and beliefs. Furthermore, Bolman and Deal (2003) believed organizations are framed in four ways: structural, human resource, political and symbolic. It was through the symbolic frame that James Spillane's work on distributed leadership showed how the development of a framework for a definition for high expectations at the secondary level was tied into leadership theory.

Spillane (2006) framed distributed leadership around the perspective of leadership practice. What are school principals doing from a practitioner's point of view that was making a difference? That practice engaged school leaders and followers in joint interactions within a situation through the use of certain practices. With the involvement of followers, the focus of leadership moved away from the formal and informal leaders within the organization. Distributed leadership began to look at leadership as a spider's web made up of leaders, followers and their situations. Together, all of those elements formed the leadership practice component of distributed leadership (Spillane, 2006). 
According to Spillane (2006), distributed leadership consisted of three elements:

- leadership practice was the central and anchoring concern,

- leadership practice was generated in the interactions of leaders, followers, and their situation; each element was essential for leadership practice, and

- the situation both defined leadership practice and was defined through leadership practice. (p. 4)

Looking at the three elements, it became apparent that distributed leadership was more than shared leadership. It was through interactions between leaders, followers and their situation that distributed leadership was best framed. Furthermore, Spillane (2006) stated that "distributed leadership presses us to investigate how leadership practice was stretched over two or more leaders and to examine how followers and the situation mutually constituted that practice" (p. $15)$.

It was the effective schools literature that equated school leadership with the principal. However, Spillane (2006) pointed out that school principals and school leadership are not one and the same. Through the distributed leadership perspective, it was the practices that are established within the school that accounted for leadership. It was not possible within a complex organization for any one person to do everything, so through distributed leadership the principal can formally and informally engage others in leadership through certain practices. For example, Spillane (2006) found that at Hillside Elementary, an inner-city Chicago school, the principal had teachers keep a writing folder that contained student writings once per month. The principal would then read and comment on each student's paper, along with making comments back to the teacher. That process involved both a teacher and principal practice. The teacher practice was to engage students in a writing activity once per month and store them in a folder. It was then the 
principal's practice to collect the folder where he/she read and made comments back to both the teacher and the students.

At Baxter Elementary School, another Chicago inner-city school, Spillane (2006) found that the principal began a Breakfast Club as a routine to engage teachers in a professional community. It was during those voluntary meetings, that teachers took turns hosting a discussion about a research topic that affected student learning. That leader-plus approach, as Spillane called it, played an integral role in the leadership of the school. Spillane stated "leadership was not simply something that was done to followers; followers in interaction with leaders and the situation contributed to defining leadership practice" (p. 17).

Followers in interaction with leaders and the situation are believed to be the manner in which high expectations would be communicated. It was through distributed leadership that the practices of high expectations could become the norm or manner in which the school building operated.

\section{History of School Effectiveness Research}

The research from the late 1960s on the effectiveness of schools produced the following question to the educational research community: Do Schools Matter? (Jansen, 1995). Stemming from the research of Coleman et al. (1966) and Jencks et al. (1972), student background characteristics was found to be more prevalent in student achievement than any school-level factors.

School effectiveness research (SER) emerged from the studies of Coleman et al. (1966) and Jencks et al. (1972) and was central to the educational discourse that schools did affect the intellectual development of children (Teddlie \& Reynolds, 2000). In America, there had been three major strands of school effectiveness research: 1. School Effects Research, 2. Effective 
Schools Research and 3. School Improvement Research. Furthermore, Teddlie and Reynolds (2000) identified four overlapping stages of SER:

1. Stage 1 - mid-1960s through the early 1970s,

2. Stage 2 - early to late 1970 s,

3. Stage 3 - Late 1970 s through the mid-1980s, and

4. Stage 4 - late 1980 s to the present day.

Stage 1 involved studies that examined the initial input-output paradigm that focused on the potential impact of a school's human and physical resources on the outcome. The outcome focused on during Stage 1 studies was overall student achievement within the classroom. Inputs were variables related to school resources and student background (i.e. student socio-economic status or SES) that predicted school outputs as viewed through standardized achievement test scores (Teddlie \& Reynolds, 2000). The results of studies using those variables concluded that there was a correlation between student achievement and student SES, not with the school-based resources (Teddlie \& Reynolds, 2000).

However, the past economic and sociological studies of school effects did not include adequate measures of school social psychological climate and other classroom or school process variables (Teddlie \& Reynolds, 2000). As cited in Teddlie and Reynolds (2000), Averch, H. A., Carroll, S. J., Donaldson, T. S., Kiesling, H. J. and Pincus, J. (1971) concluded "that very few studies had actually measured processes such as behavioral and attitudinal within schools, that the operational definitions of those processes was very crude, and that standardized achievement was the only outcome measured" (p. 6).

Unlike the input-output studies from Stage 1, Stage 2 included the beginning of what was called the effective schools studies that addressed a wider range of school outcomes (Teddlie \& 
Reynolds, 2000). Researchers began to study urban elementary schools that were doing an exceptional job of educating students from low SES backgrounds and began to describe the processes those schools used.

Early studies in Stage 2 focused on low-SES elementary schools located in urban settings. Researchers believed that success stories from those environments would quell the criticism from the Coleman et al. (1966) and Jencks et al. (1972) reports that schools made little or no difference in the academic achievement of students. Weber (1971) conducted extensive case studies of four low-SES inner-city schools characterized by high achievement at the third grade level. His research emphasized the importance of the actual on-going processes at schools (e.g., strong leadership, high expectations, good atmosphere, and the careful evaluation of pupil progress). As a result of the on-going processes, the five correlates of the effective schools movement emerged and included: (a) leadership focused on quality instruction, (b) strong instructional focus, (c) safe and orderly climate conducive to teaching and learning, (d) teacher behaviors that warranted that all students are held to high expectations through obtaining mastery and (e) the use of achievement data to evaluate programs. As SER moved out of Stage 2 and into Stage 3, researchers focused their attention on the five correlates.

In addition to the five correlates, several methodological advances occurred in the American research studies of the 1970s. One such advance was more sensitive measures of classroom input that involved the association of student-level data with the specific teachers who taught the students (Teddlie \& Reynolds, 2000). That was significant because for the first time, SER emphasized input from the classroom (teacher) level, as well as from the school level, and it associated student-level output variables with student-level input variables (Teddlie \& Reynolds, 2000). Murnane (1981), for example, concluded that "the primary resources that were 
consistently related to student achievement were teachers and other students. Other resources affected student achievement primarily through their impact on the attitudes and behaviors of teachers and students" (p. 33).

In Stage 3 schools attempted to infuse the correlates of effective schools that Edmonds (1979) found existed in high-performing schools as a device for school improvement (Teddlie \& Reynolds, 2000). Edmonds and his colleagues were no longer interested in just describing effective schools, but wished to create effective schools, especially for the urban poor (Teddlie \& Reynolds, 2000). In creating effective schools, Edmonds wanted to produce a theory based upon his research on the common factors that existed between schools identified as highly effective. Indeed, if the five correlates had a cause-effect relationship, then Edmonds would have been able to produce a theory.

An important result of the effective schools research was that it identified five correlates that existed in effective schools: strong instructional leadership from the principal, a pervasive and broadly understood instructional focus, a safe and orderly school learning environment or climate, high expectations for achievement from all students, and the use of student achievement test data for evaluating program and school success (Teddlie \& Reynolds, 2000). For the first time, studies began to emerge using the five correlates as the hypothesis for effective schools. The correlates, however, needed to exist across contexts, not just high performing elementary schools. That was the goal of Stage 4- to produce common factors between elementary, middle and high school levels that made them effective as evident in high student achievement test scores.

Stage 4 involved the introduction of context factor and more sophisticated methods, which enhanced the effect upon the quality of all three strands of SER (school effects, effective 
schools and school improvement) (Teddlie \& Reynolds, 2000). The context studies explored the factors that were producing greater effectiveness in middle-class schools, suburban schools and secondary schools (Teddlie \& Reynolds, 2000). Instead of focusing upon one particular context, those studies focused specifically on the differences in school effects that occurred across different school contexts (Teddlie \& Reynolds, 2000). What Stage 4 concluded was that effective schools, at any context, shared the five common factors of: strong instructional leadership from the principal, a pervasive and broadly understood instructional focus, a safe and orderly school learning environment or climate, high expectations for achievement from all students, and the use of student achievement test data to evaluate school success. Since a causeeffect relationship was not found to exist, a theory was not produced causing the Effective Schools research to be considered pragmatic rather than dogmatic.

When researchers were interested solely in determining what produced effective schools for the urban poor, their value orientation was that of equity: how can we produce better schools for the disadvantaged? (Teddlie \& Reynolds, 2000). However, the purpose was to produce better schools for all students. As researchers switched from looking at what produced better schools for the disadvantaged to looking at what produced better schools for all students, they produced tools such as survey items, including social-psychological indices, to better measure the educational processes on-going at the school and classroom levels (Teddlie \& Reynolds, 2000). Using those tools, schools would be able to determine what deficiencies existed and with the data develop ways to address the identified needs. Once ways were developed to address the needs of a school in terms of developing a school improvement plan, all members of the school system would have the knowledge needed to address the identified needs. When the members 
addressed the identified needs, then the school would improve the outcome, by increasing student academic achievement.

The studies were limited to classroom achievement levels and so the variation between student achievement was overlooked (Cohen, 1982). Clark, D. L., Lotto, L. B. and Astuto, T. A. (1984) attempted to re-examine the evidence based on "methodological improvements that allowed the researcher to be more sensitive to the relationship between school resources and the quality of education" (p. 45). What was the teacher doing within the classroom that affected student achievement? The teacher-student interactions seemed to be of particular importance when educators began to look at the research of Rosenthal and Jacobson (1968). It was teacherstudent interactions that became the focus of later research studies.

Specific methodological strategies in the second round of school effectiveness studies used individual students as the unit of analysis, measured progress rather than achievement as an estimate of effectiveness and developed a more complex estimate of school resources and their delivery within the classroom (Clark et al., 1984). Richard Murnane (1981) concluded that schools matter and that there was no unequivocal consensus regarding the role of any school resource in contributing to school achievement:

A judicious interpretation of the evidence (including the research methodology as well as the pattern of coefficient estimates) does suggest some tentative conclusion...primary resources are teachers and students.... Physical facilities, class size, curricular and instructional strategies can be seen as secondary resources that affect student learning through their influence on the behavior of teacher and student. (p. 45)

The conclusions of Murnane (1981) placed the focus, once again, on what was happening within the classroom between the teacher and student. Through positive teacher-to-student 
interactions, schools were making a difference in student outcomes, as measured through student achievement tests. It was logical to focus on those interactions so that cause-effect relationships would be determined and theories developed. Using the new theories, schools within the particular context would be able to improve student achievement.

Citing four studies (Armor, Conry-Oseguera, Cox, King, McDonnell, Pascal, Zellman, 1976; Hanushek, 1971; Murnane, 1975; Murnane \& Phillips, 1979) using the specific methodological strategies discussed above, and in contrasting reference to the Coleman et al. (1966) and Jencks et al. (1972) research, Murnane (1981) stated:

What have we learned from quantitative studies of school effectiveness? The most notable finding was that there were significant differences in the amount of learning taking place in different schools and in different classrooms within the same school ... even after taking into account the skills and backgrounds that children bring to school. (p. 20)

\section{The Work of Ron Edmonds}

In 1979, Ronald Edmonds produced a landmark study on Effective Schools for the Urban Poor. Within that study the characteristics of effective schools was provided (as cited in Jansen, 1995). The purpose of the study was to identify the salient characteristics found in effective schools that could be repeated in other contexts producing the same results of enhancement in student achievement. Furthermore, the study addressed how qualitative components of the school effectiveness literature provided in-depth ethnographic details of classroom life that was often lost in the large scale statistical investigations of the Coleman et al. (1966) and Jencks et al. (1972) reports (Jansen, 1995). In addition, the effective schools literature worked strictly within a positivist paradigm that schools basically consisted of interrelated units that were fixed through 
mixing policy with resource inputs, producing the greatest affect on student achievement (Jansen, 1995).

As a result of Edmonds' study, what worked in school reform produced the five correlates of Effective Schools (Taylor, 2002). Those five correlates were:

1. the leadership of the principal notable for substantial attention to the quality of instruction,

2. a pervasive and broadly understood instructional focus,

3. an orderly, safe climate conducive to teaching and learning,

4. teacher behaviors that convey the expectation that all students are expected to obtain at least minimum mastery, and

5. the use of measures of pupil achievement as the basis for program evaluation.

Educators throughout America used the correlates of effective schools as organizational and programmatic dimensions of their strategy for school improvement. What evolved from the use of the school improvement process was called the Effective Schools Movement (Taylor, 2002).

The goal of earlier work with School Effectiveness Research (SER) was to refute the "schools-don't-make-a-difference" interpretation that had been attributed to the research outcomes of Coleman et al. (1966) and Jencks et al. (1972). Through the use of correlational studies, the SER used simple linear logic (more of this was associated with more of that) and allowed conclusions concerning either the causal relations between variables or the mechanisms behind those relationships to evolve.

Therefore, SER can be conceptualized as the study of relationships among school input, school context, the schooling process (at both school and classroom levels) and school 
performance. School performance was usually expressed in terms of average student achievement by school. The main goal of SER was to identify the factors that led to the best results in student achievement (as cited in Luyten, Visscher \& Witziers, 2005).

\section{Research from the 1980s}

The effective schools movement gained its power from a simple idea: school practices that promoted learning in one school could do the same in any school environment (Richardson, 1995). For 29 years, the central tenet of the effective schools movement had been that all children can learn, and it was for that reason that the effective schools correlates became popular in urban, rural and suburban schools alike (Richardson, 1995). According to Ben A. Birdshell (as cited in Richardson, 1995), "schools or districts that had some experience with the concept were digging deeper and using the practices not just to fix what was wrong, but to fine tune and engage more members of the school community in their work" (p. 8). In order to have lasting change as a result of the effective schools practices, school districts engaged in the practices too (Richardson, 1995).

If the goal was for all children to learn, then it was pragmatic for school districts to implement the correlates of effective schools throughout all programmatic levels. If a 9-12 secondary school was to be effective, then the middle schools that fed it needed to embrace the correlates, as well as the elementary schools that fed the middle schools. At the district level, leaving one school level out broke the cycle and caused the effectiveness of the system to be negated.

As the effective schools movement entered the mid 1980s, the National Center for Effective Schools Research and Development (now called the National Alliance for Effective Schools) was founded (Taylor, 2002). The purpose of the National Alliance for Effective 
Schools (NAES) was to distribute and maintain the consistency of the Effective Schools Process, a school improvement process that was evolving from the collective experiences of educators nationwide who used the correlates of Effective Schools as organizational and programmatic dimensions for their strategy for school improvement (Taylor, 2002). The correlates of Effective Schools had become so widely used as guides for school improvement and reform in the mid1980s and early 1990s that the National Center decided to make the words Effective Schools, Effective Schools Research, and Effective Schools Process a service mark (Taylor, 2002). It was that service mark that allowed the correlates of Effective Schools to be copyrighted, protecting it from competitors who wanted to get into the school improvement market.

From the 1980 empirical research on Effective Schools, the original correlates became expanded descriptions of what worked in school reform and the then Secretary of Education, William Bennett, espoused the Effective Schools movement (Taylor, 2002). For over a decade, the 1980s through the early 1990s, the language of the correlates became the language of school improvement and school reform (Taylor, 2002). The Effective Schools Movement, its constituent research and the correlates themselves, according to Lezotte (2001), had not only withstood the test of time, but had also evolved, grown, deepened and broadened from the original five correlates into the following seven:

1. Instructional Leadership,

2. Clear and Focused Mission,

3. Safe and Orderly Environment,

4. Climate of High Expectations,

5. Frequent Monitoring of Student Progress,

6. Positive Home-School Relations, and 
7. Opportunity to Learn and Student Time on Task.

There are four professional development/training sites offered by the National Alliance for Effective Schools: (a) the Center for Education Leadership at Kent State University; (b) the California Center for Effective Schools at the University of California, Santa Barbara; (c) the Center for Professional Development and Services at Phi Delta Kappa in Bloomington, Indiana; and (d) the Association for Effective Schools in Albany, New York (Taylor, 2002). The purpose of each site was to deliver professional development activities to teachers, administrators and others and to provide supportive products, resources and services based upon the Effective Schools Processes (California Center for Effective Schools, n.d.).

In addition to the four professional development/training sites, a software package, ADAM, was available. That program aided schools in achieving comprehensive school reform and was recognized for planning and implementing school reform by the Federal Comprehensive School Reform Development Act (Taylor, 2002). ADAM allowed schools to: gather data, retrieve and disseminate student attendance, discipline records and student achievement so schools made informed decisions related to instruction and curriculum objectively, instead of subjectively (Taylor, 2002).

\section{Critiques of Effective Schools Research}

A persistent criticism of the effective schools research was that most of the research was conducted in large urban school districts with a large minority and economically disadvantaged student population (Lezotte \& Bancroft, 1985). However, Spencerport Central School District, a predominantly middle class and Caucasian population located near Rochester, New York, engaged in the effective schools correlates in 1982 (Lezotte \& Bancroft, 1985). In 1985 the 
school system's use of the effective schools correlates verified the model's versatility and adaptability to a variety of school types (Lezotte \& Bancroft, 1985).

Even though researchers (Edmonds, 1979; Lezotte, 2001) found that certain salient characteristics existed among effective schools, Purkey and Smith (as cited in Jansen, 1995) concluded: “...while all the reviews assumed that effective schools were differentiated from ineffectiveness, there was no consensus yet on just what the salient characteristics happened to be" (p. 185). In addition, Purkey and Smith (as cited in Jansen, 1995) had concluded that the case study methods used in the SER had generated critiques, noting:

While each case study had its particular strengths and weaknesses, as a group they generally share five weaknesses: small and unrepresentative samples, possible errors in identifying effective schools because of uncontrolled student body characteristics such as social class, achievement data aggregated at the school level, inappropriate comparison... and the use of subjective criteria in determining school success. (p. 185) According to Coe and Fitz-Gibbon (1998), conclusions about how specific phenomena influence school performance were incorrect, thereby jeopardizing Effective Schools' theory development. Thrupp (2001) concluded that school effectiveness researchers had failed to embrace the detailed micro-level research that could build a body of data suitable for generating theory and they had not tapped into the wealth of sociological theories of education.

Several scholars (Coe \& Fitz-Gibbon, 1998; Lauder, Jamieson \& Wikeley, 1998) doubted that the approach followed in SER would ever produce a theory of school improvement or that it would be helpful in improving the quality of schools. They doubted that universal critical success factors would be found across schools, given the extent to which they differed in context, organizational structure, culture and other aspects. Critics urged researchers to use theory rather 
than common sense when explaining the relationships they studied so progress in theoretical development continued (Luyten, Visscher \& Witziers, 2005). SER researchers had failed to embrace detailed micro-level research, which builds rich data suitable for generating theory. Hence, SER was not based on theory, but rather on pragmatism (Thrupp, 2001).

Ralph and Fennessey (1983) went on to identify three persistent problems from the simple empirically based case studies performed in the SER: "observer bias, the paucity of verifiable evidence for empirical claims, and the lack of control variables. Observer bias applied both to the reliability of classroom observations and to the identification of exemplary schools" (p. 691). Those problems helped to establish the rationale for qualitative studies.

The significance of the case studies of the 1980s was that they injected strong qualitative components into the school effectiveness literature that provided the in-depth ethnographic details of classroom life often lost in large-scale statistical investigations. Informed by extensive studies on implementation, researchers (as cited in Jansen, 1995) called for a shift in understanding the why and how pieces of implementation at the classroom level rather than the simple quantifiable outcomes. For example, the what and how much of conventional implementation studies (Odden, 1991). It was through the ethnographic studies that researchers would be able to use student achievement to understand how student outcomes were affected by what effective schools were doing.

Shifting from "what and how much" to the "why and how" had created attention to the school context. More insight was needed, however, into why and how the school context interacts with school performance and with processes at both the classroom and the school level (Luyten, Visscher \& Witziers, 2005). Looking into classroom-level factors that affect student achievement through a detailed analysis of teacher-student interaction provided the impetus for 
ethnographic studies. The ethnographic studies would provide data through direct observation supporting how teacher-student relationships affect student achievement.

\section{History of the Effective Schools Research in West Virginia}

School effectiveness research identified correlates that would impact student achievement and with the assistance of Lawrence Lezotte, the program was touted throughout America. Even though SER focused on urban, low-performing elementary schools, West Virginia began to implement the effective schools correlates for its primarily rural schools by offering professional development to the State's principals through Principal Academies.

One of the initial members of the Principals’ Academy was Mr. Charles K. Heinlein, Residential Director for the West Virginia Department of Education. Due to his having been a practitioner of the effective schools movement in West Virginia, and his association with the West Virginia Department of Education, the researcher conducted a personal interview. The interview was to find out why the Principals' Academy was formed and why it espoused the five correlates of the Effective Schools movement. During the infancy of the Principals' Academy, he served as principal of Sistersville High School located in Tyler District, West Virginia. In 1993, Sistersville High School and Middlebourne High School consolidated forming Tyler Consolidated High School where he served as principal until 1996 (C. Heinlein, personal communication, July 22, 2008).

In July 1984, West Virginia held its first Principals’ Academy. The first generation Principals' Academy sought to improve schools by teaching principals the five correlates espoused by Lezotte and Edwards' research on Effective Schools (Wallman, 1987). The Academy was an intense ten-day training where, according to Heinlein, "major keynote speakers provided a day-and-a-half training through didactic instruction on each practice" (C. Heinlein, 
personal communication, April 23, 2008). Furthermore, Heinlein stated, "through didactic training, principals were provided foundation knowledge and given practical examples illustrating practices used to address each of the five correlates by people who worked for the Effective Schools movement" (C. Heinlein, personal communication, April 23, 2008). From July 1984 through 1992, the principals' academies used that ten-day format.

One of the day-and-a-half trainings was spent on the "high expectations" correlate. What the principals learned during that day-and-a-half training, according to Heinlein, was "here's what the research said, here are examples of practice, here's what can happen if you use the examples at your school and here are the components of what the correlate means" (C. Heinlein, personal communication, April 23, 2008). As an acting principal, Heinlein used the correlate of high expectations with his faculty and staff so that they understood its meaning. The following teacher behaviors were examples of what Heinlein looked for from the teachers within their classroom: variation in delivering content, lesson plans enumerated what content was to be covered, students engaged in learning activities that made the content come alive, all students had the opportunity to be involved, appropriate wait-time given for a student to respond to a question, positive feedback provided to the students and formative evaluation used for assessing student achievement (C. Heinlein, personal communication, April 23, 2008).

Not only did Heinlein look at high expectations from the classroom point of view, but he worked with his counselors to change how a student was placed into a course. The counselors scheduled students into courses on desire to take the course, not on previous level of performance (C. Heinlein, personal communication, April 23, 2008). According to Heinlein, (personal communication, April 23, 2008) if the student had the desire to take the course, then that student was allowed to enroll because it was the job of our people to help students achieve. 
From the information provided about each correlate, each principal was able to look at the content from the context of his/her own school and make a determination about how he/she was going to use the information to improve school performance (C. Heinlein, Personal communication, April 23, 2008). Heinlein (C. Heinlein, personal communication, April 23, 2008) stated:

At the end of the ten days, principals made goals and wrote action steps used to achieve the goals, listed the person and/or people responsible for completing the action step and finally, explained how and when the action step would be completed.

That document was meant to be one to two pages in length so that upon returning to the home school, the principal had a working document to improve student performance, as seen through output indicators (C. Heinlein, personal communication, April 23, 2008).

According to Heinlein, "Brookover, Edmonds and Lezotte worked from an output model where teacher practices were focused upon to link teacher-student interactions to student learning outcomes" (C. Heinlein, personal communication, April 23, 2008). It was the teacher practices that West Virginia educators found to be so important because of its low-economic status. Heinlein continued by stating "those practices, in conjunction with the practices touted by Brookover, Edmonds, and Lezotte, could be implemented without a great influx of money" (C. Heinlein, personal communication, April 23, 2008). It was from the use of the Effective Schools initiative that the West Virginia low social-economic schools believed that student achievement would improve.

Principals could easily find a correlate to concentrate on that would tie teacher practices into the specific need of his/her school building. Heinlein, for example, stated "you could house your initiatives, whether you were looking at types of questions being asked to students by the 
teachers, school culture or even high expectations, under the correlates of Effective Schools" (C. Heinlein, personal communication, April 23, 2008). The literature provided by Brookover, Lezotte and Edmonds showed principals that schools were doing tremendous things with students from urban areas and of low social-economic status. "Once they saw what those schools did to enhance student achievement, there was a belief that they could replicate it in their school" (C. Heinlein, personal communication, April 23, 2008).

Adequate Yearly Progress and its version of school accountability did not exist at the time and schools had no way to measure how they compared to other schools throughout the nation or state. Due to the absence of this accountability, Heinlein stated that "principal attendance at the academy was voluntary and each of the 55 district superintendents invited principals to attend" (C. Heinlein, personal communication, April 23, 2008). The West Virginia Department of Education would provide room and board, but unless the principal's contract was 240 days or more, principals were not compensated for the time spent (C. Heinlein, personal communication, April 23, 2008).

In 1992 the Principals' Academy ceased and Heinlein stated "the reason it ended was because of the politics stemming from a change in the State School Superintendent" (C. Heinlein, personal communication, April 23, 2008). However, as the result of Senate Bill 300 and WV Code $\S 18 \mathrm{~A}-3 \mathrm{~A}-2 \mathrm{~b}$, the Center of Professional Development was formed with the primary responsibility of providing professional development to teachers and principals to enhance student performance (West Virginia School Laws, 2007). Beginning in the fall of 1997, the next generation of principal academies began and were half as long as the original and had no emphasis placed on teaching the correlates of Effective Schools. 


\section{High Expectations}

\section{History of High Expectations}

In the late 1960s researchers of the behavioral sciences became interested in how one person's expectation of another person's behavior seemed to predict how well that person performed. In 1966 two researchers, Rosenthal and Jacobson (1968), conducted an experiment in a public elementary school they called Oak School. The experiment was intended to show whether the students whose teacher held especially favorable expectations of them would show greater intellectual growth than the remaining (control-group) children whose teacher did not hold especially favorable expectations of them. The results provided evidence that one person's expectations of another's behavior served as a self-fulfilling prophecy. When teachers expected certain children to show greater intellectual development, those children showed greater intellectual development (Rosenthal \& Jacobson, 1968).

The Oak School experiment was the basis for the book Pygmalion in the classroom teacher expectation and pupils' intellectual development (Rosenthal \& Jacobson, 1968). Pygmalion was named after a Cypriot sculptor in a narrative by Ovid in Greek mythology. In addition, Pygmalion became widely known as the result of George Bernard Shaw's play of 1912. In that play a British professor of phonetics made a bet that he could train a poor flower girl to pass as a duchess at an ambassador's party. He believed the most important element was for her to have impeccable speech. Hence, Rosenthal and Jacobson's belief that when a teacher expected children to grow intellectually they did.

It became apparent through the experiment that the effects of teacher expectations had a profound impact on student achievement. What was the teacher doing inside the classroom to produce the significant achievement gains? When teachers had more favorable expectations for 
student intellectual development, the teachers were pleasant, friendly, and enthusiastic (Rosenthal \& Jacobson, 1968). The teachers who behaved in a more professional, competent manner and who were more likeable and relaxed were more successful in exerting unintentional influence upon the students. As the teacher raised student expectations in performance, they received positive feedback about their job performance. In raising student expectations, teachers became more engaged in preparing lesson plans that were meaningful, relevant and engaging to the students and themselves.

The results of the Oak School experiment continued even after the students moved to another group of teachers the following year. Teachers could not recall the names of the students who were labeled "late" bloomers and that provided support for a cause-effect relationship that was previously thought to have been merely accidental (Rosenthal \& Jacobson, 1968). However, the effects of teacher expectations may be quite complicated and are affected by student characteristics and situational variables that occurred in the life of a student (Rosenthal \& Jacobson, 1968). They noted that teacher Characteristics that included friendliness of the student toward the teacher and student sibling(s) taught by that same teacher determined the rapport between teacher and student.

Increased intellectual performance could have occurred because of what the teacher said, by how and when it was said, or even by the facial expression, posture or simple touch (Rosenthal \& Jacobson, 1968). Through those forms of communication, together with possible changes in teaching pedagogy, the child could had been helped by changing self-concept; expectations of his/her own behavior and motivation, as well as cognitive style and skills (Rosenthal \& Jacobson, 1968). Finding answers to those variables would be the subject for another study. 
The Oak School experiment focused directly on changing the way a teacher viewed students with changes in student competence being an indirect consequence of that change. It was the teacher who should be more directly focused upon for research. Through research, finding how teachers improved pupil competence without drastically changing teaching methods would be passed on to other professionals (Rosenthal \& Jacobson, 1968). It was believed that when teachers provided for sufficient wait time between question and answer and provided immediate feedback to the response, pupil competence improved and student achievement increased.

The concept of teacher expectancy came into existence as a result of Rosenthal and Jacobson's (1968) initial study that showed teachers did, indeed, form expectancies for student performance (Dusek, 1985). That concept, Pygmalion, has come to mean that "one person's expectation for another's behavior could come to serve as a self-fulfilling prophecy" (Rosenthal \& Jacobson, 1968, p. 174). Although researchers (e.g., Babad, 1993; Rist, 1977) have noted that the original results from Rosenthal and Jacobson's study could not be replicated.

Some researchers (e.g., Dusek, 1975; Rist, 1970, 1973) concluded that teachers may bias, positively or negatively, the education of some children (Dusek, 1985). For example, a teacher could have a positive effect on performance by probing students to answer a question when they struggle to find an answer. However, when the teacher quickly moves to another student to answer a question, that teacher behavior could have a negative effect on student performance. It was the perception of the student in regard to the probing technique of a teacher that determined how the teacher-student interactions affected student performance.

This bias was based upon Rosenthal's (as cited in Dusek, 1985) four-factor theory of the mediation of teacher expectancy effects. The theory suggested that teachers who expect superior 
performance from their pupils treat them differently than they treat other pupils in four ways. First, teachers appeared to create a warmer socio-emotional climate for high-expectancy students. Second, teachers appeared to provide high-expectancy students clearer and more favorable feedback focused on performance. Third, teachers appeared to teach more material and more difficult material to high expectancy students. Finally, teachers appeared to give high expectancy students greater opportunities to respond verbally and nonverbally to teacher questions (Rosenthal, 1985). That four-factor theory supported the belief that only the highexpectancy students were held to high expectations.

Differences existed between teachers as to what was and was not expected within the classroom. Even though principals attempted to standardize expectations within the school, it was ultimately what the teacher did within his/her classroom that was going to determine student outcomes. Teachers wanted all students to achieve, but through mutual sharing of information from one teacher to the other, teacher-student interactions were affected. If the teacher-toteacher exchange of information was positive, then the receiving teacher's expectations of his/her students were positive. However, when information exchanged was not positive, the teacher's expectation of his/her students was less positive. The belief was that increasing student achievement occurred through improving teacher-student interactions.

Researchers (Beez, 1968; Eden \& Shani, 1982; and Schrank, 1968) conducted studies where teacher expectations were manipulated and caused teachers to believe certain students or classes had an unusually high learning potential. Each study obtained the result that instructors who held high expectations of students achieved more than those instructors who did not hold high expectations (Good \& Brophy, 2003). As individuals, teachers had individual variances within the classroom and beliefs as to what constituted high expectations. 
In addition, Palardy (as cited in Good \& Brophy, 2003) found that teachers who believed boys in their classes would progress as well as girls on a reading readiness test did progress as well. Boys in this group averaged 96.5, but boys whose teachers did not believe they would perform as well as girls averaged 89.2 (Good \& Brophy, 2003). Therefore, teacher expectations about students caused them to treat students in ways that made them respond as they were expected. As teachers moved into the $21^{\text {st }}$ Century, all students treated equally became the belief that "all" students would achieve, as required by the No Child Left Behind Legislation of 2001 (2002).

It was not just the expectation that caused self-fulfillment; it was the behavior that the expectation produced (Good \& Brophy, 2003). In 1970 Brophy and Good (as cited in Good \& Brophy, 2003) developed the following model that explained how expectations are communicated:

- Early on, the teacher formed differential expectations for student behavior.

- Consistent with the differential expectation, the teacher behaved differently toward different students.

- This treatment signaled expected behavior in the classroom and performance on academic tasks to the students.

- If the teacher's treatment was consistent over time, and if the students did not actively resist or change it, self-concepts, achievement motivation, aspiration level, classroom conduct and interaction with the teacher were affected.

- These effects complemented and reinforced teacher expectations; students conformed to these expectations more than they would have on their own.

- All the above affect student achievement and other outcome measures. 
Brophy and Good stated (as cited in Good \& Brophy, 2003) "self-fulfilling prophecy effects of teachers' expectations occur only when all elements in the model are present” (p. 71).

From the student viewpoint, he/she was aware that differential treatment occurred (e.g., the teacher's interaction with students). Weinstein, Marshall, Sharp, and Botkin (as cited in Good \& Brophy, 2003) interviewed elementary students who indicated that teachers offered more opportunities and choice to high-expectancy students, but for low-expectancy students structural activities were provided. Cooper and Good (as cited in Good \& Brophy, 2003) found that high-expectancy students engaged in teacher-initiated public interactions, giving correct answers more frequently, received more praise from teachers than did low-expectancy students.

Cancell (2002), a Harvard University graduate student, completed a case study on teacher expectations at the high school level. Cancell (2002) conducted a qualitative case study of two high schools in the state of Massachusetts featuring open-ended, semi-structured interviews administered at the beginning, middle and end of a school year.

Due to Rosenthal's research (as cited in Cancell, 2002) with elementary children and the belief that teacher expectations had the greatest effect on elementary children, Cancell wanted to see if similar results occurred in high school children. Cancell (2002) further stated that "although high school teachers presumably hold standards and expectations for their students, researchers have not extensively explored the relationship between teachers' standards and expectations and student achievement" (p. 31).

Upon choosing high school as the level for the study, Cancell (2002) identified three high schools located in one Massachusetts school district to obtain his research data. Since Cancell (2002) worked as a consultant at one, his committee recommended that he not include that school. Of the remaining two schools, one was the highest scoring and most prestigious school 
in the district, while the other was where students worked part of the day and went to class part of the day.

Once the schools were chosen, the next step was to decide who to study. For study subjects, Cancell (2002) sought a sample of three to four teachers from each school who volunteered to participate in the study and who all were mathematics teachers; three male teachers at one high school and two females and one male teacher at the second high school.

Using these six teachers to obtain data, Cancell (2002) used semi-structured interviews and observations to obtain the sources of information that teachers used to formulate expectations for their students and to understand the process by which it happened. Questions asked during the semi-structured interviews focused upon student academic performance in class, performance on standards-based exams and classroom behavior. A total of 32 interviews and 30 observations were completed throughout the yearlong study.

What Cancell (2002) found was that teachers used a variety of sources to assist in the formulation of student standards and expectations. At the prestigious school, high academic standards existed for most students, but the teachers differed in the way they helped students achieve the set standard. In the school where students worked part of the day, there existed low standards throughout the building. Cancell (2002) found that a teacher's ability to motivate his/her students to learn was best facilitated by that teacher knowing his/her student and because of this knowledge, had higher expectations. In regard to students learning math, Cancell (2002) found that "if a teacher believed that all students could and would learn math, then the teacher was likely to have used multiple sources of information to learn about the student and thus had leverage when teaching the student" (p. 248). 
There are numerous factors that influenced the sources of information available to teachers. However, what this research focused upon was the types of standards and expectations teachers initially held, their personal sense of responsibility and their personal capacity to teach the subject (Cancell, 2002). Using those sources of information, teachers can affect the way students are instructed and motivated which affected the level of expectations that teachers held for their students. It was ultimately the teacher's use of information from the various sources that set the standards and expectations that affected student achievement within the classroom.

In summary, Cancell (2002) found that expectations are based upon teacher standards within the classroom. If the teacher sets a standard and then had the expectation that ALL students would successfully meet that standard, then students did. However, in order to get all students to meet the standard, the teacher needed to use various sources of information. One such source was the teacher's ability to get to know his/her students. When a teacher built a rapport with a student, then the teacher motivated that student. That motivation was used to get the student to meet or exceed the set standard.

\section{National Board Certified Teacher}

In April of 1983 a report from The National Commission on Excellence in Education released a landmark report titled $A$ Nation at Risk. Following that report in 1986 was the Carnegie Task Force on Teaching as a Profession report entitled, A Nation Prepared: Teachers for the $21^{\text {st }}$ Century. That report argued that the career of teaching needed to be redefined in America. The standards for teachers had to be strengthened so that high standards for learning and teaching prevailed over mediocrity (“A Nation Prepared," 1986).

A recommendation from the 168-page report was for the creation of a National Board for Professional Teaching Standards (“A Nation Prepared,” 1986). One year later in 1987 the 
National Board for Professional Teacher Standards (NBPTS) was born. Its mission was to "advance the quality of teaching and learning by maintaining high and rigorous standards for what accomplished teachers should know and be able to do" (Boyd \& Reese, 2006, p. 52). The NBPTS was comprised mostly of classroom teachers "dedicated to bringing quality teaching the respect and recognition it deserved" (Barker \& Robinson, 2001, p. 3). A product of the NBPTS was to provide a national voluntary system to certify teachers who met the standards and would be awarded National Board Certification .

The assessment required the candidate to demonstrate fundamental content knowledge and was based upon what accomplished teachers should know in the context of the teacher's practice (National Board for Professional Teaching Standards, 2008). The assessment was given at the assessment center and included four exercises, each 90 minutes in length (Barker \& Robinson, 2001).

In maintaining a high and rigorous standard for certification, approximately 50 percent of all candidates are successful on their first try (Boyd \& Reese, 2006). That fact, when combined with a total cost of $\$ 2,300$, may be why 40,200 or approximately one percent of the United States teaching force holds National Board Certification (Boyd \& Reese, 2006). In West Virginia there were 68 secondary (grades 7 -12) teachers who held NBPTS in 28 of the 55 district school systems in 2008 (Nancy Walker, Executive Director, WVEIS, personal communication, November 5, 2008).

The NBPTS was guided by five core propositions:

1. Teachers are committed to students and their learning,

2. Teachers know the subjects they teach and how to teach those subjects to students,

3. Teachers are responsible for managing and monitoring student learning, 
4. Teachers think systematically about their practice and learn from experience, and 5. Teachers are members of learning communities (National Board for Professional Teaching Standards, 2008, p. iii).

From those five propositions, Barker and Robinson (2001, p. 5) directly linked four of them to the correlates of effective schools as shown in Table 1:

Table 1

National Board Standards Compared to The Effective School Correlates

National Board Standard

Teachers are committed to students and their learning

Teachers know the subjects they teach and how to teach those subjects to students

Teachers are responsible for managing and monitoring student learning

Teachers are members of learning communities
Effective School Correlate

High expectation for all students

Maximize learning opportunities

Frequent monitoring of student process

Positive home, school, and community communication

Table 1 illustrates how NBPTS teachers were connected to the belief of high expectations. It was for that reason that one of the criteria used in selecting the sites was that it contained a NBPTS teacher. A teacher possessing NBPTS should be more aware of the classroom environment and conditions that enhanced high expectations.

\section{Principals and High Expectations}

Principals serve various roles and priorities in their day-to-day operation of a school building and supervisor is one such role. As supervisor, the principal creates a working 
environment that allows teachers to develop to their full potential (Wiles, 1967). It was the principal who must help staff members grow by building support, encouragement and trust throughout the school building (Wiles, 1967). Furthermore, the principal must provide an environment where teachers are creative in lesson planning; if not, teachers would sustain the status quo.

An environment where high expectations are believed to occur is one where the principal assists teachers in the development of individual plans that enhance, as oppose to maintain, the status quo. In addition, through high expectations, the principal promotes an environment where all teachers develop and purport a shared set of core values and beliefs. It is believed a school with high expectations has a principal who promotes and models high expectations. Teachers would emulate high expectations through lesson plans that reflect the school's core values and beliefs.

From the work of the 1960s, the need for more information about the leadership role of principals, especially within school improvement efforts, was begun in the 1980s at the Research and Development Center for Teacher Education at the University of Texas (Hall, Rutherford, Hord \& Huling, 1984). That research group wanted to identify and relate principals' daily interventions to what happened in the classroom when teachers attempted to implement new practices (Hall et al., 1984).

The researchers at the Research Development Center for Teacher Education (RDCTE) identified three change facilitator styles that had been used as operational descriptors of the three styles of principal leadership: Initiator, Manager and Responder (Hall et al., 1984). Initiators had clear, decisive long-range policies and goals (Hall et al., 1984). Hall et al. (1984) further defined an initiator as "having strong expectations for students, teachers and themselves. They 
conveyed and monitored these expectations through frequent contact with teachers and clear explication of how the school was to operate and how teachers are to teach" (p. 23).

Managers represented a broader range of behaviors. They were responsive to answers to situations or people and they initiated actions that were supportive of the change effort (Hall et al., 1984). The manager kept teachers informed about decisions, and defended the teachers from excessive demands placed upon them from either the district or state level (Hall et al., 1984). However, they did not move the teachers beyond maintaining the status quo.

Responders relied heavily on allowing the teachers and staff the opportunity to be leaders within the building. It was the responder's belief that they maintained a smooth running school by adhering to administrative tasks, meeting teacher demands, and treating students in a fair and equitable manner (Hall et al., 1984). The responder had a tendency to make decisions based upon immediate circumstances rather than collecting pertinent information and data. This decision making process was not in line with the long-term goals and plans of the school.

Edmonds (as cited in Hall et al., 1984) found that effective schools supported the principal's role as initiator. The principal who modeled the characteristics of initiator listened to his/her teachers, but had high expectations and kept pushing them to meet or exceed the needs of all students. It was because of the constant pressure from the principal to the teachers that this style of leadership was not well liked among the teachers. Venezky and Winfield (as cited in Hall et al., 1984) found that effective schools had leaders who exhibited characteristics outlined under the leadership style of an initiator.

The posing question was do principals of schools with high achievement exhibit any particular leadership behavior? According to Weber (as cited in Sweeney, 1982) "leadership appeared to be a significant factor; school administrators set the tone for the school and assumed 
responsibility for instruction and allocation of resources to reach school goals" (p. 346). A case study performed in 1974 by the New York State Performance Review (as cited in Sweeney, 1982) found that the differences in student achievement appeared to be attributable to factors under the school's control, some of which related directly to the behavior of the leader. Sweeney (1982) goes on to say "the principal appeared to be quietly everywhere, observing students and teachers" (p. 346). When the principal's presence was obvious throughout the building, as indicated by both students and teachers, modeling of high expectations was being accomplished. The visibility of the principal assisted in his/her pushing teachers to provide instruction that met the needs of all students and facilitated the school improvement process as opposed to maintaining the status quo.

The New York State Performance Review (as cited in Sweeney, 1982) research further identified five factors that seemed to differentiate effective schools from those labeled less effective by:

1. teachers reported receiving significantly more support,

2. there was an atmosphere conducive to learning,

3. the principal had more impact on educational decision-making,

4. there was more evidence of pupil progress monitoring, and

5. there was more emphasis on achievement.

Edmonds (as cited in Sweeney, 1982) studied 20 elementary schools in a study called Detroit's Model Cities Neighborhood which re-analyzed the 1966 Equal Educational Opportunity Survey. Based upon the analysis of that study, Edmonds (as cited in Sweeney, 1982) concluded that schools and school leadership did make a difference in the achievement gains of 
students. Furthermore, Edmonds (as cited in Sweeney, 1982) found that effective schools were marked by leaders who:

- promoted an atmosphere that was orderly, quiet, and conducive to the business at hand,

- frequently monitored pupil progress,

- ensured that it was incumbent upon the staff to be instructionally effective for all pupils,

- set clearly stated goals and learning objectives,

- developed and communicated a plan for dealing with reading and mathematics achievement problems, and

- demonstrated strong leadership with a mix of management and instructional skills (p. 438).

From Edmunds' Detroit study (as cited in Sweeney, 1982) and the work by Hall et al. (1984), leaders in effective schools were more assertive, effective disciplinarians and more inclined to assume responsibility. All of those characteristics had been identified as those exhibited by a principal whose leadership style was that labeled as an initiator. It was the initiator who placed emphasis on instruction and high expectations so that student achievement and learning for all was pervasive in the schools. When the principal exhibited a commitment to ensuring that all students achieved at relatively high levels and assumed the responsibility for those students to reach those levels, then it was believed that the principal modeled high expectations for both students and teachers.

An example where a principal exhibited a commitment that all students achieved at high levels was at McGarvin Intermediate School, located in the Garden Grove Unified School District. That school was considered to be a high poverty, high achieving school because of its academic achievement for two consecutive years. Since the arrival of its new principal three 
years ago, the school's state achievement scores increased 121 points. The question then focused on, Is the principal affecting student achievement? To answer that question, Rinder (2007) conducted a case study with one main research question and four sub-questions. The entire list will not be included here; however, one sub-question was noteworthy: How did the principal hold individuals accountable for implementing standards-based reform to improve and sustain student academic growth (Rinder, 2007, p. 15)?

The focus of this research was on how the principal exhibited an environment where high expectations existed. Rinder's case study incorporated principal high expectations through teacher accountability. Through the incorporation of teacher accountability, the author found that the principal had collaboratively built high expectations focused on the learning environment (Rinder, 2007). Rinder (2007) stated:

The principal and teachers demonstrated a culture of high expectations and work ethic for themselves and their students; focused on instruction, developed collegiality, displayed a strong commitment for learning; possessed internal motivation, and an undeniable desire to see all students succeed. (p. 85)

Furthermore, teachers were held accountable by the principal's articulation of expectations and the frequent use of classroom monitoring. Articulating high expectations for all, the principal focused on the school's common vision of success for all. Through daily classroom visits, the principal was able to monitor for classroom lessons engaging students and teachers assessed students for mastery of content (Rinder, 2007).

Rinder's (2007) case study focused on the leadership role of the principal in building school capacity and accountability. It concluded with three major findings regarding the leadership role of the principal: “(a) principal had used a combination of leadership styles, (b) 
principal empowered teachers, and (c) principal had built school capacity” (Rinder, 2007, p.

129). Furthermore, Rinder (2007) stated that "the principal in collaboration with teachers had established a culture of high academic standards driven by high expectations. It was the belief of McGarvin that high academic standards were the collective responsibility of the teachers, students and principal" (p. 135).

Another example of leadership behaviors promoting high achievement was the phenomenological study of Sweeney (1982). That case study focused upon the leadership behaviors of two principals of effective urban high schools in the state of Connecticut. That study used the following six leadership behaviors identified by Sweeney (1982) to identify what leadership behaviors that principals of effective schools possessed: (a) coordinated instructional programs, (b) emphasized achievement, (c) frequently evaluated pupil progress, (d) provided an orderly atmosphere, (e) set instructional strategies, and (f) supported teachers. The case study's research question was: What leadership behaviors of two urban high school principals have enabled their schools to improve and become effective?

To seek the answer to the research question, Sweeney (1982) selected a qualitative design study to analyze the leadership behaviors of the two principals who attempted to make their schools more effective. Through the use of a phenomenological approach, the researcher explored the perceptions of teachers and key staff members associated with the principal (Davis, 1992). Data was collected through an interview schedule, questionnaire and a field study guide. In selecting the two schools, the researcher used purposive sampling. To satisfy the conditions of such a sampling, the two schools met the following conditions:

- percentage of low-income students enrolled,

- length of time in the Connecticut Secondary School Development Project, 
- size of school, and

- being in the same school district (Davis, 1992, p. 47).

The results of the study (Davis, 1992) supported Sweeney's (1982) leadership behaviors that contributed to school effectiveness. The urban principals exhibited behaviors that fostered a school environment and vision that cared for children and was supportive of adults resulting in an effective school (Davis, 1992). Davis (1992) formed seven conclusions from the study, of which one was noteworthy to this study: both principals were able to "...focus on expectations and success as a strategy to solve problems" (p. 197). In summary, Davis' research found that effective principals of urban high schools engaged in behaviors that were consistent with effective schools. One such behavior was that the principal emphasized achievement through the promotion of high expectations.

\section{Appalachian Beliefs}

A community's beliefs are important, but maybe in the Appalachian areas those beliefs are stronger than in other areas throughout America. The Appalachia region includes portions of 13 states, but West Virginia is the only state located entirely within the Appalachian region (as cited in Marcum, 2008). Many regions within the state are isolated and have resulted in an ethic of self-reliance and independence (Woodrum, 2004). Isolation and low SES status, has limited West Virginia's participation in education (Woodrum, 2004). That may be the reason why only 58 out of 119 secondary schools had made AYP for four consecutive years (Nancy Walker, Executive Director, WVEIS, personal communication, November 5, 2008).

Limiting participation in education was a result of the industrialization of America. That caused school systems across America and Appalachia to restructure. In rural areas such as Appalachia, community-based schools that were once a part of the landscape gave way to 
consolidated district-wide or even district-wide systems (Woodrum, 2004). What that meant for West Virginia was that the power and control of education was leaving the local community and its members and going to professional administrators and to Charleston, West Virginia, where the State Board of Education was located.

As the consolidated systems emerged in West Virginia, the role of the school changed from one where students were educated for membership in their communities to one where students were educated for a future distant from, and distinctly different from, the lives that their parents led (Woodrum, 2004). Children who were sent to the consolidated schools were believed to be taught to move away from the family. That belief went against what Appalachia strongly believed in, kinship.

The belief that education was not important, because it went against family ties or kinship, was noted by Woodrum (2004) in an interview with a mother of a fourth grade student. That mother explained that she did not value state mandated testing because it didn't have anything to do with the child or the family. Furthermore, Woodrum (2004) interviewed another parent who stated that "the day'll come I believe when those schools will just take your kids away" (p. 5).

The belief that education was not important may be the reason why only forty-nine percent of all secondary schools have been able to satisfy the requirements placed upon the state of West Virginia through the No Child Left Behind Legislation of 2001 (2002). That legislation was signed into law in 2001 in an attempt to close the achievement gap. Achievement varied from school to school and state to state among minority populations, special needs students, and gender. Through the use of a high stakes test, schools and school systems had to disaggregate testing data in order to show that the achievement gap was closing between the different groups 
of identified students. The high stakes test made teachers, school building administrators, and district level administrators more accountable to the educational process.

With more than 50 percent of all secondary schools in West Virginia falling short of making Adequate Yearly Progress (AYP) for four consecutive years, it seems to be the case that schools may not have high expectations of students. In order for a school to meet AYP, it must meet the testing scores noted by the Department of Education on the WESTEST (West Virginia Educational Standards Test), have 95 percent of the school's students participate in the WESTEST and have a graduation rate of at least 80 percent.

Even with tangible characteristics associated with high expectations, the schools may not be able to implement high expectations throughout each building. Along with meeting high expectations in Appalachia comes the belief that the school's proper role was to serve the needs of the local community. It was the local community's belief that the school was to reflect and shape a sense of community belonging for its students (Woodrum, 2004). According to Becker (as cited in Woodrum, 2004) "the role of the school was to educate students for membership in their communities and, thus, the school itself becomes one of its fundamental institutions" (p. 3). As a result of that belief, many families do not want their children to go on to college. Going away to college would mean that the child would be removed from the community with the possibility of never returning. If that practice continued, then it would be possible that the community would cease to exist.

To support that belief, Woodrum (2004) found that Appalachian families placed a greater emphasis on the value of interrelationships, on their sense of community and on attachment that children had to the home over individual success. The Appalachian families believed that the school was the institution rooted in the local community that served to uphold the values of the 
community (Woodrum, 2004). With that belief, it was common for members of the community to attend high school graduation throughout West Virginia. Schools are an extension of the community and therefore, graduation should be open for any member of the community to participate in the celebration of the success of its students.

\section{Defining High Expectations In West Virginia}

A survey of literature on school effectiveness concluded that schools do affect students' academic achievement (Purkey \& Smith, 1982). Purkey and Smith (1982) found that the quality of activity at the classroom level was affected through the school environment. In addition, Edmonds continued to build on that foundation that what occurred at the classroom level did affect student achievement. In his first formally published paper on the correlates of effective schools, Edmonds concluded that effective schools were characterized by five correlates and that teacher expectations of student performance was one of the five (Lezotte, 2001). As the effective schools movement continued to grow from the 1980s, other correlates were found to exist in effective schools, but what remained consistent was that effective schools exhibited a climate of high expectations in and out of the classroom (Lezotte, 2001). It was not surprising that climate was an important correlate of effective schools. Rosenthal and Jacobson (1968) found that when teachers held especially favorable expectations, intellectual growth was greater for those children. Stemming from that research, teacher expectancy emerged as a way to help explain how teachers can affect the academic achievement of children.

As Edmonds's paper on the correlates of effective schools was being published, West Virginia schools prepared for the consequences of a circuit court ruling on equality and equity. Lincoln district parents sued the state claiming that the funding of schools was unconstitutional. Circuit Judge Arthur Recht dismissed the State Department of Education's standards for 
educational quality as ineffective (Grimes, 1982). According to Grimes (1982), Recht wrote "the very fact that that document made a district's program dependent on available resources effectively destroyed any expectation of developing high quality standards" (p. 3). The rural counties in West Virginia depended on state monies to fund programs offered within the schools. Even though state policy dictated what courses had to be offered and taught, it was the local school's availability of funds for a teacher and supplies that created a course or not. Until funding was equitable throughout the state, how could the state mandate equal course offerings?

Assisting the West Virginia Department of Education in regulating all 55-district systems, the Legislature of West Virginia passed House Bill 4306 that created the Office of Education Performance Audits (WVDE, 2007). The Education Performance Audit was an integral part of the West Virginia Department of Education's Policy 2320 (WVDE, 2007). As set forth by the West Virginia Board of Education, the Education Performance Audit assisted in determining the accreditation status of schools and the approval status of the school district (WVDE, 2007). Furthermore, the Office of Education Performance Audits (OEPA) appoints an Audit Team to conduct onsite reviews of the educational programs in a school or school district. Another purpose of the audit was to serve as a stimulus to improve all schools, and thus provide a process for continuous school improvement (WVDE, 2007).

A training manual, used by members of the OEPA audit team for an onsite review, contained key elements that determined if schools were accredited. The team members look for evidence that the schools were meeting the specified elements within each of the standards. It was within this training manual where high expectations was listed (6.1.2) and defined as: “Through curricular offerings, instructional practices, and administrative practices, staff demonstrates high expectations for the learning and achieving of all students and all students 
have equal education opportunities including reteaching, enrichment, and acceleration" (WVDE, 2006a, p. 27).

That high expectation indicator had three components that were vague: 1. curriculum offerings, 2. instructional practices and 3. administrative practices for the learning and achieving for all students. What does the State define as practices and how are high expectations demonstrated in each of these? The OEPA training manual further stated "verify through observation; principal, teacher, and student interviews; and review of documentation that staff demonstrated high expectations for each student (WVDE, 2006a, p. 27). That was a vague standard that was not helpful to teachers and principals who have to implement it.

Building off of the high expectation indicator used by OEPA, a framework for a definition can be developed. Following state regulation, the definition would have three components: (a) curriculum offerings, (b) instructional practices and (c) administrative practices. Providing a tangible definition for each of the three components would better serve an audit team, practicing teacher, and practicing principal in determining if high expectations are being implemented in the school and classroom.

Curriculum offerings. The master schedule may be the simplest, yet most important, element when establishing an environment where high expectations existed. What kinds of courses were offered and how were students chosen to participate at the secondary level? Through Policy 2510 Assuring the Quality of Education (WVDE, 2008) specific graduation requirements were listed. Also listed are required and optional electives for all public, secondary schools in West Virginia. Using this policy, schools developed the courses included in the master schedule. From the list of courses, students chose the courses that met requirements for their career path. 
Using Policy 2510 as the basis of the curriculum would not provide an environment of high expectations. Within the policy high expectation courses (e.g., English college courses, Calculus, advanced placement courses and honors courses) are listed as optional electives (WVDE, 2008). Therefore based on the limited resources of a school, only those courses that meet the minimum state graduation requirements are usually taught.

An environment where high expectations existed would provide all students opportunity for the selection of courses that exhibited high expectations. High expectation courses would be included in the master schedule, not just offered. Furthermore, prerequisites needed to take the Advanced Placement and Honor courses would be well publicized. Those prerequisites would be found in the description of each course, located in the school's course catalog. All students would be provided a copy of the course catalog during the scheduling process.

Adding Advanced Placement and Honors courses to the curriculum, and encouraging all students the opportunity to take them, would promote an environment of high expectations. Further enhancement of the curriculum would be to align courses with the state and/or national assessment tools. Good and Brophy (2003) indicated that school curriculum and tests need to be aligned or false conclusions would be drawn about the effects of schooling. The curriculum goals should determine the assessment, not vice versa (Good \& Brophy, 2003). In aligning course tests with the goals of the curriculum, a one-to-one match to course content and student assessment occurs. Using that process, the hope was that student achievement for all would rise.

Instructional practices. Teachers who use a variety of modes for delivering content provide classroom practices that exhibit high expectations. Students need to be engaged in relevant, meaningful learning activities provided through student-centered projects or hands-on activities. WVDE Policy 2510 notes twice that instructional practices must be varied (WVDE, 
2008). In addition, Good and Brophy (2003) found that if students were motivated to achieve, then the teacher's presentation of material should be interesting, meaningful or worthwhile to learn.

An activity where a student is on task may not be such that it entails higher-level cognitive skills. Student seatwork that includes the completion of worksheets that recalls information is considered a lower-level cognitive skill (knowledge level), according to Bloom's taxonomy ("Major Categories," 2008). When the students are engaged in hands-on, studentcentered projects, higher-level cognitive skills (synthesis level) are used according to Bloom ("Major Categories," 2008). Bamburg (1994) states that "lessons need to be exciting, meaningful, and offer students abundant choices" (p. 17). It was believed that classrooms where high expectations are exhibited, students are engaged in hands-on activities or student-centered projects not individual seatwork.

In order to provide students appropriate background knowledge necessary to complete hands-on activities or student-centered activities, the teacher has to articulate the goals and objectives for the lesson. Purpose and reason to learn the information of the day's lesson is important to motivate student learning (Good \& Brophy, 2003). When the students do not know the purpose of the lesson they tend to become disengaged in the activity leading to boredom, daydreaming and even classroom disruption. Through the development of goals and objectives that are aligned with the assessment tool, the lesson has clarity and purpose, leading to increased student achievement (Good \& Brophy, 2003).

When the goals and objectives aligned to assessment and articulated to the students, teachers plan student-centered activities that actively engage students in the learning process. As students are engaged, teacher feedback becomes an integral part of the learning environment. 
Scholars (i.e., Brophy, 1998; Good \& Brophy, 2003; Weinstein, as cited in Dusek, 1985) have found that feedback by teachers shape student perception of performance. Feedback does not need to be long and elaborate, but acknowledgment of student answers to teacher questions should be done (Good \& Brophy, 2003). The use of teacher feedback provides a learning environment where high expectations exist due to the guidance provided to students that enhances performance.

Finally, an environment of high expectations should have a system in place that recognizes and rewards students for academic attainment. Scholars (i.e., Good \& Brophy, 2003; Jacobson \& Rosenthal, 1968; Teddlie \& Reynolds, 2000) found that effective schools recognized student success through verbal praise and tangible rewards. Such a system recognizes all students who make progress, not just those who are high achievers (Good \& Brophy, 2003). Students who work to their potential may not always be those who are high achievers. By recognizing them for working to their potential, the teacher continued to move that student to the mastery of set goals.

Those at a school with high expectations believe that all students can obtain mastery of the set goals. The No Child Left Behind Act of 2001 (2002) requires that all students achieve mastery. That cannot happen until all students have mastered the set goals established in the classrooms. A system employed at schools that provides student recognition also provides the impetus to achieve the requirement that all students be at or above mastery (No Child Left Behind Act of 2001, 2002).

Administrative practices. The third component in the definition for high expectations is administrative practices. What types of administrative practices occur at schools that incorporate 
high expectations? The researcher believes the following five important practices occur when an administrator models a climate of high expectations:

1. the administrator assists teachers in the development of individual plans for instructional improvement,

2. principal designs a master schedule to include a common planning period,

3. the administrator provides feedback to the teacher after classroom observations,

4. the administrator aligns teacher professional development with state and district goals, and

5. the administrator collaborates with teachers in setting core values and beliefs.

The administrator assists teachers in the development of individual plans for instructional improvement. Principals are required by WVDE Policy 2510 to assist the teachers in such activities (WVDE, 2008). Bamburg (1994) believed that school leaders create conditions that promote and enhance learning for everyone. Promoting and enhancing learning for everyone includes assisting teachers in the development of lesson plans that enhance instruction.

If the principal designs the teacher schedule to include a common planning between teachers who teach the same subject, then that group of professionals will be able to work on curriculum through planning, designing and evaluating each other's work as a team. Warren (as cited in Bamburg, 1994) believed that getting the teachers together for the purpose of planning was one way to increase collegiality among individuals who taught the same subject. Teachers' sharing of information between one another is a method the principal uses to assist the teachers in developing lesson plans that enhance instructional improvement. Collegiality supported by the principal is the best technique to enhance instructional pedagogy among teachers. That process creates a learning environment conducive to high expectations. 
The second practice a principal can use to enhance instruction is to provide feedback after a teacher observation (WVDE, 2008). With that requirement, it is essential that the principal make teacher classroom observations a priority. Work on school effectiveness by Teddlie and Reynolds (2000) showed that in high achieving schools, the principal was involved in academic matters and visited classrooms often. Further, Good and Brophy (2003) believed that the quality of dialogue and informed feedback was the most important aspect of a classroom visitation.

Feedback needs to be as specific as possible in order to help teachers improve pedagogy. Wallace (as cited in Good \& Brophy, 2003) found that teacher observation and feedback tended to be nonspecific. Improved instruction through the observation process has to provide as much detail as possible in order that principal feedback has credibility. It is believed that principals of schools that exhibit high expectations make daily classroom observations that provide specific feedback.

It is through classroom visitations that principals are able to determine areas of weakness that can be addressed through professional development sessions. The individual needs of the teachers arise during the principal-to-teacher feedback component to the classroom observations. Good and Brophy (2003) believed that staff development should help teachers address individual needs.

The third administrative practice is professional development. According to WVDE Policy 2510, professional development must be research based (WVDE, 2008). In addition, teacher needs are used to schedule professional development sessions. Both individual needs and needs determined by the principal become a part of the school's continuous improvement plan, i.e. five-year strategic plan (WVDE, 2008). Areas where professional development is conducted are derived from the principal-teacher observation feedback and analysis of student 
achievement data. The analysis of student data identifies problematic areas within classroom delivery of content. Professional development would address and attempt to correct deficiencies. Making problematic areas a part of the school's continuous improvement plan provides credibility to the delivery of professional development in that area. It is through research-based professional development that changes are made to enhance and promote an environment of high expectations.

Finally, in planning the continuous improvement plan, priorities of the school are established. As the plan is developed, the school comes together and forms the shared set of core values and beliefs. If the school does not have a common thrust to serve as the root from which all improvement stems, then the school can be seen as not effective (Lezotte, 2001). Bamburg (1994) concluded:

When faced with a lack of clarity about the school's vision, most teachers retreat to the classroom. Such behavior often leads to a school that in reality is not a school at all but a collection of cottage industries operating in isolation under the same roof. (p. 14) Schools that had increased student achievement had clarity of purpose that was grounded in a shared set of core values and beliefs (Bamburg, 1994). Both a purpose and direction are elements of WVDE Policy 2510 and must be addressed by the principal and faculty (WVDE, 2008). When students operated under "one" set of standards, then the consistency can lead toward an environment of high expectations.

A summary of the thirteen elements the researcher is proposing to be included in the definition of high expectations follows.

First, curriculum offerings would contain: 
- high expectation classes to include: college courses, advanced placement courses and honors courses,

- all students provided an opportunity to select high expectation courses, and

- curriculum aligned with state assessment.

Second, instructional practices that provide an environment where high expectations exist would contain:

- variety of modes for learning to occur,

- student learning centered on hands-on activities,

- teacher has articulated goals and objectives for the lesson,

- teacher-to-student feedback is provided through oral or written comments, and

- $\quad$ system in place to recognize and reward attainment of expectations.

Third, administrative practices that provide an environment where high expectations exist would contain:

- assistance for teachers in developing individual plans for instructional improvement,

- common planning periods exist within the master schedule,

- observations completed with feedback provided to the teacher,

- professional development aligned with state and district goals, and

- shared set of core values and beliefs.

\section{Summary of Chapter}

This chapter focused on school effectiveness and high expectations, and then ended with a framework for a definition of what high expectations would be in a secondary school. The beginning of the school effectiveness movement was found to be in the early 1970 s as the direct result of Coleman et al. (1966) and Jencks et al. (1972) who found schools did not matter in the 
success of students. However, scholars such as Edmonds (1979) and Lezotte and Bancroft (1985) found that certain characteristics existed in schools that had high achievement. These characteristics were labeled correlates and in Edmonds' first produced paper he identified five correlates that were present in schools identified as effective. Lezotte (2001) defined these effective schools as: "a school that was successful in educating all students regardless of their socioeconomic status or family background" (p. 1).

During the 1980s the Effective Schools research expanded the descriptions of what works in school reform to include seven correlates: instructional leadership, clear and focused mission, safe and orderly environment, climate of high expectations, frequent monitoring of student progress, positive home-school relations, and opportunity to learn and time on task. It was then Secretary of Education, William Bennett's affirmation of the Effective Schools movement that catapulted it into being a leader in initiating school reform across America.

Even though the Effective Schools research and its correlates were being touted throughout America, there existed critiques that believed that most of the research was conducted in large, urban school districts with a large minority and economically disadvantaged student population (Lezotte \& Bancroft, 1985). This led critiques (i.e., Purkey \& Smith, as cited in Jansen, 1995) to strongly believe that "there was no consensus yet on just what the salient characteristics happen to be" (p. 185). This however did not stop West Virginia in considering what the implementation of the five correlates would do for school reform across its 55-district system.

West Virginia believed that the correlates would be placed into the framework of its educational system at a relatively minimum cost to the state. To roll the program out to the principals of the 55 counties state wide, the West Virginia Department of Education developed 
the Principals' Academy. It was during the Principals’ Academies, from 1984 to 1992, that principals learned of the correlates found to exist in effective schools. One of those correlates was that high expectations should exist.

Of the seven correlates found in the Effective Schools program, the researcher chose to focus on the correlate associated with high expectations. It was the work of Rosenthal and Jacobson (1968) that underscored what high expectations can do for student achievement in the Oak School experiment. The experiment showed that students whose teacher held especially favorable expectations showed greater intellectual growth than those students in a control group. But how was this being done?

Teachers who expected high expectations were found to be friendlier, enthusiastic and more pleasant toward the students. The overall belief is that through improved teacher-student interactions student achievement would be increased. These interactions include: teacher varies instructional practices, teacher uses hands-on learning activities, teacher articulates the goals and objectives of the lesson, teacher provides feedback to student work, and the teacher has a system in place that recognizes and rewards student attainment of the expectations.

Teachers who obtain National Board Certification maintain an environment where high, rigorous standards exist because that's the mission of the National Board for Professional Teacher Standards (NBPTS). The NBPTS has five propositions that are its pillars and the pillar whereby teachers are committed to students and their learning is directly correlated to the correlate of high expectations. This is why it is important to link National Board Certified teachers to high expectations.

This chapter noted two case studies that highlighted the importance of principal leadership within the school. Rinder (2007) was the first case study that looked at the leadership 
role of the principal in building school capacity and accountability in a high achieving, high poverty, and urban middle school. What the study found was the principal built a culture of high academic standards driven by high expectations through collaboration with teachers.

The second case study focused upon the leadership behaviors of two high school principals in an urban area. This case study was done by Davis (1992) who found that the two principals engaged in behaviors that are consistent with the correlate of high expectations found in the Effective Schools program.

As this study will focus on secondary schools in Appalachia, the beliefs of communities found within the Appalachian area related to education were discussed. The Appalachian culture believes that education is not important because it goes against family ties or kinship. It is the school that strengthens the ties built at home. When sons and daughters leave the home to seek higher education and leave for jobs, parents become defensive through opposing public schools in the area. They believed that schools destroy the community by taking kids away. Because of this, high expectations have to be tied into community beliefs to be effective.

From the literature review, the following framework for a definition of high expectations is proposed: high expectations are indicated to exist through curriculum offerings, instructional practices and administrative practices. The curriculum offerings will include: high expectation courses such as college courses, advanced placement and honors course; all students provided an opportunity to select high expectations courses; and curriculum aligned with state assessment. The instructional practices will include: varied instructional strategies; student learning centered on hands-on activities; teacher articulates goals and objectives for the lesson; teacher provides feedback to the student; and the teacher has a system in place to recognize and reward attainment of expectations. Finally, the administrative practices will include: providing assistance to 
teachers in developing lesson plans for instructional improvement; classroom observations that include principal feedback; professional development aligned with the state and district goals; and a shared set of core values and beliefs.

Table 2 identifies the elements believed to be a part of the framework for a definition of high expectations and their link to policy or scholar reference.

Table 2

Elements of High Expectations Definition Linked to Policy or Scholar Reference

Element of Definition

Policy or Scholar Reference

High expectation course (i.e., college, and honor courses).

WVDE Policy 2510, p. 25.

All students provided an opportunity to select high expectation courses.

Heinlein, personal communication.

Curriculum aligned with state assessment

WVDE Policy 2510 8.3, p. 44.

Good \& Brophy (2003), p. 29.

Variety of modes for learning

WVDE Policy 2510 8.2.4, p. 44 and 8.3.13 p. 45.

Good \& Brophy (2003), p. 214.

Bloom's Taxonomy.

Student learning centered on hands-on activities.

Good \& Brophy (2003), pp. 213, 230, 231.

Teacher has articulated goals and objectives for the lesson.

Good \& Brophy (2003), p. 372.

Teacher-student feedback

Dusek (1985), p. 144 and 337.

Brophy (1998), p. xi.

Good \& Brophy (2003), p. 493.

System in place to recognize and reward

Teddlie \& Reynolds (2000), p. 139.

attainment of expectation. 
Table 2. (continued)

Elements of High Expectations Definition Linked to Policy or Scholar Reference

System in place to recognized and reward attainment of expectation.

Teachers assisted in developing individual plans for instructional improvement.

Teachers provided common planning periods.

Observations completed with feedback to teacher.

Professional development aligned with state, district, school goals.

Shared set of core values and beliefs provide purpose and direction.
Good \& Brophy (2003), p. 223.

No Child Left Behind Act (2002).

WVDE Policy 2510 8.1.1(e), p. 44.

Bamburg (1994), p. 26.

Bamburg (1994), pp. $26-27$.

WVDE Policy 2510 8.1.1(b), p. 43.

WVDE Policy 5310, p. 4, section 9.2 and p. 5 section 9.3 .

Teddlie \& Reynolds (2000), p. 135.

Good \& Brophy (2003), pp. 487, $489-491$.

WVDE Policy 2510 8.1.5(b), p. 43.

Good \& Brophy (2003), pp. 493 - 494.

Lezotte (2001), p. 4.

WVDE Policy 2510 8.1.3, p. 43.

Bamburg (1994), p. 14.

This tables illustrates that a connection exists between the proposed elements of the framework for a definition for high expectations and the Department of Education Policy or literary scholar, indicating how the research study can add to the previous literature on the subject of high expectations. 


\section{Chapter Three \\ Research Design}

\section{Introduction}

The purpose of this study was to examine the curricular, instructional and administrative practices that teachers and principals used in establishing high expectations in selected secondary schools in West Virginia. A qualitative research design was used to focus on the specific practices that teachers and principals used. It was the researcher who was the primary tool in collecting the data from documents, interviews and observations.

The research had three research questions: 1 . What instructional practices and curriculum methods do teachers use to communicate high expectations to the students? 2. What do principals perceive to be high expectations in these classrooms? 3 . What are the administrative and curriculum practices that principals use to promote high expectations within the school?

The chapter begins by building rationales used in choosing a qualitative research design and the case study. Since the research design was qualitative, the researcher was the main instrument used in data collection, so his background is discussed. Next, how the research sites were chosen including the criteria used in the selection process is described. The following section describes how the participants were selected from each site. Data collection techniques included interview management; observation management and document management were discussed. A section on how the data was analyzed follows. Following this, the interpretation and reporting of the data analysis is described. The chapter ends with the section addressing how the quality of the research is judged. 


\section{Qualitative Research}

Soltis (1984), “argued for a comprehensive concept of educational research requiring not just a pluralistic tolerance of different research philosophies” (p. 5), but mutual support among educational researchers. He further made claim that "pedagogy as a basic and universal human activity requires empirical, interpretive, and normative approaches for its proper study" (p. 6). As the researcher builds the case for a qualitative study, the focus will be to approach the study using an interpretive inquiry mode.

It is interpretive inquiry that seeks to answer how and why a particular phenomenon occurs so that it can be better understood. Soltis (1984) believed that empirical evidence of a phenomenon was too narrow and failed to find the human element. This study sought to find the human element that existed in how teachers and principals set high expectations in the classroom and building. Using an interpretive inquiry design was the best way to gather the information needed to answer "how" high expectations were established.

The selection of method for the study was based upon three beliefs found to be pervasive in other research on high expectations (e.g., Brophy, 1998; Good \& Brophy, 2003; Lezotte, 2001). First, effective schools were found to have principals that exhibited high expectations. Second, teachers in effective schools exhibited strong teacher efficacy and third, the schools had a strong belief that all students could learn. From these, the researcher was interested in finding out how each belief was manifested within the school building.

Using those beliefs, the researcher proposed to use a qualitative approach to gather data that would reveal what teachers and principals did to develop high expectations. From that data, a description of the practices used by teachers and principals would help define what the phrase high expectations meant. Strauss and Corbin (1990) found that a qualitative study "produced 
findings not arrived at by means of statistical procedures or other means of quantification. It can refer to research about persons' lives, stories, behavior, but also about organization functioning, social movements, or interactional relationships" (p. 17).

As Merriam (1998, p. 5) aptly phrased qualitative research "it helps us understand and explain the meaning of social phenomena with as little disruption to the natural setting as possible." Furthermore, Patton (2002) stated that "qualitative methods permit inquiry into selected issues in great depth with careful attention to detail, context, and nuance; that data collection need not be constrained by predetermined analytical categories contributed [sic] to the potential breadth of qualitative inquiry" (p. 227). Finally, Merriam (1998) stated that "qualitative research implied that reality was holistic, multidimensional, and ever-changing; it was not a single, fixed, objective phenomenon waiting to be discovered, observed and measured as in quantitative research" (p. 202). From Merriam and Patton, it was the researcher's belief that the practices that teachers and principals used to establish high expectations would be best highlighted through a qualitative study that used interviews, observations and document collection.

Teachers and principals have set practices within the classroom and building that the students follow. Those practices are what the researcher investigated by way of semi-structured interviews, observations of teachers and the school, and document review. Established practices involved making decisions on how curriculum and pedagogy were chosen to best meet the needs of all students. In using a qualitative study, the researcher was able to retrieve that information.

The data collection methods immersed the researcher in what Soltis (1984) claims was "the human realm of intersubjective meaning by using the evidence of everyday social life" (p. 
6). As the researcher engaged in interviews and observations, the teacher-to-student human interactions illuminated the practices used in meeting higher expectations.

Having described qualitative inquiry and how this study was best suited to this design, the researcher then completed a review of Dissertation Abstracts Online, from 1980 - 2008, since the Effective Schools movement started in the 1980s. Looking at other dissertations provided a means for the researcher to check what had been done in the area of high expectations.

A review of both quantitative and qualitative methods was performed by searching Dissertation Abstracts Online using the keyword "secondary" and ("principal and teacher") and “expectations." From those keywords, a total of 93 studies were found. Of those, 32 used qualitative methods for the collection and analysis of data, 53 used quantitative methods, and eight used a mixed methods approach.

In the 53 quantitative studies, questionnaires were used most frequently as the instrument in seeking what the principal's role was in schools identified as effective. Of the 53 studies, 19 were conducted at the secondary level (grades $9-12$ ), one at the middle level, seven at the elementary level, and 19 incorporated mixed levels. Six were conducted in foreign countries and one used district superintendents.

Researchers deemed schools effective by the use of either national or state recognition programs (e.g., secondary school recognition, blue ribbon schools, or state schools of excellence). Data was collected through correlational studies using test scores to measure student achievement. The collected data was analyzed using a variety of statistical techniques such as t-tests, one-way analysis of variance, Chi-square tests, linear model analysis, and Pearson 
correlation coefficients. Of the 53 studies, 26 used a statewide sample pool and two studies used multiple states as the sample.

An example of a quantitative study was by Koger (1987) who examined the principal's role in providing instructional leadership in effective schools. The study's subjects were principals from 209 secondary schools recognized in 1984-85 by the United States Department of Education in its Secondary School Recognition Program. Each principal completed a questionnaire of 39 instructional leadership activities. The most important and most frequently engaged activities of principals in those effective schools were: the principal formally visited classes as part of the teacher evaluation process, the principal recognized and rewarded student achievement, and the principal encouraged the belief that all students could learn. It was the work of Good and Brophy (2003) that linked high expectations to learning for all.

Of the qualitative studies, the most frequently used methods of collecting data were interviews of teachers and principals and observations of classrooms. Three studies were found that used a qualitative research design of subjects at the secondary level(e.g., Cosner, 2005; Davis, 1992; Mizelle, 1995).

The search revealed that only three of the 32 studies involved secondary schools, defined as schools serving grades 9 -12. This was not unique because the work of Edmonds (1979) through the School Effectiveness Research, and Good and Brophy (2003) all took place in primarily elementary schools. However, a goal of the School Effectiveness Research was to have the correlates exist in all contexts. This research will contribute to the literature of School Effectiveness Research because the study was qualitative and occurred in the secondary context, two areas the School Effectiveness Research had been found to be weak in. 
Each of the three studies used both participant interviews and document collection in obtaining data. Cosner (2005) used a multiple, in-depth interview technique that was spread over an 18-month period. As for the other two studies, the researcher completed a one-time interview of participants. Each study included the collection of documents that could be used to substantiate the interviews. For example, in the Cosner (2005) study, documents from each principal's school were collected, noting how principal leadership for school capacity was attempted. Both Davis (1992) and Mizelle (1995) noted that documents were collected relative to the principal's role within the building.

In addition to the three qualitative case studies found at the secondary level, two were case studies of participants at the intermediate level (e.g., Nordheim, 2006; Rinder, 2007). The criterion used in selecting the schools was that student performance, as measured by the state Academic Performance Index (API), be extremely high. This was evident in Rinder's (2007) study where the API score was above 800 .

Nordheim (2006) used a qualitative case study where an urban public intermediate school serving grades seven and eight was selected for the study. Data was collected from 39 participants, including the Superintendent, Assistant Superintendent, Director of Secondary Instructional Services and 25 teachers. Methods used in the data collection included individual interviews with the participants and voluntary teacher participation in a survey.

The Rinder (2007) study was a qualitative case study of an intermediate school located in an urban area. For two consecutive years the school scored above the state required 800 on the Academic Performance Index. Data was collected from a total of 15 participants ranging from principal to parents. Methods used in the collection of data included face-to-face, semi- 
structured interviews, classroom observations, campus observations, document review and observation of faculty and leadership meetings (Rinder, 2007).

In the Rinder (2007) study three major findings were reported that are relevant to this study's purpose. The principal's leadership style focused on standard-based instruction through clearly defined expectations, the principal empowered teachers, and he/she built school capacity that sustained student academic growth. It was the compilation of all three that allowed this principal to turn a high poverty school into a high achieving school. How the principal was able to articulate expectations and then held teachers accountable to that was an important facet that tied this study's purpose of defining the principal's role pertaining to what high expectations were to the Rinder (2007) study.

Having completed the analysis of dissertations using the words "secondary" and ("principal and teacher") and "expectation," the keywords "rural schools" was added. This search spanned from $1980-2009$ and resulted in two studies. The first was a quantitative study with the purpose of analyzing teacher perceptions of female secondary principal dress. In the second it, too, used quantitative methods to analyze the factors identified by secondary school principals in deciding to change from a traditional schedule to a block format. Both of the studies contained no information pertaining to high expectations from the perspective of teachers and principals. From this search, it was believed that this study may be the first to seek the definitions and practices for high expectations at the secondary level from the perspective of teachers and principals.

\section{Case Study}

Creswell (1998) defined a case study as "and exploration of a bounded system or a case over time through detailed, in-depth data collection involving multiple sources of information 
rich in context" (p. 61). From that definition, the researcher explored three schools where indepth information was obtained to answer the three research questions. Information was obtained through teacher and principal interviews, classroom and school observations and the collection of various documents from each site.

Stake (1995) made the point that if the researcher gained insight about a question through studying a particular case, then the inquiry was called an instrumental case study. In answering the proposed research questions, the researcher is able to better understand, as well as the reader, the description and explanation of the practices used by teachers and principals when high expectations were sought. From that, the researcher proposed to use the instrumental case study.

In an attempt to maximize what was learned the researcher picked three sites, where each site was a separate case study. Stake (1995) referred to studies that involved more than one case as multi-case or a collective case study.

Each of the sites was instrumental in learning about the definitions and practices used by secondary teachers and principals when high expectations were established. The researcher used criterion based sampling to choose the three sites. Goetz \& LeCompte (as cited in Merriam, 1988) defined this as selecting a sample based on a "unique or rare attribute inherent in a population" (p. 50).

The unique attribute chosen for the selection of the three sites was schools that had obtained adequate yearly progress (AYP) for four consecutive years beginning with the 20042005 academic year. Adequate yearly progress was chosen because in order for a secondary school to meet that standard, students' performance on the West Virginia Educational Standards Test (WESTEST) had to meet the yearly goal set by the state, had a participation rate equal to or above 95 percent for the WESTEST, and had a graduation rate for the school at or above 80 
percent (WVDE, 2007). To obtain a list of those schools meeting the criteria, the researcher contacted Nancy Walker, Executive Director, West Virginia Educational Information System, WVEIS (personal communication, November 5, 2008).

\section{The Researcher}

The instrument used to collect data in a qualitative study is the researcher. Therefore, it is important to disclose his background and experiences. This type of disclosure was important because the researcher's background and experiences contributes to the investigation and results (Peshkin, 1988). Furthermore, Patton (1990) described the strength of qualitative research as "fully using human insight and experience" (p. 432). A description of the researcher's experiences follows and served in establishing rigor to the qualitative research.

I have 22.5 years of experience in public education in two states. For the first year, I served as a classroom teacher in a district that had one building serving grades $\mathrm{K}-12$ with a total student population of approximately 500 . Following that experience, I relocated to West Virginia where I served as a classroom teacher in a rural school district with a total student population of approximately 1,000 for ten and one-half years. It wasn't until after relocating to West Virginia that I learned it was the only state fully immersed in Appalachia.

For the past eleven years I served as principal of two different schools. The first three of those eleven years I served as principal of the smallest public high school in West Virginia, serving approximately 120 students. That school was one of four high schools in a district that served approximately 2,500 students. I spent the remaining years at a consolidated high school that is located in a rural area. The school has an approximate enrollment of 750 students in grades 9-12 with the total district enrollment of approximately 2,300 students. 
During the first two years in the classroom, I struggled to meet the needs of the students. I found that students were not grasping the material presented and blamed them for not putting enough effort into the class. After numerous conversations with another teacher, I changed my teaching strategies. Teaching for understanding became the priority over quantity of content. That resulted in an emphasis on quality over quantity in planning and implementing lesson plans.

As I implemented the new approach I discovered two trends in student achievement. First, when homework was checked daily, the number of students successfully completing the assignment significantly increased. Second, the number of students failing the course was significantly less. I believed that both of those trends centered the classroom atmosphere on learning for all rather than the amount of curriculum covered.

Moving from the classroom to the principalship, I was required to receive training on personnel evaluation. In accordance with West Virginia State Board of Education Policy 5310 (WVDE, 2006b) "all supervisors shall receive training in (a) conducting observations and conferences, (b) completing evaluations, and (c) writing and monitoring improvement plans" ( p. 3). During the training, I focused upon section 14.3.1(d) that stated, "sets high positive expectations for student performance" (p. 9). The reason for focusing on that particular section was my personal belief that what I did as a classroom teacher satisfied that condition. However, even though that was listed as a criterion to check when going into classrooms, no tangible state definition existed.

Since the training session, I completed classroom observations using my own belief as to what the concept high expectations meant. Those included the following teacher behaviors: engaged all students, had a positive rapport with students, monitored student progress during the lesson, recognized positive behaviors, acknowledged student achievement and kept students on 
task. However, during the post-observation conference with teachers, I had encountered the following responses from them as to what high expectations meant: "I expect students to do their homework," "I make them work the entire period," "I give homework every day of the week," and "I don't allow anyone to sleep." Those varied responses, in combination with what I believed, resulted in my becoming engaged in the Effective Schools movement.

In retrospect, those beliefs moved me into participating in the Effective Schools movement that I did not know about at the time. I began to read about the work of Edmonds, Lezotte and Brookover. What became evident during the readings was how high expectations were one of the key correlates, but yet no tangible definition was given. How could I, as principal, begin to address teacher high expectations if no tangible definition existed?

In seeking to find the answer to that question, I was hopeful that this research would assist me. Through the interpretive case study, qualitative method that involved the use of semistructured, in-depth interviews, participant observations, and document review, I would be able to gain valuable information from participants with hopes of finding recurring themes that madeup participant practices identified in establishing high expectations. From those recurring themes, it was believed that a tangible definition of high expectations would emerge.

Those recurring themes would be the key to explaining how it was that teachers developed high expectations within the classroom and what principals did to promote and sustain those expectations throughout the school. According to Patton (1990), "a qualitative analysis emphasized illumination, understanding, and extrapolation rather than causal determination, prediction, and generalization" (p. 424). I used the information and themes collected from the participants to paint a holistic picture of how high expectations were created and sustained in the chosen sites. 


\section{Research Sites}

Purposeful sampling was used to select the sites based on four criteria. Patton (2002) stated the following about purposeful sampling: "it focused on selecting information-rich cases whose study would illuminate the questions under study" (p. 230). To obtain the data necessary to answer the research questions the following four criteria were used: 1 . sites were secondary schools that met AYP for four consecutive years; 2. sites contained at least one teacher who was Nationally Board Certified; 3. convenience; 4. sites would participate voluntarily.

The study focused on secondary schools so that the results would contribute to the School Effectiveness Research. The literature review revealed that most of the research completed on School Effectiveness Research centered on low SES, elementary schools. It was the use of the different context, secondary, that provided the contribution to this research. So for the purpose of this research study, a secondary school was defined as any school that contained grade 12 .

According to Nancy Walker, Executive Director, West Virginia Educational Information System (WVEIS) (personal communication, November 5, 2008) there were a total of 119 secondary schools in West Virginia in 2008. Due to the organization of West Virginia, the 119 schools were found in 55 district school systems. Nancy Walker provided the researcher with a list of secondary schools that made adequate yearly progress (AYP) for the past four consecutive years beginning with the 2004-2005 academic year. Fifty-eight out of 119 secondary schools met AYP for four consecutive years.

Table 3 displays the grade configuration of the 58 secondary schools in West Virginia that made AYP for four consecutive years as of 2008. According to WVDE Policy 2320 (WVDE, 2007), grade 10 was the determining factor when considering a school be listed as secondary. 
Table 3

Grade Configuration of West Virginia Secondary Schools that made AYP for Four Consecutive Years.

\begin{tabular}{llc} 
Grade Range & Number of Schools & Percent \\
\hline K -12 & 3 & 5.2 \\
$7-12$ & 7 & 12.1 \\
$9-12$ & 48 & 82.7 \\
TOTAL & 58 & 100.0
\end{tabular}

Table 3 shows there were 58 secondary schools in West Virginia that made AYP for four consecutive years $(2004-2008)$. In addition, the most commonly used grade configuration for secondary schools was grades 9-12 (48 out of 58).

The researcher believed that the 58 schools were schools that exhibited an environment of high expectations. Why those schools had been able to achieve AYP for four consecutive years will be highlighted in answering the research questions of this study. Information garnered from this research will assist the state in addressing the needs of the 61 schools that did not make the list.

Another criteria used in selecting participants was that the school contained at least one National Board Certified Teacher (NBCT). According to the 2008 guide to National Board Certification (National Board for Professional Teaching Standards, 2008), there were 25 fields available for National Board Certification. Each field required the teacher applicant to submit a portfolio. The portfolio contained four different entries. Three of the entries were based upon 
classroom work with two of the three requiring video recordings of interactions between the teacher applicant and his/her students. In addition, a detailed analysis of the instruction reflected in the student work or video was required (National Board for Professional Teaching Standards, 2008). The remaining entry could be student work samples.

When looking at the portfolio requirements, the instructional practice that Ainscow, Hopkins, Southworth and West (as cited in Teddlie \& Reynolds, 2000) prescribed came to mind. They believed that inquiry and reflection was essential to facilitating effective teaching and high expectations at the classroom level. Through detailed analysis of the instruction, each National Board Certified Teacher (NBCT) applicant engaged in inquiry and reflective practices. Because this study sought to find the specific practices teachers and principals used in establishing an environment of high expectations, schools with at least one NBCT were selected to add to the rich description of data. As the study evolved this became less important to research; the fourth question in the original proposal was omitted.

In determining schools where National Board Certified Teachers (NBCTs) existed, the researcher contacted Nancy Walker, Executive Director, WVEIS (personal communication, November 5, 2008). As of 2008 seventeen out of 119 secondary schools contained at least one NBCT, and had met AYP for the last four consecutive years. Furthermore, in 2008 there were a total of 68 teachers in West Virginia that held National Board Certification. Twenty-six of the 68 teachers were staff members at the 17 secondary schools that met AYP for four consecutive years.

For criteria three, the researcher looked at the 17 secondary schools provided by Nancy Walker and determined how many were convenient to the researcher. Convenient was defined as a school within a 100-mile radius of the researcher's residence. Using that criterion the field 
of 17 was narrowed down to three. It was then those three schools that moved on to fulfill criteria number four.

To satisfy criteria four, a letter of notification was sent to the principals of the three sites seeking their approval for participation in the study. A copy of this letter is found in Appendix A. After three weeks, a letter to a central office representative of the three districts was sent that included an explanation of the purpose and methods of the study, and that a principal in the district was asked to have his/her school participate in the study. A copy of this letter is found in Appendix B. Three days after the central office representative letter was sent an email was sent to each principal as a follow up to their letter. Once approval was granted by the central office representative, the researcher contacted each principal by phone to set dates for the researcher to be on campus for data collection.

In choosing schools that satisfied all four criteria, rich information could be provided in answering the question of what were the practices teachers and principals used to create high expectations? The final preparation to the data collection was to conduct a pilot study. A secondary school principal and three teachers, other than those at the chosen sites, were selected for a pilot case study. The pilot case study process assisted in the refinement of the interview questions. Yin (1984) states that having a case study protocol is "essential if you are using a multiple-case design" (p. 64). In addition, it is the protocol that helps increase the rigor of the case study (Yin, 1984). The case study protocol is to contain the overview of the project, field procedures, case study questions, and a guide for the report. Within the protocol will be the interview questions along with the analysis and interpretation processes. These items are addressed in later sections. 


\section{Data Collection}

The criterion used to judge when to stop sampling the different schools was theoretical saturation. According to Glaser and Strauss (as cited in Flick, 1998) "saturation means that no additional data are being found whereby the sociologist can develop properties of the category" (p. 66). Furthermore, Flick (1998) concluded that sampling further material was finished when nothing new emerges.

The research data was collected through the use of participant interviews, observations, document review, and field notes. In order to gain valuable opinions, perceptions and attitudes about the research topic, the researcher specifically used semi-structured interview questions. Using the data obtained from the interview questions, the researcher was able to describe the practices that secondary teachers and principals used to establish high expectations.

Merriam (1998) considers semi-structured questions to be in the middle of the pendulum with highly structured questions being to the extreme right and unstructured questions to the extreme left. The semi-structured interview, according to Patton (2002) is considered:

A combined strategy that offers the interviewer flexibility in probing and in determining when it is appropriate to explore certain subjects in greater depth, or even to pose questions about new areas of inquiry that were not originally anticipated in the interview instrument's development. (p. 347)

Due to the use of probing, the majority of data collected in this interpretive case study used semistructured, one-on-one interviews with teachers who were self-selected, and principals. The interview questions will be addressed in more detail in the section titled interview management. The guiding purpose of the questions was to describe the practices secondary teachers and principals used when establishing high expectations. 


\section{Interview Management}

The goal of the proposed research was to seek information about the practices teachers and principals used to establish and sustain high expectations. The researcher was the interviewer and attempted to set up a situation where the teachers and principals revealed their feelings, meanings and thoughts about the practices used. No student interviews occurred during the data collection process.

In association with the Effective Schools Correlates, the principals at each site were interviewed first. It is the principal's leadership that builds and supports an environment where substantial attention to the quality of instruction was listed as the number one correlate. So, the interview questions were based on seeking information about the practices principals used to establish and sustain high expectations. A copy of the interview questions and probes used can be found in Appendix C. The interviews occurred in the principal office the first day of the visit. To show the willingness of the principals to participate in the research project, each one spoke as brief as 53 minutes and as long as two hours. A copy of a completed interview can be found in Appendix D. The interviews were recorded and transcribed.

Teacher interviews occurred during the five-day-week of the site visitation. The list of teachers who volunteered to participate was obtained from the principal. Using the master schedule the researcher was able to determine when the teachers of each building were available. The researcher then contacted each teacher to set up the interview time and a copy of the questions was offered.

Interviews occurred in the teacher's classroom when no students were present or in a secured conference room. A copy of the interview questions and probes can be found in Appendix E. The researcher continued to interview teachers who volunteered until theoretical 
saturation was reached. Theoretical saturation means that "no additional data are being found whereby the sociologist can develop properties of the category," (Glaser \& Strauss as cited in Flick, 1998, p. 66).

The total number of teachers interviewed at each site varied from a minimum of eight to a maximum of 14 , depending on when theoretical saturation occurred. The willing volunteers spoke as brief as twenty-four minutes and as long as one hour and thirty minutes. The interviewees believed that the research was important and they were pleased to be a part of this research. An example of this was the teacher who provided the researcher her cell phone number so that the interview could be completed by a phone conference the following week. After a few minutes of getting to know each other, the interviews were recorded and then transcribed. A copy of a completed interview can be found in Appendix F.

A matrix for both principal and teacher interview questions is found in Appendices $G$ and H. Each matrix was developed to check for correspondence between the proposed interview questions and the study's guiding research questions. Each interview question was matched with a corresponding research question and author(s) found in Chapter two, the literature review. In addition, the matrix included anticipated responses from the respondents. The anticipated responses assisted the researcher in developing probes. Probing is considered to be a strategy used in questioning (Lichtman, 2006). Probing is one of six ways to "get the respondent to talk and reveal what he or she thinks or believes about something" (p. 124). The pilot study found the interview questions and probes to be sufficient in addressing the research questions.

Participants were interviewed using an in-depth interview technique with open-ended questions. This technique, described by Lichtman (2006), is "a conversation between interviewer and participant" (p. 119). Developing the questions used for the in-depth interview 
required much planning and thought. Lichtman (2006) described five types of questions used during the interview; this interview used four of the five: grand tour, specific examples, comparison/contrast and a closing question.

The interview began with a grand tour question about each participant's definition of high expectations. For the teachers, the next nine questions were designed to provide the researcher with specific examples related to high expectations. Principals had seven questions designed to provide the researcher with specific examples related to high expectations. Following the specific examples was one question where both teachers and principals compared and contrasted National Board of Professional Teacher Standards to the current classroom standards. The interview ended with a closing question where the participant was provided the opportunity to share any other thoughts or beliefs on high expectations.

From the questions, the researcher developed tentative answers to help construct probing questions that asked for more elaborate information. Patton (2002) described probes as, "questions used to deepen the response to a question, increase the richness and depth of responses, and give cues to the interviewee about the level of response that is desired" (p. 372). The probes were used to elicit who, where, what, when and how responses so that a detailed picture could be obtained (Patton, 2002). Using the probes required time and there were periods of silence from the interviewee. The researcher was patient and allowed the interviewee time in order to give proper attention and deliberation to the responses (Lichtman, 2006). The researcher did not use the word probe during the interview, but probes were prepared and included with the interview questions. The probes are included with the interview questions that are found in Appendices $\mathrm{C}$ and $\mathrm{E}$. 
As previously mentioned, a pilot study was conducted over a two-day period. On July 23, 2009 the principal and two teachers of a selected secondary school were interviewed. The following day, July 24, 2009, the third teacher, who was Nationally Certified, was interviewed in a nearby college library conference room. From the pilot study, it was determined that the questions and corresponding probes were sufficient in securing the data needed to answer the research questions.

\section{Observation Management}

Rather than relying on one type of data source, the researcher engaged in the observation of the teachers and activities that occurred at each site. The intent of the observations was to assist the researcher's understanding of the practices that teachers and principals used in the development of high expectations.

Teachers were observed during instructional time in their classrooms. The focus of the classroom observations was to check if items such as the following occurred: 1 . the use of a variety of instructional modes, 2. student learning centered on hands-on activities, 3. teacher had articulated the goals and objectives for the lesson, 4. teacher feedback was provided to students and, 5. a system was in place that recognized and rewarded students for attaining the teacher's expectation(s). Refer to Appendix I for the classroom observation form.

The classroom observations lasted for approximately 30 minutes, where Appendix I was completed by marking an X next to the item observed. Anecdotes were provided at the bottom of the form during the observation to capture activity(ies) that the researcher found profound or contributed to the research. The researcher checked to see how students were rewarded for academic accomplishments by posting student work, or posting a student of the week or month. 
In addition, the researcher looked to see if classroom rules and expectations were posted or if the objective for the day was posted.

Collecting data in a holistic manner was done as observer-as-participant (Junker, as cited in Merriam, 1988). Junker (as cited in Merriam, 1988) described the observer-as-participant method as, "the researcher's activities are known to the group and the group endorses them." This research study was presented to the principal of each site, who picked the dates the researcher would return to collect the data. It was then the principal's decision as to how the faculty and staff were made aware of the research project. For example, at one site the first day of the visit was set up to be a day when the school had a faculty meeting and parent-teacher conferences. That principal allowed the researcher time during the faculty meeting to speak about the research project and seek volunteers. At the other two schools, the principal had communicated to the teachers when the researcher would be on campus and the purpose of the visit. For that reason, the observer-as-participant method was the technique used in observing both classrooms and sites.

The researcher also observed the day-to-day operation during the five day site visit. The researcher specifically looked for the nonverbal cues that occurred in the building by looking to see if student recognition was displayed in the hallways and what was displayed upon entering the building (i.e., student awards, school accolades, school mascot, athletic awards, school calendar, etc.). In addition, the researcher looked to see if student work was displayed in the hallways, tutoring schedules or availability of tutoring, student organizations, or motivational posters, murals, and/or slogans posted in the hallways. The observations occurred before school, after school, in the hallways between classes and during classes, and at lunch without time limits. The anecdotal information was recorded, noting the date and at times the time of day. 
Patton (2002) stated that, "direct, personal contact with and observations of a setting have several advantages" (262):

- the inquirer is better able to understand and capture the context within which people interact,

- inquirer can be open,

- inquirer has the opportunity to see things that may routinely escape awareness of the people within the setting,

- inquirer has the chance to learn things that people would not talk about during an interview,

- inquirer provides the opportunity to move beyond the selective perceptions of others,

- inquirer draws upon personal knowledge during the formal interpretation stage of data analysis (pp $262-264)$.

The direct experience of the day-to-day operation provided anecdotal knowledge of how teachers and principals communicated high expectations to the students, beyond what was said during the taped interviews. Patton (2002) states "everything that goes on in or around the program is data" (p. 286). When the researcher was immersed in the day-to-day operations, he was able to hear, see cues and experience the reality in the same way as the students. It was not just what was said that was important, but the non-verbal symbols used throughout the building and classrooms was important too. Patton (2002) states, "to capture a holistic view of the program, the evaluator observer must stay alert to what happens informally" (p. 287). It was from those experiences that the researcher was able to gather information from a holistic descriptive manner. 


\section{Document Management}

In order to assure rigor, an analysis of school documents was completed so that the researcher was able to provide triangulation (Patton, 2002). Furthermore, Marshall and Rossman (1995) found that "the review of documents was an unobtrusive method, one rich in portraying the values and beliefs of participants in the setting" (p. 85). Merriam (1988) adds that documents can be used to "furnish descriptive information, verify emerging hypothesis, advance new categories and hypothesis, and offer historical understanding, and track change and development" (p. 108).

Documents were collected at each of the three sites. Documents included minutes of meetings (i.e., faculty senate, curriculum, local school improvement, and department), teacher lesson plans, student work, student handbook, teacher handbook, course syllabi, school newsletter, state testing data, and the master schedule. Each of those items pertained to meeting high expectations. All of that information was brought together and stored in a physical folder labeled with each site's name. That allowed the researcher to establish a complete and manageable data file for each site.

At one of the sites, while looking through principal copies of teacher lesson plans if a document was found that exuded high expectations the principal of that site was contacted and permission was given to make a copy. When at another site during the interview process a teacher brought out information about his/her lesson plans that were believed to be important to the research proposal. The researcher then asked the teacher for a copy of that lesson plan at the end of the interview. These kinds of techniques were used to seek out documents that would assist in providing rich details to the case study. Merriam (1988) described seeking such 
documents as "good sources for qualitative case studies because they can ground an investigation in the context of the problem being investigated" (p. 109).

\section{Data Analysis}

Patton (1990) wrote:

Because each qualitative study is unique, the analytical approach used will be unique. Because qualitative inquiry depends, at every stage, on the skills, training, insights, and capabilities of the researcher, qualitative analysis ultimately depends on the analytical intellect and style of the analyst. (p. 372)

The manner in which data is collected in a qualitative study makes the distinction between data gathering and analysis far less absolute (Patton, 2002). Because of no hard fast beginning and ending point in qualitative research data gathering and analysis, Patton (1990) claims "there are no formulas for determining significance. In short, do the very best with your full intellect to fairly represent the data and communicate what the data reveal given the purpose of the study" (p. 372)

Data analysis began during the data collection process for this research project. As interviews occurred, documents collected, observations completed, and field notes written initial data was recorded. Merriam (1988) stated "data collection and analysis is a simultaneous activity in qualitative research" (p. 119).

The data analysis is the process of making sense of the volume of qualitative material and attempts to identify core consistencies and meanings (Patton, 2002). For this purpose then the first step was to make a case record for each site.

Each case record contained: interview transcripts, documents, observations and field notes. These items were used for the within-case analysis and cross-case analysis. Coding 
procedures were used to categorize the data based upon the research questions and the themes that emerged during analysis. The case record must be complete but manageable, and organized at a level that is above the raw data (Patton, 2002).

Each of the thirty-six interviews were coded with categories based on the research questions and aligned with the three themes identified from the proposed definition of high expectations. For each case record the coding categories were revised as new ones emerged during the data analysis. It was through inductive analysis that the categories evolved. Patton (2002) defined inductive analysis as "findings that emerge out of the data, through the analyst's interactions with the data" (p. 453). The case record was a way to reduce the amount of data and perform a within-case analysis.

In writing the first case study, the researcher tried to identify what the teachers most frequently reported. Say for example, at Cherry High School the teachers kept saying how the schedule drove the students to high expectations. It was through the unscheduled time built into the schedule that provided students self-discipline in seeking out additional help, making up work, working on research projects, and completing assignments. While the state's definition of high expectations merely provided the framework, the researcher tried to listen to the voices of the teachers as they responded to the interview questions.

Due to the researcher transcribing each interview, he was able to not only hear the responses to the interviews once, but twice. From the transcription process arose the categories that teachers and principals were saying most frequently that lead to the identification of prominent categories. The state's definition was then used later to organize the categories.

Even though the categories emerged inductively, the themes arose from the research questions and subjectivity of the researcher. Peshkin (1988) writes that "researchers should 
systematically identify their subjectivity throughout the course of their research" (p. 17). He further writes that "if researchers are informed about the qualities that have emerged during their research, they can at least disclose to their readers where self and subject became joined" (p. 17). Then in accordance to Peshkin I must reveal that it was during the transcription of the interviews that I became joined with the subject. It was my beliefs in how teachers and principals can portray high expectations that I was truly searching for. Because of that, I deductively chose the themes from which the study was based. I believed that the three components of the research questions determined how it was that I would be able to answer the purpose of the study.

Once the data analysis was completed the next thing to be done was to provide a detailed description of each case. Creswell (1998) suggested that when multiple cases are used to first provide a detailed description of each case and theme. The detailed description contained the school setting, administrative practices, curricular practices and instructional practices.

The school setting provided information that allowed the reader to become immersed in the setting from which administrators, teachers, and students worked and lived each day. That description included: the student population of the site, how many teachers and administrators were on staff, the educational level of the teachers compared to that of the state, a description of the administrative team, a listing of the student WESTEST math and reading/language arts scores for the years 2008 and 2009, student ACT scores for 2008 and 2009, as well as SAT scores for 2007 and 2009, a listing of Advanced Placement courses taught.

Next, the case description included those categories that were found through the data analysis that described each theme that arose from the proposed definition of high expectations. The first of the themes to be described was the practices found in each case study that illuminated administrative practices. After administrative practices came the categories that 
highlighted curricular practices. Ending the case study was the categories found to exude the instructional practices.

To assure rigor when writing the case description triangulation was incorporated through the use of interviews, documents, observations and field notes. Triangulation is used to demonstrate that consistency exists between data sources (Patton, 2002). Along with triangulation, within-case and cross-case analysis methods were used to assure rigor.

The cross-case analysis allowed for each site to be compared and contrasted against the other two. It was this process that looked at the three themes and what categories were identified to be common among all three sites. Each site had numerous categories that were unique to that site's reflection of high expectations. It is the cross-case analysis that "attempts to build a general explanation that fits each of the individual cases, even though the cases will vary in their details" (Yin, 1984, p. 108).

The commonalities obtained during the data analysis lead to the decision to present the findings as a cross-case report. Through the cross-case analysis, validity of the study was enhanced because of the potential for generalizing beyond one case (Merriam, 1988).

Data analysis continued during the writing and revising of drafts for the results and conclusions chapters. As more information was needed to verify or dismiss categories interviewees were contacted at each site. In addition to seeking information from the interviewees, further documents were requested, too. For example Orange High School was contacted in the summer of 2010 to obtain copies of the prioritized curriculum map, and examples of gifts that were provided to students during the community student achievement recognition program. 


\section{Interpretation and Reporting}

After collecting the data and its corresponding analysis, the researcher must then ask, "What does this mean?" and "What does this tell me about the proposed research question?" (Patton, 2002). From the beginning of this interpretive case study research, finding the practices that teachers and principals use to establish high expectations has been the primary focus. Through the data interpretation, it is the responsibility of the researcher to choreograph the information obtained from the analysis of the data so that the research questions are given meaning.

It is the intent of the research proposal to make sense, offer explanations, draw conclusions, and consider meanings of what is happening inside classrooms and schools that create high expectations. This is the reason a qualitative study was chosen. The study portrayed a holistic picture of the practices teachers and principals use within the selected sites.

After interpreting the data, the final step in a qualitative study is the written report. Through description and direct quotes, the reader is brought into the natural setting. Qualitative studies use the term thick description to set up and make possible the reader's belief that he/she is present. The researcher covers the pertinent details of the interviews and observations, but does not make the information seem trivial or mundane (Patton, 2002). Merriam (1988) recommended including both particular and general descriptions: "particular description consists of quotes from people interviewed, quotes from field notes, and narrative vignettes of everyday life" (p. 200). In addition, metaphors and analogies will be used.

In addition to the metaphors and analogies, the researcher will provide details of the interviews and observations through interpretive commentary. Erickson (as cited in Merriam, 1988) described interpretive commentary as a way to "point the reader to those details that are 
salient for the author, and to the meaning-interpretations of the author" (p. 200). It is the intent of the case study to allow "the reader to understand the case as a unique, holistic entity" (Patton, 2002, p. 450).

Finally, a member check was performed by providing principals of the three schools with a copy of the results and soliciting their feedback. In addition, two administrators (one central office and a high school principal) were provided a copy of the results to determine usefulness of the study to secondary administrators. Merriam (1988) defined member checks as "taking data and interpretations back to the people from whom they were derived and asking them if the results are plausible" (p. 169).

\section{Quality of the Research}

The critics to qualitative studies have always questioned validity. The term validity is strictly used when quantitative research is judged. As for a qualitative study, the term becomes quality (Garman, 1994). Garman (1994) defines eight criteria used for judging qualitative research: verite', integrity, rigor, utility, vitality, aesthetics, ethics and verisimilitude.

In assessing this research proposal, verite' was taken into account through the description of the researcher and experiences that he had with the topic. The researcher immersed himself into the actual setting to attempt to represent the multiple realities of the case studies adequately. The experiences were monitored through observation notes and field notes to the cases to assist in answering the question, “does the work ring true?” (Garman, 1994).

The integrity of the study can be judged through the structurally sound foundation that was laid of the topic in Chapters one and two. Similar topics were researched and found that qualitative studies helped to portray the rich details of classroom life. Through this qualitative study, interviews, observations, and the collection of written documents provided a view of the 
classroom life found at each site. The data was displayed through a rich description portraying a holistic view of classroom life. In addition, salient categories emerged as a result of within-case analyses of individual sites followed by cross-case analysis.

The third criterion was rigor. To establish rigor the researcher showed that there was sufficient depth of intellect (Garman, 1994). Sufficient depth was established through triangulation, saturation and coding of the salient categories. As data saturation was reached in a site and across sites as categories emerged, selected participants confirmed categories or descriptions in member checks. Merriam (1988) defines member checks as, "taking data and interpretations back to the people from whom they were derived and asking them if the results are plausible" (p. 169). The categories were shared with the principal at selected sites. It was that process that checked the participants' information to assure saturation and rigor.

Garman (1994) described the utility of a study as the ability of the work to be useful and professionally relevant. The proposed study hoped to identify salient characteristics that teachers and principals could use when establishing high expectations in secondary schools. Using the results from the three schools in West Virginia, the researcher presented them to a central office person and secondary principal to judge its utility.

Next on Garman's list is the vitality of a study. The vitality assists in explaining the importance and meaning of the research proposal (Garman, 1994). The data collected emphasized interviewee vivid descriptions and quotes, and used metaphors to express portrayals of information. All of these assisted the researcher to display rich content that conveyed meaning as to what practices teachers and principals used in establishing high expectations. 
The sixth criterion is that of ethics. Through the use of pseudonyms, and site names the interviewees and sites remained anonymous. In addition, the research proposal was approved by the Institute Research Board (IRB) at West Virginia University.

The final criteria used to judge the research was verisimilitude. Verisimilitude looks for how well the work represents human experiences with sufficient detail so that the portrayals are truly reflective of the experience (Garman, 1994). To satisfy that condition, the researcher became immersed in the environment of each site for five workdays. During that time, classrooms and meetings were observed so that rich details used to communicate high expectations were portrayed. The researcher used school and classroom observations to describe non-verbal communication. Using the observation notes, portrayals were used to display the rich content of the data and conveyed meaning to what practices teachers and principals used to establish high expectations.

\section{Summary of the Chapter}

Through the use of a qualitative, interpretive, case study design, the researcher hoped to find the practices teachers and principals' used in establishing or sustaining high expectations. The study was guided by the following research questions: 1 . What instructional practices and curriculum methods do teachers use to communicate high expectations to the students? 2. What do principals perceive to be high expectations in these classrooms? and 3 . What are the administrative and curriculum practices that principals use to promote high expectations within the school?

Data was collected from interviews, observations, document collection and field notes from three sites chosen through purposeful sampling. The interviews used semi-structured, open-ended questions of teachers and principals who were also chosen purposefully. All 
information was stored within a case so that cross-case analysis of the data was completed revealing rich descriptions, portrayals and interpretations.

During the development of the interview questions for the participants (teachers and principals), the matrix (Appendices $\mathrm{G}$ and $\mathrm{H}$ ) helped to assure that questions related back to each of the research questions. A pilot study was completed to further refine the questions.

Observations were used as a way to provide utility to the proposed study. Completing classroom observations of the interviewed teachers provided portrayals of the categories brought forth from the interviews. Those portrayals were created to interpret and represent the themes that had been identified as a way to answer each of the research questions. Working collaboratively with the interviews, a thick description (Denzin \& Lincoln, 2000) was provided.

Finally, in working to answer the research questions, a collection of documents occurred. Documents collected included: teacher lesson plans; student work; course syllabi; the master schedule; minutes of faculty senate meetings, curriculum meetings, local school improvement council meetings and department meetings; student handbook; teacher handbook; and the school newsletter. Mining those documents was a way to provide rigor to the interviews and observations. Using all three provided triangulation and worked to address the research questions.

The written report provided answers to the research questions leading to address the overall purpose of what practices teachers and principals used to establish high expectations. Seven practices were found that contributed to the existence of high expectations in selected West Virginia secondary schools. 


\section{Chapter Four}

\section{Presentation of Findings and Conclusions}

\section{Introduction}

The purpose of this study was to examine the curricular, instructional and administrative practices that teachers and principals used in establishing high expectations in selected secondary schools in West Virginia. The three research questions were: 1. What instructional practices and curriculum methods do teachers use to communicate high expectations to the students? 2 . What do principals perceive to be high expectations in these classrooms? 3 . What are the administrative and curriculum practices that principals use to promote high expectations within the school? Three secondary schools, selected using purposeful sampling, were used in this multi-site case study. A total of 32 teachers, three principals and one assistant principal were interviewed for this research using semi-structured, open-ended questions. These interviews occurred during the fall of 2009 where the researcher was on site for five-days. In addition to the interviews, relevant documents were collected.

The findings are presented as three case studies and then a cross-case analysis. The three case studies selected three secondary schools using the following criteria: each school contained grade 12 and had met AYP for four consecutive years, contained at least one Nationally Board Certified Teacher, convenience, and participation was voluntary. Using that criterion, 17 of the 119 secondary schools in West Virginia were eligible. Of the remaining 17, only three were considered for participation because convenience was defined as a school being within a 100mile radius of the researcher's residence. Fictional names were given to the three schools. The names chosen were Cherry High School, Apple High School, and Orange High School. 
Each case study begins with a description of the setting, which included: the school's grade configuration and total student population, which contained if the student population was increasing, decreasing or remaining the same. Furthermore, the educational level of the professional staff was included as was the total number of professional staff in the building; a brief overview of the principal and his/her administrative staff that included how long each principal had been at the site and how long the administrative staff had worked together; each site's standardized test scores, both nationally (SAT and ACT) and locally (WESTEST) for two corresponding years. Finally, the total number of AP courses taught at each case study site and the corresponding scores (out of a maximum score of five) for the last two years.

The case studies then used the three identified themes from the proposed definition of high expectations to expand on how each theme was believed to define high expectations. The three themes were: administrative practices, curricular practices and instructional practices. Data collected during the five-day site visit was presented to portray each theme. Data collected included: interviewing; classroom observations; school observations before school, at lunch and in-between classes; and document collection. Documents collected included: lesson plans, minutes from meetings, examples of student work, master schedule, student handbook, and teacher handbook.

The data was presented in the case study by using quotations to address each of the three themes and the research questions. A quotation, document or personal observation was given to illustrate each finding. Quotes from the interview transcript, documents and observations used in this chapter and the final chapter were identified by school, interviewee (principal, assistant principal, and teacher), document or observation. For example, (C.P.1) represents Cherry High School, principal, transcript page one. For teachers, (C.T8.1) represents Cherry High School, 
teacher interviewee number 8 , transcript page one. For documents, (C.D.1) represents Cherry High School, document one. For personal observations, (C.O.1) represents Cherry High School, observation one.

Merriam (1988) believed that interpretation based upon several cases becomes more compelling to the reader. For that reason a cross-case analysis was completed. Using the data from each case study, the researcher looked across all three studies in search of what patterns or categories were common. Out of that cross-case analysis arose seven commonalities that assisted in identifying practices that led to high expectations among selected West Virginia secondary schools.

\section{Case Study One}

School setting. Cherry High School consisted of grades 9-12 and was found in one of West Virginia's largest school systems. The school first opened in 1965 housing grades $10-12$. In the fall of 2002 the school added grade 9 because the school district moved away from the junior high concept and incorporated the middle school belief (On-line XXX school website, 2010). From the 2002-2003 school year, the student population had grown to approximately 1138 (On-line XXX School Report Card, 2009).

A unique characteristic of Cherry High School was its bell schedule. The schedule was based upon a nine period day that included a twelve-minute homeroom period after first period. All nine-class periods were 43-minutes long. In accordance to WVDE Policy 2510, any high school class taught for a full credit must meet for 8100 instructional minutes (WVDE, 2008). Since the school's 43-minute class periods fell short of that requirement, the school had to submit a waiver to the WVDE. 
With the nine 43-minute instructional periods, the length of the school day was seven hours and twenty-four minutes. Classes began promptly at 7:45 am and concluded at 3:09 pm (C.D.7). Since all nine-class periods were considered instructional, Cherry High School was able to meet the total number of instructional minutes per day per WVDE Policy 2510. The minimum number of total minutes was 345 and Cherry High School offered 348 (WVDE, 2008).

Due to the district's size numerous high schools were located throughout the region. Each one carried a label that identified it by its strength. For example, Cherry High School provided the most Advanced Placement (AP) courses in the district and state and was labeled the AP magnet school. That label provided students the ability to transfer from another school in the district in order to take certain AP courses. The total number of AP courses taught on campus for the 2009-2010 school was 14 .

Serving students during the instructional day are fifty-two regular classroom teachers, including one ninth grade initiative teacher and a graduation coach; three assistant principals, including one who oversaw curriculum; one principal; four counselors; one librarian; five special education teachers; and four classroom aides (Principal, personal communication, January 11, 2010). Table 4 displays the educational level of the teachers compared to the state average. This table was constructed from the Cherry High School report card (On-line XXX School Report Card, 2009). 
Table 4

Cherry High School Teacher Education Levels Compared to State Levels

\begin{tabular}{lcc}
\hline Level of Education & School & State \\
Bachelor's Degree & $10.6 \%$ & $15.6 \%$ \\
Bachelor's plus 15 & $16.2 \%$ & $23.7 \%$ \\
Master's Degree & $4.5 \%$ & $7.5 \%$ \\
Master's plus 15 & $9.1 \%$ & $9.3 \%$ \\
Master's plus 30 & $9.1 \%$ & $13.0 \%$ \\
Master's plus 45 & $42.4 \%$ & $30.3 \%$ \\
Doctorate & $6.1 \%$ & $.6 \%$ \\
\hline
\end{tabular}

The table illustrates how teachers at Cherry High School hold advanced degrees above those in the state. Out of 52 faculty members, three held Doctorates and 22 had a Master's plus 45.

Out of 52 teaching positions, two positions were created for the 2009-2010 school year, and those positions were a ninth grade initiative teacher and graduation coach. The ninth grade initiative teacher position was the result of a change in the master schedule for the 2009-2010 school year made by the administration (Principal, personal communication, January 11, 2010). That change involved assigning all incoming freshmen a study skills/study hall class for the first semester. That class assisted students in learning how to optimize the "free" time provided through the incorporation of unscheduled time in a student's schedule that began second semester of freshmen year.

The graduation coach was an initiative from the district office. Through district funds a person was hired at each high school to work with seniors who were at-risk for not graduating. 
The district's intent was to increase the graduation rate district wide. The district's graduation rate was 78.6 percent for 2009, falling below the required 80.0 percent needed to meet Adequate Yearly Progress, but Cherry High School's graduation rate was 84.89 percent (On-line XXX School Report Card, 2009). With a graduation coach, Cherry High School hoped to increase their graduation rate to be at or above 90.0 percent

Four administrators worked with the faculty. The administrators began at Cherry High School in the 2008-2009 school year. Previously all four had worked at either middle/junior high schools or high schools in the district. Of the four, only one administrator had previous administrative experience (On-line XXX school website, 2010).

The principal had worked for the district for the past 22 years. She spent her first seven years as a high school English/Journalism teacher. From there she worked as an assistant principal for 7 years, in two different high schools in the district. After serving as assistant principal she was selected to serve as principal of a middle school, where she had worked for five years prior to accepting her current principalship. During her tenure as a middle school principal, she was named West Virginia's Middle School Principal of the Year (C.N.1). In addition, she had served as the President of the West Virginia Association of Secondary School Principals (Principal, personal communication, December 15, 2009).

Staffed with faculty who had earned educational levels above other schools in the state, and as a decorated middle school principal, high academic achievement at Cherry High School was noted. Cherry High School students succeeded at levels above the student average in West Virginia and nationally.

Table 5 underscores the academic achievement for the past two years in the two subtests of mathematics and reading/language arts (On-line XXX School Report Card, 2009). 
Table 5

Cherry High School Percent of Students at or Above Proficiency in Mathematics and Reading/Language Arts

\begin{tabular}{llll}
\hline Year & Subtest & School \% proficient & State \% proficient \\
\hline 2008 & Math & $83.8 \%$ & $75.3 \%$ \\
2009 & Math & $76.3 \%$ & $59.5 \%$ \\
2008 & Reading/Language Arts & $86.5 \%$ & $80.0 \%$ \\
2009 & Reading/Language Arts & $72.1 \%$ & $58.8 \%$ \\
\hline
\end{tabular}

In Table 5, in both 2008 and 2009 Cherry High School's student performance on the state mandated test, the WESTEST, was higher than the state average. However, the across the board drop from 2008 to 2009 was due to a change from lower level thinking skill questions to questions that used higher level thinking skills.

Table 6 displays the composite score, as reported from a written document provided by the assistant principal for curriculum (C.D.6) That report provided the ACT composite scores for Cherry High School students as compared to the state's average composite score and the national average composite score (C.D.6). 
Table 6

Cherry High School ACT Scores Compared to State and National Averages for 2008 and 2009

Year

School Average

Composite Score

State Average

National Average

Composite Score

Composite Score

2008

23.3

20.7

21.1

2009

23.8

20.7

21.1

For both 2008 and 2009, Cherry High School exceeded the national and state average scores by at least two full points. Later in this section, the reader will be presented what was believed to be the administrative, curricular and instructional practices of teachers and principals that provided clues for the enhanced academic performance of the students.

Since students applied to attend out of state colleges and universities, the SAT (Scholastic Aptitude Test) was taken in the areas of mathematics and writing. Table 7 includes student SAT data from the years 2007 and 2009 obtained from the assistant principal for curriculum (C.D.6). Table 7

Cherry High School SAT Average Scores Compared to State Average Scores

School Average Scores

State Average Scores

$\begin{array}{llll}\text { Year } & \text { Math Writing } \quad \text { Mriting }\end{array}$

2007

$567 \quad$ N/A

$505 \quad 503$

2009

$568 \quad 558$

487

483 
In 2007, Cherry High School's SAT math score was 567 as compared to the state's 505 . The difference was 62 points or 12.2 percent higher than the state average score. There was no data provided for Cherry High School's writing portion of the SAT in 2007 (C.D.6). Then in 2009, the math score for Cherry High School was 568 as compared to the state's 487 . The difference here was 81 points or 16.6 percent higher than the state average score. The writing scores show that in 2009 Cherry scored 558 as compared to the state's 483 . The difference was 75 points or 15.5 percent higher than the state average score. For those two years, Cherry High School out performed in the area of mathematics when compared to students across the state.

In addition to the state and national tests, Cherry High School not only offered the most AP courses but they excelled in the percent of students that scored a three or greater on the AP exams. There were 15 AP courses offered during the 2007-2008 school year. A total of 228 students took the AP exams where 65 percent received a three or greater. There were 15 AP courses offered during the 2008-2009 school year. A total of 279 students took the AP exams where 67 percent received a three or greater (C.D.6).

According to the master schedule (C.D.1) there were 14 AP classes taught on campus for the 2009-2010 school year. Advanced Placement courses were: AP Language, AP Literature, AP US History, AP Government and Politics, AP Calculus AB, AP Statistics, AP Chemistry, AP Environmental Earth, AP Biology, AP Studio Art, AP Art History, AP Spanish, AP Physics, and AP World (C.D.1). In addition, the number of AP courses was increased by one due to two students who had taken AP Macroeconomics through West Virginia Virtual Schools (WVVS).

Not only was West Virginia Virtual Schools used during the 2009-2010 school year, but two students had taken AP Calculus AB in 2008-2009 (S. Gainer, personal communication, January 23, 2011). West Virginia Virtual Schools used several virtual providers throughout the 
country. The dominant providers were Aventa Learning and Florida Virtual School (S. Gainer, personal communication, January 23, 2011).

Going beyond a high number of AP courses was that Cherry High School had offered twelve college classes. The twelve college classes are provided through three in-state colleges and are available to all students (C.D.6). The difference between the on campus college courses and the AP courses was that students earned college credits with an average of D or better per course, whereas in the AP course a student must take the AP exam and score at least a three in order for most colleges and universities to accept it as college credit. The classes offered at Cherry High School were: English Composition 101/102, Psychology 151, Sociology 101, College Algebra, Calculus (BC), History of the Holocaust, Astronomy, Art 101, Art 102, Environmental Science and Speech 101 (C.D.6).

Cherry High School was a relatively large school where the staff was well educated and state and national test scores fell above the norm. Those factors set the school apart from others in the state of West Virginia as high achieving. It was believed that certain administrtaive, curricular and insturctional practices led to a culture of high expectations.

\section{Administrative Practices}

Six administrative practices that tied into the proposed definition of high expectations found in Chapter two, the literature review, were found at Cherry High School. What will be presented in this section was how the following administrative practices promoted high expectations: teachers and students had unscheduled time; the principal chose out of attendance area transfers on a first come basis; the principal used data to assist students in the use of unstructured time; professional development was organized around professional learning 
communities; students were supported through a special freshmen course; and the principal was highly visible in the building.

Teacher/student unscheduled time. The schedule was based upon a three-day cycle where teachers and students had different classes that used different teaching strategies on each of the three days. On day four the schedule repeated. Unscheduled class time was provided to teachers and students.

The four core courses of English, Mathematics, Science and Social Studies used the three-class format of lecture, quest and seminar. Each course started a presentation with information in lecture, next was a smaller group activity done in quest and then the final format was an even smaller group called seminar.

Lecture consisted of the teacher having up to 80 students in one of the four lecture halls, where basic foundational information was presented in a college lecture format. Some teachers used that time for testing, too. Quest was made up of a smaller number of students from the lecture. Quest was the method where students did labs or engaged in cooperative learning activities. Seminar was smaller than the Quest. In seminar teachers engaged students in discussions and open questions (C.P.7). As a result of the three-class format, students had a different class each day during the three-day cycle.

One of the first actions the principal took upon starting the position was to post this fourword sentence in the overflow area of the cafeteria: "With privilege comes responsibility." The word privilege in that sentence referred to the unscheduled class periods students were allowed within the day's nine instructional periods. Ennis (1989) believed that when students had sufficient control of the learning environment they began to have higher expectations for themselves. Because students had control of their unscheduled time the principal and teachers 
believed that they had high expectations. The unscheduled time was made available because of Cherry High School's total number of credits needed for graduation.

According to Cherry High School's handbook (On-line XXX school website, 2010) the total number of credits needed to graduate was 25 , that was one credit above the state minimum of 24 . Within the 25 credits at least eighteen had to be earned in grades ten through twelve. With the nine period instructional day, students had the opportunity to earn 36 total credits. The remaining eleven credits provided the flexibility for unscheduled class periods and the staffs' belief of students being self-directed second semester of freshmen year. The term self-directed or self-direction was best defined as "that a student is supposed to realize what should be done and do it to the best of their ability" (C.T8.2).

When the building first opened, the cafeteria served as the Quiet Study Area (QSA) where students went during unscheduled class periods (C.T6.7). Several teachers were assigned to monitor that area so that it was quiet. From its conception in 1965 to 2010, the concept of a quiet study area had changed because "when kids go home they go to their room, turn their TV on, plug their I-pod in and do their homework" (C.T6.7). That was underscored during an observation when the large screen television in the QSA was on and tuned to a basketball game on ESPN (C.N.5).

As the school day progressed, the QSA area began to take on the atmosphere of a student union building/area found on many college campuses. Students hung out, played cards, watched TV, listened to music, made phone calls or even sat and talked with friends (C.N.5). The researcher noted that no students were studying or completing work in the area designated as the QSA (C.N.5). 
Because of that atmosphere, teachers stated "the non-traditional schedule is a reason why students are successful after graduation" (C.T5.8; C.T8.2; C.T7.2). Even the principal stated "the concept of high expectations is intertwined in this non-traditional, non-scheduled class time" (C.P.1). The principal said "students are expected to learn how to be self-directed by the time they leave here so whatever they move onto they can make good decisions" (C.P.1). Through the unscheduled time, academics were enhanced through self-direction and that was what made Cherry High School different and attractive to many parents and students through out the region and state.

The non-traditional schedule was comprised of a modular three-day schedule where students went to different classes each day during the three-day cycle. One of the key principles to the modular schedule was teachers had up to three class periods (counting lunch) to set-up office hours (C.D.1). During that time students who did not have a scheduled class could meet with their teacher to receive extra help or receive make-up work, due to an absence. Maintaining the modular schedule was an administrative practice that continued.

Since teachers had unscheduled class periods, the building also contained office areas where the English, social studies and science departments were housed. Within the office area each teacher had his/her designated space, complete with a desk and computer (C.N.2) To assist students, the office hours of all teachers were published; students had a copy of what teacher had office hours and where those teacher's offices were (C.P.1). A unit plan contained the teacher's office hours and location was found as well (C.D.2). So, "if students want the extra help, it's out there for them" (C.P.2).

The belief of scheduling both teachers and students with unscheduled time was the premise behind the design of the building. That type of schedule was picked from the beginning 
so that the students" "decision-making processes were designed to assist the students in their quest to become productive, self-directed people" (C.D.3). Students learned to be successful at a job, college, technical school, or wherever they may go by the time they left (C.P.1).

Out of area transfers. Brophy (1998) summarized the work of Robert Rosenthal and Lenore Jacobson from the 1968 publication of Pygmalion in the Classroom as:

If a teacher expects a certain pattern of behavior or level of performance from a student, that expectation can cause the teacher to treat the student in ways that reflect this expectation and increase the probability that it will come true. (p. x)

In the above quote, replace the word teacher with the word principal and that was the belief that the principal at Cherry High School had when determining out of area transfers to the school.

The district allowed students to transfer to a high school outside of their attendance area and left that decision to the receiving school's principal. Since no set criterion was used, the principal took them in the order they applied. The principal summarized the out of area transfers as:

I take them in the order they come in. I give any kid a chance. I do have the option, if you're not doing what you're suppose to here, you're not trying, you're not working, I can send you back to your home school. I would rather work with a kid and try to bring up the academics. I had teachers that were very upset about that. Why do we keep taking these kids $[$ sic $]$. It's public education, that's my answer to them, most of the time. We educate all. I'm not going to make this an elitist school. (C.P.16)

So, as long as a student was willing to work, to meet the standards and expectations set by the school, he/she was able to attend. 
Principal use of behavioral data. The principal received data from the district office that contained: students who failed two or more classes, ninth grade students age 15 and over, discipline offenses, current monthly dropout report, per period attendance and suspensions. That data was checked for patterns that noted: number of absences per period to determine if a student was skipping, using discipline action codes to check that the assistant principals were being consistent, referrals to the School Assistance Team were checked to note if students who had a lot of referrals were being referred, and how many students were suspended and for what infraction (C.D.4). The principal believed that this proactive approach helped the school to teach students to be self-directed. That in turn created a school atmosphere that was conducive to learning and success for all.

Professional development. According to the principal, "the school district did an awesome job at staff development" (C.P.6). Every month the district dismissed students twohours early so that the teachers could meet and discuss planned activities in their Professional Learning Communities (C.P.6).

DuFour (2004) believed that professional learning communities focused on student learning, promoted a collaborative culture and focused on student assessment results. At Cherry High School the communities were made up of teachers in two ways: 1) departments/subject matter and 2) vertical teaming (C.P.6). The department professional learning communities (PLCs) contained teachers that taught the same subject or discipline, whereas the vertical teams contained teachers from several different disciplines.

An Assistant Superintendent oversaw the PLCs, and each school in the district had designated PLC coordinators. At Cherry High School there were eight coordinators that met with the assistant superintendent quarterly for training (C.P.7). It was during those meetings that 
the PLC activities were planned for the next three months. For example, the last PLC activity was on second chances and corrective instruction (C.D.5).

This activity used vertical teams, of which there were five, to discuss and provide a response to five questions. The five questions were: 1 . What do we know to be true about second chances and corrective instruction? 2. What was the counter argument to that perspective? 3. What point could you make to help our staff understand? 4. What were two things we could do to support teachers to integrate that idea? and 5. What resources will our teachers need to accomplish that goal? (C.D.5) All of those questions centered on how the school could improve instruction so that each student was successful.

In addition to the early out days, West Virginia School Law $§ 18-5-45(5)(d)$ states that "the instructional term for students shall include one instructional day in each of the months of October, December, February, April and June which is an instructional support and enhancement day scheduled by the board to include both instructional activities for students and professional activities for teachers to improve student instruction" (West Virginia School Laws, 2007). Another example of professional development occurred when the teachers watched and discussed a movie entitled "Two Million Minutes." That documentary compared six high school students from China, the U.S. and India and how they used their time in high school to prepare for college and ultimately a career. Four years of high school in the U.S. equated to two million minutes. The movie pointed out that American students did not have the same discipline and structure toward their course of study as the students from the other two countries.

Following the movie, Cherry High School teachers met in their vertical teams to discuss how instructional time was used in their classes (C.P.7). The principal stated "our students don't have the hunger that the students had in other countries and our kids had gotten somewhat 
apathetic" (C.P.7). In addition to addressing the use of classroom time for instructional practices, the teachers talked about how student apathy toward learning and college could be addressed at the school. Teachers wanted to assure that high academic expectations continued so that all students were successful.

Student support. Teachers and administration believed that students were successful in the classroom. However, last year's freshmen were not meeting up to this expectation. They chose to spend more time talking with friends and visiting with one another than they did studying and seeking help from the teachers (Teacher, personal communication, April 6, 2010). Schein (as cited in Bolman \& Deal, 2003) defined a culture as: A pattern of shared basic assumptions that a group learned as it solved its problems of external adaptation and integration that has worked well enough to be considered valid and therefore to be taught to new members as the correct way to perceive, think, and feel in relation to those problems. (p. 243)

Since the freshmen were not using the unscheduled time as had been previously done within the school's culture, the administration scheduled all freshmen for seven periods, lunch and then a learning skills class (C.P.2).

During the learning skills class, students had the opportunity to seek out help in a subject from one of the teachers in that department. That was when students went to a teacher during their unscheduled time for extra help or tutoring. An excellent example of how freshmen and teachers used that learning skills time was best exemplified when a teacher shared that he had anywhere from 10-15 kids in his office on any given unscheduled period (C.T1.2). Students were plastered around the department office doing a make-up test and asking questions (C.T1.2). 
Furthermore, on Friday of the school visit, students were observed in two science classes receiving extra help and making up labs at approximately 6:30 a.m. (C.N.7). Students even accessed help after school, as was noted on Thursday of the school site visit. Five students were observed in the guidance department suite using computers to access a computer based remediation/recovery software program called PLATO (C.N.6). At the same time, a student was getting help on an assignment from a math teacher. Before and after school, students had the ability to receive extra support that provided all students the ability to be successful.

Along with the motto "with privilege comes responsibility," students were expected to do their very best. According to the principal, "high expectations, I think it's more the culture of our building" (C.P.1). All at Cherry High School expected students to do their very best and that college was the next step after high school. To support student responsibility and the teachers was parents. One of the teachers supported how strong the parental expectations were by saying, "parents here that $[s i c]$ are very involved and have high expectations. And I would say a big part of what we do right was because of that. They come in that way" (C.T12.9).

Principal visibility. The culture of the building drove the students to be their very best. To monitor how well students were doing, the principal was visible throughout the day. What teachers noted was that the principal was most visible in the mornings and at lunchtime in the QSA (C.T1.5; C.T2.4; C.T4.3; C.T10.3). Because of the implementation of a curriculum assistant principal, the principal was not as visible within classrooms. It was the curriculum assistant principal who completed teacher observation/evaluations and the five by five walkthroughs (C.T1.5; C.T4.3; C.T11.4). A five by five walkthrough was where the curriculum assistant principal visited five classrooms per week for five minutes to observe what was going 
on. She would then meet with the teacher and provide him/her feedback based upon what was seen during the walkthrough.

With the five by five walkthroughs came the practice called double team - this was where both the principal and curriculum assistant observed a teacher during different class periods on the same day (C.P.8). The purpose of the double team was to determine if a particular problem was noted from two different observers on the same day. That removed particular bias from the evaluation tool and the problem(s) could be addressed so that student learning was maximized.

The above administrative practices: teacher and student unscheduled time; choosing student transfers from out of attendance area; the use of discipline data to maintain consistency to all; engaging staff in meaningful professional development through professional learning communities; freshmen scheduled into a learning skills class first semester; and a principal who was visible throughout the school were found to be pervasive at this school. Those practices, along with the practices found to exist in the curricular and instructional areas, helped in defining the term high expectations.

\section{Curricular Practices}

Cherry High School used three curricular practices that will be shown to tie into the proposed definition of high expectations: all freshmen were scheduled to take a learning skills class; the school provided both Advanced Placement and Advanced/Honors courses; and teachers used curriculum plans to develop units of instruction. Through the use of those curricular practices, high expectations were promoted throughout the building. 
Learning skills. One curricular practice that Cherry High School used was that all freshmen were assigned a learning skills class. Thomas Good and Jere E. Brophy (2003) believed that teachers needed to maximize each student's achievement progress by providing individualized tutoring and time to study and practice.

This class was a study skill or kind of a study hall for the freshmen during the first semester (C.P.2). Students were encouraged to go meet with teachers, use the computers, go to the library, read, or study during that time (Teacher, personal communication, April 6, 2010). An example of how students effectively used that scheduled class time was during teacher interview number twelve; two freshmen students came to seek help on an assignment (C.T12.6).

At the end of the first semester, a freshman with a $\mathrm{C}$ or better grade in all classes was able to drop the learning skills class and have a period of unscheduled time (C.P.2). Because of that course, the students had learned how to use the unscheduled time, on their own, to seek out help when needed, or to use the time to complete assignments or research. Some of the students had already said that they wanted to stay in it regardless because it's a good time for them to get extra help (C.P.2). That established curricular practice was teaching the freshmen to become self-directed, and responsible, leading to enhanced learning for all at Cherry High School.

Advanced placement courses. According to Policy 2510 of the West Virginia Department of Education (2008) each school was to offer four AP courses. In that Cherry High School was an AP magnet school, not only were there more than four AP courses offered, but a total of 16 were offered throughout the year.

From freshmen year on students were able to take Advanced Placement (AP) courses. Even though AP courses were offered all four years, students in grades 11 and 12 commonly took the AP courses. The principal said, "the classes sell themselves. The kids want to take it 
because their friends take it. There's a lot of peer pressure here to do well" (C.P.5).

Furthermore, if some kids don't sign up for AP classes, "we sometimes had to pull them in and say look based upon your PSAT scores you would do well in that class" (C.P.5). The principal continued, "that has been the biggest difference from some other high schools. We don't have a huge amount of electives because we have so many AP classes and kids take those at the same time" (C.P.6). Because of its status as an AP magnet school, the school must offer the number of AP courses provided. That cut down on the number of non-core electives.

Since Cherry High was considered the AP magnet school of the district it drew students from other attendance areas. The students from the other areas could not come to the school for just an AP class or two. It was required that a student be full-time at one area school. For that reason, the school's enrollment had been increasing to its current number of 1138 .

In considering what courses to offer from year to year, if an AP course had the same number of students enrolled as an elective, the AP course would be offered. For example, for the 2009-2010 schedule, seven kids signed up for Great Books and seven signed up for AP Physics. Because the school was an AP magnet school the AP Physics class was chosen to be the course taught (C.P.4). There are even students who challenged an AP course by taking the exam in May without having completed the class (C.P.3).

In addition to the AP courses offered on campus, the school also provided AP courses through West Virginia Virtual Schools (WVVS). In the 2008-2009 school year, no additional AP courses were provided through WVVS, but in 2009-2010 the school had two students enrolled in the AP Macroeconomics course through WVVS. Included in the list of AP courses for the 2009-2010 school, three students chose to take AP English Literature and AP Government and Politics: United States respectively through WVVS (S. Gainer, personal 
communication, January 23, 2011). This practice allowed students to maximize the total number of AP courses available.

As an AP magnet school with 14 courses taught on campus, and two offered through WVVS, the school had the belief that any student at Cherry High can take an AP class.

However, the school made the student and his/her parent aware that if the student took it, he/she was in that class until the semester ended, and he/she had to take the AP exam, although the College Board does not mandate this. But, the principal did say "rarely do we have kids that take AP that want to drop out of AP" (C.P.4). With 67 percent of last year's 279 test takers receiving a three or better, it was evident that students completed the class and were successful (C.D.6).

Advanced and honors courses. West Virginia Board Policy 2510 (2008) also required that advanced/honors courses be offered to students. According to document C.D.6, Cherry High School offered advanced/honors courses in all major disciplines. In addition, the student handbook listed advanced/honors courses as those receiving weighted grades, where an A would equal five quality grade points, a B would equal four quality grade points, a $\mathrm{C}$ would equal three quality grade points, a D would equal two quality grade points, and an F would equal zero quality grade points (C.D.7).

To be identified as an honors course, the class had to be advanced in terms of content and performance expectations (C.D.7). They were designed to meet the needs of students who had the potential to complete curriculum more demanding than that offered in the regular classroom (C.D.7). The honors experience included, "research and in-depth studies, mentorships, contentfocused seminars and extended learning outcomes instruction in the content areas," as defined in the student handbook, page 9 (C.D.7). 
As a mathematics teacher explained, "in order for a course to be listed or given honors status, the school required that teachers provide two outside projects" (C.T12.3). As an example, in her honors geometry class the first project was on curves. Students had to make a project using straight lines to make curves. In addition to the project, students had to write a one page paper that discussed what a tangent line was, what symmetry was, what symmetry was in their project and tell her "a little bit about why they picked" their design (C.T12.3). The second project was scheduled for second semester and involved the "golden ratio." The regular geometry classes did not do the above projects and were based solely on the CSOs.

Curriculum plans. Teachers at Cherry High School were provided curriculum maps from the district office that identified the essential content standards to cover during the length of the course. Personnel at the district level had listed essential content standards in order of importance. From that document, teachers planned out their units of instruction that contained the learning outcomes, a portrayal of the content associated with the outcome, and one or more learning activities that provoked students to interact with the content (C.D.2).

Cherry High School teachers used the units, in place of daily lesson plans to portray what was accomplished in the classroom. With each unit, the teachers provided students a detailed outline of what content was to be covered, what the assignments would be, the dates for tests and other materials to be collected. That document was similar to a course syllabus provided in a college course (C.D.8; C.D.9; C.D.10). The structure that document provided allowed teachers the latitude to make adjustments based upon their particular style.

The unit plan only provided the answer to what to teach, it was then up to the teacher to determine how to teach. Kennedy (2005) found that the issue in planning a day's agenda was "what kind of learning activities teachers used to acquaint students with that content" (p. 132). 
An example of the kind of activity used at Cherry High School was provided by one of the social studies teachers. This teacher related music of the Great Depression in an activity to show students the mood or tune of that time era. In that activity, the teacher stated:

With the Depression Era music, I assigned each individual a different song and they had to go out Google it, print the lyrics and then analyze it. You know, what's the song about, what's the mood of the song, give me examples of the mood from the lyrics. What can you learn about the Depression from this song? (C.T7.5)

In addition, another teacher planned a unit on polygons. That unit listed three objectives for the students, followed by a day-by-day description of what would be covered, what section of the textbook would be used and the daily assignment (C.D.8). In that unit, the dates for quizzes and the unit test was clearly identified (C.D.8).

The curricular practice of using curriculum maps to plan units of material was the way Cherry High School teachers based instruction on the state required content standards. Each content standard was checked to assure that the units covered all standards listed. Therefore, teachers were not responsible for daily lesson plans, but they did have a unit guide that explained and drove daily instruction.

The following curricular activities were displayed at Cherry High School: all freshmen were required to take a learning skills class that allowed them the opportunity to seek out extra help from a teacher, complete make-up work, use computers, or read; school labeled as an AP magnet school due to its many AP courses, both in the classroom and on-line; advance/honors courses provided in all major disciplines and open to all students, where the curriculum was enhanced with outside projects; teachers focused instruction around essential content standards through the use of curriculum maps provided from the district office; teachers used unit plans to 
portray content of material to students. Through those activities high expectations was believed to have occurred at Cherry High School.

\section{Instructional Practices}

Good and Brophy (2003) stated: "learning should not be viewed as transmission of knowledge from a teacher to students who imitate or memorize it" (p. 303). The teachers at Cherry High School used four instructional practices that enhanced their role as a classroom facilitator. The four instructional practices used by the teachers included: alignment of curriculum to the state approved content standards and use of benchmarks to monitor students engaged in interactive lessons or projects; immediate feedback provided to all; and students were recognized for academic excellence in the classroom and school. All of those practices provided an environment where learning for all was the belief.

Curriculum alignment. Good and Brophy (2003) found that unless course curriculum was aligned to the assessment tool (i.e., WESTEST2) then incorrect conclusions would be made in regard to the effectiveness of the school. At Cherry High School twelve classroom teachers were interviewed, and ten of those teachers used the state approved Content Standards and Objectives (CSOs) when designing classroom instruction. One teacher stated that "we do have pacing guides for every subject, every grade level that teachers worked on. We took the CSOs from the state and reworded them. It's the same CSOs but in a different format" (C.T3.4). Another teacher stated "no matter what I teach, I use the CSOs. I can teach CSOs off of Dr. Seuss" (C.T1.3). Yet another teacher stated "I'm teaching the subject and following the CSOs for the subject" (C.T12.3).

The CSOs do not dictate how to present the content that was left up to the discretion of the classroom teacher. Another example of how teachers presented material so that the CSOs 
were followed was provided by this teacher comment, "we can take those CSO standards and plug them in and simplify them" (C.T9.2). The first teacher interviewed further underscored that belief when he did a research project with his ninth grade students. That project lasted two weeks and during that time students had to design a themed trip that would be presented to the class. So, "instead of a paper, they did a trifold brochure. On the back of was [sic] the sources. The CSOs were done; the way I did it was different" (C.T1.3). So, one instructional practice used by the teachers was that they followed the prescribed content standards and objectives when planning the content of their lesson.

In addition to teachers following the course CSOs, both English and mathematics, teachers monitored student comprehension through the benchmark test called ACUITY (C.P.8). Throughout the year each subject administered three benchmark tests using the computer. The times of the tests were determined at the district level. Once a teacher had administered a benchmark test the assistant principal in charge of curriculum met with that teacher to go over class and individual data (C.P.8). Teachers had received the proper training so that student progress was assessed and monitored. It was believed that because the teachers were trained to monitor and assess student progress, the needs of all students were better met.

Teaching strategies. Presentation of material, in combination with assignments, needs to be both familiar and easy enough for the students to complete successfully, and varied to sustain student motivation (Good \& Brophy, 2003). Those elements, when presented in a classroom, encouraged students to remain focused. At Cherry High School eleven of the 12 classroom teachers interviewed provided motivation to students by engaging them in the learning process. A science teacher stated "turning the lights out and doing power points consisting of 
lists and lists of 'stuff' is a recipe for disaster. You have to engage kids by making the subject as 'real world' as possible" (C.T14.4).

In addition to the science teacher making his subject more "real world" like, a mathematics teacher also used outside projects to bring the "real world" to her classroom. An example of how she did this was when she was doing patterns and expressions, she introduced the Fibonacci sequence. She stated "I had them do an outside homework project off the Internet on Fibonacci sequence in nature, and in music and I gave the students about five choices" (C.T12.3).

Engaging students in the evaluation of other's written work was something used by a Cherry English teacher. She stated "I had individuals come up and we were evaluating an essay and so they would say what's good about this essay and what's not good about this essay" (C.T11.2). Another English teacher described her teaching techniques as "I have more freedom to involve the kids" (C.T8.4). The teacher used the interactive white board called the "smart board" to have students come up and underline the verb of a sentence or erase the given verb and put another in its place (C.T8.4).

Another teaching strategy that was noted involved the teachers using student-centered activities. Those student-centered activities moved the teacher from providing direct instruction to serving as the facilitator. Students were engaged in activities that reinforced a concept that was presented to them earlier on in the lesson or unit. The following two examples highlighted the teacher's changing role from direct presenter to facilitator.

A Cherry science teacher had students working on a respiration laboratory activity (C.O.1). Students in the classroom were using pieces of paper labeled with the process (steps) for respiration. From those pieces of paper, students placed them in the correct sequence. The 
finished product was a flow chart denoting the process of respiration. As the teacher walked around, student progress was monitored and help was provided when asked. Through student engagement, students were simultaneously learning and having fun. A group of students were getting loud so the teacher came over and made the comment "you guys are having too much fun." (C.O.1). The response from the student group was "but, Cherry teacher, biology is fun" (C.O.1).

During another classroom observation, a Cherry Foreign language teacher used the smart board (C.O.2). Students volunteered to go up to the board and correctly identified the word that was the best choice for the sentence. The students would take their finger and tap the correct word choice. Prior to the use of the smart board, the teacher had given each student a small dryerase board and marker (C.O.2). Using that board, the students converted a word given to them in singular form to plural form. Once the student had written the plural form, he/she had to hold the board up so that the teacher was able to check it (C.O.2).

Through the use of projects and interactive learning activities, teachers at Cherry High School engaged students in the learning process. In the 1980s the movie Teachers was released. In that movie there was a teacher by the name Ditto who sat at his desk and as the students entered the room in single file they took worksheets off of the desk and proceeded to their seats. As the students worked on the worksheets the teacher sat at his desk and read the daily newspaper. The teachers at Cherry High School are moving away from the Mr. Ditto model of instruction by incorporating hands-on activities.

Immediate feedback. It was found that all 12-classroom teachers gave oral feedback, written feedback or both. When providing oral feedback, a Cherry teacher stated "I try to call on every student every single day. If they make a mistake, I try to correct them" (C.T4.3). Another 
Cherry teacher made a lot of personal positive compliments to the students. For example, he said that when a student's response was not the correct response he would say 'I'm glad you're in the right direction" (C.T9.3).

Complimenting student responses to questions was one of the four kinds of routines for asking and answering questions that Kennedy (2005) referred to when teachers planned their lessons. When a teacher reinforced the student's answer or compliments it, as in the previous paragraph, then Kennedy (2005) specifically called that I-R-Reinforcement

In I-R-Reinforcement, the teacher initiates a question to a student, the student responds, and then the teacher either reinforces the answer by repeating it or compliments the student on the response (Kennedy, 2005). Even though the student's answer from the teacher was not correct, the teacher then reinforced the student by providing a compliment. This technique or method provided a means where rapport was built between the teacher and student. Hence, students did not feel threatened when asked to respond to a question in class.

As for written responses to student work, an English teacher stated "I provide written comments on first few assignments. First essay I bleed all over it. I don't shy away from using red" (C.T1.4). Another Cherry teacher said that "I'm very careful when I'm evaluating their papers. Put what they're doing well and what they need to work on" (C.T11.3). Finally, another teacher stated "if I've marked something wrong, then I want to provide them an opportunity to explain their reasoning and argue their point. I want them to challenge me" (C.T14.5).

It was through this invitation that students were provided a chance to explain their thought process. That technique built a bridge between student and teacher so that the classroom environment was friendly and supportive of learning. Good and Brophy (2003) had found that 
maintaining a supportive learning environment was a factor associated with student achievement gains.

Through feedback, each student was provided information related to his/her performance in the class. Teachers at Cherry High School took the time to provide students comments that they may use to better individual performance in that subject (C.T1.5; C.T4.3; C.T6.3; C.T14.5). As one teacher stated "I think a lot of them have a tendency to go right to the grade and then put the paper away" (C.T8.5). The students at Cherry High School are driven by grades alone and so the first priority when a paper was handed back seemed to be the letter grade at the top. But the teachers want the students to go beyond the letter grade and begin to develop the thought process.

The thought process began by taking what a science teacher described as test notes (C.T6.3). During the test notes, students were expected to write down what they missed from the graded work and then used the comments provided by the teacher to correct the missed work (C.T6.3). The corrections were then focused upon when studying for the next test. Or, in an English teacher's class if a student wanted to know why he/she got a 7 not a 9, then it was up to him/her to make an appointment with that teacher to sit down and go over the document (C.T1.4). It may take many one-on-one appointments for the student to learn what was happening and how to best study, but through the unscheduled periods, students could find time to seek additional assistance.

Through the various modes of feedback, the teachers at Cherry High School developed rapport with the students that resulted in a supportive learning environment. By fostering the learning environment, learning for all was enhanced (Brophy, 1998). 
Recognition for achievement. Under standard 7.1.2, high expectations, of the training manual for the Office of Education and Performance Audits, the following sentence was written for verification procedures to the standard: "examine the mission and goal statements, recognition and awards, and student work to determine if all students are expected to achieve" (Office of Education Performance Audits, 2008, pp. 27-28). From that document the importance of recognizing students for achievement was noted. During the visit to Cherry High School recognition occurred.

Students were recognized for their achievements school wide, as noted in the hallway outside of the office. Pictures were posted on bulletin boards of all 13 National Merit Semifinalists. In addition, AP scholar students and freshmen of the month pictures were posted in the main hallway (C.N.3). Along with the pictures, the school did use the daily announcements to recognize students.

Ten of the twelve teachers stated that they recognized students individually in class. A fine arts teacher stated "I make a strong effort for everybody to get their name called because they did something good. Praise publicly, punish privately" (C.T3.5). A science teacher explained that she gave a lot of "that-a-boy" pats on the back (C.T13.3). The "that-a-boy" pats referred to the teacher's use of encouraging words that made the student feel good about himself/herself. A student was not allowed to use the words "I can't," because the science teacher explained "if you keep telling somebody you can do this, this was good, they learn" (C.T13.3).

Three of the twelve teachers included praises on written work, too. For example, one of the teachers puts stickers with a smiley face on "A" papers (C.T8.5). Another teacher stated: 
If it was an A, I'll write excellent, if it was a B type grade very good [sic], if it was a C grade I'll write good, if it was something less than that something encouraging, you know, practice this a lot more, you need to be busy. (C.T6.3)

Even though a combination of both types of praise was given, the underlying theme appeared to be that students wanted to do well. There does not have to be a lot of special acknowledgment made of success within the school. A mathematics teacher stated:

This is a pretty good place to be smart. It's okay to be smart here. Students feed off of each other and recognize that failing at something is not the trend. Students expect each other to be performing at his/her best at all times. Getting an $\mathrm{F}$ is not the pervasive climate, no definitely not. (C.T12.7)

Aligning the curriculum with the state content standards; actively engaging students in learning through the implementation of projects; using meaningful, relevant feedback; and recognizing the academic excellence of the students sustained a learning environment where learning for all took place. Hence, it was believed that Cherry High School used those practices to establish an environment where high expectations existed.

\section{Community involvement}

The community was very involved at Cherry High School, too. Many of the parents were alumni of the school. So, not only was the culture of the building full of expectations of academic success, but so was the community. The principal said "we only have them eight hours a day. We can make a difference, but that expectation had to be there at the home at the same time, too" (C.P.11). Parents are college educated and want their child(ren) to go to college, too. A teacher stated that "these kids know probably before they get into high school, maybe in grade school, middle school, that they are expected to go to college" (C.T5.2). 
With experience at other schools in the district, the principal experienced working with the community and parental expectations. She knew coming into the job that parental expectations were different here at Cherry High (C.P.1). While the principal was an assistant principal, at another high school in the district, she told of the following occurrence:

I was at a high school that I loved being at. Some of the sweetest kids in the world, but they had no goals, no future goals. I'll never forget the little girl telling me her goal in life was to get a doublewide, have a baby and graduate high school. And it was in that order. (C.P.11)

Staff believed having students, parents, and community working together to prepare students to go on to college had made a difference at this school.

A total of 13 practices were identified from the areas of administrative, curricular and instruction that were believed to provide high expectations at Cherry High School. The area found to have the most exhibited practices was administrative. There existed six practices that involved the administration. Those six areas were: (a) a three-day schedule where students had different classes on different days that included unscheduled time; (b) students had the opportunity to become a part of the learning community through the established practice of granting incoming transfers on a first come first serve basis; (c) the learning environment was enhanced through the use of discipline data; (d) professional development was provided to teachers each month in department or vertical team meetings for two-hours; (e) freshmen provided a special course first semester that focused on the three-day schedule and (f) the principal was visible and present in the QSA in the morning, afternoon and end of day. In addition to the administrative practices that occurred at Cherry High School three practices were found in curriculum. Those practices were (a) the use of a learning skills class for 
all freshmen; (b) the availability of AP courses on campus, on-line AP courses, and a strong honors program for all disciplines and (c) teachers use of unit plans similar to college course syllabi.

The final area where practices existed that was believed to have established high expectations was in the instructional area. Those instructional practices included: (a) curriculum alignment to state approved content standards; (b) hands-on projects, student-centered activities and real world activities; (c) a combination of oral and written comments used to drive students to succeed and (d) student achievement recognized through student pictures being posted, student work posted and teachers saying positive comments or providing a gentle pat on the back.

To complement the administrative, curricular and instructional practices at Cherry High School was how the community supported the school. Community involvement was listed separately as it was a common theme found during the transcription of interviews. It was evident that the teachers and principal strongly believed that the school's presence of high expectations was in part due to the community.

\section{Case Study Two}

School setting. Apple High School consisted of grades 9-12 and was found in one of the fastest growing regions of the state. From the 2002-2003 school year, the school system had grown from 8,732 total students to 9,517 total students (WVDE, 2010). Apple High School's student population had increased from 1,057 in 2002-2003 to 1,146 students due to the increase district wide (On-line XXX School Report Card, 2009).

Fifty-eight regular classroom teachers; three assistant principals, including one who oversaw curriculum; a half-time athletic director; one principal; three counselors; one librarian; 
twelve special education teachers; one English as a second language teacher, one Reading specialist, a half-time community work-based learning teacher, and three classroom aides serviced the 1,146 students (A.D.1). Table 8 displays the educational levels of the teachers compared to the state average. The table was constructed from the Apple High School report card (On-line XXX School Report Card, 2009).

Table 8

Apple High School Teacher Education Levels Compared To State Levels

$\begin{array}{lcc}\text { Level of Education } & \text { School } & \text { State } \\ \text { Bachelor's Degree } & 13.8 \% & 15.6 \% \\ \text { Bachelor's plus 15 } & 34.2 \% & 23.7 \% \\ \text { Master's Degree } & 7.6 \% & 7.5 \% \\ \text { Master's plus 15 } & 7.6 \% & 9.3 \% \\ \text { Master's plus 30 } & 13.9 \% & 13.0 \% \\ \text { Master's plus } 45 & 32.9 \% & 30.3 \% \\ \text { Doctorate } & 0.0 \% & .6 \%\end{array}$

The table illustrates how teachers at Apple High School hold advanced degrees above those in the state. From the table, using the school column, the sum of master's plus 30 and master's plus 45 is 46.8 percent. Using the same data under the state column, the sum is 43.3 percent. When compared to the state percentage, teachers at Apple High School with a Master's plus 30 and beyond hours exceeded the state average.

The teachers were assisted by a new administrative team for the 2008-2009 school year. Those individuals had not worked together prior to the summer of 2008 . That new team was 
brought in as a result of two retirements and one transfer (Assistant principal, personal communication, June 1, 2010).

The principal's experience included being a teacher and coach for over 20 years in the neighboring district. He left the classroom 10 years ago to serve as assistant principal at an urban high school in the same district he taught, where he remained for nine years (Principal, personal communication, November 16, 2009). While an assistant principal he was instrumental in going out into the community and building strong relationships between the local businesses and school, which he did as principal of Apple High School (A.P.4).

Upon being hired as principal, he told the superintendent that "if you want me to take this job, you need to give me the tools I need to be successful" (A.P.12). One of the tools the principal was referring to was an assistant principal who oversaw curriculum. So, at the end of the principal's first year (2008-2009), the superintendent gave him permission to hire a curriculum assistant principal (A.P.12).

The new assistant principal was the district's Advanced Placement coordinator. Due to her role as the district's AP coordinator, she had knowledge of the academic success of the school and wanted to be a part of the new administrative team (Assistant principal, personal communication, June 16, 2009).

The other two assistant principals were hired, along with the principal, in the summer of 2008 (Assistant principal, personal communication, June 1, 2010). One had taught science at Apple High School for nine years before moving out of the district for his first administrative position. The other had experience as an Assistant Principal in another high school in the district before moving to Apple High School. 
With the new administrative team, academic achievement at Apple High School continued as noted in Table 9. Table 9 underscores the academic achievement for the past two years in the two subtests of mathematics and reading/language arts (On-line XXX School Report Card, 2009).

Table 9

Apple High School Percent of Students at or Above Proficiency in Mathematics and Reading/Language Arts

\begin{tabular}{llll}
\hline Year & Subtest & School \% proficient & State \% proficient \\
\hline 2008 & Math & $72.0 \%$ & $75.3 \%$ \\
2009 & Math & $72.0 \%$ & $59.5 \%$ \\
2008 & Reading/Language Arts & $71.0 \%$ & $80.0 \%$ \\
2009 & Reading/Language Arts & $63.0 \%$ & $58.8 \%$ \\
\hline
\end{tabular}

In both 2008 and 2009 Apple High School's student performance on the math subtest of the state mandated WESTEST was higher than the state average. However, in 2008 the school dropped below the state average in reading/language arts, but that was corrected in 2009. The drop in both mathematics and reading/language arts scores in 2009 was due to a change in the format of the test questions. To comply with the No Child Left Behind legislation, the WVDE, increased the rigor of the exam. The new test was first administered in the spring of 2009.

Complementing the state's WESTEST scores was the school's ACT scores. Table 10 displays the composite score for Apple High School students taking the ACT compared to that of the state and national average scores (On-line XXX School Report Card, 2009). 
Table 10

Apple High School ACT Scores Compared to State and National Averages for 2008 and 2009

\begin{tabular}{llll}
\hline Year & $\begin{array}{l}\text { School Average } \\
\text { Composite Score }\end{array}$ & $\begin{array}{l}\text { State Average } \\
\text { Composite Score }\end{array}$ & $\begin{array}{l}\text { National Average } \\
\text { Composite Score }\end{array}$ \\
\hline 2008 & 21.9 & 20.7 & 21.1 \\
2009 & 22.0 & 20.7 & 21.1 \\
\hline
\end{tabular}

In 2008 Apple High School exceeded the state average composite score by one and two-tenths of a point and in 2009 exceeded the state average by one and three-tenths of a point. Apple High School exceeded the national average score by eight-tenths of one point and nine-tenths of one point respectively in 2008 and 2009.

In addition to the ACT exam, students at Apple High School take the SAT in both mathematics and writing. Table 11 shows the 2007 and 2009 SAT scores for Apple High School compared to the state scores (On-line XXX School Report Card, 2009). The 2008 scores were not noted on the report card, so 2007 scores were used. 
Table 11

Apple High School SAT Average Scores Compared to the State Average Scores

\begin{tabular}{lllll}
\hline & \multicolumn{2}{l}{ School Average Scores } & \multicolumn{2}{l}{ State Average Scores } \\
\hline Year & Math & Writing & Math & Writing \\
\hline 2007 & 535 & 512 & 505 & 503 \\
2009 & 543 & 525 & 487 & 483 \\
\hline
\end{tabular}

Apple High School outperformed the students across the state both years. In 2007, the math scores for Apple High School exceeded the state average scores by 5.9 percent, and the writing scores exceeded the state average scores by 1.7 percent. Then in 2009, the math scores for Apple High School exceeded the state average scores by 11.5 percent, and the writing scores exceeded the state average scores by 8.7 percent.

Apple High School was among the top schools in the state in regard to the number of Advanced Placement (AP) courses taught. Apple High School taught twelve AP classes which was the second highest in the state (A.P.11). Advanced Placement courses taught in the 20092010 school were: AP Psychology, AP Language, AP Literature, AP US History, AP Government and Politics, AP Calculus AB, AP Calculus BC, AP Statistics, AP Chemistry, AP Environmental Earth, AP Biology, AP Studio Art (A.D.1). In addition to those AP classes taught on campus, in 2009-2010 the school had students enrolled in four WVVS classes. Those classes were: AP Art History, AP Macroeconomics, AP Microeconomics and AP German. The principal believed that "it gives students a chance to really excel there in an AP program" (A.P.11). In addition to the AP classes, there were seven college courses offered through the 
university located in close proximity. Those courses were: Math 121; Math 127; English 101; English 102; Communications 103; Psychology 201; Sociology 200 (A.D.1).

Due to its teachers, administrative team, outstanding test scores and the second most abundant number of Advanced Placement courses, Apple High School exhibited high expectations. It was believed that through certain administrative, curricular, and instructional practices, a definition of high expectations would exist.

\section{Administrative Practices}

Four administrative practices were identified at Apple High School that was believed to fit the proposed definition of high expectations found in Chapter two, the literature review. What will be presented in this section was how the following administrative practices promoted high expectations: principal used two additional blocks of time (one before school and the other after school) to complement the 4 X 4 block schedule; a freshmen program that helped transition all freshmen to high school and provided the opportunity to assure success in all classes; an atrisk program that focused on freshmen students and provided assistance to them so that graduation was obtained within four years; and the principal had instituted a reward system where students were afforded the opportunity to be exempt from the comprehensive final exam, when certain attendance and grade criteria were met.

Two additional instructional blocks. Apple High School's schedule was a four-by-four block schedule where students had four 90 -minute class periods for 90 days. Flexibility was added to the block schedule through two additional blocks. Those additional blocks were called zero block and fifth block.

Learning in America has been a prisoner of time. For the past 150 years, public schools in America have kept time constant but yet learning was varied (Lankford, 1994). At Apple 
High School time was not constant as evident through the implementation of the zero block. That block met prior to the start of the regular school day for 45-minutes every day. The most popular use of zero block was for AP courses (i.e., AP Chemistry, AP US History, and AP Environmental Science) (A.D.1). For example, AP Chemistry met everyday during zero block for lecture, and then the laboratory component was twice a week during a 90-minute block of time. (A.D.1). In some instances, it allowed students more choices because an AP course could be taught both zero block or during the day (A.D.1). For example, AP US History was taught during zero block all year or first block spring term (A.D.1). Building that kind of schedule provided flexibility that met the needs of all students.

The zero block also provided students who did not have access to the Internet to enroll in the E2020 class (A.P.3). That class was for students who needed to make up credits due to failure. For those students that did not have Internet access, they were allowed to come during the zero block time and use a school's computer to complete E2020 assignments. That before school time afforded students who were in band or involved in athletics the opportunity to complete E2020 assignments. Having that flexibility within the master schedule assisted students to make-up credits needed for graduation. Apple High School's principal said "we offer it at least three times a day; morning, noon and after school," (A.P.3) so that students have maximum access to the credit recovery program.

The fifth block was used to offer both English and Mathematics courses to students who received a sub-passing grade and needed to make up the credit (A.D.2). "That's actually a class that met five days a week." (A.P.2). Both classes are taught by certified teachers who are provided a stipend. In an effort to offset the cost of the courses to the school, a small fee was charged to those enrolled. All in all, the $5^{\text {th }}$ block class allowed those students who were short 
credits to pick up that credit and remain on course to graduate on time. In addition to making up credits, the band program was taught during $5^{\text {th }}$ block in the fall and the concert band in the spring (A.D.1).

The innovation of using zero block classes also helped students excel through the availability of AP courses each semester according to those interviewed at Apple High School. Not only could the zero block be used to make-up credits, but the fifth block provided extra time too. Through the two extra blocks of time, students who were behind in credits had the opportunity to make up credits and stay on track to graduate. Serving both accelerated and low performing students assisted Apple High School to meet the needs of all students.

Freshmen focus. When a freshman entered the school building at the beginning of his/her high school career, the transition period was frequently marked by a decline in grades, increased absences, and increased behavior problems. Because of those factors, freshmen were more at-risk than any other group of students in the school (Fritzer \& Herbst as cited in McCallumore \& Sparapani, 2010). To assist the freshmen in becoming successful, they were scheduled for Freshmen Focus during the first 19 minutes of the lunch hour. Monday, Wednesday, and Friday sessions were designed to give students an opportunity to finish their coursework, similar to a study hall. On Tuesday and Thursday students learned skills that helped in the transition to high school (A.D.2).

Freshmen were able to earn a full hour lunch period after the first midterm grading period (four and one-half weeks). Students who had a "C" or better in all classes, three or fewer unexcused absences and no skipped session got to have the full hour lunch (A.D.2). Those with Ds and Fs were assigned specialized Freshmen Focus sessions that provided academic support in that area (A.D.2). At each grading period, students were reassigned to Freshmen Focus when 
necessary. Apple High principal said 'I'll tell you what, that Freshmen Focus has been a motivator. Freshmen want out of that focus session" (A.P.16).

Assistance to at-risk students. Students who fell behind and struggled in school were referred to as the at-risk students. Apple High School principal stated, "when we find students that start falling behind (i.e., high absenteeism, high number of discipline referrals) we assigned them to a mentor" (A.P.7). Teachers were used as the mentors so that contact was made with the student during the school day. The principal said "students would be stopped in the hall and asked, did you do your homework? or do you have your paper and pencil?" (A.P.7). Mentors provided the students help in organizing things and studying by offering the students one-to-one time during lunch or their planning periods. The principal even said "they would go by their teacher and he/she would say 'how's Joey doing in class today?,' and that's direct contact" (A.P.7).

If the at-risk student was low SES, then he/she was able to enroll in the fifth block class where the tuition was paid for through the Navigate program (A.P.8). It was through the generosity of the local businesses that allowed for a fund to be set up to provide financial assistance to those in need (A.P.8).

With the funds from the business partners, the principal said "another thing we do with that, which I think was the best part was we take an at-risk kid and get them a job; students are provided up to 15 hours of work per week and the school pays half the salary" (A.P.8). He continued to state "we find that at-risk kids have low self-esteem and anytime a kid was working, making money he felt great about himself (A.P.8). Watts (2000) found that a student's selfesteem needs would replace the social needs leading individuals searching for confidence and self-worth. Furthermore Watts (2000) found that when students had low self-esteem providing 
them with an opportunity to experience success worked best to improve their self-worth. According to the principal "it was the work place program that Apple High School had implemented the past two years that has helped the at-risk student to achieve" (A.P.8).

Final exam exemption. The 90 day, 18-week course schedule was further broken into two 9-week grading periods per semester. All students must take comprehensive exams the first and third nine weeks (A.D.1). But "students may earn an exam exemption for the semester finals at the end of the $1^{\text {st }}$ and $2^{\text {nd }}$ terms by earning satisfactory grades ( $\mathrm{C}$ or better) and attending school faithfully (3 or fewer absences) in a term" (A.D.1). Apple High School called this "ABC/123" (A.D.1). The principal further stated "I mean, if you're saying, if you missed less than three days and you have an A, B, or C, was that an incentive to raise academically [sic]?" (A.P.17).

Students were able to exempt from the final exam, but everyone had to take the first and third nine weeks exams (A.D.1). In order to assure the rigor of each test, the principal stated "I made it clear that on that $[s i c]$ nine weeks final that's the biggee, no open book test" (A.P.17).

According to the 2008-2009 Apple High School report card, the attendance rate was 94.81 percent. In 2007-2008, Apple High School's attendance rate was 94.15 percent (On-line XXX School Report Card, 2008). The increase in student attendance may have been affected by the exemption policy.

Apple High School's integration of two additional instructional blocks, a Freshmen Focus program, support to at-risk students, and a final exam exemption policy were believed to be indicators for high expectations. The two additional instructional blocks provided students the time to take AP classes or earn back lost credits. Freshmen Focus was a program where ninth graders were assisted in the transition from middle school to high school. When a freshman was 
identified to be an at-risk student, he/she received a teacher mentor who worked to guide him/her successfully through all four classes. If a student earned a $\mathrm{C}$ or better average with less than three absences, he/she earned the privilege of not taking the final exam in that class. It was through these administrative practices that Apple High School was believed to exhibit high expectations.

\section{Curricular Practices}

Apple High School used three curricular practices that they believed contributed to high expectations: a credit recovery program open to all students; Advanced Placement courses; and teachers who provided extra help during the lunch hour and after school. Through the use of those curricular practices, teachers believed high expectations were promoted throughout the building.

Credit recovery programs. Within Apple High School there existed two, but distinct, programs that provided opportunity for all students to earn credits necessary for graduation. The two programs were entitled E2020 and $5^{\text {th }}$ block.

According to Dessoff (2009), more districts are using a credit recovery program in order to help students in trouble of graduating to get back on track. Credit recovery programs provided the opportunity for students to earn credit from courses that they had failed through computer generated programs. PLATO was an example of a computer generated program that was used in case study one, by Cherry High School.

At Apple High School the E2020 was a computer based program where students had access before school, lunch, after school, and at home if they had failed a class. Apple High's principal stated "there were students that, let's say, got within 10 percent from passing. They would go into that program" (A.P.2). Students took a test to see where they were and what they 
hadn't mastered in relation to the West Virginia Content Standards (A.P.2). Based upon that test, students completed a program on the computer, doing only those CSOs that the student did not pass or comprehend (A.P.2). Because the program used summative tests and quizzes, access to them was denied and the students were required to take them at school (A.P.2).

In addition to the E2020 class, Apple High School offered a $5^{\text {th }}$ block class that met after school. The $5^{\text {th }}$ block class was different from the E2020 in two ways: there was a fee associated with it, and there was a certified teacher who prepared lessons and instructed the students. Parents did not question the extra cost of $\$ 125.00$ as that money was used to assist the district in paying a stipend to the teachers. The principal believed that "when the parents paid, they had buy-in to the class" (A.P.3). There were two classes available and they were math and English.

Whether it was math or English, the school posted an extra duty contract to hire a certified teacher in those areas that provided instruction to the students. The fifth block class met five days a week, just as a regular class did. Students not only paid to take it, but they had to provide their own transportation too.

Advanced placement courses. As noted under the School setting section, Apple High School had 12 AP courses available to all students (A.P.11). The assistant principal for curriculum stated "we're proud of our AP" (A.AP.3). In addition, she further explained:

The culture here was just a lot of kids take AP. We like to offer a lot of different AP classes so that any [emphasis added] student practically has a choice in an AP if they [sic] want to take something. We say everybody's allowed to do it. (A.AP.3)

Table 12 shows the data on how many students had taken the exam the past three years, and what percent received a three or better on one exam, per grade level. Included was the total 
number of students who took at least one exam. The data was provided by the assistant principal for curriculum (A.D.4).

Table 12

Percent of Apple High School AP Students Scoring 3 or Better On One AP Exam

\begin{tabular}{lccc}
\hline & $2006-07$ & $2007-08$ & $2008-09$ \\
& & & \\
& & & \\
$10^{\text {th }}$ grade & $5.5 \%$ & $4.8 \%$ & $1.3 \%$ \\
$11^{\text {th }}$ grade & $9.2 \%$ & $12.3 \%$ & $10.2 \%$ \\
$12^{\text {th }}$ grade & $13.2 \%$ & $14.6 \%$ & $15.2 \%$ \\
\hline Total & 166 & 183 & 119
\end{tabular}

From the table it can be noted that the number of $12^{\text {th }}$ grade students who received a 3 or better on an AP exam had increased from 13.2 percent in 2006-2007 to 15.2 percent in $2008-2009$.

To further elaborate on the accessibility of the AP courses at Apple High School, the assistant principal for curriculum spoke of two exemptions to enrollment. Two freshmen enrolled in an AP environmental science class this past school year (A.AP.” (A.AP.5). There is a belief that all students can achieve.

Another driving force for the AP program was students who planned 4). In addition, she said "that through the years there had been kids with IEPs in the AP classes to attend out of state schools considered to be more prestigious (A.T9.1). Because of the competitiveness of those schools, students needed to take more AP classes, and earn the title AP Scholar (A.T9.2). That 
award was granted to any student who received a score of three or higher on three or more AP exams (A.D.3).

Students seeking to take the maximum number of AP courses possible during high school were seeking out ways to earn credit outside of the classroom. For that reason, students enrolled in on-line AP courses so that access to courses not available through the school may be obtained. In 2009-2010 there were 13 students enrolled in on-line AP courses. Those courses provided through WVVS included: AP Art History, AP Macroeconomics, AP Microeconomics, AP German, and AP Psychology (S. Gainer, personal communication, January 23, 2011). Students may access those on-line courses at school through the library computers during lunch or other free time (A.T9.1).

To help prepare students for the AP exams, it was noted during a classroom observation that a teacher provided students time to work on a practice AP exam (A.O.1). What was found to be a true testament for the drive to score three or better on the exams was the following statement made by a student upon scoring her practice test, "Oh my Gosh, I'm good at these" (A.O.1). She even pumped her arm, as observed by the researcher, to accent her excitement in her score when she made the statement.

Academic support. If an environment where learning for all exists, then support mechanisms had to be in place for students who were not able to grasp and understand the content the first time through. For students who needed extra time to succeed, Apple High School had provided time during the lunch hour when teachers were available.

When the principal first came to Apple High School, he thought he was going to change the hour long lunch to two 30-minute lunch periods (A.P.16). "It's something that the staff and the students enjoyed", so he said that he would wait to see how it worked (A.P.16). Even though 
the lunch period was referred to as the lunch hour, according to the student/parent handbook, (A.D.2) lunch was 53-minutes long.

During that time, students went to teachers for extra help, if needed. For example, when a math teacher was asked what she did to support the students she stated, "I have them come in at lunch" (A.T2.2). Another teacher said that "to help them, we have noon labs the first of lunch. They can come in and work on anything they want to" (A.T1.2). One of the science teachers stated, "this year and last year we had tutoring. I personally see teachers giving up more of their time the past year and one-half just to help students" (A.T8.1). Even the library was open the entire lunch hour for students to use the computers, work, read or even watch CNN on the large screen television (A.N.1).

The assistant principal for curriculum stated:

Not every teacher was their duty $[\mathrm{sic}]$ to be in the classroom to help. But, anytime he/she needs to be in there for something they could request, and we would say yes. Don't be on duty in the hallway first half of lunch. You can be in your room that day. (A.AP.4) The school offered free tutoring after school on Tuesdays and Thursdays (A.N.2). Two teachers stated that "I encouraged students to go to tutoring," (A.T2.2) and "free tutoring for kids was available after school" (A.T8.1). Not only are the students aware of that service through their teachers, but the outside marquee had it posted for all who drive by the school to see (A.N.2).

When one of the teachers was asked how the school promoted high expectations among the students she responded "we provide them the means" (A.T1.1). Providing support during the school day and after school was an example of how Apple High School believed they provided high expectations to all students. 
Through a combination of credit recovery, a plethora of AP courses and an outstanding academic support system, Apple High School was able to provide curricular ways to show how high expectations were obtained. The credit recovery program was computer based or teacher driven depending on individual needs. For those students who sought college preparatory class work, the school offered twelve AP classes available during the regular day, but on-line AP courses were also available. Finally, Apple High School had an academic support system that provided tutoring during the lunch hour and after school. Both tutoring programs were free and available to all students.

\section{Instructional Practices}

From the work of Rosenthal and Jacobson came the saying that “one person's expectations of another's behavior may come to serve as a self-fulfilling prophecy" (Rosenthal \& Jacobson, 1968, p. 82). What the self-fulfilling prophecy referred to was that when teachers expected students to do well intellectually, as evident through academic achievement, then the students did indeed perform. Apple High School teachers used three instructional practices that promoted high expectations. The three instructional practices were: teachers used the state approved curriculum through implementing all course CSOs, analysis of student test scores, and all teachers provided students the goals and objectives at the beginning of each class.

Curriculum based on CSOs. According to Kennedy (2005), the number one source of ideas for establishing learning outcomes came from institutional policies. Within WVDE Policy 2520.1-19 specific standards and objectives were found for all courses in West Virginia. For example, WVDE Policy 2520.1 defined the content standards and objectives for the reading and English language arts programs (WVDE, 2009). From those documents, the teachers at Apple High School determined the content of their lesson plans. 
Eight teachers were interviewed at Apple High School, and all eight stated they used the state approved Content Standards and Objectives (CSOs) when designing classroom instruction. One teacher stated that "I've gone through and with each lesson I put down the CSO that I'm at" (A.T1.2). Another teacher commented "I don't just cover them, I make sure that as at [sic] a minimum they are taught and mastered" (A.T2.3). Another teacher stated "so, I'm using the CSOs and finding those objectives in the book. I'm not just starting at Ch.1 and finishing through Ch. 8" (A.T5.1).

An English teacher commented "I actually takes [sic] part of the test and use them with my students in a whole class instruction to get them to be better critical readers" (A.T6.3). A science teacher noted that his CSOs were vague so he had to fill in the gaps. He explained his process as:

Sometimes the CSOs may say you need to talk about biochemistry. Well, there's some in the book, but it doesn't have the ones I think the kids should know. I decided I was going to get other materials and put them into my slide show, and kind of fill in the gaps of what the CSOs point me in this direction, but then I elaborated on that and put more into it. (A.T8.2)

Analysis of data. Apple High School was a school that embraced higher achievement through the use of frequent monitoring of the core objectives or CSOs in the curriculum. Teachers believed that through the use of data analysis and then continuous monitoring through ACUITY, high expectations pervaded the school.

Lezotte and McKee (2002) believe that "in the effective school, pupil progress over the essential objectives were measured frequently, monitored frequently, and the results of those assessments were used to improve the individual student behaviors and performance" (p. 18). 
This was evident at Apple High School because after a committee had analyzed the WESTEST scores, they took it back to the departments where time was provided to break it down and strategies for improvement determined. In addition, it was noted that teachers continued to retrieve data to determine if students were improving. The tool used in obtaining additional data was an assessment data system called "ACUITY."

The assistant principal for curriculum stated that "we had a committee to analyze WESTEST scores and they took it back to their departments" (A.AP.9). One of the science teachers stated, "usually during one of our IS days or CE days they'll give us all of our scores and we will sit down as a department and we go over it" (A.T7.2). A math teacher stated:

I was on a committee this year for analyzing WESTEST scores, and I was the math representative. What we did was we sat down and looked at some of the problem areas, some of the lowest scoring areas percent wise.” (A.T2.3)

A social studies teacher commented "at the beginning, when just teachers were here, met as a department, go over it, and discussed strategies to implement to correct deficiencies" (A.T5.2). Finally, an English teacher stated, "I try to use my test assessments. I try to make them similar to the questions they used on the WESTEST 2" (A.T6.3).

During a mathematics classroom observation, it was noted that the teacher told the students to place the bell ringer under the WESTEST section of the notebook (A.O.2). The bell ringer used upper level thinking skills through the application of a formula when finding the coordinates of a point (A.O.2). Using the bell ringer problem assisted the teacher in making the connection of the content of the lesson to the content of the questions found on WESTEST.

From the initial analysis of the data, teachers were then driven to use the ACUITY program as a monitoring device during the course. For example, a math teacher stated, "we do 
go to the computer lab to work on ACUITY. At least three times during the semester, which was the minimum required to do" (A.T2.3). An English teacher, who had administered the ACUITY test the second time, noted that "I've seen a big improvement because in our second ACUITY, I actually had somebody get 23 out of 25 which was actually awesome" (A.T6.2). It was evident that both mathematics and English teachers were using ACUITY to gather further data. As for science and social studies, the assistant principal stated "looking forward to science and social studies ACUITY coming out," because those two subjects do not have tests available for use (A.AP.9).

Goals and objectives. Kennedy (2005) believed that classroom routines were established and that each day's lesson was planned to foster student learning by establishing a learning outcome. At Apple High School seven of the eight teachers interviewed stated "that the students know where we were and where we are going" (A.T1.2, A.T2.2, A.T3.2, A.T4.2, A.T6.1, A.T7.1, and A.T8.2).

Teachers communicated the goals and objectives of the lessons in several ways to the students. For example, a business teacher stated "we go over those at the beginning of a new section" (A.T1.2). A science teacher stated "I would give that to them verbally or, tell them here's what we are accomplishing today" (A.T7.2). A mathematics teacher said "I discuss exactly what the objectives are" (A.T4.1).

During two classroom observations the teachers had the objectives written down for the students (A.O.3, A.O.5). During the observation of a science teacher, the objective was displayed on the front screen through the power point slide, and two little dry erase boards had the objectives written too (A.O.3). During a classroom observation of a social studies teacher, 
the objective was written in large font across the front blackboard and students were writing it down in their notebooks (A.O.4).

One of the English teachers stated "I write on the board, this is what we're going to do, this is what we're going to cover" (A.T6.2). Some teachers say them and write them down as evident by a mathematics teacher who said "I give them a copy of the minimum CSOs and I put on the board things that are specific, like a daily schedule" (A.T2.6).

The main component of each day's lesson was the learning outcome. It was evident that the teachers at Apple High School established a daily learning outcome for the students through both oral and written statements. Providing the specific learning outcome(s) to the students was one of the practices Apple High School used when establishing high expectations for all students.

Evident at Apple High School was that teachers used the three instructional practices of: based instruction on approved course curriculum (CSOs), analyzed testing data, and teachers referenced the goals and objectives to each unit or lesson. All teachers interviewed used the state approved curriculum (CSOs) when lessons were developed and delivered. State achievement test data was used to identify areas that needed improvement. Not only was CSOs and data analysis completed to enhance instructional strengths, teachers communicated to the students the goals and objectives of the units/lessons. It was believed that those practices enhanced student high expectations at Apple High School.

It has been pointed out that the following ten practices found at Apple High School under the areas of administrative practices, curricular practices and instructional practices, were believed to be associated with high expectations: additional instructional blocks, a Freshmen Focus program, at-risk students provided assistance, a policy on final exam exemption, credit 
recovery, a plethora of AP courses, academic support to all students, teachers use of state approved curriculum (CSOs), teacher analysis of testing data, and teacher communication of the goals and objectives to the units/lessons.

\section{Case Study Three}

School setting. Orange High School was located in the center of a town that had a total population of 2,996, according to the 2000 census (West Virginia HomeTownLocator, 2010). It consisted of grades 7-12 and had an approximate enrollment of 645. The school was a member of a school system containing over 13,000 students that was one of the top three systems in the state for total number of students served.

The school was built on its current property in the 1950s and opened its doors in 1958 (Principal, personal communication, June 22, 2010). Orange High School has served students in grades $7-12$ since its opening. In 2004 the school system passed a bond levy that provided funds used to build eight new classrooms and a new gym. The existing rooms obtained new paint, floor tile, ceiling tile, lights and individual heating/air conditioning units. All of the renovations were completed by the fall of 2008 (Principal, personal communication, June 22, 2010)

In looking at school enrollment data from 2002 to 2009, the records indicate that for 2002-2003 the total $7-12$ enrollment was 620 students. From that time, the maximum enrollment was 676 in the 2006-2007 school year, and for the 2008-2009 school year was 645 (O.D.1). The data underscores that the total enrollment at Orange High School during the seven years remained above 600 .

Thirty-six regular classroom teachers; two assistant principals, including one who served as full-time athletic director; one principal; two counselors; one librarian; four special education 
teachers; and one classroom aide served the 645 students (O.D.2). Table 13 displays the educational level of the teachers compared to the state average. This table was constructed from the Orange High School report card (On-line XXX School Report Card, 2009).

Table 13

Orange High School Teacher Educational Levels Compared to State Levels

$\begin{array}{lcc}\text { Level of Education } & \text { School } & \text { State } \\ \text { Bachelor's Degree } & 14.9 \% & 15.6 \% \\ \text { Bachelor's plus 15 } & 25.5 \% & 23.7 \% \\ \text { Master's Degree } & 8.5 \% & 7.5 \% \\ \text { Master's plus 15 } & 8.5 \% & 9.3 \% \\ \text { Master's plus 30 } & 19.1 \% & 13.0 \% \\ \text { Master's plus } 45 & 23.4 \% & 30.3 \% \\ \text { Doctorate } & 0.0 \% & .6 \%\end{array}$

The table illustrates how the educational levels of teachers at Orange High School vary when compared to teachers in the state.

Faculty were served by a principal who was a graduate of Orange High School and had been on the staff since 1992 as teacher, coach and administrator. He began his administrative career as the assistant principal in 2005 and became the acting principal in March of 2007, with the appointment to principal in June of 2007 (Principal, personal communication, June 22, 2010).

The principal resided within the local community where his children had attended the elementary school and then graduated from Orange High School. The principal had served as a 
city council member for 11 years and was an active member of the local Lions club (Principal, personal communication, June 22, 2010).

Working with the principal since 2008 was the assistant principal in charge of discipline. His previous experience included serving as the assistant principal for over five years in the neighboring district. Due to that experience, he helped lower the number of discipline referrals during the 2008-2009 school year (O.P.3). The principal believed that the drop in discipline referrals was the result of the assistant principal's proactive approach with athletic organizations, parental clubs and student government (O.P.3).

State achievement test scores from the 2008 and 2009 school years were analyzed to note how achievement compared to the state average. Table 14 shows the mathematics and reading/language arts scores compared to the state for 2008 and 2009 (On-line XXX School Report Card, 2009).

Table 14

Orange High School Percent of Students at or Above Proficiency in Mathematics and Reading/Language Arts

\begin{tabular}{llll}
\hline Year & Subtest & School \% proficient & State \% proficient \\
\hline 2008 & Math & $78.4 \%$ & $75.3 \%$ \\
2009 & Math & $56.3 \%$ & $59.5 \%$ \\
2008 & Reading/Language Arts & $77.4 \%$ & $80.0 \%$ \\
2009 & Reading/Language Arts & $53.9 \%$ & $58.8 \%$ \\
\hline
\end{tabular}


The table illustrates that in 2008 Orange High School exceeded the state average by 4.1 percent for the percent of students at or above proficiency in mathematics. In reading/language arts Orange High School fell below the state average by 2.6 percent. In 2009 the scores at both the state level and school level dropped. This drop was contributed to a change in the level of questions from basic low cognitive questions to questions that incorporated higher level thinking skills on the new version of the WESTEST.

Table 15 displays the composite scores for the ACT at Orange High School in comparison to the state's average composite score and the national average composite score (XXX report card, 2009).

Table 15

Orange High School ACT Scores Compared to State and National Averages for 2008 and 2009

$\begin{array}{llll}\text { Year } & \text { School Average } & \text { State Average } & \text { National Average } \\ \text { Composite Score } & \text { Composite Score } & \text { Composite Score }\end{array}$

$\begin{array}{llll}2008 & 21.7 & 20.7 & 21.1\end{array}$

$\begin{array}{llll}2009 & 21.3 & 20.7 & 21.1\end{array}$

In 2008 Orange High School exceeded the state average by one point and nationally by fourtenths of one point. For 2009 Orange High School exceeded the state average by six-tenths of one point and nationally by two-tenths of one point.

Table 16 highlights the SAT average mathematics and writing scores for Orange High School compared to state averages in mathematics and writing for the 2007 and 2009 school years. Scores for the 2008 school year were not available from the report card (On-line XXX School Report Card, 2009). 
Table 16

Orange High School SAT Average Scores Compared to State Average Scores

\begin{tabular}{lllll}
\hline & \multicolumn{2}{l}{ School Average Scores } & \multicolumn{2}{l}{ State Average Scores } \\
\hline Year & Math & Writing & Math & Writing \\
\hline 2007 & 508 & 496 & 505 & 503 \\
2009 & 487 & 494 & 487 & 483 \\
\hline
\end{tabular}

In 2007 Orange High School student scores exceeded the state's average math score by less than one percent (.59). Then in 2009 Orange High School student scores exceeded the state's average writing score by 2.3 percent. So, the SAT scores reported in 2007 and in 2009 indicate Orange High School met or exceeded the state's average scores in mathematics and writing.

Orange High School participated in the Advanced Placement program. For the 20072008 school year there were four classes taught with 37 percent of the enrolled students receiving a three or greater on the AP exam. In 2008-2009 there were five classes taught with 38 percent of the enrolled students receiving a three or greater on the AP exam. In 2009-2010 the number of AP courses had grown to seven and included: AP US History, AP Language, AP French, AP Spanish, AP Studio Art, AP Calculus AB, and AP Literature (Principal, personal communication, June 24, 2010). Unlike the other two case studies, students at Orange High School did not enroll in AP courses provided through WVVS. (S. Gainer, personal communication, January 23, 2011). 
Having described the school setting, along with data indicating the academic success the school has had, what will be introduced next are the administrative practices, curriculum offerings and instructional practices believed to be a part of the definition of high expectations.

\section{Administrative Practices}

There were three administrative practices found at Orange High School that fit into the proposed definition of high expectations found in Chapter two, the literature review. Those practices found included: course drop date, communication, and community organization involvement. It was believed that those practices contributed to the definition of high expectations.

Drop date for courses. At one time Orange High School allowed students to drop courses at the end of the first nine weeks. Students would complain that they had to work or had to study in a class so they would want to drop it and take an easier course.

That practice was stopped at Orange High School. The principal said "they had the first week to determine if they're going to drop a class or not" (O.P.2). Earlier it was mentioned how important the principal believed communication was in the school, and an example of that was how he worked with kids during the scheduling process. He stated "we're upfront with the kids. They are told not every kid was going to get an A in that class" (O.P.2). After that first week of school kids know they are in that class until the end of the year.

As with all practices or policies, there are exceptions. The principal explained that when a situation arose where a borderline student may have been in a regular class where he/she was not achieving, then Orange High School had a form that was used to drop that class (O.D.9). That form contained the following questions that had to be answered affirmatively by the teacher in order for that student to drop: (a) was the student asking for help, extra help, (b) was he/she 
asking questions in class, (c) was he/she seeking tutoring and (d) was the student attending class regularly (O.D.9). This form allowed all students the ability to try challenging courses in a fearless environment. The principal stated "now we're making kids stay in classes that they may have to work for" (O.P.2).

Communication. In looking at communication, Bamburg (1994) notes that effective communication comes when the adults in the building talk about practice and help each other to learn and teach. To set the stage for this type of communication, the principal had set up collaborative learning teams based upon the grade level the teacher taught. The principal stated "we tried to get them at grade level. Since they are at grade level, they shared the same kids and if a child was dropping off in grades, they could talk among each other to find out why" (O.P.20,21). A teacher summed up her beliefs about those meetings as "we've had some wonderful discussion in those two brief times we met about individual kids and about how they're doing" (O.T6.9).

In the document collection process, two forms related to the collaborative learning teams were obtained. The first form was a copy of the minutes taken from the $11^{\text {th }}$ grade team meeting held on Friday, August 21, 2009. During that meeting the team was provided three questions to lead the discussion. The three questions were: (a) do we know of at-risk students who could benefit from some specialized help? (b) could we as team members help one another? and, (c) what was the mission statement of our team? (O.D.6).

The second form was a general team log that contained the following four statements: (a) topic of discussion, (b) clarifying questions, (c) ideas and suggestions, and (d) concerns and reflections (O.D.7). Each statement was used as a guide to meaningful, relevant team 
discussions. The principal required that the teams hand in notes of what was discussed, including any recommendations (O.P.21).

Communication from faculty to faculty was not the only lines of communication that occurred in the building. The principal also communicated with students at Orange High School. During the interview with the principal, he noted "I did weekly meetings with the team leaders of each grade level (i.e., class officers and representatives)" (O.P.35). He went to his calendar and noted that on the $28^{\text {th }}$, Wednesday at 10:20 am he would be meeting with the seventh grade team leaders for the first time (O.P.35). Those meetings allowed the students to openly express concerns in a fearless environment. The principal stated:

I sat down with them and chatted with them. I said what's working for you? What's happening with you guys? What are you upset with? What changes would you like to see? What do we need to do? (O.P.35)

Information shared at those meetings reflected that students at Orange High School took responsibility for their learning and they had high expectations of staff. "The kids wanted to achieve, they wanted to do well, they wanted to improve," stated the principal (O.P.35).

Opening up the communication lines between the office, teachers and students was helping to improve the school and was believed to represent high expectations. The following statement written in the teacher handbook summarized the principal's belief about communication: "it was his intent to be available to help in any way he could" (O.D.5).

Community organization involvement. Although there was no clear mandate of parent-teacher organizations in statute, the closest regulation was the Local School Improvement Council, School Laws of West Virginia §18-5A-1 (2007). Orange High School was the first high school to go beyond the requirements of this statute through its formation of a Parent- 
Teacher-Organization [PTA] (O.N.1). A foreign language teacher added "we were the first high school in the state that had a PTA" (O.T7.3). The PTA began in the 2008-2009 school year for the purpose of taking on projects that visually promoted academics within the building (i.e., academic calendar posted in the hallway, pictures of the National Honor Society inductees, and pictures of valedictorians) (O.P.8).

In addition to those projects, the PTA supported the teachers by providing dinner each year at the fall parent-teacher conference night (O.N.1). The date of this year's parent-teacher night was October 26, 2009 from 4-8 pm. At approximately 5:00 pm the PTA set up a table containing a variety of food dishes outside of the office (O.N.1). A foreign language teacher made the comment "they fed us dinner Monday night at the parent-teacher conferences" (O.T7.3). Parent volunteers not only prepared the food but they also served and cleaned up. All of that was done as a gesture of appreciation for the work teachers do. One of the foreign language teachers said "the school was well supported in our community" (O.T7.4).

Another way that the principal had enabled community members to become active in the educational process was through an organization called Academic Investment Group (AIG). This organization was made up of "individual parents that were academic, they were the academic boosters" (O.P.6). Just as other schools had a sports boosters club that supported the athletic teams in a school, this club supported academics (O.P.6).

\section{Curricular Practices}

Orange High School used three curricular practices that tied into high expectations: the school provided Advanced Placement courses; core teachers used a prioritized curriculum; and teachers enhanced rigor within their instruction. Through the use of those curricular practices, high expectations were promoted throughout the building. 
Advanced Placement course offerings. In accordance to WVDE Policy 2510 (WVDE, 2008) high schools must offer "a minimum of four college Board AP courses annually" (p. 25). Orange High School exceeded the minimum number and had increased the number of Advanced Placement courses provided over the past three years. In the 2007-2008 school year Orange High School taught four AP classes to a total of 426 eligible students; in 2008-2009 five with 437 eligible students; and in 2009-2010 seven classes to 447 eligible students (O.D.1 \& WVDE, $2010 \mathrm{~b}$ ). From 2007-2008 to 2009-2010 the number of AP courses taught had increased 75 percent in a school were there were 447 students eligible to enroll in an AP course.

It was believed that the number of AP courses reflected Orange High School's use of the traditional eight period course schedule. During the principal interview the principal explained the scheduling decision as:

Our schedule was driven by the middle school seventh and eighth graders. You have your double block of English, you have your math, your science and your social studies. And then we offer three groups of cluster classes. Two groups of clusters have classes that are required by 2510 . The third one is a cluster that has what I call disposable classes or non-required courses and, uhm, during that time a child has a choice between band, choir, strings and/or gifted. I try to get the seventh and eighth grades scheduled and then I go through and start looking at the schedules and I try, as I said before, try to place the AP, honors courses, where the kids can get to those without giving up a credit. (O.P.22)

The original four AP courses were: AP US History, AP Language/Comp., AP English Literature, and AP Calculus. Since then Orange High School has added: AP Studio Art, AP French and AP Spanish. All of the AP courses were taught by a teacher in a traditional 45- 
minute class period. Not only had the number of courses increased, but the total number of students enrolled in the AP program had, too. In the 2007-2008 school year a total of 19 students of the eligible $426(4.4 \%)$ were enrolled, as compared to 85 students of the eligible 447 (19\%) were enrolled in the 2009-2010 school year. That amounted to an increase of 66 students or over 77 percent. However, Orange High School did not have any students enrolled in the WVVS for the $2008-2009$ or $2009-2010$ school year. Teachers helped the school counselors and administrators in getting students to take AP courses as evidenced by an English teacher's comments "we've been incorporating more and more of the AP programs and honors programs here recently. We've told them, research showed that anyone who takes those kind of classes was going to increase chances [sic] of graduating from college" (O.T3.6).

The English teacher explained that there were no criteria used to get students enrolled in those courses. She stated "we don't have any criteria to get into those classes, except for by choice. We say, if you want in there you can do it" (O.T3.6). Through the use of the WVVS Orange High School may be able to further increase the number of students enrolled in AP courses.

Curriculum maps. A common practice among the core teachers was to follow the district provided curriculum map. Teachers throughout the school system were asked to convene for three days at the Board of Education Office to develop the maps (O.T4.8). During that time, teachers took the state mandated CSOs and decided what order the core standards would be taught. A math teacher described the process as:

We went as a group of math teachers and decided what we had to cover or what the essential standards that you had to cover were. Then after we got those down we talked 
about the ones that should be covered. There's a few that we looked at and said if I had to leave one or two out, these would be the ones least missed. (O.T1.8)

The final product (O.D.10) shows what CSOs to cover and the approximate amount of time given for each CSO.

Another math teacher explained that those maps were only guides to be used. She said "I slow it down. The map gives us way too much for those kids to know and they can't get it that fast. So, I slow down" (O.T4.3). She further explained "if I can get them knowing at least threefourths of the material, at least when they go to college they would feel comfortable. It won't be as scary for them" (O.T4.4). An English teacher noted the use of the map as evident in her comment 'even though we've mapped out that we want those covered that nine-weeks, they're all covered all nine-weeks in a lot of cases" (O.T3.7). A senior math teacher summed up the curriculum maps best by "I think the prioritized curriculum was one of the greatest things we've ever done here" (O.T1.4).

Rigor of curriculum. When the emphasis was added for $21^{\text {st }}$ century learning from the West Virginia Department of Education, one of the buzz words was rigor. The very first sentence of the principal interview was "I as the administrator had asked the staff to show more rigor in the classroom" (O.P.1). One of the teachers believed that the word rigor meant, "rigor, a lot of that was making sure you're teaching from bell to bell” (O.T2.3). During a classroom visit, it was noted that the students worked bell to bell (O.O.1).

Since rigor can be ambiguous, the researcher attempted to get the principal to provide examples of how he was interjecting rigor into the school program. What follows were some examples he provided. 
The principal had created various teacher groups whereby discussion occurred in regard to the school's curriculum. Two groups that were mentioned were the curriculum team and department teams (O.P.1). He said, "the curriculum team looked at different ways to strengthen our schedule to strengthen issues that we had in the classroom and we met monthly" (O.P.1). A member of the curriculum team noted that the principal mentioned in the curriculum team meetings "rigor, rigor [emphasis added]. Bring rigor back into the system" (O.T7.4). The importance of "rigor" came about in 2008 as the state changed the WESTEST.

A copy of the agenda for the September meeting noted 14 items for discussion (O.D.8). Items on the agenda found specific to curriculum and instruction were mimeos (document projectors), technology, Acuity (state required benchmark assessment program), Grant money ( $\$ 5,000$ for projects that seek to increase awareness of Japan), and substitute teacher usage.

In addition to the groups, the principal stated "we had mid-term (semester) and final tests. We had asked the teachers to make their tests more rigorous" (O.P.2). So that teachers understood how to do so, the principal said "we've went over those and we've discussed those as to how much more rigorous they can be. But, rigor didn't mean they had to be all essay questions. We asked that a variety of questions be added too" (O.P.2).

\section{Instructional Practices}

Good and Brophy (2003) stated: "teachers cannot simply follow the suggestions that come with their textbooks and expect to achieve coherent programs of curriculum and instruction" (p. 366). They must be willing to go away from the textbook and incorporate new ideas, new ways to present the material so that all students achieve. The teachers at Orange High School used five instructional practices that enhanced their instruction beyond the textbook. The five instructional practices used by the teachers included: project based learning, alignment of 
curriculum to the state approved content standards; varied instructional practices; built in times for student tutoring; and student recognition for achievement. All of those practices provided an environment where learning for all was believed to lead to high expectations.

Project based learning. The principal had asked the staff to look at implementing units that would incorporate project based learning. The Department of Education had posted on its website examples of project-based learning projects teachers could do. He said "I've asked the staff to look at some project based learning projects when they do projects. The projects should be something the students do throughout their career here as a student" (O.P.2).

A teacher example of a project based learning project was provided by an English teacher. In her class students had four or five projects per year that dealt with providing a response to a play or story (O.T3.1). One of the responses to Romeo \& Juliet was to write a scene in a modern sense, develop it into a script, have the costumes, video it, and show it to the class for review (O.T3.1). That project was something that was a culmination of the play and the teacher looked it over along the way and provided suggestions (O.T3.3).

Curriculum alignment. West Virginia Department of Education Policy 2510, section 8.3.5 states "teach all state content standards and objectives" (WVDE, 2008, p. 45). In following policy, Orange High School teachers used the state approved Content Standards and Objectives (CSOs) when designing classroom instruction.

Ten teachers were interviewed during the researcher's stay and all ten said they used the CSOs. An English teacher stated "My curriculum was aligned with the CSOs (O.T3.6). Another general education teacher stated "I used the CSOs and the book matches up with them," when planning the content of a lesson (O.T6.3). A science teacher included "my content was based 
upon the classroom assessment and the CSOs" (O.T8.4). In conclusion, a special education teacher stated:

The content of the lesson was based upon the CSOs. The IEP was based upon the CSOs. Take a CSO and make it manageable for the students. I may not go as far in-depth as regular education students or I may not go at the same speed. We're trying to hit that main concept. (O.T10.4)

Varied instructional practices. According to the West Virginia Department of Education Policy 2510, section 8.2.4 teachers are responsible for "engaging students successfully in meaningful age appropriate instructional activities" (p. 44). Orange High School teachers explained that they presented material in numerous ways so that instruction was meaningful. A math teacher described his instructional activities as:

I try to present it in just about every way, every learning style that you can present it [sic]. I lead the students, I go through the problem and show them why this happens and why this was true. I even help them discover it on their own. (O.T1.3)

An English teacher explained her teaching strategies as "I don't like to keep doing the same thing everyday in a row. I can sense when people are tired of that kind of thing. I like to do a lot of variety in my classroom" (O.T3.7). An art teacher explained that she used collaborative learning (O.T5.3). She further explained that process as "students do a grid drawing of a masterpiece where they had to work together. They each had a section of it that they did and then I match them up with another to work collaboratively" (O.T5.3). A foreign language teacher stated: 
I used on-line resources and a lot of other resources you can integrate in. We do a lot of supplementary things outside of the textbook like websites. I try to keep instruction varied so that they don't expect to come in and have face in book [sic]. (O.T2.6,7) A science teacher believed that students learned best through visual presentations. She said "I try to teach in all three ways: visual, hands-on and oral" (O.T8.5). Finally, another foreign language teacher said that "I try to change the activity every 10 minutes. I try to give a 10 minute maximum for reading, writing, listening and speaking" (O.T7.6).

Tutoring. According to Good and Brophy (2003) some students "tend to give up at the first sign of difficulty or frustration and need more intensive and individualized encouragement" (p. 220). To help provide assistance to the students the assistant principal at Orange High School began a remediation program staffed by student volunteers. According to the principal:

My assistant had set up a tutoring program where we had tutoring volunteers. We made it accessible to those kids who need it. Parents can go out and hire a kid to come in and work with their child. But if a family cannot afford that, then we used community service. I want our kids to give back to the community. (O.P.3,4)

In addition to the student volunteers, Orange High School had built into the bell schedule three times a day when a student was able to go to a teacher for extra help (O.P.3). According to both the teacher handbook (O.D.5) and the student planner (O.D.11) the times are from 7:40 am $-7: 55 \mathrm{am}, 10: 45 \mathrm{am}-10: 55 \mathrm{am}$, and 3:15 - 3:30 pm. Some teachers stayed beyond 3:30 pm on set days of the week to provide additional assistance (O.T4.10).

One of the foreign language teachers encouraged students to come for tutoring (O.T2.8) She even explained that "I had them sit with me and do a similar exercise to what they'll be evaluated on" (O.T2.8). A health education teacher explained that she let the students know that 
“they could come at lunch. I'm here all lunch period and I'm here every morning at 7:30 am" (O.T6.5). A math teacher explained 'I'm always available to them after school if they don't understand something or if they need help with anything" (O.T1.13).

What was noted during the researcher's stay was how one math teacher had kids lined up at the end of the day to come in for extra help (O.N.2). At times, students who came for extra help were not enrolled in one of her classes. For example, the math teacher stated "I had kids coming in for Chemistry tutoring and I don't even teach that or I had people come in for trig, and I don't even teach that either" (O.T4.3). That math teacher not only serviced students from a variety of classes, but she was willing to stay until 4:00 pm or sometimes 4:15 pm (O.T4.10). She said "I try to do it twice a week: Tuesdays and Thursdays and some weeks I'll stay more" (O.T4.10).

One of the math teachers had established an unique practice within her classroom that provided the impetus for students to stay after school and receive tutoring. She stated, "if they (a student) made a D or F on anything, they had to come in and we go over it" (O.T4.1). When asked if students skip the after school session she said "they come in. It's amazing. They know I mean business" (O.T4.1). She explained that what she did worked because "parents want teachers to be accessible to help students and be a quality teacher (O.T4.5).

Recognition for achievement. Good and Brophy (2003) noted that they believed rewards could be used effectively in classrooms. At Orange High School they strongly believed in rewarding students. However, it was not the school themselves that rewarded the students; it was one of the parent organizations mentioned earlier called the Academic Investment Group (AIG). 
That group rewarded students at the end of each nine week grading period according to GPA. The principal explained that the AIG took "those kids that were on the principal's list, commendations list, or honor roll list and excused them on a school day to go down to the cafeteria where there were drawings for gifts" (O.P.6). The GPA for each of those groups was as follows: principal's list (4.000), honor roll (3.6 - 3.999) and commendation list (3.000 - 3.599) (O.D.8).

In addition to the principal stressing the AIG, all ten teachers interviewed noted how AIG was an important tradition at Orange High School. So that all students had a chance to earn this reward, in addition to those students who had obtained the grade criteria, any student who improved their previous GPA by .5 or more got included, too (O.T2.3). A special education teacher stated "the kids had a real sense of accomplishment for that. Very pleased to be recognized at that level" (O.T10.3). Another teacher said "kind of an incentive for the children who don't do well because if they had raised their grades .5 or higher for the next nine weeks they got to go" (O.T6.2).

According to a teacher, "students liked the idea that the reward was during the school day and lasted for approximately 45 minutes" (O.T7.4). A foreign language teacher said "even the juniors and seniors were very excited to see if their name was on the list" (O.T7.4). Another teacher explained how important that was to the students because "you did hear the kids talk about like, 'are you getting to go,' or 'oh, man, I missed it by like you know one'” (O.T 2.3,4). The foreign language teacher summed up how unique it was to have a parental organization organizing a reward program for students, "I've worked at several high schools in the state, and I don't remember that ever happening. That's a very nice thing" (O.T7.4). 
Students were recognized within the classroom for various accomplishments, too. A math teacher said "if they make an A, I give them stickers" (O.T4.6). Even though stickers may seem to be an idea from an elementary setting, the teacher said "it was my upper classmen that wanted them" (O.T4.6). To add how important stickers can be to high school students she explained "they will work for an A for me because they want stickers" (O.T4.6).

To complement the use of stickers in the classroom, the math teacher also provided written comments to the students based upon grade. Based upon the letter grade obtained, the teacher wrote certain comments. She said "an A gets wonderful and a B gets great" (O.T4.11). She will even provide a written comment when students improved from one test to another. She stated "if a kid had an F on the last test and made a C on that one I'll put 'wow, you are doing much better"' (O.T4.11). In addition, it was noted that six other teachers stated they used written comments on student work (O.T3.9, O.T5.4, O.T6.5, O.T7.5, O.T8.6, and O.T10.6).

This case study was unique in that the school was in the center of the community; the principal was a graduate of the school and had been a long standing member of the community. It was believed that because of this, a theme that became apparent during the transcription of the interviews was that the teachers were a closely knit group that cared for their students. On the second day the second teacher interviewed stated "we're a smaller school so we get to know the students a little better and we can hopefully tailor our schedule, tailor a student's schedule to meet their needs" (O.T2.3). Another teacher said "with us being closely knit here, the community I think wants to be successful. They want to show that to everyone else. The smaller community gets behind you" (O.T4.5).

A fine arts teacher who was not a member of the community explained that "parents and faculty are tight knit" (O.T5.2). She even commented that the "principal was caring and 
compassionate" (O.T5.7). One of the English teachers explained "students feel a real strong connection to our school and pride in our school. They like the teachers, the teachers like them...very family oriented" (O.T3.5).

The sense of community belonging was also noted through the interviews. A senior teacher who was born, raised and graduated from Orange High School said "this community was unbelievable. This community expects us to be the number one school in the district. You had no idea how wonderful this community was and how much they cared about this school" (O.T6.10). A science teacher who commutes approximately 20 miles one way to work stated: A lot of people stay and so there was a pride. People that come to ball games, people that support and give money do so just because they lived here and went here. I wouldn't want to go anywhere else. The kids accept each other. The camaraderie I think was much more here. I was shocked to see the support, enthusiasm and competitiveness versus the nonchalant, not caring, nobody showing up for things that sometimes you got at a bigger school. (O.T8.3)

It was evident that three administrative practices, three curricular practices and five instructional practices were found to contribute to a belief of high expectations at Orange High School. The three administrative practices included communication mechanisms set in place where the administration, faculty and students were able to communicate to one another; before a student could drop a class a form was used to document that the student sought out extra help; and finally their existed strong community support for the school as noted in the PTA and AIG organizations.

The three curricular practices included an increase in the number of AP courses taught over the last three years, in addition to an increase in the total number of students enrolled in the 
AP program; core teachers provided a prioritized curriculum map to use when making lesson plans; and rigor was found to occur through instruction going from bell to bell, more written essays on exams and teachers encouraged to implement project based learning.

The five instructional practices included teachers using project based learning, all teachers aligned course content to the state approved curriculum (CSOs), teachers used varied instructional practices to accommodate all learning styles, a tutoring program that included student volunteers, and a student recognition program founded by one of the parent organizations (AIG).

\section{Cross-Case Analysis}

A cross-case analysis was completed comparing the three case studies in an attempt to make generalizations about what constituted high expectations. This process increased the generalizability of the study as it went beyond a particular case. It was here that the researcher looked for what categories arose from the administrative, curricular and instructional themes that appeared to be evident in each case study. The following seven categories were found to be present across all three sites: administrative practices-scheduling and professional learning communities; curricular practices-strong advanced placement program and extra help/extra time provided; instructional practices-curriculum aligned to the state assessment tool and teacher teaching the prescribed curriculum. What was found to be prevalent among all three sites was that a strong parental involvement/support piece existed and can be listed under any of the three themes. A unified description is presented to explain how each contributed to the proposed definition of high expectations.

Scheduling. Harmston, Pliska, Ziomek, and Hackman (2003) investigated 450 public high schools in Illinois and Iowa and found the schools used either a traditional eight-period 
daily schedule, 4 X 4 block semester schedule, or an eight-block alternating day block schedule. In addition, Hackmann (1999) discovered that at the secondary level those three schedules were found to be the most commonly used.

The longest standing scheduling type is the eight period daily schedule of less than one hour because of its association with the $20^{\text {th }}$ century scientific management beliefs (Harmston, et al., 2003). Due to the industrial revolution the daily-period model promoted an efficient, factorymodel approach to teaching. However, in the 1990s this was believed to result in fragmented instruction that included an over-arching emphasis on teacher lecture (Harmston, et al., 2003).

In an effort to move away from the scientific management approach to teaching, the 1990s saw the introduction of the 4 X 4 block schedule. The belief in this schedule was that teachers would be provided 90-minutes of instructional time whereby creative, student-focused instructional strategies could be used to promote more in-depth treatment of content and student learning (Harmston, et al., 2003). These 90-minute blocks of time were believed to promote indepth exploration of content through a myriad of instructional practices that included hands-on activities.

The research on scheduling type was limited and non-conclusive as to its effect on student achievement (Harmston, et al., 2003). Hess, Wronkovich, and Robinson (1999) found that students in block-scheduled schools performed significantly better on SAT-II English and Biology tests than did students from non-block schools. Whereas, Raphael, Wahlstrom, and McLean (1986) found that student achievement was lower under the block-scheduling format. The College Board (1998) determined that students enrolled in semester-blocked schools generally received lower scores on Advanced Placement Calculus and US History examinations than students enrolled in year long daily-period classes. 
In this study teachers and administrators in two schools believed that the schedule promoted high expectations. The first was Cherry High School. Teachers at Cherry High School believed it was the 3-day cyclical nine period daily schedule that promoted high expectations. This schedule used nine instructional class periods that were 42-minutes in length each day, but the teaching style used for content delivery changed each of the three days with the cycle repeating on day four.

The three teacher delivery styles used were lecture, seminar and quest. Students were scheduled to meet each day for a particular class, but it was the teacher delivery method that varied each of the three days. For example, in a ninth grade English class, students may go to lecture on the first day to receive general facts and information of the unit in a large group format. Then during the next two days students went to smaller classes where in-depth knowledge of the general information was developed and reinforced. Through this flexible approach, students were provided varied instruction over a large block of time over the three days. Using the three-day flexible schedule allowed students the opportunity to work with information over 126 minutes. Students repeated this cycle on the fourth day.

The librarian at Cherry High School was able to speak to many students who visited the school when home on college break. He would always ask the returning student how school was going and he said her reply was "school's okay, it's not a whole lot different then high school. I was really prepared" (C.T6.11). In addition, a science teacher believed that the schedule set high expectations. She stated "students come to me and they say I want a course, I want that, instead of the other way around" (C.T14.2). These students are initiating the drive for learning that created an environment where students were not satisfied with the status quo. These two statements showed evidence that the schedule was contributing to high expectations for students. 
Bottoms, Presson and Johnson (1992) believed that non-traditional scheduling systems provided opportunities for college prep courses, but yet provided time for students that needed more time to learn concepts and skills. That was evident at Cherry High School through the unstructured, independent study time. Students used that time to see teachers who had office hours, to complete science labs, or to go to the library to complete research for a class project. During the researcher's visit to the school he was able to speak to the librarian while he was supervising the library. The librarian believed that the schedule provided students the opportunity to succeed. He stated 'I'm looking up at the computer screens and don't see e-mail or games. Kids in here are getting ready for today" (C.T6.9).

The second school where teachers believed that the schedule promoted high expectations was Apple High School. Those at Apple High School believed strongly in the 4 X 4 block schedule that had been used for years. The students at Apple High School attended four classes a day that were 90-minutes long and lasted for 90 days. With the block schedule Apple High School's ACT composite scores for the past two years was consistently higher than the national average (as shown earlier in Table 10).

Furthermore, Apple High School used a before school block of time where two AP courses were taught that they believed needed yet more time than the $4 \mathrm{X} 4$ block provided. The block before school was referred to as zero block. Zero block began at 7:15 am and ended at 8:00 am. According to the master schedule (A.D.1) there were two AP classes taught all year before school. One of those classes was AP Chemistry which also had the laboratory component taught all year third block. That flexibility allowed students to cover knowledge in-depth that in turn was believed to produce AP test scores and ACT test scores that exceeded the state and national averages. 
Another class taught all year was AP Calculus. Students took the first class (AP Calculus $\mathrm{AB}$ ) the first half of the year and then in the second half continued on in the AP Calculus BC class. That enabled students to enroll for a full year in a course that met for 90 -minutes. Scheduling students with such flexibility promoted high expectations. It was believed that having high expectations, that included the commitment from students to arrive at school before the normal start time, may have produced test scores on both ACT and AP exams that had been shown to be above both state and national averages.

Harmston, et al (2003) believed there was a lack of evidence in relation to scheduling type and academic achievement to determine if a relationship existed between the two. However, from this research study, the teachers and administrators of two of the schools believed that the type of schedule used promoted student achievement through high expectations.

Learning communities. DuFour, DuFour, Eaker, \& Many (2006) define a learning community as "educators committed to working collaboratively in ongoing processes of collective inquiry to achieve better results for the students they serve" (p. 14). This researcher found that the three schools engaged in collective inquiry through the use of the learning community. Each of the schools had a different approach to learning communities, but the concept was evident.

In this study learning communities provided the means by which teachers were able to talk about ways to enhance student achievement. The best example of how learning communities worked to achieve high expectations and high student achievement was at Cherry High School. At Cherry High School they called their learning community a "Professional Learning Community (PLC)". The district provided the time and resources necessary for each of its schools to have PLC coordinators. An assistant superintendent held quarterly meetings with 
all PLC coordinators so that continuity was provided throughout the district. In addition, the district provided a two-hour block of time each month for PLC meetings to be held at each school.

There were eight PLC coordinators at Cherry High School. Each month the PLC coordinators would meet with the administration team to plan the local agenda. During the researcher's visit he was able to attend the December's planning meeting. The members (coordinators, principal and curriculum assistant principal) agreed that the agenda for the next meeting would be to provide a follow up to the second chances and corrective instruction discussion held in November.

At the November PLC meeting the five PLC groups were provided the following five questions on second chances and corrective instruction: 1 . What do we know to be true about second chances and corrective instruction?, 2. What is the counter argument to this perspective?, 3. What point could you make to help our staff understand?, 4. What are two things we could do to support teachers to integrate this idea?, and 5. What resources will our teachers need to accomplish this goal? (C.D.5). The curriculum assistant principal collected the responses and developed a one page document that was given to the principal. For the December PLC meeting, that document was provided to everyone for further discussion.

At Apple High School there were department meetings held periodically in addition to curriculum team meetings. During the researcher's visit, a mathematics departmental meeting and curriculum team meeting were observed. The main agenda of the math department meeting was to seek input into what each teacher would accept when it came to students handing in late work. The principal wanted the school to seek some kind of common ground on expectations. These common points would be used to develop a late work policy. He believed that the school 
culture should provide students the opportunity to complete an assignment whereby their level of knowledge would be enhanced and differences between departments minimized.

The curriculum team meeting agenda focused on two important points: late work policy and test/retesting. Apple High School's principal asked each of the members, who were the department heads, to go back and discuss with their team members the idea of developing a policy on each. He explained to the members that he wanted a school-wide minimum policy on late work and retesting. He believed that a common ground existed between teachers so that students would be able to have consistency across departments.

At Orange High School grade level teams served as the learning communities. The principal stated "since teachers are at grade level, they shared the same kids and if a child was dropping off in grades, they could talk among each other to find out why" (O.P.20,21). Hord (1997) believed that dialogue and inquiry are primary methods of learning communities, in which staff communicate about students, teaching and learning, and identify related issues and problems (p. 785). Teachers believed this was working as evident by this teacher's comment, "we've had some wonderful discussion in those two brief times we met about individual kids and about how they're doing" (O.T6.9).

The principal had asked that monthly grade level meetings be held and minutes provided to him. Common planning time was not provided for each grade level, so meetings were held outside of the regular school day. A copy of the minutes from a grade level meeting was collected during the researcher's visit. The minutes of the meeting reflected that teachers discussed each of the three questions provided by the principal, as these questions provided the impetus for the discussion. 
Student academic achievement at each school was high and each school had teachers engaged in some type of learning community. What was found to be a common thread between the school learning communities was student achievement The researcher believed that the learning communities may be another indication of high expectations in the schools.

Advanced placement course offerings. In 1955 the College Board introduced a program whereby students in public high schools could take introductory college-level courses in eighteen subjects. In addition to taking introductory college-level courses, students had the opportunity to earn college credit that could be accepted at colleges or Universities. It was the student's performance on the AP exam that determined eligibility to receive college credit and/or placement from the institution of the student's choice. The exam was based upon a five point grading scale where a score of five reflects the highest level of mastery. A grade of three on the AP exam often qualifies a student to receive course credit from participating institutions; however the decision to award credit varies across institutions and subjects within institutions (Handwerk, Tognatta, Conley, \& Gitomer, 2008).

Included in the eighteen subjects was calculus, physics and political science (Highsmith, 1989). Today that number has grown to 33 (Wakelyn, 2009). This program is commonly referred to as AP or Advanced Placement.

Advanced Placement is the nation's oldest example of a rigorous, common curriculum with over 140,000 high school teachers seeking approval of their course to be titled AP in 2007 (Wakelyn, 2009). Furthermore, the class of 2008 had 758,000 seniors take at least one AP exam during their high school years (2009).

The National Center for Education Statistics 2001 report (NCES, 2001), High School Academic Curriculum and the Persistence Path Through College, described a rigorous 
curriculum as four years of English, three years of a foreign language, three years of social studies, four years of math (including pre-calculus or higher), three years of science and at least one AP course. Within West Virginia, WVDE Policy 2510 requires every high school to offer at least four AP classes in the core content areas: English, mathematics, science, and social studies (WVDE, 2008).

According to research completed by Creech (1995), when a high school added AP courses to its curriculum, there was often a ripple effect that raised the academic level of the entire school. For example, when a school offered AP calculus in grade 11 or 12 the ripple effect that it created was for algebra II, trigonometry and other pre-calculus courses to be made available to students in earlier grades. The researcher believed high expectations may be contributed through offering higher level mathematics courses to students in the lower grades.

The ripple effect that Creech (1995) spoke about was illustrated by Apple High School's Assistant Principal for Curriculum when she mentioned that there were eight ninth graders coming from the middle school to take Honors Geometry first semester and then Algebra II second semester (A.AP.5). She further explained (A.AP.6) that these accelerated students would take AP Statistics and Trigonometry their freshmen year, pre-Calculus sophomore year, AP Calculus junior year and Physics senior year. For the 2009-2010 school year there were two freshmen in the AP Statistics course and two juniors in the AP Calculus course.

Offering advanced level courses to students in lower grades wasn't where Apple High School stopped. A variety of AP courses were provided to students in grades 9 -12 at Apple High School and Cherry High School. Apple High School offered 12 and Cherry High School offered 14. It was found through an analysis of the master schedule from both schools that multiple sections of certain AP courses were also taught (C.D.1 \& A.D.1). For example, at 
Apple High School there were two sections of both AP Language and AP Literature. Cherry High School taught two sections of AP Language and two sections of AP Chemistry. The principal at Apple High School believed that the school exhibited high expectations with the statements, "I think our AP program is what promotes high expectations" and "it gives students a chance to really excel" (A.P.6).

Wakelyn (2009) believed that a culture of high expectations can be found in schools where a strong AP program existed. The AP programs at both schools were found to be strong through the AP test scores and the number of courses available to students. Middle school students were provided the opportunity to take AP courses on site, both schools offered an abundant number of AP courses to all students, and multiple sections of AP courses were provided. The researcher believed that the AP programs contributed to the schools exhibiting a culture of high expectations.

Extra time/extra help. Another common theme found to be present among all three schools during the cross-case analysis was extra time/extra help. Each school provided extra time/extra help to the students during school, before school, and after school. What this section will describe is how the three high performing schools structured a system where students were able to get extra time/extra help in meeting teacher expectations.

Searching for information pertinent to extra time/extra help led the researcher to a research agency named SREB (Southern Regional Education Board). The agency, created in 1948, was the nation's first interstate compact for education and continues to be based in Atlanta, Georgia (Southern Regional Education Board [SREB], 2000). Governors from the following seventeen states formed the compact: Alabama, Arkansas, Delaware, Florida, Georgia, Kentucky, Louisiana, Maryland, Missouri, North Carolina, Oklahoma, South Carolina, 
Tennessee, Texas, Virginal and West Virginal (Denton, 2001). Its purpose was to "assist state leaders by identifying and directing attention to key issues; collecting, compiling and analyzing comparable data; and initiating studies and discussions that lead to recommendations for state and institutional action" (SREB, 2000, p. 2).

In 2000 the SREB began an initiative called Making Schools Work (MSW) that worked with high schools and their feeder middle schools to help raise student achievement. As a result of that imitative, a list of nine key practices was formed that provided the framework for improving middle schools and high schools that increased student achievement (SREB, 2000). Of the nine key practices the one that will be focused upon here is that of extra help. The following definition for extra help was provided in a report produced by the SREB: "provide a structured system of extra help and quality time that will enable middle grades and high school students to complete an accelerated program of study and to meet rigorous and consistent standards" (SREB, 2000, p. 3). So that this definition followed the belief of high expectations, the word "all" was to be added. The belief was that all students be provided the extra help and quality time that led to increased student achievement through high expectations.

In a paper presented in Washington, DC on April 4, 2002, Balfanz, McPartland, and Shaw noted that "providing large numbers of students with extra help so they can succeed in challenging courses was not part of the existing organization or culture of high schools" (p. 23). However, all three schools in this study had built into their daily routine a system where time was provided for extra help for all students. Providing the means for extra help was believed, by the teachers and principals, to lead toward a culture of high expectations.

Even though all three schools provided the means for extra help, Cherry High School's inclusion of unscheduled time within a student's schedule appeared to work well. Cherry High's 
schedule was structured so that all students in grades $10-12$ had the opportunity for three unscheduled class periods. It was during those unscheduled class periods that the students had the opportunity to seek out extra help from their teachers. The principal at Cherry High School stated, "if they had unscheduled time they could choose to go get extra help from a math teacher. They could go to an English office to meet with an English teacher to get extra help" (C.P.2).

The teachers at Cherry High School are also provided three unscheduled class periods so that office hours could be set up. It was at those times that students and teachers were able to meet for one-on-one appointments. In designing the building, except for the math department, each department had an office area where each teacher had a designated spot. This was similar to a college professor's office on campus. An English teacher stated, "it goes back to the college philosophy of having office hours. We're available and it made a difference" (C.T1.5).

To facilitate the use of the unscheduled class periods to meet with teachers, each teacher listed his/her office hours on the Unit Plans distributed to all students (C.D.2). In addition, during the researcher's visit to the school he found a listing of teacher office hours posted in the hallways and outside of the department offices (C.N1.5). A social studies teacher stated, "office hours are found on every single Unit sheet that goes out" (C.T2.2).

Cherry High School built in a freshmen learning skills class as a way to introduce them to the concept of unscheduled periods. The principal stated, "they're scheduled into a full seven periods of classes and then they had one period of learning skills which was a study skill. Kind of a study hall, but they also get extra help during that time" (C.P.3). An English teacher stated, "it also was the time to touch base and that's why my day, even though I may have three periods of unscheduled time, I usually had students" (C.T1.4). The teacher further stated, "I had them plastered around, doing make-up tests, asking questions, saying poetry. The unscheduled time 
can be effectively used" (C.T1.4). During a mathematics teacher interview within one of her unscheduled periods, the researcher noted that the interview was interrupted because two freshmen students entered the room asking if she would be available to answer some questions (C.N2.1).

In addition to the unscheduled periods, teachers made themselves available before school, too. A science teacher stated, "we actually had available time before school started. Sometimes students would come in and do a lab if they were sick or absent for whatever reason" (C.T6.4). A social studies teacher stated, "I'm here in the morning and after school. I had probably ten of them in there this morning finishing up a map" (C.T7.6) As the researcher was making general notes, he observed that approximately six students were in the science rooms at 6:30 am making up labs and asking teachers for extra help that Friday of the week long visit (C.N1.9).

Besides coming in before school for extra-help the students are able to come back in the evenings. Teachers make themselves available in the evening for extra-help as the principal noted through the statement:

I was here last night for the ballgame. I saw some kids coming down the steps going out, and I said "what are you all doing here?" They said they were here for a science class. This was at 8:15 pm. They said that the science teacher was upstairs and we've been studying for our big exam coming up tomorrow. I went upstairs; there were 35 kids up there naming bones with the teacher at 8:15 pm last night. It was really awesome. Then I walked downstairs, I walked down the far steps and another teacher, social studies, had a bunch of kids in his room watching a movie. That's a difference I see here, teachers that are willing to give that kind of time to go the extra mile. (C.P.15) 
Teachers were willing to not only help students during their unscheduled periods, but gave of their own time after school, too.

At Cherry High School all students had the opportunity to access teachers before school, during school and after school to obtain extra help. It was the belief of the teachers and principal that because of the extra time provided to students, high expectations permeated throughout the building.

Using the unscheduled time to provide extra help/extra time was not the only method used in the three schools. Apple High School's schedule was such that students were provided a 53-minute lunch period where different student oriented extra help/extra time activities occurred.

What appeared to be a common theme across Apple High School was that program that provided freshmen extra time for extra help to assure academic success. That program was referred to as Freshmen Focus. The principal described the program as, "the first four-and-onehalf weeks of school all freshmen went to a freshman group 19 minutes at lunch. That was trying to work on basic skills" (A.P.16). If a freshman had a D or F in any subject at the midterm report card, then he/she would be sent to a teacher that taught that subject. The principal then described what happened during that time as, "you sit in there for 19 minutes either getting some tutoring or doing make-up work" (A.P.16).

One of the English teachers stated, "we do a lot with freshmen. We're putting a lot into trying to help the freshmen get a good start" (A.T3.2). Later in the interview she stated, "we're doing freshmen focus. It's a lunchtime activity Monday-Friday at lunch where they get tutoring" (A.T3.2). A science teacher believed the freshmen focus was the most effective program used for high expectations in the building. He described the program the following way: 
Students have to give up first 20-minutes of lunch. They hate it because that's the only time when they can use their cell phone and socialize with friends. They also can use it as tutor time. Teachers will send the work they didn't get done in class or the test they need to re-take, or some of the material that they are failing on. They get an opportunity to retake it during this freshmen focus time. That's what that 20 -minute is used for. I think that it's pretty effective. (A.T8.3)

He believed that the program was effective because, "the kids get started on the right foot understanding that good behavior and good grades are something that was expected here from the school" (A.T8.2).

For upperclassmen the principal stated, "we also tutor at lunch time. Kids can go upstairs and get tutoring anytime they want at lunch. That helped us reach all those students" (A.P.20). The curriculum assistant principal added, "almost anytime a teacher needed to be in their classroom at lunch time, for something, they could request to miss their assigned duty" (A.AP.4).

Two teachers further added to the tutoring concept during the hour long lunch. The business teacher stated, "to help them, we have noon labs. The first half of lunch they can come in. They can come in and work on anything they want to. We also have a main computer lab that was open at lunch time for them to go to" (A.T1.1). A math teacher said, "I have them come in first half of lunch. I'll encourage them to go to tutoring (A.T2.2).

In general, two teachers (A.T5,7) had mentioned that there was tutoring available. In addition, the researcher noticed that a sign was in the hallway advertising that free tutoring was available after school on Tuesdays and Thursdays (A.N.2). The curriculum assistant principal had mentioned, too, that on Tuesdays and Thursdays free math and science tutoring was 
available for freshmen, and on Tuesdays free tutoring was available to the upperclassmen (A.AP.1). The tutoring was done by faculty at the school.

To tie tutoring into the academic success of the students at Apple High School, during the principal interview he talked about using tutoring for leverage when speaking to parents concerned about their child's success. He stated, "and when we sit down with a parent the first thing, if a kid's not being successful, are you going to tutoring? No, well why not, it's free? You know they know we are trying to help them" (A.P.20). A science teacher stated "I personally see teachers giving up more of their time in the past year-and-a-half just to help students" (A.T8.2). He believed that was helping the school set high positive expectations for learning for all.

The third school, Orange High School, had two times during the day built into the bell schedule in which students had extra time for extra support. Those times were, 7:40 - 7:55 am and 9:20 - 9:35 am (O.D8.5). In addition to those times during school, the school handbook had listed a section titled "extra help." Under that section the following paragraph was found:

All teachers are available after school from 3:15-3:30 pm to offer extra help. Students who experience difficulty with any subject are encouraged to take advantage of the opportunity to meet with any of their subject teachers for one-on-one assistance. (p.19) Extra help was given written homage but evidence of its use was limited during the researcher's on-campus visit.

The principal stated that, "we have kids that go in and they get help from an individual teacher, but we've set up tutoring. We also have tutoring volunteers. We make it accessible to those kids who need it" (O.P.3). He stated later on in the interview that, during the extra fifteen minutes of third period, if a student had a note from say teacher A to go work on a question 
about math, he/she was able to go to that classroom and get some extra help" (O.P.12). A foreign language teacher made the comment that, "we have extra time third period that was also used for tutoring" (O.T2.8).

A math teacher stated, 'I'm always available to them after school if they don't understand something. They have the opportunity to come in after school to get what they missed" (O.T1.13). A foreign language teacher stated, "they can come in for one-on-one outside of class time. I encourage them to come in for tutoring. I'll have them sit there with me and do a similar exercise to what they'll be evaluated on" (O.T2.8).

The best illustration of how a teacher spends time after school with students was with a math teacher. She stated, "if they make a D or F on my tests they have to come in and we go over it" (O.T4.1). She gave the following example of how she gets students to stay after school, "I looked at him today and said you are going to have to come in. You are either going to do it during class or you're coming in after school" (O.T4.2). The researcher did note during the interviewing sessions on two different days that the teacher had approximately ten students coming into her room, as he was leaving, immediately after school for extra help (O.N2.1).

Affirming the belief that high expectations are evident throughout the building due to teachers providing the extra help/extra time, a math teacher stated, "most of the teachers here will go above and beyond to help them" (O.T4.6). She even stated, "I'm here until 4:00 pm, sometimes 15 after. I try to do it twice a week - Tuesdays and Thursdays" (O.T4.10).

Orange High School had time built into the schedule for students to go to individual teacher rooms for extra help. During the researcher's visit, the only visible sign of extra time being used for extra help was after school with that particular math teacher. Even though the researcher did not observe extra help happening at the other times, the school had extra time 
available for extra help to the students. Teachers and principal believed that the extra time for extra help helped maintain a culture of high expectations.

Alignment of curriculum. English (2010) defined curriculum alignment as "the match or overlap between the content, format, and level of cognition of the curriculum (or curriculum surrogate such as the textbook)" (p. 77). It is therefore a process used to match what is to be taught to what was actually taught in the classroom that any test will measure.

A part of the No Child Left Behind Act of 2001 (2002), legislation required schools to develop rigorous content standards and standardized tests to measure the progress of students and placed more accountability on the local districts. Along with this increased accountability for local districts came the importance of aligning standards to assessments (Fulmer, 2010).

In order for students to do well on the standardized test, school districts, schools and teachers had to engage in curriculum alignment. The student must be provided the opportunity to learn what is expected from the curriculum so that the test accurately assesses what he/she can do.

The definition of curriculum provided by English (2010) was:

That it consisted of any document or plan that existed in a school or school system that defined the work of teachers, at least to the extent of identifying the content to be taught children and the possible methods to be used in the process. (p.10) In West Virginia what was to be taught had been clearly identified through Policy 2520 as content standards.

English (2010) stated "the minute that curriculum became focused on and connected to, as well as aligned with tests, the influence of socioeconomic level on test performance began to decline" (p. 15). One of the correlates of the effective schools movement, a pervasive and 
broadly understood instructional focus, encompasses that belief. Furthermore, English (2010) believed that districts that focused upon deep alignment and good teaching improved their normreferenced test scores. Within this study, the three schools had high student achievement as measured by high WESTEST, ACT, and SAT scores. Teachers and administrators among the three schools believed that through the use of curricular alignment, student academic achievement was high.

The school that exemplified the best use of curricular alignment was Orange High School. In 2008, the district produced a document titled Prioritized Curriculum for Mathematics (O.D.10) that included concept maps. Those maps addressed a significant topic in mathematics that was correlated to the content standards. Essential questions were included in that document and used to frame the learning processes. Rather than using the textbook to determine the content of the lesson, teachers used the document titled prioritized curriculum for mathematics provided by the district.

One of the math teachers at Orange High School stated "I start with that concept map, found in the prioritized curriculum handbook, and do all that [sic] stuff' (O.T3.8). Another math teacher added, "we teach basically the standards, the West Virginia state standards that are put out for us. In addition, we use a prioritized curriculum that basically prioritized those standards" (O.T1.7).

Content standards. In addition to the prioritized curriculum handbook, teachers used the state approved content standards. For example an English teacher stated "my curriculum was aligned with the CSOs" (O.T3.6). Another general education teacher stated "when planning the content of a lesson I used the CSOs and the book matches up with them" (O.T6.3). A science 
teacher stated "my content was based upon the classroom assessment and the CSOs" (O.T8.4). In conclusion, a special education teacher stated:

The content of the lesson was based upon the CSOs. The IEP was based upon the CSOs. I take a CSO and make it manageable for the students. I may not go as far in-depth as regular education students or I may not go at the same speed. We're trying to hit that main concept. (O.T10.4)

Ten of the twelve classroom teachers interviewed at Cherry High School used the state approved Content Standards and Objectives (CSOs) when designing classroom instruction. One of the ten stated "we took the CSOs from the state and reworded them. It's the same CSOs but in a different format" (C.T3.4). Another one of the ten teachers stated "no matter what I teach, I use the CSOs. I can teach CSOs off of Dr. Seuss" (C.T1.3).

The CSOs did not dictate how content was presented. It was the classroom teacher who determined the method(s) used in delivering the material. Another example of how teachers presented material so that the CSOs were followed was provided by this teacher's comment, "we can take those CSO standards and plug them in and simplify them" (C.T9.2). The first teacher interviewed further underscored that belief when he did a research project with his ninth grade students. That project lasted two weeks and during that time students designed a themed trip that was presented to the class. So, "instead of a paper, they did a trifold brochure. On the back of was $[$ sic $]$ the sources. The CSOs were done; the way I did it was different" (C.T1.3).

Teachers at Apple High School used the state approved content standards to teach courses. That was best represented by the following teacher's comment, "So, I'm using the CSOs and finding those objectives in the book. I'm not just starting at Chapter one and finishing through Chapter 8" (A.T5.1). This, too, showed that teachers are not just handing out the 
textbooks and opening to page one and progressing through the book page by page. Teachers used the textbook to augment instruction as needed.

The following math teacher's comments highlighted how instruction was augmented. "I try to teach them things in addition to the basic minimum CSOs that they need to know for future math classes" (A.T2.5).

Good and Brophy (2003) found that unless course curriculum was aligned to the assessment tool then incorrect conclusions would be made in regard to the effectiveness of the school. Teachers at all three high schools in this study believed that their curriculum was aligned to the state approved content standards. Because the content of the WESTEST2 was based upon the approved content standards, students of teachers who follow the content standards are believed to have higher academic achievement scores. High academic achievement through high expectations was believed to be supported by the alignment of the curriculum to the approved content standards.

Parental involvement. Lezotte's (2001) research on effective schools led to the formation of the correlates of effective schools. Two of those correlates included high expectations and positive home-school relations. This research focused upon the correlate high expectations where the researcher hoped to lead to a definition of that phrase. What came out of the cross-case analysis of the three schools was that teachers and principals believed that each school had high expectations due to the parents and community of each school having high expectations. This finding embraces the correlate of positive home-school relations.

Lezotte (2001) described positive home-school relations as "parents understand and support the basic mission of the school and are given opportunities to play important roles in helping the school to achieve its mission" (p. 19). It is possible for schools to reach their goals 
and mission without extraordinary involvement from the parents. But, Lezotte states "it is much easier if parents are part of the collaborative team and are seen by the school as partners in education" (p. 19).

Michael, Dittrus, and Epstein (2007) found home-school relations to be important, too. In the 1980 s they developed a theoretical perspective called "overlapping spheres of influence" (p. 568). What this refers to is how the home, school and community act as spheres of influence on children and on the relationships of all three working together. That denotes the importance of how the home, school and community can interact for the benefit of student success, whether that be social, athletic or academic. Each of the three schools appeared successful in connecting the three spheres and those interviewed believed that connection was an important part as to why the schools exhibited high expectations.

Getting parental involvement at the secondary level can be daunting. Parental involvement tends to decrease as students move from elementary, middle and secondary levels (Epstein, 2008). At the secondary level Epstein (2008) stated:

When families are involved more students earn higher grades in English and math, improve their reading and writing skills, complete more course credits, set higher aspirations, have better attendance, come to class prepared to learn, and have fewer behavioral problems. (p. 2)

The academic success of the three schools in this research was pointed out earlier in this chapter. Schools reported that each one had done an extraordinary job involving the parents, community and school. That common thread was found to exist in all three schools during the cross-case analysis. 
The first school that represented a strong parent/community support was Orange High School. The principal at the school believed that a part of his school's high expectations was because "we have the academic investment group (AIG) that was made up of parents who meet every nine weeks to reward students who are on the principal's list, accommodation list or honor list" (O.P.6). In addition, he further went on to state that his school had a Parent-TeacherOrganization (PTA) that promoted academics in the building. That organization was looking into ways that the school could display academic accolades along with the sporting accolades upon entering the building.

The French teacher was proud of the PTA and stated "we are the first high school in the state to have a PTA" (O.T7.4). She explained how the PTA had provided the faculty and staff dinner for the past two years during the fall parent-teacher conference night. The parent-teacher conference night was held while the researcher was on site, and as the teacher explained a buffet was set up by the PTA for the faculty and staff. In addition, the teacher believed that the school was supported in the community through this statement: "we're well supported in our little community as evidenced through passing levies when seeking money" (O.T7.4).

A science teacher made the following comments about home-community support: The whole town has pride in the school. People that come to ballgames, people that support give money to the school just because they live here and went to school here. Parents here are more involved with students in high school life. (O.T8.3) These comments show the strong support that the community provided to the school and to the students.

The librarian was an Orange High School alumnus who had deep roots in the community. She summed up the strong support provided to the school through these comments: "the 
community is unbelievable. This community expects us to be the number one school in the district. You have no idea how wonderful this community is and how much they care about this school" (O.T6.10).

Hill and Taylor (2004) noted that "parents' own experiences as students shape their involvement in their children's schooling" (p. 162). This was evident in talking to the faculty and principal of Orange High School. So many were graduates from the school and their children were either current students or recent grads. They didn't move away from the area due to wanting their children to attend Orange High School. Many positive memories still existed in regard to when the teachers were students themselves.

Cherry High School was similar to Orange High School because there were several faculty members that graduated from the school, and held strong beliefs as to the school's commitment to high expectations. The principal was not a graduate of the school, but believed that high expectations came from parental expectations. She stated: "the parents show up at ballgames and it's very much a pride" (C.P.6). She even went on to make the claim that "parents are very involved, the community is very involved. The parents want everything offered to their kids" (C.P.6).

A social studies teacher stated: "high expectations are driven by parental support in that the community pushes toward it" (C.T2.6). In addition to social studies, the following comment was made by an English teacher: "have [sic] a really good population of parents that live in this area. Lots of professional people who live in this area that $[s i c]$ have high expectations for their children. I think that's the number one factor in getting high expectations" (C.T4.2). The teacher made the following additional comment about expectations: "we are expected, as a 
faculty, by the community to perform at a high level. The community expects it of us and we need to deliver. Community driven" (C.T4.2).

Three other teachers made comments related to how the parents/community drive the school to be its very best. Another English teacher stated: "the third thing that allows us to have high expectations is the parents, the community. We have really supportive parents" (C.T8.5). A math teacher stated: "parents here that $[$ sic $]$ are very involved and have high expectations. I would say a big part of what we do right is because of that" (C.T12.16). The last teacher who referred to parent/community expectations stated: "the parental involvement has made a big difference and has contributed to the amount of success this school has had" (C.T13.12).

Five of the teachers interviewed strongly believed that it was the parent and community support that drove the school to be its very best. That strong home-school relationship that Lezotte (2001) found to be in existence in effective schools was found at Cherry High School. Lezotte also noted in his writings that effective schools are not focusing on one correlate. Effective schools are found to have all seven correlates working in conjunction with one another (Lezotte, 2001). At least at Cherry High School, it was evident that both high expectations and home-school relations were working together.

The third school, Apple High School, had a parent/community piece, too. At Apple High School the principal believed that the community was supportive because of the monetary assistance provided to the school. He stated that "local businesses gave $\$ 50.00$ savings bonds to each student of the month recipient" (A.P.7). In addition he was able to get funds from businesses that helped sustain his reward system for perfect attendance. Students with monthly perfect attendance had a chance to win fifteen seconds in the money machine during a designated date. That money machine was provided by an outside vendor and the charges for the vendor's 
service came from the school's general fund. That enabled the winning student to enter the money machine where for fifteen seconds he/she could grab as much money as possible. The principal believed that had helped his school stay at or around a 93\% daily attendance rate.

The assistant principal for curriculum stated: "parents value education" (A.AP.1). In addition to that she stated: "I would say that high expectations probably started from community expectations" (A.AP.12). Along with the assistant principal, a math teacher stated: "our parents have high expectations and that always helps. It's hard to do any job all by yourself. The parents definitely helped drive the school to succeed" (A.T4.9).

Two other teachers interviewed made statements in regard to the parent/community support given for the school. The first teacher stated: "we have a very strong parent support in the community. Parents get involved, they had high expectations. They're not going to settle for a teacher that's not doing what they're suppose to be doing" (A.T2.12). Finally, an English teacher stated: "I think the parent expectation does play a huge part in this. I think we do have a good community base, yes I do! I think we are lucky in that we have parent support" (A.T3.10).

All three schools believed that high expectations were due to the parents and community that surrounded them. Teachers and principals made supporting comments for the presence of both community and parental support. Through this support the teachers believed that they exhibited a culture of high expectations that enhance student achievement.

\section{Summary of the Chapter}

The purpose of this study was to examine the curricular, instructional and administrative practices that teachers and principals used in establishing high expectations in selected secondary schools in West Virginia. Its three research questions were: 1. What instructional practices and curriculum methods do teachers use to communicate high expectations to the students? 2. What 
do principals perceive to be high expectations in these classrooms? 3 . What are the administrative and curriculum practices that principals use to promote high expectations within the school? Three secondary schools, selected using purposeful sampling, were used in this multi-site case study.

Each of the three schools was represented as a separate case study identifying the categories that were present under the three themes: administrative, curricular and instructional practices. The number of categories found under administrative ranged from four to six; curricular had three or four; and instructional ranged from three to five. Using quotes and documents from the data collection, each category was described. Each case study then ended with a summary.

After the three case studies were presented, a section on the cross-case analysis was written. The findings during the cross-case analysis found that seven commonalities existed between the three sites. Six of the commonalities were identified from the three themes that originated from the proposed definition of high expectations. Under administrative practices was found master schedule and professional learning communities. Under curricular practices was found a strong advanced placement program and extra help/extra time provided. Under instructional practices was found curriculum aligned to the state assessment tool and teachers teach the prescribed curriculum. What was found to be across all three sites and under all three themes was that of a strong parental involvement and/or support of the school. 
Table 17 provides a list of practices found in common, and those practices found per site.

Table 17

Practices of High Expectations Found at the Sites

\begin{tabular}{lccc} 
Practice & Cherry HS & Apple HS & Orange HS \\
\hline Common Practices & & & \\
Unique Scheduling & $\mathrm{X}$ & $\mathrm{X}$ & $\mathrm{X}$ \\
PLC & $\mathrm{X}$ & $\mathrm{X}$ & $\mathrm{X}$ \\
AP Courses & $\mathrm{X}$ & $\mathrm{X}$ & $\mathrm{X}$ \\
Extra Help/time & $\mathrm{X}$ & $\mathrm{X}$ & $\mathrm{X}$ \\
Cur. Alignment & $\mathrm{X}$ & $\mathrm{X}$ & $\mathrm{X}$ \\
Teach to CSOs & $\mathrm{X}$ & $\mathrm{X}$ & $\mathrm{X}$ \\
Parent Involvement & $\mathrm{X}$ & $\mathrm{X}$ &
\end{tabular}

Uncommon Practices

Unscheduled Time $\quad \mathrm{X}$

Out of Area Transfers $\mathrm{X}$

Principal Use of

Behavioral Data $\quad \mathrm{X}$

Principal Visibility $\quad X$ 
Table 17 (continued)

\begin{tabular}{|c|c|c|c|}
\hline Practice & herry HS & Apple HS & Orange HS \\
\hline \multicolumn{4}{|l|}{ Adv. and Honors } \\
\hline Courses & $\mathrm{X}$ & & \\
\hline Varied Instruction & $\mathrm{X}$ & & $X$ \\
\hline Immediate Feedback & $\mathrm{X}$ & & \\
\hline \multicolumn{4}{|l|}{ Recognition for } \\
\hline Achievement & $\mathrm{X}$ & & $\mathrm{X}$ \\
\hline \multicolumn{2}{|l|}{ Final Exam Exempt } & $\mathrm{X}$ & \\
\hline \multicolumn{2}{|l|}{ Credit Recovery } & $\mathrm{X}$ & \\
\hline \multicolumn{2}{|l|}{ Analysis of Data } & $\mathrm{X}$ & \\
\hline \multicolumn{4}{|l|}{ Assistance to at-risk } \\
\hline \multicolumn{2}{|l|}{ Students } & $\mathrm{X}$ & \\
\hline \multicolumn{2}{|l|}{ Drop Date for Classes } & & $\mathrm{X}$ \\
\hline \multicolumn{2}{|l|}{ Rigor of Cur. } & & $\mathrm{X}$ \\
\hline \multicolumn{2}{|l|}{ Project Based Learning } & & $\mathrm{X}$ \\
\hline
\end{tabular}




\section{Chapter Five}

\section{Conclusion, discussion, and recommendations for future research}

\section{Conclusion}

The purpose of the study was to examine the curricular, instructional and administrative practices that teachers and principals used in establishing high expectations from interpretive case studies of selected West Virginia secondary schools. The Office of Educational Performance Audits produces a training manual where high expectations is listed (6.1.2) and defined as: "through curricular offerings, instructional practices, and administrative practices, staff demonstrates high expectations for the learning and achieving of all students and all students have equal education opportunities including reteaching, enrichment, and acceleration" (WVDE, 2006a, p. 27).

Seeking actual practices that would illustrate the definition in the areas of curriculum, instruction, and administration was the primary focus of this study. Good and Brophy (2003) found that it was teacher beliefs that make up high expectations. Furthermore, Cancel (2002) stated "although high school teachers presumably hold standards and expectations for their students, researchers have not extensively explained the relationship between teachers' standards and expectations and student achievement" (p. 31).

I conclude that a unified definition of high expectations cannot exist because of the lack of unified communities throughout West Virginia. The teachers and principals in each building created the practices of high expectations unique to their values and beliefs. Each building provided a microcosm of the community the teachers and principals were members of. Just as each community throughout West Virginia varies, so, did the practices used in pursuing high expectations. 
Lezotte (2001) found seven correlates among effective schools (as defined by student academic achievement). This research found the existence of seven commonalities in schools that promoted practices of high academic achievement and hence high expectations in selected West Virginia secondary schools. The commonalities found in this study were: 1 . master schedule, 2. strong professional learning community, 3 . course curriculum aligned to the state assessment tool, 4. teachers teaching the prescribed curriculum, 5. strong offering of AP courses, 6. strong parental involvement/support, and 7. time where extra help/extra time is provided.

Due to other factors (i.e., socioeconomic, size, grade levels) schools will exhibit these seven commonalities in different ways. Bolman and Deal (2003) believe the culture of an organization unites workers around shared values and beliefs. No two buildings are going to have the same values and beliefs. However, working together toward the academic achievement of all students was found to be a common belief that existed in schools where high expectations prevailed along with high academic achievement.

\section{Discussion}

School effectiveness research contributions. The schools effectiveness research (SER) has been criticized for not including qualitative studies that would help reveal detailed microlevel sociological characteristics to explain what schools do for student achievement (Purkey \& Smith, as cited in Jansen, 1995). This research answered that criticism by the collection of classroom data, documents, and field notes through a qualitative, interpretive, multi-case study. From this rich data, salient characteristics were found that were used to describe what teachers and principals believed to be practices where high expectations existed. Qualitative research provides information that could not be discovered any other way. 
Another important characteristic of this research study is that one of the schools was a small rural school. SER was also criticized in that its research focused on urban, large elementary schools. SER has been addressed in this study using three secondary schools. One of the schools was also a rural school that had a student population of approximately 500 . Therefore, adding the characteristics of small and rural to the descriptors used in school effectiveness research.

This study's focus was on developing a framework for a definition of high expectations, a contribution to the SER. Lezotte (2001) described the seven characteristics of effective schools. Among the seven characteristics are high expectations where no descriptors existed to assist the practitioner in establishing high expectations. This research has now identified seven commonalities used to describe high expectations that were found to be present in high achieving secondary schools. These commonalities can now help in describing Lezotte's high expectation correlate.

Appalachian values. Woodrum (2004) mentioned that education was not important in Appalachia and went against family ties or kinship. In addition, he mentioned how school consolidation took schools away from the community. The schools of this research study were all soundly rooted in their local communities and two of the three were in the central location of the town and/or region. What appeared to be present in each of the three schools is that the community was supportive of the schools and reflected a sense of community belonging for the students (Woodrum, 2004).

Appalachia strongly believes in keeping the children home and in the local community. What was prevalent at the three sites was that the community expected the students to go on to college and leave the community. Each of the communities valued education and supported 
students in the quest for academic achievement, even if it meant to go to college. For high performing schools it appeared that the community supported academics by affording students the opportunity to leave to seek further education.

Leadership styles. In Chapter two, Hall, Rutherford, Hord and Huling (1984) described three types of principal leadership styles: Initiator, Manager and Responder. The semistructured interview did not contain questions related to leadership styles. However, it was believed that the three leadership styles of the three principals were different but yet effective due to the presence of high expectations in the building. Does the leadership style have an affect on high expectations? This question will be mentioned under the recommendations for future research section to follow.

Teacher efficacy. This study found that where student achievement was high, teachers and principals believed that high expectations were practiced. Where the teachers believed that students would do well then they adjusted their behavior to make it happen (Good \& Brophy, 2003). Teachers who reported that they practiced high expectations appeared to have higher student achievement. The belief in the academic success of students has been linked to individual teacher belief in his/her own efforts or teacher efficacy (Ross, 1998). Ross (1998) defined teacher efficacy as "a teacher's belief that his/her efforts, individually or collectively, will bring about student learning" (pg. 49-50).

It's the desire to get students to achieve that sets the high efficacy teachers from the low efficacy teachers. Ross (1998) stated "teachers who expected to do well set higher goals and persisted through obstacles" (pg. 50). Therefore, schools where teacher efficacy was high may be schools where teachers set high goals for student academic success. That in turn was believed to contribute to the school's culture where high student academic achievement for all was found 
to exist. Chuck Heinlein believed that a school where academic achievement for all is present is one way where students are scheduled into courses on desire to take the course. That was prevalent at the three schools, especially in enrolling students in the AP course. What this research found was that there existed certain curricular, instructional and administrative practices that teachers and principals used that may have contributed to a culture where high expectations existed for all students.

High expectations with no evidence. All three schools noted practices that the teachers and principals believed to have affirmed high expectations existed in the school. However, what would happen if the school believed to have high expectations but did not have any practices that supported the belief? This can happen. It just didn't happen in this research study.

In the movie Dead Poets Society, Robin Williams played a teacher at a prestigious preparatory school. Robin Williams communicated high expectations to his students by engaging all students in learning activities. Through this engagement he brought forth his belief in high expectations to the students. That was made evident in the scene where the students stood on the desks and hailed him as "Captain oh captain."

How could one possibly believe in setting high expectations in words only? Good and Brophy (2003) found that schools where high expectations existed there were behaviors where student learning and achievement were maximized. The emphasis here needs to be that there exist behaviors, or in this research, practices that illustrate high expectations, but words are the first place to start.

Improving low performing schools. Beginning in the 1980s scholars of the SER attempted to produce common factors that exist between contexts that can describe effective schools. This research identified seven commonalities that existed in three secondary schools. 
The question is: Can a principal take these seven and implement any one or all of them to improve a low performing school?

To answer that question we must go back and look at the characteristics of each school's administrator. A commonality that existed among the administrators in all three schools was that each had served as the principal for one year. The importance to that is that when we look at all seven commonalities could a principal produce those in one year? The answer is most likely no.

Teddlie and Reynolds (2000) found the relationship between teachers and students had an impact on achievement. When a new principal comes to the building, he/she would need to take the first year to learn about the relationships that each faculty member has with students. Going into a new building, as two of the three principals did, that principal would have to learn about the staff and any traditions that exist at the school before attempting to initiate change. The achievement data provided under the school setting of each case study notes that prior to the principal's arrival to each school achievement was high. This data supports that a cultural change probably would not occur during that first year.

In July of 2007 the Office of Educational Performance Audits produced a document titled Commonalities in low performing schools: trend education performance audit finding. The schools identified as low performing were based on not meeting AYP. Academic success of all students was one of the criteria for making AYP. What was most interesting in that report was that nine areas were identified to be similar among the 15 lowest performing schools out of a total of 39 (OEPA, 2007). Three of the nine most identified standards that were not in compliance were high expectations, instructional strategies and leadership. This research pointed out that where high expectations was believed to exist then certain practices were found in the areas of curriculum, instruction and administration (leadership). 
Chapter three noted three qualitative studies (Cosner, 2005, Davis, 1992, and Mizelle, 1995) had been completed. These studies collected data at the secondary level from principal and teacher interviews, as well as classroom observations. This research adds to the qualitative studies completed at the secondary level.

From chapter three, one of the criteria used in selecting the three sites for this study was that they had met AYP for four consecutive years. If a comparison was made between any of the 15 lowest performing schools and the schools in this study, then I believe that there would be a high probability that high expectations would not exist in the low performing schools, or that they might have reported them in word but not in practice.

Using the proposed definition of high expectations found in chapter two, high expectations are indicated to exist through curriculum offerings, instructional practices and administrative practices. I believe that the low performing schools would not contain the curricular, instructional and administrative practices found to exist in high performing schools. This was supported by the data provided in the July, 2007 OEPA report.

The practices found to support high expectations in this research study were: master schedule, strong professional learning community, course curriculum aligned to the state assessment tool, teachers teaching to the prescribed curriculum, strong offering of AP courses, strong parental involvement/support, and time where extra help/extra time was provided. In looking at these seven practices would it be practical to say that any school can implement these with the result of increased student achievement? I believe that student achievement can be increased with the implementation of the seven practices found in this study.

What needs to be stressed at this point is that all seven of these practices co-existed in the three high performing schools of this study. To single one practice out may or may not lead to 
increased student achievement. Back to the question in regard to implementation, it must be said that it would be best to implement all seven. That task would not be quick and simple.

A master schedule that promotes student achievement has been shown in this research study to depend on the school and the beliefs of the administration, teachers, parents, students, and community. All three of the schools had different schedules that the constituents believed helped in developing and sustaining an environment of high expectations. Researching and evaluating what would and wouldn't work for a certain school would take time and diligence on the part of all constituents.

Building professional learning communities where teachers had the time and skills necessary to be able to talk and engage in activities that lead to the success of all students cannot occur instantly. This occurs over time as the teachers and administration build trust and respect. Those two items are needed to begin to move forward in creating a discussion where everyone is comfortable and open to discuss ways to move teaching to learning for all. The end result would be to build a culture of high expectations.

Aligning the course content to the state assessment tool is a practice that would be easier than others to implement in a school. The state of West Virginia has provided the framework that teachers can use to assure that what is being taught will be tested. This is called a curriculum map. Through the use of the local Regional Educational Service Agency (RESA), principals can obtain help in setting up professional development in the development of curriculum maps.

Teachers then need to teach to the prescribed curriculum. Principals are responsible to check lesson plans a minimum of once per nine weeks. It is at that time that the principal would be able to verify if instruction was based upon state approved content. Providing students non- 
essential content will put them at an unfair advantage come test time. To enhance student performance through high expectations, the teachers have to teach the state approved curriculum to all students. This, too, will be an easy item for administrators to implement because it's madated by the Department of Education.

Schools that had a strong AP program went beyond offering AP courses. As evidenced in this research, two of the schools (Cherry and Apple High School) had double digit AP courses taught. Students also need to be provided the opportunity to pursue AP courses in a nontraditional way. The state of West Virginia is actively engaged in the use of virtual courses provided by Florida Virtual Schools of Florida. Using virtual courses enhances the AP offerings to include such courses as Macroeconomics, Microeconomics, Computer Science, Statistics, and Drawing, all of which can be done without adding personnel.

Through virtual schools it can be easy for any school to include a plethora of AP courses in its course offerings, but not all students are ready to learn virtually. As the schools in this study showed, 14 AP courses were taught on campus by a teacher. This required the school to get teacher buy-in. The College Board strongly suggests that teachers attend a training session provided by them before teaching an AP course. This is not a state board requirement, but some districts do require an $\mathrm{AP}$ teacher to attend the training sessions once every three years in order to teach an AP course.

Once there is teacher buy-in and teachers are willing to go to the trainings, the next stage of implementation is getting the support of the local board of education. Again, many schools are able to offer the required four AP courses, as mandated by state Policy 2510 (WVDE, 2008) through the use of virtual learning. However, this study found that schools where the AP courses are taught on campus contributed to high expectations. That required that additional teachers be 
on staff because AP courses are considered to be electives. So, to implement a strong AP program, as was seen at Apple High School and Cherry High School, takes board support through providing the necessary funding, not only for personnel, but for textbook and materials, too.

Strong parental involvement at a school may depend on its location. As more and more districts consolidate small, rural schools the more parents are turned away from being involved. All three of the schools in this research were based within the community and people saw it as the focal point. The consolidated schools are located in an area that creates a long driving distance to get to, and that may be what determines whether a parent will become involved with the school or not.

Orange High School used parents to show students they value education. This was done through the parent organization called the Academic Investment Group (AIG). This group was made up of individual parents that were the academic boosters who rewarded students at the end of each nine week grading period according to GPA (O.P.6). While at Cherry High School parental support was a part of the push for high expectations (C.T2.6). A teacher at Apple High School stated "we have a very strong parent support in the community. Parents get involved, they have high expectations. They're not going to settle for a teacher that's not doing what they're supposed to be doing" (A.T2.12). These are just examples of how parents can get involved in their child's education. Actively involving parents at the secondary level is needed for high expectations to be present, as this research supported.

Providing extra help/extra time was shown to be provided, but yet each school in this study did it a different way. Scheduling open class periods, where students could seek extra 
help/extra time, to using a part of the lunch hour to provide a special class were two of the ways this research showed how students could receive extra help/extra time when needed.

Using a flexible schedule where students and teachers were provided unstructured time within the school was believed to be the best way to enhance extra help/extra time for the students at Cherry High School. This afforded opportunities for students to seek help when needed or even to make-up missed work or science labs.

However, a flexible schedule was also the reason why students at Apple High School had time for extra help, too. It was the 52 minute lunch period (A.D.2) that promoted the use of a special program called Freshmen Focus. That was where students went to a classroom for the first 19 minutes of the lunch period to work on assignments. If a student had grades of Cs or better at the end of the first four and one-half weeks, then he/she earned the full lunch period.

Being able to develop time within the daily schedule has been shown to enhance the opportunities for all students to seek extra help/extra time. Through the use of the extra time, all students were provided the academic support so that failure was not an option. Teachers and principals strongly believed that the extra help/extra time provided a culture of high expectations. To not succeed a student had to work especially hard at it.

Getting the teachers to buy-in to providing extra help/extra time goes back to building trust and respect between staff and administration. Showing the staff how this can help produce high expectations will take time because the teachers have to be shown that there is a problem and through extra help/extra time student achievement will improve. However, I believe that given the correct information related to student achievement and how it could best be improved, the staff of a school would buy-into a "new" method for improving student achievement. 
Principal training. Having the knowledge of how to create a schedule that would support extra help/extra time is gained through an effective principal training program. Inappropriate principal training may impede effective implementation of the practices found to promote high expectations in this study.

In West Virginia there is a variance in obtaining principal licensure. According to West Virginia University, there are two different approaches for obtaining the principal licensure in West Virginia (West Virginia University, n.d.). First, any person who has a master's degree in education plus three years teaching experience may complete 21 credits at either West Virginia University or Marshall University in an administration program, pass the principal standardized test called PRAXIS II, and complete an evaluation skills training seminar offered through the West Virginia Center for Professional Development. The other method would be to enroll in a master's program in administration at either University that requires 42 credits to complete. This, too, requires the PRAXIS II test and completion of the evaluation skills training seminar.

I believe that the person who seeks his/her principal licensure through the 21 -credit program will not gain the necessary theory needed to understand how student achievement can be affected through high expectations. The principal's chair is convoluted and on any given day, the mundane tasks can overrun the need to stay focused on academic achievement.

Learning theory such as distributive leadership, assessment for learning, and just the general teaching practices theory has to be given precedent over completing the day-to-day tasks. This sound foundation in theory is not possible to obtain in just six courses and a standardized test (PRAXIS II).

Moving to a 42-credit program where a person would need to take 14 courses would provide the theory necessary to enhance academic achievement. The theory would lead the 
person to discover what practices work best for what situations. Using the theory and developing best practices would be the hope for anyone who completed a rigorous program that involved 14 courses.

So, depending on how a person ascends to the principal chair is reflected upon how that person is going to be able to lead teachers to seek the best practices for enhancing academic achievement in a changing environment. To implement the practices found to exist in the high performing schools of this study I believe will indeed take a person who has knowledge in leadership theory. That knowledge would best be obtained through the 42-credit program.

To complement the foundation in leadership theory, the principal would need to have experience. This study noted that all three principals worked in the classroom and as assistant principals prior to becoming principal. That additional administrative experience adds an additional skill set to the theory foundation of the course work.

Dick Flanary, senior director for leadership programs and services for the National Association of Secondary School Principals, said "most programs for principals have focused simply on preparation" (Aarons, 2010, p. 16). According to Mr. Flanary school districts are ready to change the way principals perform and want to shift from "universal access to universal performance" (Aarons, 2010, p. 16). The universal performance is believed to relate to student performance and that then leads into what practices the principal will establish to create a culture where high expectations prevail. High expectation practices can then be seen as the way to move from universal access to universal performance in schools.

How then will principal training relate to administrative practices identified in this research study? Aarons (2010) believes that the principalship needs to view leadership as a responsive service. Is she referring to education being more flexible so that it meets the needs of 
its clientele (students)? I believe that through this research the practices found to exist in all three schools showed that flexibility. The best illustration of that practice was in the type of master schedule the school had in place. Each of the three schools had a different schedule that was specifically designed to meet the needs of that set of students. What works well for one set of students may not be able to be applied across all schools.

Just as no two children are the same are no two schools the same. The make-up of the school is going to determine how each of the practices identified in this research study come to the surface. Seeking a common core definition to high expectations is similar to seeking a common core belief or culture. The people who serve the students at each school in West Virginia have different core beliefs, just as do the students who walk through the doors. So even though no core, unified definition of high expectations is believed to exist, common practices have been found to exist in the selected high performing schools. How one approaches each of the practices will be determined by the culture, norms and beliefs, and length of service in staff and administration.

Missing elements in the proposed definition. Table 2 found at the end of chapter two presented thirteen elements that were proposed to be a part of the definition of high expectations. The interview questions were based from those elements in hopes of obtaining data to substantiate the existence of each element. However, upon a review of the thirteen, three of the elements were found to be absent at the schools. Those three elements are teachers assisted in developing individual plans for instructional improvement, teachers provided common planning periods, and observations completed with feedback to the teacher.

The rationale for why those elements came up missing could be due to state policy, constraints within the system and lack of clarity and/or articulation. About state policy, a 
principal has to observe a teacher during his/her first five years. Starting year six, the principal may observe. In addition, two of the schools had curriculum assistant principals that were delegated teacher observation responsibilities. Rather than observations, the principals stated they completed walk throughs with feedback during the interviews.

Common planning periods did not occur at the schools. The rationale for that may be that the schedule could not afford to have more than one department off at one time. Due to the design of the schedule and the need for classes it was not possible.

Teachers assisted in developing lesson plans and shared values were not present at the schools. Lack of clarity and articulation may be why these do not occur. Teachers are provided training in the development of lesson plans during their training programs. The principals may believe that training is enough and so do not provide it. In addition, when the principals check lesson plans they may not see any problems with how the lesson plans are written. Finally, the principals may believe that due to union constraints they cannot mandate what is or is not to be in the lesson plan. As long as student achievement remains high, there may be no need for lesson plan assistance.

Different practices occurred at each site. Table 17 listed the practices that were found to be common between the three sites as well as those practices that occurred singularly or in two of the sites. The conclusion of the study was that high expectations was dependent upon what the community, teachers and principals valued. The practices that the teachers and principals employed to show high expectations may have been different at the three sites because of the community from which each site belonged was different.

The three sites were from different regions of the state and therefore the way in which high expectations were believed to occur may have been different, but yet present. The norms 
and beliefs of West Virginia are believed to vary from region to region. For all three sites to have exactly the same practices that produce high expectations may be to say that the students at all three sites came from the same background. This is believed to not occur, but yet practices that lead to high expectations can exist in different forms, just as they did in this research study.

Value of qualitative inquiry in studying schools. Similar data could have been obtained from a quantitative study through a survey. However, what the qualitative inquiry adds to this research was how the researcher was able to pick up on the beliefs that the teachers and principals had that contributed to high expectations. Saying that one has high expectations can be checked off through a survey, but to have someone go into the school and see the practices come alive is what makes qualitative research so valuable in studying schools. It was through the qualitative inquiry that the rich categories were able to be extracted and written about. The reader was able to get a vivid picture of how each school was able to make high expectations come to fruition.

\section{Recommendations for Future Research}

This research found seven areas that were present in all three schools that assisted in contributing to high expectations. From the seven areas potential future research questions can be found. They are: (a) What type of scheduling (i.e., number and length of instructional periods) impacts high expectations the most as seen through student achievement? (b) How does the presence of a professional learning community contribute to a culture of high expectations?

(c) How does curriculum design and alignment to the state testing tool impact high expectations?

(d) How do teachers teaching the prescribed curriculum impact high expectations? (e) How do the number and delivery style of AP courses affect high expectations? (f) How do schools 
involve parents in the educational process? (g) How is extra help/extra time provided during the school day or before/after the school day affect high expectations?

Another potential area for further research is the length of time a particular administrative staff has worked together in the same building. Each of the three schools in this research had a new administrative staff that had no prior working experience with each other, this included teaching experience. Bringing in an all new administrative staff may or may not be found to be universally effective. Using a qualitative study to observe how the selection process of a "new" administrative staff occurs can seek to add to the culture of the school. From the culture arises the belief that high expectations are prevalent.

Schools are being held accountable for student achievement throughout West Virginia. So from this study another area for further research would be to see how principals use student data to drive achievement. What specific student data are principals using in highly effective schools that produces high student achievement?

An area that would encompass a broader approach to the area of high expectations in the $21^{\text {st }}$ century is that of high stakes testing. This research pointed out how No Child Left Behind legislation has placed accountability upon districts, schools and then classroom teachers. The accountability tool that was chosen by the Federal government was some type of high stakes test. In West Virginia that high stakes test is called WESTEST.

Through the use of a qualitative study, data can be collected on how administrators and teachers feel the high stakes testing environment affects high expectations. Knowing how one particular test affects high expectations may be able to change the belief in the assessment policies of the state and nation. All students exhibiting high expectations may best be obtained 
through a holistic approach. The data from the qualitative study may provide credence to the holistic assessment approach.

From the discussion, a future research question arose. In schools where high expectations exist, what is the leadership style of the principal? The literature review noted that Hall, et al. (1984) described three types of leadership styles: initiator, manager, and responder. A quantitative study is suggested to determine which of the three leadership styles are found to exist in schools where high expectations are prevalent. This information would assist in developing appropriate course work in a principal preparatory program.

Woodrum (2004) refers to the lack of educational values in Appalachia. From this research, the stereotypical views of Appalachia were not evident. So, future research that includes interviews with communities might better understand their values and if they differed from the typical or stereotypical of education and Appalachia. 


\section{References}

A Nation Prepared: Teachers for the $21{ }^{\text {st }}$ Century. (1986). The Report of the Task Force on Teaching as a Profession. New York, New York: Carnegie Corporation.of New York. Angus, L. (1993). The sociology of school effectiveness. British Journal of Sociology of Education, 14, 333-345.

Armor, D., Conry-Oseguera, P., Cox, M., King, N. J., McDonnell, L. M., Pascal, Pauly, E., Zellman, G. L., (1976). Analysis of the school preferred reading program in selected Los Angeles minority schools. Santa Monica, CA: Rand Corporation.

Arrons, D. I. (2010). Initiative aims to refashion training path for principals. Education Week, $30(6), 1,4$.

Babad, E. (1993). Pygmalion-25 years after interpersonal expectations. In P. D. Blanck (Ed), Interpersonal expectations: pp. 125-153. Cambridge, England: Cambridge University Press.

Balfanz, R., McPartland, J., Shaw, A. (2002, April). Re-conceptualizing extra help for high school students in a high standards era. Paper commissioned for Preparing America's Future: The High School Symposium. Retrieved from ERIC database. (ED465089)

Bamburg, J. D. (1994). Raising expectations to improve student learning. (Contract NO. RP91002007). Oak Brook, IL: North Central Regional Educational Laboratory.

Barker, B. O., \& Robinson, K. L. (2001). Effective rural schools and national board professional teaching standards. Paper presented at the $93^{\text {rd }}$ Annual national Rural Education Conference, Albuquerque, New Mexico. (ERIC Document Reproduction Service NO. ED467778). 
Beez, W. (1968). Influence of biased psychological reports on teacher behavior and pupil performance. Proceedings of the $76^{\text {th }}$ Annual Convention of the American Psychological Association, 3, 605-606.

Bolman, L. G., \& Deal, T. E. (2003). Reframing organizations artistry, choice, and leadership ( $3^{\text {rd }}$ ed.). San Francisco, CA: Jossey-Bass.

Bottoms, G., Presson, A., \& Johnson, M. (1992). Making high schools work through integration of academic and vocational education. Atlanta, GA: Southern Regional Education Board.

Boyd, W. L., \& Reese, J. P. (2006, Spring). Great expectations: the impact of the national board for professional teaching standards. Education Next, 6(2), 50-57.

Brophy, J. (1998). Introduction. In J. Brophy (Ed.), Advances in research on teaching: Vol. 7. Expectations in the classroom (pp. ix - xvii). London, England: JAI Press, Inc.

Brophy, J., \& Good, T. (1974). Teacher-student relationships. Causes and consequences. New York: Holt, Rinehart, and Winston.

California Center for Effective Schools. (n.d.). California center for effective schools: connections for success. Retrieved March 25, 2008, from http://effectiveschools.education.ucsb.edu/indes.html

Cancell, E.R. (2002). Not what you'd expect: An exploration of teachers' expectations for their students. Dissertation Abstracts International, 63, 06A. (UMI No. 3055840).

Clark, D. L., Lotto, L. B., \& Astuto, T. A. (1984). Effective schools and school improvement: a comparative analysis of two lines of inquiry. Educational Administration Quarterly, 20(3), 41-68. 
Coe, R., \& Fitz-Gibbon, C. T. (1998). School effectiveness research: Criticisms and recommendations. Oxford Review of Education, 24(4), 421-438.

Cohen, M. (1982). Effective schools: accumulating research finding. American Education, 18, $13-16$.

Coleman, J. S., Campbell, E., Hobson, C., McPartland, J., Mood, A., Weinfeld, R. and York, R. (1966). Equality of educational opportunity. Washington, DC: US Department of Health, Education and Welfare.

Cosner, S.A. (2005). High school principals and school capacity: An exploratory study of capacity building from a social and human capital perspective (Doctoral dissertation, The University of Wisconsin, 2005). Dissertation Abstracts International, 66, 08A.

Creech, J. D. (1995). Challenging students to higher standards through advanced placement. Atlanta, GA: Southern Regional Education Board.

Creswell, J. W. (1998). Qualitative inquiry and research design: Choosing among five traditions. London, England: Sage.

Davis E. L. (1992). The leadership behaviors of principals and their effect on school improvement in effective urban high schools. Dissertation Abstracts International, 53, 12A. (UMI No. 9310290).

Denton, D. (2001, January). Finding alternatives to failure: Can states end social promotion and reduce retention rates? Atlanta, GA: Southern Regional Education Board.

Denzin, N., \& Lincoln, Y. (Eds.) (2000). Handbook of qualitative research $\left(2^{\text {nd }}\right.$ ed.). Thousand Oaks, CA: Sage.

Dessoff, A. (2009, October). Reaching graduation with credit recovery. District Administration 45(9), $43-48$. 
DuFour, R. (2004, May). What is a "professional learning community”? Educational Leadership 61(8), 6-11.

DuFour, R., DuFour, R., Eaker, R., \& Many, T. (2006). Learning by doing: A handbookfor professional learning communities at work. Bloomington, IN: Solution Tree Press.

Dusek, J. B. (1975). Do teachers bias children's learning? Review of Educational Research, 45, $661-684$.

Dusek, J. B. (1985). Introduction to teacher expectancy research. In J. B. Dusek (Ed.), Teacher expectancies (pp. 1-6). Hillsdale, NJ: Lawrence Erlbaum Associates.

Eden, D., \& Shani, A. (1982). Pygmalion goes to bootcamp: Expectancy, leadership, and trainee performance. Journal of Applied Psychology, 67, 194-199.

Edmonds, R. (1979). Effective schools for the urban poor. Educational Leadership, 37(1), 15 27.

English, F. W. (2010). Deciding what to teach and test: Developing, aligning, and leading the curriculum (3rd ed.). Thousand Oaks, California: Corwin.

Ennis, C. D. (1989). Shared expectations: Creating a joint vision for urban schools. In J. Brophy (Ed), Advances in research on teaching: Vol. 7 (pp. 151-182). London, England: JAI Press Inc.

Epstein, J. L. (2008, February). Improving family and community involvement in secondary schools. Education Digest, 73(6), 9-12.

Flick, U. (1998). An introduction to qualitative research. London, England: Sage.

Fulmer, G. W. (2010, May 1). Estimating critical values for strength of alignment among curriculum, assessments, and instruction. Paper presented at the 2010 annual meeting of the American Educational Research Association, Arlington, VA. 
Garman, N. (1994, August 5). Qualitative inquiry: Meaning and menace for educational researchers. Keynote speech at the mini-conference on qualitative research, Flinders Institute for the Study of Teaching, The Flinders University of South Australia, Adelaide.

Good, T. L., \& Brophy, J. E. (2003). Looking in classrooms ( $9^{\text {th }}$ ed.). Boston, MA: Allyn and Bacon.

Grimes, R. (1982, May 14). The Recht decision [Electronic version]. Charleston Daily Mail. Retrieved July 19, 2008, from http://www.wvculture.org/HiStory/education/recht02.html

Hackmann, D.G. (1999). The cautious pace of school reform: High school scheduling in Iowa. NASSP Bulletin, 83(609), 69-76.

Hall, G., Rutherford, W. L., Hord, S. M., Huling, L. L. (1984, February). Effects of three principal styles on school improvement. Educational Leadership, 41(5), 22-29.

Hall, V. C., \& Merkel, S. P. (1985). Teacher expectancy effects and educational psychology. In J. B. Dusek (Ed.), Teacher expectancies (pp. 67-92). Hillsdale, NJ: Lawrence Erlbaum Associates.

Handwerk, P., Tognatta, N., Coley, R. J., Gitomer, D. H. (2008, July). Access to success: Patterns of advanced placement participation in U.S. high schools. Princeton, NJ: Educational Testing Service.

Hanushek, E.A. (1971). Teacher characteristics and gains in student achievement: estimation using micro data. The American Economic Review, 61, 280-288.

Harmston, M. T., Pliska, A, Ziomek, R. L., Hackman, D. G. (2003). The relationship between schedule type and ACT assessment scores: A longitudinal study. ACT Research report series. (ERIC Document Reproduction Service NO. ED478492). 
Hess, C., Wronkovich, M., \& Robinson, J. (1999). Measured outcomes of learning under block scheduling. NASSP Bulletin, 83(611), 87-95.

Highsmith, R. J. (1989, winter). The advanced placement program. Journal of Economic Education, 115-120.

Hill, N. E., Taylor, L. C. (2004, August). Parental school involvement and children's academic achievement pragmatics and issues. Current Directions in Psychological Science, 13(4), $161-164$.

Hord, S. (1997). Professional learning communities: communities of continuous inquiry and improvement Austin, TX: Southwest Educational Development Laboratory.

Jansen, J.D. (1995, June). Effective Schools? Comparative Education, 31(2), 181-200.

Jencks, C. S., Smith, M., Ackland, H., Bane, M. J., Cohen, D., Ginter, H., Heyns, B. and Michelson, S. (1972). Inequality: A reassessment of the effect of the family and schooling in America. New York: Basic Books.

Kennedy, M. M. (2005). Inside teaching: How classroom life undermines reform. Cambridge, Massachusetts: Harvard University Press.

Koger, P. C. (1987). The instructional leadership activities, beliefs and characteristics of principals of effective secondary schools (Doctoral dissertation, University of South Carolina, 1987). Dissertation Abstracts International, 48, 08A.

Lankford, M. D. (1994, August). Flexible access: foundation for student achievement. School Library Journal 40(8), 21-23.

Lauder, H., Jamieson, I., \& Wikeley, F. (1998). School effects in postmodern conditions. In R. Slee \& G. Weiner (with S. Tomlinson) (Eds.), School effectiveness for whom? 
Challenges to the school effectiveness and school improvement movements (pp. 84-100). London, England: Falmer Press.

Lezotte, L. W. \& Bancroft, B. A. (1985, March). Growing use of the effective schools model for school improvement. Educational Leadership, 42(6), 23-27.

Lezotte, L. (2001). Revolutionary and evolutionary: The effective schools movement. Michigan: Effective School Products, Ltd.

Lezotte, L. W., \& McKee, K. M. (2002). Assembly required: A continuous school improvement system. Michigan: Effective School Products, Ltd.

Lichtman, M. (2006). Qualitative research in education: A user's guide. Thousand Oaks: Sage Publications.

Luyten, H., Visscher, A., Witziers, B. (2005, September). School effectiveness research review of the criticism to recommendations for further development. School Effectiveness and School Improvement 16(3), 249-279.

Major categories in the taxonomy of educational objectives. Retrieved July 29, 2008, from http://krummefamily.org/guides/bloom.html

Marcum, C. (2008). Appalachian cultural awareness and community development. Retrieved May 23, 2009, from West Virginia University, Extension Service Families and Health Programs Web site: http://fh.ext.wvu.edu/r/download/23476

Marshall, C., \& Rossman, G. (1995). Designing qualitative research $\left(2^{\text {nd }}\right.$ ed.). Newbury Park: Sage.

McCallumore, K. M., Sparapani, E. F. (2010, Spring). The importance of the ninth grade on high school graduation rates and student success in high school. Education 130(3), 447456. 
Merriam, S. B. (1988). Case study research in education: A qualitative approach. San Francisco: Jossey-Bass.

Merriam, S. B. (1998). Qualitative research and case study applications in education (Rev. ed.). San Francisco: Jossey-Bass.

Michael, S., Dittus, P., Epstein, J., (2007, October). Family and Community Involvement in Schools: Results from the School Health Policies and Programs Study 2006. Journal of School Health, 77 (8), $567-587$.

Miskel, C. G., \& Hoy, W. K. (2005). Educational administration theory, research and practice ( $7^{\text {th }}$ ed.). New York, New York: McGraw-Hill.

Mizelle, T. K. (1995). An examination of the role of the assistant principal in high schools in Virginia that are restructuring (Doctoral dissertation, Old Dominion University, 1995). Dissertation Abstracts International, 56, 10A.

Murnane, R. J. (1975). The Impact of School Resources on the Learning of Inner City Children. Cambridge: Ballinger.

Murnane, R. J. (1981). Interpreting the evidence on school effectiveness. Teachers College Record, 83, 19-35.

Murnane, R. J., \& Phillips, B. R. (1979). Effective teachers of inner city children: who are they and what do they do. Cambridge, MA: Harvard University.

National Board for Professional Teaching Standards (2008). National Board for Professional Teaching Standards: 2008 Guide to National Board Certification. Retrieved May 23, 2009 from http://www.nbpts.org 
National Center for Educational Statistics (2001, August). High School Academic Curriculum and the Persistence Pattern Through College. Retrieved from National Center for Educational Statistics website: http://nces.ed.gov/pubs2001/2001163.pdf

National School Lunch Program (2011). National School Lunch Program fact sheet. Retrieved April 19, 2011 from http://www.fns.usda.gov/cnd/lunch/AboutLunch/NSLPFactSheet.pdf No Child Left Behind Act of 2001, Pub. L. No. 107-110, §115 Stat. 1425 (2002).

Nordheim, S. L. (2006). Beating the odds: Does the formal teacher evaluation process make the difference in teacher performance? Dissertation Abstracts International, 67, 09A.

Odden, A. (1991). Education Policy Implementation. New York: SUNY Press.

Office of Education Performance Audits (2007, July). Commonalities in low performing schools: Trend education performance audit findings. Retrieved February 1, 2009 from http://oepa.state.wv.usPDFs/resources/Commalities\%20in\%20low\%20performing\%20sc hools $\% 2006-2007$ doc

Patton, M. Q. (1990). Qualitative evaluation and research methods (2 ${ }^{\text {nd }}$ ed.) Newbury Park: Sage Publications, Inc.

Patton, M. Q. (2002). Qualitative research and evaluation methods $\left(3^{\text {rd }} \mathrm{ed}\right.$.). Thousand Oakes, California: Sage Publications, Inc.

Peshkin, A. (1988). In search of subjectivity_One's own. Educational Researcher, October, $17-21$.

Purkey, R. C., \& Smith, M. S. (1982, December). Too soon to cheer? Synthesis of research on effective schools. Educational Leadership, 40(3), 64-69.

Ralph, J. H., \& Fennessey, J. (1983). Science or reform: Some questions about effective schools. Phi Delta Kappan, 64, 689. 
Raphael, D., Wahlstrom, M., \& McLean, L. D. (1986). The semestered secondary school and student achievement: Results from the Second Ontario International Science Study. Canadian Journal of Education, 11(2), 180-183.

Richardson, J. (1995, April 12). Next generation of effective schools looks to districts for lasting change. Education Week, 14(29), 8-10.

Rinder, D. E. (2007). In the implementation of standards-based reform: What is the leadership role of the principal in building school capacity and accountability to sustain student academic growth? Dissertation Abstracts International, 68, 10A. (UMI No. 3278487).

Rist, R. (1970). Student social class and teacher expectations: The self-fulfilling prophecy in ghetto education. Harvard Educational Review, 40, 411-451.

Rist, R. (1973). The urban school: A factory for failure. Cambridge, MA: MIT Press.

Rist, R. (1977). On understanding the processes of schooling: The contributions of labeling theory. In J. Karabel \& A. H. Halsey (Eds.), Power and ideology in education (pp. 292305. New York, NY: Oxford University Press.

Rosenthal, R. (1985). From unconscious experimenter bias to teacher expectancy effects. In J. B. Dusek (Ed.), Teacher expectancies (pp. 37-65). Hillsdale, NJ: Lawrence Erlbaum Associates.

Rosenthal, R., \& Jacobson, L. (1968). Pygmalion in the classroom teacher expectation and pupils' intellectual development. New York: Holt, Rinehart and Winston, Inc.

Ross, J. A. (1998). The antecedents and consequences of teacher efficacy. In J. Brophy (Ed), Advances in research on teaching: Vol. 7 (pp. 49-73). London, England: JAI Press Inc. Scheerens, J., \& Bosker, R.J. (1997). The foundations of educational effectiveness. Oxford: Pergamon. 
Schrank, W. (1968). The labeling effect of ability grouping. Journal of Educational Research, $62,51-52$.

Shafritz, J. M., Ott, J. S., \& Jang, Y. S. (2005). Classics of organization theory $\left(6^{\text {th }}\right.$ ed.). Belmont, CA: Thomson Wadsworth.

Slee, R., \& Weiner, G. (2001). Education reform and reconstruction as a challenge to research genres: Reconsidering school effectiveness research and inclusive schooling. School Effectiveness and School Improvement, 12, 83-98.

Soltis, J. (1984). On the nature of educational research. Educational Researcher, 13(10), 5-10. Southern Educational Regional Board (2000). Making schools work: Raising student achievement in rural middle grades and high schools. Atlanta, GA: Southern Education Regional Board.

Spillane, J. P. (2006). Distributed leadership. San Francisco, CA: Jossey-Bass.

Stake, R. E. (1995). The art of case study. Thousand Oaks: Sage Publications.

Strauss, A., \& Corbin, J. (1990). Basics of qualitative research: Grounded theory procedures and techniques. Newbury Park: Sage.

Sweeney, J. (1982, February). Research synthesis on effective school leadership. Educational Leadership 39(5), 346-352.

Taylor, B. O. (2002, January). The effective schools process: Alive and well. Phi Delta Kappan, 83(5), 375-378.

Teddlie, C., \& Reynolds, D. (2000). The international handbook of school effectiveness research. New York: Routledge.

The College Board (1998, May). Block schedules and student performance on AP examinations. Research Notes, RN-03. New York: Office of Research and Development, The College 
Board. Retrieved September 11, 2010, from

http://www.collegeboard.org/research/html/m03.pdf.

Thrupp, M. (2001). Sociological and political concerns about school effectiveness research:

Time for a new research agenda. School Effectiveness and School Improvement, 12(1), 740.

Wakelyn, D. (2009, August). Raising rigor, getting results: Lessons learned from AP expansion. Washington, DC: National Governors Association Center for Best Practices.

Wallman, D. G. (1987). Leadership styles, change facilitator styles, and actions of selected West Virginia principals involved in school improvement (Doctoral dissertation, West Virginia University, 1987).

Watts, R.S. (2000, November). An alternative school within a school: A case study on meeting motivational, curricula, and instructional needs of at-risk students. Paper presented at the annual meeting of the Mid-South educational research association, Bowling Green, KY. (ERIC Document Reproduction Service No. ED448992).

Weber, G. (1971). Inner city children can be taught to read: Four successful schools. Washington, DC: Council for Basic Education.

West Virginia Department of Education (2006a, August). Training manual and handbook for education performance audits. Charleston, WV: Author.

West Virginia Department of Education (2006b, September). Policy 5310: Performance evaluation of school personnel. Charleston, WV: Author.

West Virginia Department of Education (2007, November). Policy 2320: A process for improving education: performance based accreditation system. Charleston, WV: Author. 
West Virginia Department of Education (2008, July). Policy 2510: Assuring the quality of education. Charleston, WV: Author.

West Virginia Department of Education (2009, August). Policy 2520.1: $21^{\text {st }}$ Century reading and English language arts content standards and objectives for West Virginia schools. Charleston, WV: Author.

West Virginia Department of Education enrollment data (2010). Retrieved June 12, 2010 from http://wveis.k12.wv.us/nclb/pub/enroll/e06size.cfm

West Virginia Department of Education enrollment data (2010b). Retrieved February 18, 2011 from http://wveis.k12.wv.us/nclb/pub/enroll/e06size.cfm

West Virginia HomeTownLocator (2010). Orangetown Maps, Pacts and Features. Retrieved from http://westvirginia.hometownlocator.com/wv/xxx/xxx.cfm

West Virginia School Laws Annotated §18A-3A-2b (2007).

West Virginia School Laws Annotated §18-5A-1 (2007).

West Virginia School Laws Annotated §18-5-45(5)(d) (2007).

West Virginia University (n.d.). Retrieved January 15, 2011 from http://edls.wvu.edu/principal_certification

Wiles, K. (1967). Supervision for better schools (3 ${ }^{\text {rd }}$ ed.). Englewood Cliffs, NJ: Prentice-Hall, Inc.

Woodrum, A. (2004, September 7). State-mandated testing and cultural resistance in Appalachian schools: Competing values and expectations. Journal of Research in Rural Education, 19(1). Retrieved November 23, 2008 from http://jrre.psu.edu/articles/192.pdf

Yin, R. (1984). Case study research: Design and methods. Beverly Hills: Sage 
Appendix A

Principal Letter of Participation 
Dear Principal:

\section{Principal Letter of Participation}

My name is David S. Tupper and I am writing to request your and your school's participation in a research study focusing on the tools and routines that principals and teachers use in establishing high expectations in selected secondary schools in West Virginia. The purpose of the study is to lead toward a definition of high expectations in public secondary schools. A benefit of your participation in this study is the opportunity to express your role within the building that assists in establishing high expectations. The data will be collected through an interview, observations and document collection (i.e., master schedule, teacher lesson plans, course syllabus, school course catalog, etc.). This data is a critical component of my doctoral dissertation which will be conducted under the direction of Dr. Helen Hazi, Professor of Educational Leadership Studies at West Virginia University.

By agreeing to have me come visit your school for a period of not more than five days, you will provide valuable data for the research study. The five day visit will occur at a time you and your staff so indicate. I will interview you for approximately 50 minutes. During the visit, I will also observe you interacting informally with students and staff in the hallways, before school and at lunch time for approximately 30 minutes. In addition, you will be interviewed as well as up to nine teachers who volunteer to participate. Each of the teachers will be interviewed for approximately 50 minutes and will be asked to allow their classroom to be observed for approximately 30 minutes. Finally, I will observe the school during class changes, before school and at lunch time.

The following assurances, as required by West Virginia University, will be respected: participation in the study is voluntary; information will be kept confidential; and the participant may refuse to participate, quit at any time, or skip any question with no negative effect in employment status. Further, West Virginia University's Institutional Review Board acknowledgement for this research is on file.

Please contact me at dtupper@access.k12.wv.us or 304-927-6420 to participate in this study.

Participants may obtain a copy of final research results upon request from the researcher during the interview process. Questions regarding the research study or other contents of this letter can be addressed to dtupper@access.k12.wv.us or 304-927-6420. Thank you for your consideration in this request.

Sincerely,

Helen Hazi, Principal Investigator Educational Leadership Professor
David S. Tupper, Primary Contact Doctoral Student 


\section{Appendix B}

Central Office Letter of Participation 
Central Office Letter of Participation

Dear Central Office Representative

My name is David S. Tupper and I am writing to notify you that I have contacted a principal at one of your high schools to request participation in a researched-based study focusing on improving educational leadership practice. The purpose of the study is to lead toward a definition of high expectations in public secondary schools. The data will be collected through interviews, observations and document collection (i.e., master schedule, teacher lesson plans, course syllabus, school course catalog, etc.). This data is a critical component of my doctoral dissertation which will be conducted under the direction of Dr. Helen Hazi, Professor of Educational Leadership Studies at West Virginian University.

The following assurances, as required by West Virginia University, will be respected; participation in the study is voluntary; information will be kept confidential; and the participant may refuse to participate, quit at any time, or skip any question with no negative effect in employment status. Further, West Virginia University's Institutional Review board acknowledgement for this research is on file.

If you have further questions contact Dr. Helen Hazi at Helen.Hazi@mail.wvu.edu or by phone at 304-293-1885. Thank you for your consideration.

Sincerely,

Helen Hazi, Principal Investigator Educational Leadership Professor
David S. Tupper, Primary Contact Doctoral Student 


\section{Appendix C}

Principal Interview Questions 


\section{Principal Interview Questions \\ - Probes}

1. What do you think the phrase high expectations for students mean in this school?

- If a student is not succeeding in a classroom, what support system does the school provide?

- How would you describe the school environment/attitude toward student achievement?

- How would you describe the relationship between the students and faculty?

2. What are some activities or traditions at this school that promote high expectations?

- What is the school slogan or motto?

- Where is the slogan or motto displayed/exhibited?

- Which activity is effective and why?

- What kind of things happen at this school that promote high expectations?

3. How are high expectation courses such as advanced placement, honors and college classes chosen to be offered?

- Who decides what courses to offer?

- What is the minimum number of students needed to place a course within the master schedule?

- If a low ability student wants to take a course, what would you do?

- How are teachers assigned to teach these courses?

4. How do teachers vary instructional teaching strategies?

- How is this verified?

- Where do teachers learn the best instructional strategies to use?

- How do you support/nurture teachers to use varied instructional strategies?

- If a student were asked to identify the best instructional strategy, what would he/she say?

5. Tell me the ways students are recognized and rewarded in this school?

- What is the procedure for choosing students to be recognized?

- How often are student recognition assemblies held and where is it done?

- What awards are available for students that make progress?

6. How is communication within the teachers related to instruction and instructional activities?

- What is your involvement with teachers during this time?

- How does common planning facilitate this?

- How did this idea come about? 
7. Describe how you assist teachers in meeting the needs of all students?

- During an observation, you identify any student(s) off task. How is the identified student doing in the teacher's class and how does he/she address the student's needs?

- How often are students being monitored for comprehension?

- How are you involved in providing techniques used for student monitoring?

- During an observation, it was noted that a low achieving student was asked a question and when he/she did not respond, no additional probes were given. What is happening to get low achieving students to be actively engaged in answering questions?

8. What professional development activities are planned for the school year?

- How was professional development decided?

- Which professional development activities will you have that best promote teachers having high expectations?

- When do follow up activities and discussions occur that reinforce high expectations?

- How will data be collected to show whether the professional development activity augments high expectations?

9. Some say National Board Certification for teachers is important to increase student achievement in schools, what is your belief on national Board Certification?

- How has having a teacher who is National Board Certified promoted or enhanced high expectations in the school?

- What leadership role does the National Board Certified teacher serve?

\section{Closing}

1. We've talked about the ways the principal and teachers contribute to high expectations. Are there other aspects within the school or district that you would like to discuss related to high expectations? 
Appendix D

Principal Interview 
This transcription is of the interview with Principal A on Monday, October 26, 2009. The interview occurred in principal's office.

Researcher: Principal what do you think the phrase high expectations means for students at your school?

Principal A: it's our staff knowing the goals and expectations set forth by the district by the LSIC, their goals, but the most important thing is I as the administrator have asked the staff to be to show more rigor in the classroom and with the promise scholarship, I see, a lot of our kids getting the promise scholarship. Two years ago we had a graduating class of $88 \mathrm{kids}, 22$ of them got the promise scholarship, which is a great, great numbers but of those 22 less than half were able to keep it after their first year of college. So, I think you know, the kids, the parents have driven teachers to be more relaxed in the classroom, that allows kids to get better grades and we're fortunate enough that the kids do very well on the ACT or the SAT that allow them to get the promise scholarship, but our concerns is they're not maintaining that when they get to school. So we want to be more rigorous in the classroom and yes it may cause us not to have as many promise scholarship people. But I think that in the long run, more kids will be able to retain that after their first or second year of college. We have discussions through groups and some of the teams I didn't talk to you earlier about, but we have department team meetings, we have curriculum team meetings, basically the curriculum team is the department heads that come meet together and we look at different ways to help strengthen our schedule to strengthen issues that we have in the classroom and we meet monthly. I require the teachers to meet as a department, the department chairs meet with them their departments and they come back with information or I will meet with the curriculum team which are the department heads and I use them to distribute information back to staff members and it works very well. I require them to meet once a month, and they're to give me minutes of what took place in their meetings. So that has helped us try to bring some rigor back into the school. Of course, we're all the time looking at our test scores, test data as probably everyone else does. The one thing that concerns us, we were always had high scores and we have shown some decline, but it's not the decline that worries us as much as the other schools in the district and the rest of the state have not only risen but are starting to catch up. So, uhm, that's a concern that the staff have and we're looking at different ways of trying to increase those test scores to try to make them better and to make us the very top, as we used to be at one time.

Researcher: Okay, you keep mentioning more rigor in the classroom. Could you give some examples of what either you are setting to the teachers as more rigor or what your committees are sharing with you and then you all brainstorm as to what rigor are we doing now, versus?

Principal A: Uhm, we have set standards where, uhm, we have a drop date and this is fresh in my head, so that's what I'm talking about now. But, we had kids at one time that would take classes would get to the first nine weeks and realize they were in a class that they'd have to work or have to study for and they'd want to coast so they'd take or drop a class and try to take something easier. Well, you have the first week to determine if you're going to drop a class or not. So now we're making kids stay in classes that they may have to work for and then we're upfront with the kids and we tell the kids not every kid is going to get an A in this class that you 
know, there's going to be some s C's, some B's, and D's and we're looking at also we do mid terms, and finals and mid-semesters and final exams, uhm, so, we are asking the teachers to be more rigorous there to make their test more rigorous. Uhm, we had kids that make a poor grade and they want to do extra credit or they want to re-test and we allow that but we make limits on number of times you can retest, and we tried to ask the staff to, you know, you don't have to grade everything, but we have Ed-Line, which is a great communication tool for our parents and our teachers, and we asked them to put their syllabus online, some teachers actually put their lessons, lesson plans online so if you have a kid absent that they can pull up Ed-Line and see what they're missing for the week. We've made it mandatory and it's a district policy that the ed line accounts are updated every two weeks. So those are a lot of little things that we've asked and we're also looking at, what more can we do as far as testing. As far as how we can improve our test scores by simple things as bell ringers in the classroom to open up, look at test questions and in the past we've had kids. The district we as a school has decided to buy or purchase calculators for the Westest, and so we went to the district and said look, we're testing now that we're testing 7, 8, 9, 10, 11 - five grades. We don't have enough calculators for all those. So the district has actually allowed us to separate and test math at certain grade levels certain days of the week. So now we have enough calculators. So we now get those to the teachers, which use them in the classrooms so the kids can see and have some familiarity with the calculators. So, that their, when it comes Westest time, they don't have a brand-new calculator that they don't know how to use. Uhm, we try to pull up things from the teach 21 site that we can use in the classroom. As far as bell ringers to get questions that we can formulate that the teachers can use so they have some familiar with some of the Westest questions themselves and there's some samples of WESTEST questions that they see, so they know how the questions are worded. So they have some, they are familiar with that. Uhm, there's a lot of other things and I'm sure you'll come in the question you'll probably pull those out. There's a lot of other things that we do, I just can't think of right now.

Researcher: Okay. Could you, to keep going on this rigor you mentioned teachers' tests reflect rigor. Principal A: Yes. Researcher: Are you talking their tests being more reflective of the teach 21 st site? How, if you've seen the teacher's tests? I mean.

Principal A: The individual test we've not seen but they're required to turn in to us the semester and the final test, along with an answer key, and we've went over those and we've discussed those and how much more rigorous they can be and rigor doesn't mean that they have to be all essay questions but we asked them to do a variety of questions and to make them some teachers think that they can come in and do the last nine weeks, and that's a final. Well, no we wanted a comprehensive final of the entire year uhm, so teachers that the kids have to go back and research and look at things in the past. Uhm, we've also in the past we've had uhm they do a senior project, and uhm in your going down the hallway and talking to our one teacher you realize that we have the lab and that we have freshman work on the Microsoft and the PowerPoint and the Excel. A lot of kids never saw the PowerPoint until they were juniors and seniors. Now their getting that much earlier. Uhm, and so what I've asked the staff to look at is some project based learning, where they do projects and they do it throughout the career here as a student. One of the web sites that, uhm, Web top is a program that the State uses that we have become aware of through the principals Academy, and that allows kids to have an excess account and to be able to save things there that they can create a portfolio here and start as a seventh 
graders and allow it to follow through all the way to their senior year. Uhm, if they we ask the teachers and we're asking teachers to do projects and project based learning well they now have projects they can do each year, and we now have you can keep those you know, electronic portfolios there at the state level, and they're always accessible by the kids and the teachers, uhm, lost my train of thought here, (long pause). Uhm, Google docs is a thing that we're trying to get the teachers to use and what it does. We have kids that bring the thumb drives in. Well, it brings in a lot of the schools, and you are technology driven but when they bring the thumb drives in they also bring in viruses and things from outside. Google docs is a system that it's an external site that they use, they can type the documents teachers have access to it. If they group that does it then the child can set up where he allows other people in the group to share the site and they can all go in, make changes to the sites the teachers can pull it up its all external where it doesn't go through our server, and it doesn't carry in the viruses the programs that we have. So it's a great system. It's just finding the time to educate our teachers, and to get them where they want to use this system and some of our teachers, young teachers, have picked up on it and starten to use it and like it so.

Researcher: You mentioned in the rigor about allowing some of the students to retake tests but have a limit on the number of tests that they can make, so if a student is not succeeding in the classroom, what support system does the school provide other than this possibility of retesting so many tests, so many times?

Principal A: Uhm, we do have at some level and chemistry is one that we, that she requires that kids have a proficiency at a certain level before they go on, and with the lab safety test and some of those things. So, she actually gives tests over and over and over until the kids achieve a certain level. What we asked the teachers to do take a look at their own tests and and see if if. Teacher A who is a veteran teacher, he's been here thirty-five years, uhm, and does an excellent job in the math department, uhm. He will look at his own test, and he'll go back and look and see you know, 75\% of the kids missed number 14 why? He'll go back and look at, did I not teach it correctly, did the kids not understand it. So, he uses that to go back and reteach a lot of times, and that's great. You know, a lot of teachers are set in their ways, especially older ones. And here's one that wants to go find out what he needs to do to change to make the kids understand so he can go on. We look at reteaching and remediation, the assistant has set up We have kids that go in and they get help from an individual teachers, but we've set up tutoring, a tutoring program where we have tutoring volunteers. We make it accessible to those kids who need it and then, what we've done is parents here can actually go out and they can pay for, if they want to hire a kid to come in and work with their child, they can do that and the kid makes a little bit of money and the other child gets the help that they need. But if we have a system, if we have a child that can not afford that or a family that cannot afford that, then we use that as community service, and we're. That's one of the big things I want our kids to give back. As I told you earlier, we get a lot from the community and the community helps Orange High School a lot. And so, one of the things that we want to try to do is to teach our kids to do more to give back to the community that helps them so much. Uhm, I don't know if you noticed in the hallways last week was our canned food drive, and so, that will go to the local food pantries here. That's just ways our kids give back, but. There's other ways that our kids work and one of those, as I've said, is the volunteerism and we have a program where as we've set up the tutoring. These kids volunteer to help out and not all of them are in it for the money and some of them do it as a 
volunteer thing, where they work and try to help our kids to get them remediated and back on task.

Researcher: You mentioned the tutoring, some of which the people pay for and bring in their home. Others of which could be community service, uhm, with that. I'm going to try, how would you describe the school environment or attitude toward student achievement?

Principal A: Uhm, they want to achieve, the kids want to do well. The one thing when we took over we had. It's amazing, there was a decline in discipline and so when we took over we looked at more rigor not in education but also in discipline and make the kids more accountable and it's amazing how many kids that welcomed that change that wanted that change. Who wanted. The kids are the same way they want to do well, they want to be educated but at the same time you have some kids out there that want to take the easy pathway and they talk to their kids and we look at it and we inform the parents that we want to look at making it more rigorous and that they should take programs that are in honors or AP programs to try to strengthen those. Uhm, in the past kids have kind of dodged AP or honors, because they have a chance to change their grade where they don't get a good grade. So, you know, they may make a $\mathrm{C}$ when they need a higher grade, you know, higher average to make the AP. What we're doing is trying to educate the parents and telling them that in the long run, you know, they may make a lower grade but they're going to be better off in the long run when they take the honors classes or the AP courses.

Researcher: with the change in the state grading policy has that helped the students here at Orange High School to take the honors classes? In addition to you wanting more rigor but do they now see.

Principal A: Are you talking about leveling as far the the.

Researcher: well with the grade change being that a B for their GPA counts as an A. So, so, so a student that may be a borderline A/B student, from what I'm hearing you say, may not opt to take the AP course under the old grading scale, where an A was an A and a B was a B, but now with changing that that student may say okay, even if I falter by a point and slip to that high B it's going down as an A my GPA still shows the A so I feel better in choosing an AP course now.

Principal A: In the district, Orange High School was probably the first school that had, the grade that had the grading system where it was 93 to a 100 . We were the first one that, to adapt the higher-level. Latter on it became a district policy where it's across-the-board and it's all schools. Uhm, grade weighting is only used in the AP courses, and that helps them decide a little bit. But one of the big things that we're having trouble with here at Orange High School is we have kids that are taking the AP courses, but they're not taking the AP exam to try to get the. And I don't think it's financial cause our kids can afford it they just choose not to do that, and we're trying to instruct them and let them know that they can use that out there in college if they go to a state college that they can accept this AP course as a college-level course that may help them not financially in the long run. Uhm, but for some reason that's a stigmatism that our kids are not taking. I would like to have every kid that takes an AP course take the AP exam and they are not. We're less than half, and that's one of the things that we are looking at strengthening, is 
trying to drive them and get them to take the test and we've had actually offered and it's the same way across the state. Those kids that can't afford it we make it available to them. You know, we have funding that we can help them, and through, uhm, the AP site itself, we can look at those kids that are in need that can take it without having to make payment on that, so, uhm, the policy has helped, but still kids want to shy away from the AP courses and we tried, as we said, we are trying to educate parents and educate the kids that it's, in the importance in taking the higher level courses. Uhm, and then the state itself, you know, they have done away with the CAT9 and the CAT 10, and you're looking at more biology, more science, more math. Uhm, it has, we're getting more and more higher level kids taking more and more math but at the same time making four math credits and the science credits you need for graduation, uhm, has created more rigor in all the schools. But what's happening is, uhm, for us, and I'm sure you are seeing it too, it's the lower kids that are not quite special ed that don't meet the qualifications for special ed they are the ones that are lost. And they need the help to make it a little bit more and we're looking at ways, uhm, that we can, uhm, get them through without taking trig their senior year, uhm, and ah, you know we try to use 2510 and pull out what we can to help those lower level kids. But at the same time keep the kids that are on task and on level taking those more advanced classes.

Researcher: How would you describe the relationship between the students and the faculty here?

Principal A: Uhm, they have a good relationship. Uhm, as I said earlier, the staff here is very supportive. They do a lot of things, uhm, with the kids as far as dances, programs that are outside. You'll go to football games, you'll go to basketball games you see a lot of kids, uhm, a lot of parents, teachers their supporting the kids, and the kids actually know. It's amazing they know who the teachers are that are there supporting them and who's not. Uhm, and they're pleased to see the teachers there supporting them. And so, it creates a good relationship between the student and the teacher, and I think it makes a better quality classroom when you have that relationship where they see the staff being supportive and not, uhm. It brings about a more positive attitude in the classroom. Researcher: When you're in the classrooms are you seeing that positive attitude then? Mr. Principal: Yea, I meant uh. As I said earlier, the kids want discipline. We had, last year was the first year for myself and the new assistant principal and he brought with him a system and did a very good job with advertising it. Uhm, he came here, he was a new person, he met with every athlete in every sport, he went to every practice and told them look, here's what's coming at you here's the new discipline policy. Uhm, he had parents meetings, he met with the student government people, he met with every group out there and let them know that here's the new policy, here's what's going to happen it is as I said more rigorous. Uh, what we did was we had an after school detention that was a half-hour long and we had Saturday school that was two hours long. What we did was we tied, we created an after school detention that was two hours every evening, and when you're in that detention you are on social probation. That means, you may have a practice at seven o'clock, but if you're in detention you don't go to practice. You don't go the dances, anything extracurricular you are out of it until your detention is over with. So you know, we were tested right off the bat in that we had last year, in that we won the state in football, we had a couple kids that were All state in football and one of the All state members missed two games last year because he was on probation. Uhm, the kids see that we apply that discipline evenly and fairly across-the-board this year discipline is much easier, and we don't have quite the number of referrals, because the policy is in place. They know what's going to happen, and they accept it and they go with it. Uhm, you asked about 
fights. We had maybe three flights last year. I can't think of. I don't think we've had one flight this year. Being a seven through 12, kids walk in the hallways, the juniors and seniors kind of set the precedents for the younger kids, and they fall in line. And we don't see the programs that. The problems that you see at a lot of middle schools because of the older kids are saying, you know, guys you don't need to do that just cut it out and it's amazing our kids do a great job with that (supervising the younger kids). Uhm, in the classroom you see. I hope that you would go into any classroom and see, the classroom rules and expectations posted. You should see a grading scale posted. You should see the teachers, you know, what makes a good teacher posted in the classroom. And I hope when you are out observing you'll see that. The kids know what they can do and what they can't do, and you know, they have, they know they want to make the right choices, and we try to help them do that.

Researcher: You mention uh, uh a more seasoned faculty, so with that you mentioned come traditions. So what are some activities or traditions at this school that promote high expectations?

Principal A: We have, as I told you earlier, we have the academic investment group. It's a group of individual parents that are academic, instead of athletic boosters, they are academic boosters. They meet every nine weeks, and those kids that are on principals list, accommodations list, or honor roll list are excused on the school day and they get to go down and we have drawings that they actually receive gifts from. They raise money towards that. The, this academic group does. But they also uhm, you can also letter, and you get a certificate at the end of the school year. Just like you letter in in football or basketball or baseball, you can letter here in academics, if you make good grades throughout the year then you receive a certificate and a letter. That promotes academics here. Uhm, and we're constantly, as I said, the teachers work at trying to make their classrooms and their subjects more rigorous.

Researcher: Uhm, is there a school slogan or motto? I did see in the gym the, uhm, Alma Mater. I guess song or I'm not too couth when it comes to that but there's something about Orange High School. Is that hung their obviously out of pride? Do students know this and sing it, you know during certain assemblies?

Principal A: Uhm, every kid that comes through Orange High School has at the middle school level has music and part of that is teaching them the school fight song and the school Alma Mater. Uhm, every senior that we play it at football games we play it at basketball games. Uhm, at graduations, the senior class will sing the Alma Mater before they graduate. So it's a rich tradition and its just one, we have a lot of things that I guess is tradition. A lot of things that we take for granted that are tradition, that you don't realize, but it is part of this school's tradition that we do.

Researcher: The, I mentioned that it was displayed in the gymnasium, and obviously they're given the music or something as middle school students. Is there anywhere else such as you mentioned the teachers displaying class room rules, the grading policy? Is this part of what is posted within the classroom?, because again, you're saying taken for granted. Or, again, once they come up from the middle school they already know it so there doesn't need to be much posting. 
Principal A: There's not much posting because they get it at the middle school level. And that's the one thing that I thought about earlier. I was trying to say. Uhm, we are are. When schools like $\mathrm{Z}$ and $\mathrm{W}$ get their kids, they may have them their ninth, tenth, 11th and 12th grade years now. But being a seven through 12, we have our kids' longer periods and so we tell our teachers that, you know, we control our own destiny. A lot, we have a lot more control of our own destiny than the other schools in the district. We're the only school in the district that is seven through 12, you know, if we need to make changes and look at testing, and that's why we look at every. Each year we look at our kids and how they did on the Westest and we go over those each school year. That let's us know looking at the test how the kids did if we're if at grade level. Did we righted a large percentage of kids miss this part. Was it not taught, did we not get to it? And then at the next level the teacher understands where she starts she may have to go back and reteach some of this material. Our teachers have a lot more control their own destiny as a school than a lot of other schools when they get kids because that communication is a lot better here at this level than you have at a lot of other places.

Researcher: You mentioned, the, uhm, academic boosters every nine weeks having the drawing and etc. Do you feel that that is a effective tool that you use to promote high expectations, because again of the kids are seeing, seeing that hey if I if I bust a gut and get those grades, then hey I'm going to go down there and be part of this drawing and win this.

Principal A: Well, we evaluate and I'll let you take a look at, we still have some cause each year we do a student survey, and it's at grade level. We have six levels of student surveys that give us an idea what's happening in the classroom at that grade level, what some of their concerns are, what their expectations are, what some of our issues are. We do a parent survey which the LSIC does that let's us know what the parents are saying, you just took a tour of our high school, no matter how and it's amazing in the parent surveys you'll see, no matter how much we promote academics. You look at our school, and you look at the parent surveys, and they say in the parent surveys that we promote academics more than we do academ, or we promote athletics more than we do academics. Well after talking to parents and looking at the surveys and just standing back and looking at us as a school, if you walk in the first thing you walk into is the trophy case that has all sports things. You walk down into the new gym, you walk in you see the trophies, you see the All state pictures. So we are the academic group and the PTA are taking on projects that they want to promote academics more so when you walk into the school, not only do you see the athletics, but you now see academics. The poster outside that you took a, the large wall hanging out there that you saw that had the test dates on it, That's something new this year, but you're also going to see now if you come back. I'll hopefully have it up by the end of the year. But you'll also see the rows of pictures as you see down in the gym but you're also going to see now, uhm, the national honor society inductees and then you'll going to also see the valedictorians of the senior class. So, those are things that we're going to put up on the walls that we're going to try to promote academics too. So, as a parent walking into the school you just don't see the athletics around but you'll also see that we also promote the academics and I hope that will change the mind set of these parents that when they come in the only thing we promote is athletics when it is not and you'll see that from a lot of parents that they know what we do but those parents that just stop in from time to time, they see just the athletics they think that's all we promote and it's not. 
Researcher: Okay. How are high expectation courses such as advanced placement honors and college classes chosen to be offered?

Principal A: Uhm, with the advanced placement classes, uhh, we try to get certified teachers in that area that are willing to teach that. Uh, currently we have AP English, AP lit, uh, AP Spanish, AP French, AP art, AP history. So six AP classes. Honors classes, uh, the teachers. There's not much effort or work put into those because there is no special certification needed or special classes needed to do that. Uhm, schedule wise uhm, what we look at is again one we're looking at the senior schedules. When we block out, we know that there's certain classes that we have to stay away from that the majority of seniors may want this class. So, we tried to schedule, uhm, the AP courses away from those areas. Uhm, last year in making the scheduling, I made a mistake and I had scheduled an AP class eighth period which anyone that's in band could not take. So, you learn from year-to-year and you try to keep a mental record of what you have to schedule away from and there's certain times. Uhm, the lunches or there's core classes that the seniors have to take the English the Civics, those are things that seniors have to take so, therefore, you want to try to schedule the AP's or the honor courses away from those areas. Uhm, the we work closely with nearby college and they provide us. We're basically at their uhm. They determine by the number of kids that sign up. We offer the class, we may have enough to hold the class, or we may not, but the nearby college will determine if we have enough people and then what courses that want to teach here. We have a history class, the college history and will have a college psych. I think we're down now to the college psych, and the history class we don't offer because we didn't have enough individuals to take that. But we are close enough that when we look at the scheduling, uhm, and we've done this in the past. We've had seniors that, uhm, to be active in athletics they have to be scheduled a half a day. So we've had kids take a half day high school, half a day they go to the college, whether it be the nearby college or another college across the river. Which is, shoot you can almost throw a rock and hit the college from here. It's right there, and so those kids were able to go across the bridge or to the nearby college and pick up classes. So you know, again, that has helped them. They have got some classes that out of the way that they didn't need and a lot of times uhm, you can pick up the class here a lot more cheaply than you can being at college and paying more for so. And then we've had some individuals, uhm, that uh. A teacher's daughter, uhm, I'm not sure if he got transferred or not, but a lot of times, when College M or College B. We've got three or four colleges right here in the area that they send us student teachers. And they give credit for classes, and so sometimes that's transferable to the sibling. And so that has helped the financial aid as far as helping the sibling take a class here and there, so.

Researcher: How do you get around policy 2510 and the attendance policy if you release students at half day?

Principal A: We do it to college assigned, uhm, and, uhm, we code it that way in WVEIS. There's a code that allows you to sign kids out. Uhm, we don't do it as much. Researcher: college release is what we use. Principal A: Yea, uhm, we don't use there is another one there that $\mathrm{Z}$ and $\mathrm{W}$ uses, and it's a hardship. If you have kids that are trying to earn money for college, and they have a part-time job. Or they're doing childcare or something for the family. Uhm, it's a release that they can use and $\mathrm{Z}$ and $\mathrm{W}$ uses a lot. We don't. I have a fear that too many kids will try to take advantage of it, but it's a release that allows them to do that. Researcher: is that board 
policy then? Principal A: Uhm. Researcher: Board policy can circumvent the state policy, but there has to be a board approved policy to not keep them a full day. Principal A: Right, and there's a policy and, uhm, if you brought your laptop, and that's the one thing I don't know about the, uhm, the Hotel. I'm not sure if there're wireless or not. I do know, uhm, over by Wal-Mart there is a place there that has wireless. I don't know if you need to use your wireless or not, but you may want to check before you check in to see if they do have wireless out here to help you out if you need on. But if you go to district's web site you can look at the district policies are all there if you want to pull those up.

Researcher: Who ultimately decides what courses, uhm, to offer? Specifically, the high school courses, because you talked about the college courses that's in the hands of the nearby college in terms of numbers, but you mentioned your six AP courses.

Principal A: We try to automatically offer those, what we do is, uhm, we promote. The teachers promote, you know their classes. Uhm, then we sign up and we look up the number of people who have registered for the classes and determine if we have enough to do that. With the honors courses and AP courses, uhm, if I get. Usually I ask at least 15 in the class to have a regular class. But if we've got nine and 10, and if it's a small class like that I go ahead and allow it. And we take smaller numbers in those higher-level classes. So it works out for us that way.

Researcher: And you just said, what's the minimum number of students needed to place a course in the master schedule? Nine, 10 with the AP courses and the others at least 15. Principal A: Ya. Researcher: Uhm, if a low ability student wants to take a course, what would you do? What this question is referring to is you may have somebody that's a 2.0, a C over achiever student but yet. Let me back up, what I mean by a low ability student. Do you have criteria set for students eligible for AP?

Principal A: We have prerequisites that the kids have to take. A lot of them, it's teacher recommendation. So if the teachers know the kids and we look at recommendations but we also use test scores sometimes whether it be the Westest. Depends on the subject. Uhm, some of the higher-level math, we ask, because you, we've got, we had three kids that wanted to take algebra as an eighth-grader and so you have to score, uhm, there's a test that we give that, uhm, we look at the scores to see how will they do on that and we also look at the WESTEST scores. Uhm, but we look at testing and we take teacher recommendation. And a lot of times we've set up where we have classes that you have to take in order, and the prerequisites could be those three there: testing, teacher recommendation, and what classes they had prior to that. Researcher: so if a low ability student wants to take a course, what would you do, seek teacher recommendation in that case?

Principal A: yes, we would look at and see. Remember I told you that we have a deadline now that students have to, they have one week to determine if they want to be in this class or not. We have situations where we have borderline students that maybe in a regular class, but there're not achieving, and there's a paper that we send around. The kid wants to drop a class. What we look at is, uhm, these are the recommendations from the teacher: is a student asking for help, extra help; are they asking for questions in class; are they seeking tutoring; you know, if all of these questions are yes. If they're attending class regularly. If all these things are yes, and they're still 
failing then we allow them to drop that class without any issue. And we removed all, uhm, everything from their transcript like they've never had the class, and a lot of times we have kids that are in situations where there're an average kid. Their in a class that they just do not understand and they have trouble with it. And so, what we try to do is try to get them out of the class and into something that is would be easier for them. And they can, they can achieve, you know, pass the class.

Researcher: Now, now that student you denied.

Principal A: Yes, uhm, she had not asked for any extra help. She was actually passing the class with a D, and, uhm, what else was it. She was one of the kids that talking with the teacher, uhm, she could do the work. She just wasn't applying herself, and you know, a lot of that comes from the teacher and knowing the kid. And you know, we have some kids that I'm sorry to say that never take a book home. And I'm not sure if she's one of them or not, but those are times when, you know, they need to stay in the class and failing is part of it.

Researcher: What would the next step be when the parent comes in and starts demanding that their child be dropped?

Principal A: Well, uhm, it's our, what I did was letter home. Uhm, I sent a letter home, getting all the parents information and in that letter is a deadline and I explained to them that they missed the deadline and I'm sorry. Uhm, I've talked to my boss, who is in charge of secondary education with the district. At our next principals' meeting we are going to discuss, because I may have five days, $\mathrm{Z}$ may have two weeks, uhm, and what we're trying to do across the district is get everyone, uhm, the same. Where it's the same across the district. And I think we're going to ask if they would make, create a policy where you have so many days that you're in a class before you can drop it. Or you have enough time to drop it without any consequences.

Researcher: So with the low ability student, based upon teacher recommendation, would there ever be the possibility if the teacher's borderline to sit down with that student. In other words, I'm trying to create the grey that, that, that, that classroom teacher may well I don't really know them will it come back to it is possible then to sit down with that student and say, okay we're not really sure you now sell us on why you want to take this AP class.

Principal A, what we did this year, and the state kind of frowns on leveling. But a lot of times in creating certain classes you pretty much level. But what we did was we took. I asked the teacher if she would teach a biology course for me and it's teacher B and he/she said that what he/she would like to do was to go through. And we have, right now we have three teachers that teach biology. And, what he/she wanted to do was go through and picked the kids that were the weaker kids in science, and we looked at test scores, we looked at, and he'd/she'd had most of them in class previously. So he/she knew the kids. So he/she took, uhm, the weaker kids, he/she took the special ed kids, and we created a class, and it's more or less like a conceptual biology. We got a lower level textbook which allowed them to supply a lot easier in that classroom and so far it's going well. Uhm, in math we couldn't do it here. School W is doing it and they picked it up from Warren, Ohio. What they do is, uhm, you get half credits in math. So at the semester time you would test and see how the kid does. If they get picked up and have the grades to pass 
the class in math, then they go on. But if you fail the first two marking periods, they put you back in and they start the same class over again. And you have to keep passing to keep going in the class. They're set up a lot easier to do that then we are here. And it's been hard, they've had to re-change their schedule a few times. Uhm, you know, but it's worked. Uhm, it's working for them and they're seeing a difference in their math scores. So, uhm, here, uhm, we're when you have a year-long class they passed the two first marking periods and then District policy says if you fail the last two you automatically fail. Well than the next year they start all over again from day one. Well, they've already passed that part of it, but still that's the way the school and the district is set up. With school W, they've done that differently. You start where you left off. If you're in the middle of, you know, if you've made it through the first couple nine weeks then when you start failing that's where you start. So you have got kids at the same grade level, but they could be at different sections of the book or the unit or however they do that. So, uhm, here looking at the lower level kid. Uhm, we try to, we look at tutoring, uhm, the teachers bring in, come in and they work a lot of times with kids before school, after school. Uhm, in the middle of the day we have Channel 1, I don't know if you have that at your school or not, uhm, but it's a news program, which is about 15 minutes long. Uhm, kids are that time, when they're tuned in to channel 1, if they have a note from, uhm, say teacher A. I need to go work, I have a question about math. They can actually go to the classrooms and get some extra help there to. And then we have the tutoring with the students that we work on.

Researcher: Can that student who wants to take the AP course, just one more time, want to make sure I'm hearing. Is there a window of opportunity for them to to to take that AP course?

Principal A: Yeah, if you have a borderline student, uhm, you know, we let them know that it is much difficult but, uhm, if, with teacher recommendation they feel like they can pass the class, yea. And we've had some kids that started out in AP and not done well and we've actually moved them back into regular English to try to salvage the year for them.

Researcher: How are teachers assigned to teach these courses. Now the honors class you say you don't have honors. So the AP,

Principal A: We have some honors classes, but they're no different than other than being called honors' class. There's no leveling as far as grade or the AP courses are the classes that we look at and they have a leveling where you have an A you get five points, a B is three. Uhm, basically, uhm, just talking to the staff members, uhm, a lot of it is volunteer in that we don't assign teachers to teach, but we asked them and, uhm, they do that. Uhm, they fill out, uhm, the paperwork to do that and then the classes the district will pay for them to take the class but they don't receive compensation. So they ask to voluntarily take that during the summertime. And a lot of our teachers have done that without, you know, compensation, but the district pays for the class. It just doesn't pay them their, you know, wage over the summertime, while they're taking the class.

Researcher: But it will pay for everything while their there, right?

Principal A: Yea. 
Researcher: Room and Board and

Principal A: Yea

Researcher: Things like that much.

Principal A: Yea.

Researcher: So, the AP, your AP teachers have to go every year to the AP training or just.

Principal A: The initial, just the initial, just the initial. Uhm, and then. I'm trying, I think most of them, uhm, have contacts and made friends with other AP teachers, and the people that, that worked the AP. And they do a lot of mailing back-and-forth through the e-mail system to. And you know, I know the one English teacher she's wrote to others and asked for suggestions on some ideas that she had and some plans, and she's picked up some good information. And it's you know, it's a, it's a community that they can share some information and some knowledge, it's very helpful to do that.

Researcher: How do teachers vary instructional teaching strategies.

Principal A: Uhm, it varies. We've worked a lot with differentiated instruction. And, uhm. I'm trying to think of, right off hand a teacher and what they've done. Uhm, but teachers try to arrange their work to the level of the kid, of the individual, and sometimes that. You know, they can look at here, mentoring where you get a peer to help the student work. We've also, uhm, there's done some group work, they have done, uhm. I know that some of the SATs and some of the special ed classes we have set up where the kids has modifications that they take care of, uhm, and then I know. I'm trying to think of one right off hand, I can't. Uhm, one of the science teachers; and I think it is, uhm, she does a lot of individual work in the classroom where she will sign different levels of the subject to different kids in the class to try to get more out of them. And I'm trying to think who it is. It's not teacher C. Teacher D, you may want to check with her to see some of the skills that she uses in the classroom. So

Researcher: Okay, Uhm, how is this verified? The differentiated instruction, how do you verify?

Principal A: Uhm, The assistant and I both. When we do the walk throughs, uhm, we check through walk-throughs, we check lesson plans. Uhm, actually they turn lesson plans in on a weekly basis into the office. We have them in a file cabinet out here. Uhm, last year, it's, it's a change in policy for us. Uhm, I tried to save paper and made. I would, when I did my 5 x 5's I use to stop in and sign off on the lesson plans. Uhm, some teachers get behind in doing lesson plans and then we had issues with when you walked into the classroom if the lesson plans were not there, uhm, on your 5 x 5 you had to disrupt things or, if you were making an observation in the classroom you had to stop and have the teacher get the materials out. Now, those are kept here in the office. So, if we are doing an observation, we will pull the lesson plans and go down to classroom and see how things are going, and what techniques they are using in the classroom. 
Researcher: Where do teachers learn the best instructional strategies to use?

Principal A: Uhm, I think a lot of them, uh, through mentoring. Uh, what we've done here. I, I've, I have, I asked a lot out of my department heads. And I told you that they meet with me in the curriculum team and then they meet in their own departments. But, I've asked the department heads to, uhm, what we're trying to do this year is teacher A is a wealth of knowledge and, uhm, what I've asked the new people that, not new but they've have been here two or three years, uhm. What he's doing is, someone will cover his class which allows him to go into the classroom, observe the younger teachers, and give them some ideas of what they're doing, what they need to do. Uh, we've also asked teachers to cover for one another, where they get to leave their classroom and go watch teacher A to see what he does in his classroom. And, you know, share information there. Uh, our staff is very good at, at working together sharing information with one another and helping each other out. Uh, same way with the English department. They're making observations, uhm, they're going to cover, someone will cover teacher E's class and she will be able to go into a classroom watch the teachers teach, give them some ideas. And also, they will do the same, uh, someone will actually cover their class and allow them to come in and watch teacher $\mathrm{E}$ as she does a lesson.

Researcher: They're getting the release time to watch them. When do they then, the two individuals get to sit down and discuss?

Principal A: Uhm, like I said, our teachers are very good at giving their time. Uhm, it's nothing to walk down the hallway, uh, after school and see teachers in their room working together on different things. Uhm, we, uhm, we have a new, well we have three new English teachers. Uhm, teacher F is the youngest. She is a second year out of college and what's neat is some of our more experienced teachers, uhm, they also get knowledge from the younger teachers. They come in with the techniques and tools and you now. Uh, our, are English person in the district. You know the, the preaching to the choir is over. You've got to engage the kids more. And so that's the one thing that we look through with when we're making our five by fives is how much the kids engaged and what is the level of or depth of knowledge that is taking place in the classroom. So, uhm, you know the days stand behind the podium and lecturing are over. They have to get out, they got to move. They got to do things to keep the kid's attention and make it more interesting. And, and you now. Dr. Paine you know, he says that we, we often tune kid, turn kids off before we try to tune them in and we basically got to work on trying to get our knowledge of, of, technology at a much higher where these kids can understand. We, we're so far behind the kids it's amazing on some things, on the computers. It's amazing.

Researcher: You're absolutely right. The, uhm, when you're saying after school. It's my understanding that teachers stay until 3:45 pm. Uhm, is there verification

Principal A: on what part on of that

Researcher: well, not that. Not this staying until 3:45pm. Is there verification when the teachers, when the two teachers the senior mentor is working with the new teacher. Is there, uhm, any way to document, uh, that this is being, that this is being done? In other words, I'm 
back to that question that you're saying that they're going in and, and, and the younger teacher's are watching more senior teacher and vice versa all that's gone but if they don't have that conference time

Principal A: And, and there is no documentation. I meant, we, I've, I've not asked for any. So there's no verification on my part, uhm, and, and I've not. I don't think I need to ask the $\mathrm{k}$.You know, to provide some type of proof. I think they do a pretty good job of, of working together. So I don't, I meant I've not felt the need to ask them for any type of verification on that.

Researcher: Okay. Uhm, how do you support, nurture teachers to use varied instructional strategies? You kept saying, you know, people our age and definitely more senior are far, so far behind students in today's, uh, particularly technology use. So how are you saying okay folks, I recognize that I'm in the same boat as you are. You know, we're in that age where we're the socalled technology immigrants and the students are the natives, so...

Principal A: Uhm, the. What I have tried to plan, and have not been able to to use it was to. I came back with a lot of knowledge, technology wise, but, uh, limited time on how to get that information out to the staff. Uh, so I was really happy at the beginning of the school year, when they we did the in-service on like I said, on techsteps and acuity and and writing roadmaps and we also looked at. We went back and did some re-teaching, because we had some teachers that had trouble with uhm, uh Ed-Line and uh, gradequick and so, uh, we have teachers that have volunteered to give up their plans to go over and help a teacher that may be having trouble with Ed-Line or gradequick or something like that. And they help each other out. Uhm. Teacher G that you talked to in the one lab is very good, and she gives a lot of her time trying to help the teachers get the technology set-up where it's, where it's can be used in their classrooms. The mimeos that we just received and we received 13 mimeos. And that was through a LSIC grant. Uhm, we were able to get those out. The district purchased so many and they were given so many days of training to allow teachers to be trained. I think it was every 25 mimeos, uhm, the district received a day of in-service. So there was Title, I think it was Title II money that was used to help those teachers. We got teachers subs, they went down, I think it was at an area conference center, but everyone who had a mimeo had an opportunity to go down and be trained. And they spent the morning actually hands-on training, and then in the afternoon, uh, teachers had their own laptops, and they were able to set up some lessons, and they had individuals there that walked around and helped them if they needed assistance in any way. That was a tremendous help and, uhm, that was probably one of the workshops that we've had that the teachers seemed to get a lot more out of then some of the other ones we've had in the past. So

Researcher: was that this past summer, because

Principal A: We got the mimeos this fall, actual the mimeo training was about three weeks ago.

Researcher: Oh, that soon, okay. So I was on task, I knew it was this current...okay. So did the district provide the sub money?

Principal A: The District provided the sub money and we sent not everyone took advantage of it, but we sent, I think ten teachers total down and everyone of them came back, came back very 
positive, and even teacher A as I said you know, he's one of those he's still used to a slide rule, and he still came back and enjoyed the technology, and I'm waiting to see if it's going to be used in his classroom. But he was really impressed with some the things that they did.

Researcher: Great. If a student were asked to identify the best instructional strategy, what would he or she say; out of all the teachers?

Principal A: Long pause. Uhm, probably. I don't know, uhm, it varies. Uhm, I meant every teacher has their strengths and their weaknesses. I hear a lot from teacher A, uh with the teacher, with the kids saying that, you know, they got a lot out of his class, and he did a good job, especially with reteaching and remediation. Uh, teacher $\mathrm{H}$ is another one that spends a lot of time. Uh, with remediation in the classroom, and she is the calculus teacher, and we have I think, there's not maybe seven kids in calculus class. Uhm, so you know, it's a higher-level class but I still, it still has low numbers in it but that's something that we try to promote even if it's. We make some of the core classes, the numbers a little bit higher that gives us a chance to schedule classes that have fewer numbers in them. And, uh, she is one that the kids talk about, that really helps them and works with remediation good and she would be someone that you may want to sit down and talk with to. Her name is ....

Researcher: How does that go over with the other teachers when somebody else is pulling a load of 28, and maybe even 30 lets say, and somebody down the hall has seven?

Principal A: Uhm, the, the kids that the staff uhm, there are some, some disapprovement in the scheduling in some of the staff members. Other staff members know that it is Orange High School, and they do their best. Uhm, this year in science and in English, I knew that with some teachers that were interested in the positions and I did not necessarily want the teachers that were interested. So, I had to creatively think of ways to, as I said earlier, try to discourage them from taking the class. Uhm, the English, uh, teacher I is one and teacher $\mathrm{H}$ is another one that I made the schedule where they've taken on more preps so I could create a classroom schedule, uhm, in it's a math, science; math/science position that is kind of ugly; and an English position tha's kind of ugly. Because, I wanted the certain teachers, and they agreed to do this for one year to allow me to do that. Uhm, next year we'll go back to some old scheduling, and I call it a more pure but it will be an easier schedule where there's not as many preps. But, for one year to try to get who I wanted, I asked them and they agreed to have a rougher schedule with more preps, and you know, that's just the staff. You know, you ask them to do something and they're more than willing to step up and do it.

Researcher: Okay, now tell me the way students are recognized and rewarded at this school?

Principal A: Uhm, we have as I said, the quarterly after each nine weeks. We have a recognition where the kids are recognized and uhm. We have drawings, we have a year end assembly, where we give out awards and those include good attendance, uhm, we also look at the seniors. If you are a senior and have above 3.5 then, they call, the kids call it a senior dinner, but there's no actual dinner served, what happens is, you're allowed. You're asked to recognize a teacher that has the biggest impact on your life and uhm, we do it to the local church. They have punch, food and stuff, not food but finger some finger foods and some desserts they layout, but what happens 
is, the uhm the kids recognize a teacher. Uhm, that teacher comes over and is also invited and the kids invite the teacher in and and they have a letter that they've wrote to the teacher, and they get up and read that letter on how this teacher has made an impact on their life, and it's not necessarily high school teachers. It could be an elementary school teacher, somebody that's in education that has made an impact on their lives and they bring the teacher up. They read the letter, and then the teacher gets a iceberg like we present to the kids that they get that and we recognize them as being wonderful teachers, and it's a great ceremony that the academic investment group has started, and it's kind of become tradition now and we do it every year.

Researcher: so that's taken off the state example, where the state will have, you know, and they go to different college campuses. Shut I can't remember because I received that award once too from a student where he nominated. It's through the Governor's Honors Academy. I think it is then. As part of that your favorite educator award, I think maybe what it is and those kids you go there and I don't know if you were ever there as a principal. You know, even invited to it. It's amazing, the one that I went to was in Morgantown, many, many, well seems to me many years ago now. But, uh, yea that was the same idea, my favorite teacher, and they, you know, they and they get up and they read the letter that they composed during this thing about you. Yea, it was just absolutely so that, that is awesome. Uhm, good attendance. Is that above and beyond what the state says is faithful attendance?

Principal A: we, we do, we do perfect and faithful attendance.

Researcher: so, just like under the state guidelines. Uhm, now your teacher, teacher A was telling me, and let me reiterate with you if this is correct. That one of the recognition programs that you all have involves if a student. Here it is. The honors, no you're talking about the honors banquet. The academic recognition banquet that those that have improved .5 or better get to go.

Principal A: Get to go, yes. I let those off yes. They do. Uhm, so you have a kid that it is not on the honor role, is not on the principal's list, not on the accommodation list, but he has improved his grade-point average by .5\%, then they are invited. So

Researcher: $.5 \%$ for the whole year, per nine weeks, how long are these?

Principal A: we do it every nine weeks.

Researcher: so if somebody goes from a 2.00 to 2.5 they are recognized

Principal A: They are recognized.

Researcher: 1.0 to 1.5 ?

Principal A: Yes.

Researcher: So as long as they have increased .5, it doesn't, they could have gone from .5 to a 1.0 
Principal A: They could go from a 0 to a .5 , as long as they had made that .5 improvement we recognize them. I forgot about that, yes.

Researcher: what is the procedure for choosing students to be recognized and and I think unless there's something else out there the seniors we're looking at greater than 3.5, and then the other one it's, uhm, there is a set criteria according to teacher A but he didn't know what the actual GPA was or those who have improved .5.

Principal A: Right

Researcher: Do you know what the criteria is for just the regular GPA?

Principal A: I think it's, uh, 3.0 and above.

Researcher: 3.0 and above

Principal A: Yes

Researcher: or a .5 improvement.

Principal A: Yea.

Researcher: Okay. How often are student recognition assemblies held and where is it done? So, are you saying every quarter?

Principal A: Every quarter uhm well the first one you know you have to wait for the first quarter. So, we will have. Grades are due next week. Kids will get their first nine weeks grades next week, and then right after that I'll get a printout from uhm, WVEIS that tells who the principal's list, who's accommodations list, and with that we gather that information and send it out to the teachers and uhm grades 7, 8, 9 meet and then grades 10,11, 12 meet. And that's when we have the drawings and

Researcher: now, is this again meeting in the cafeteria?

Principal A: we actually meet in the cafeteria.

Researcher: so that's, you never go in the gym with the bleachers?

Principal A: Uhm, the very last one is. Uhm, we bring them into the gymnasium and that is done. The seniors are done when we have the senior awards assembly and then the very last day of school, uhm, we have the ceremony for everybody else. And uhm that's because we have taken up books, and there's not much. We do a final all the way up to the last day. But in that afternoon is when we have our awards assembly for the underclassmen. And so, uhm, we get the kids together and we try to time it so when we're done we don't send them back into the school we just dismiss them and let them go. So 
Researcher: so there is, there, yea that's one thing you did not show me so I gather it does not exist, an auditorium?

Principal A: Right, we don't have an auditorium. It was a cut (laughter) it was slashed.

Researcher: the last question, uh a sub question I have under this category. What awards are available for students who make progress, again to reiterate, its the if they've improved the GPA .5. No other ones exist school wide, that is?

Principal A: Right, Right.

Researcher: Or, let me ask you this. Do you have any involvement in the teachers picking a student of the month?

Principal A: No

Researcher: because it is. Okay, it's, because it's to my understanding that it's possible actually to go back to this question: what awards are available for students who make progress? That, if a teacher could nominate somebody that has made a total turnaround and etc, etc, etc and nominate that and if the faculty agree that student could possibly be recognized.

Principal A: Right. We have student of the month which we take teacher nominations and

Researcher: But, no criteria's. Do the teachers

Principal A: Yea, they just. They nominate we try to get someone nominated. And it's not always academics. It could be, uhm, volunteerism, it could be, it could be anything. I meant, what we're looking at is not necessarily academics. But something that's school related. Uhm, we have another thing that we do and the kids don't actually receive anything but recognition. And it's called the hero award and uhm the assistant tries it and that was brought here by him and he does that and, and what he tries to do is do a hero of the week. And what we do is, the art department created this Superman in a cape, and he takes the kids shots that we get from, uhm, oh I can't think of the photo company, photo company A, and he does, takes the headshot and put's it on that figure, and then tells, you know, he's the hero of the week for this reason. And that's down in the cafeteria, and it's nothing big, but it, the kids get to see their pictures up there. And, it's amaz. You know, any time you can promote things like that with the kids it's a plus. Uhm, he also does something, uhm, if kids. What he does is, uhm, those kids that are attendance wise. What he does is, he has a weekly printout from WVEIS and those kids that have not missed a lot of school. He will do a drawing each week, he pulls out five or 10 names, and he will give them a free pass that allows them to get out of class a little bit early. Or maybe they get out of one homework assignment or something. And it's a pass to help promote kids being here, and we work on attendance. For high schools we are the, of the three high schools we have the best attendance of the three schools. Last month was, I think about 94\%. So, you now, he's doing some good things to help increase that. It was at 92, and I would like to see it up to 95, and he's working towards that. 
Researcher: how was teacher perception of particular the homework pass?

Principal A: Uhm, he talked to the staff and he, the assistant is good. He promotes everything and gets everyone on board before we take action on anything. And he's really good at that. Uhm, like I said, when he first came in with the discipline. He met with the football team. He met with the cross-country team. He met with every sports organization. He met with the athletic boosters. He met with the band boosters. He came. He introduced himself. Here's the new policy. This is how it's going to affect your kid. This is why we're doing it and he did a great job with it. And so, he's taken that, he's taken action like that with all of the groups. Where he's, when he has something he wants to try he promotes it first, gets everyone's approval and gets everyone on board and then we take action on that.

Researcher: How is communication within the teachers related to instruction and instructional activities?

Principal A: Uhm, a couple things we do. The assistant does the SAT teams a little differently. When we have a SAT meeting on a student, he will actually bring in the parents, and try to get as many teachers as he can to be at the meetings, and these meetings are held after school. And I've had teachers here at 4:30 or 5:00 and they volunteer to give up their time. And he does a good job with that, uhm, the other things we do besides the curriculum team and uhm. The department, the department teams, what we have are, you know what we try to look at vertical and horizontal. Some teaming and we have six teams where uhm the staff gets together. And, uhm, we try to get them at grade level. And you've got people assigned to each team, and we try to get them to meet at least once a month. And that we've asked the teachers to give up a lot of their time, but when they get together they're to discuss what's working in the classroom, what's not. Since they are at grade level, they share the same kids, and so, we ask them to discuss uhm students. You know, where, if you have a child that you're seeing a drop-off in grades. You know, try to talk among each other to find out. Do you know something that reasons why he has kind of dropped off the face of the earth or why his attendance has dropped off for some reason. And so, that's just one more method that we try to get out there that the staff uses to try to get some interaction with the students where we get some feedback. And I've got them here, I've got some notes, and they've actually made referrals to the SAT team. From the group getting together and saying we're noticing this as a group out of this child. And we may want to look at starting the testing process or starting the referral process there. So it's, its we've had them in on, I'm trying to think what group it was they made a team conference call and talked to a parent about a child and some of the problems the child is having and everyone was at the meeting. And everyone was able to discuss what's going on, what's happening with this child. So those are two ways that you know, not just vertical teams but horizontal teams we look at.

Researcher: now when you're looking at the, teaming. If you have a particular math. How would we know, if you're going to meet with all 10th graders teachers. How would we know which math teacher, or as long as you service.

Principal A: We have 
Researcher: because I can understand your seventh and eighth grade

Principal A: and, and not only and we do have some English. We, there's some teams that we can have to gather that they may not have the student in class. But somebody in that group will, and that's one of the things they talk about is: you know, the student how can they improve instruction? What's working, what's not working.

Researcher: Okay. What's your involvement with teachers during this time. So with these vertical and horizontal uhm meetings. Do you meet with them or

Principal A: I meet with the department chairs, as I said in curriculum teams. The assistant and I. We want to set in on at least one department meeting that they're having s we can one, ask questions or two, you know, provide some feedback or assistance. Uhm, we won't make every team meeting. But we do want to get out there and be in departments when they meet. The other ones, uhm, all of them provide feedback and information back to me, and that's part of my; one of my goals for my portfolio is the teams and they provide. I do a checklist, but they provide notes of what they discussed, what they talked about. Researcher: so like the minutes. Principal A: Yea, of the meetings, and then curriculum team minutes and agendas. I also keep, and that's what I turn in as my documentation of having met with the staff and what we have done. So, if you want to take a look at those you are more than welcome to leaf through those.

Researcher: the one thing you haven't talked about yet, is that there is no common plan correct because of

Principal A: because of the scheduling, we would love to have a common plan uhm and with our schedule the way that it is there is no way. Where is scheduling? Where is the scheduling on the questions, where is that?

Researcher: It's not.

Principal A: It's not. Can I tell you a little bit about scheduling?

Researcher: Yes.

Principal A: Okay. What we look at when we do scheduling is, as I said, our schedule is driven by the middle school seventh and eighth graders. Uhm, because there's no electives. You have your double block of English, you have your math, your science and your social studies, so that's seven periods. And then we offer three groups of cluster classes. Uhm, two groups of clusters have classes that are required by 2510 . The third one is a cluster that has what I call disposable classes or non-required courses and, uhm, during that time a child has a choice between band, choir, strings and/or gifted. So those kids that are not in band, choir gifted, uhm, or strings are placed in a cluster and and in this cluster class. It's a 9 week class and a lot of what we do is remediation. Uhm, they have, uhm, they have additional math class that we do, they have, it could be uhm additional reading class, that has an additional writing class, where they learn to write a little bit. Uhm, the reading it's not necessarily for grades. I based it on kind of what the kids do with DEAR at the elementary level where it's drop everything and read. Uhm, it's the 
teacher's way of trying to promote books and make reading a little fun to try to get kids to read more. The math, it's an accelerated math program, that they work at their own pace and to the get scores in the class it is based upon how many units that you complete, not what you got on the test or how you do it. But on the units that you complete. So those are things that we do at the seventh and eighth grade level. Now because of our location in the district. There are certain things I have to do with the schedule. Uhm, I try to get the seventh and eighth grades scheduled and then I go through and start looking at the schedules and I try, as I said before, try to place the AP, honors courses, where the kids can get to those without giving up a credit or in a something in a core class that they need. The other thing I have to look at for juniors and seniors. I have to schedule core classes, both morning and afternoon, because we can have a vocational student that is gone in the morning. So we try to offer what we can for those students in the afternoon. Well once I get all that looked at. We also look at, I try to plan have teachers plans, where every period I have at least two teachers that are planned. That way, uhm last week we had five teachers out. We had four subs, and so I went to the staff and those individuals I went through and said, hey look can you cover this class, and I provided teacher coverage throughout the day, and then they are compensated through salary for them covering those classes. If I ask them to cover a class, I reimburse them. If they and we're good at letting the teachers off, if you've got a doctors appointment at 2:30 pm, and you've got one class. I don't make you take a whole halfday of school to do that. I say look, you find someone to cover your class and go ahead and take/do your appointment. And, so that allows them to save days, and then also they worked together on. You know, if I cover your class this time somewhere down the road I may need you to cover my class. And so, they just work that out between them. If I asked them to cover a class I compensate them. But, you know, making sure that I've got people covered throughout the day with enough plans is one of the things I need to look at, because of our location in the district a lot of people don't want to come North this far up to sub. So sometimes we don't have enough coverage sub wise. So we have to do things like that. Uhm, the other thing that we look at is, uh, the lunch times. I've got to evenly make sure that the lunches are divided up where you have an overlap. Classes are 45 minutes, lunches are a half hour. So, there's an overlap there some of about 15 minutes. I've got to make sure I have teachers prepared for kids coming back from lunch. So, there's a lot that goes into the scheduling besides just trying to keep classes apart. And that's what I'm trying to get to you with plans I can't. I would love to be able to have all the English have all the same plan or the math, but because we are seven through 12, uhm, there's not a lot of teachers that teach a pure grade level subject. They are spread out. You may have middle school classes, you may have some high school classes, and there's a mixture of it by the time you add to three different lunches in there it's really hard. Well, it's impossible to try to have a common plan time.

Researcher: what I'm amazed at is you have six AP courses, eight periods. When you're saying you don't want them to miss a core class then somewhere. There's still got to be a decision the child has to make.

Principal A: Yea, there is.

Researcher: I just don't see how out of eight periods, so I mean somewhere you're going to have English 12 at a time of an AP class. 
Principal A: A, there's going to be times when uhm.

Researcher: Because, again, at a school your size you can't have English 12 eight periods a day.

Principal A: Exactly, exactly. So those are the issues that we have and try to work around. You try to eliminate as many problems like that. And then. Besides the AP courses, there are singletons. The, the uh calculus class. The, uh, (Researcher said physics) physics. The, uh (Researcher said Art III), Art III, the Anatomy and Human. You know, these are all single classes that we try to look at and we say a lot of times a kid that wants calculus he will probably want AP English. He probably won't want AP Art or he might not necessarily want AP Spanish. So, that's how we try to separate them out a little bit. And it's a process. And it takes a while and, and you know there's a learning curve. Sometimes we make mistakes and we have to go back in and change some things. But, all in all, uhm, the one thing that the staff knows, they are not always happy about, but I do what's best for the kids first. And then try to make the teachers happy and uhm, some teachers they don't care when their plans are some teachers they want it in the afternoon. Uhm, we got a couple of coaches that would like to have it $8^{\text {th }}$ period so they can go prepare to get ready, and I, what I can, I do what I can do accommodate. You know the ones I can but some there's no way I'm going to be able to accommodate.

Researcher: describe how you assist teachers in meeting the needs of all students?

Principal A: A long pause. Basically, the biggest thing I do to help teachers meet the needs of the students, is going back to the scheduling, is the scheduling. Uhm, like I said we do what's best, what we think is for the kids. Uh, and we try to help them out as much as we can there with the scheduling. Uhm, we try to be very supportive and try to uh get what the teachers need. Uh, for their classrooms. The mimeos we just received as I've said. You saw faculty senate, we ordered textbooks, we ordered additional reading books. Uhm, we try to get what the teachers want or need to teach the class. And then, we're very supportive in the classroom discipline. We ask that the staff takes an active part in the student's discipline. But as you heard the assistant say earlier, we are not there to punish the kids, we are there to change their behavior. Uhm, what we want is to empower the teacher. We have a lot of teachers that the first time there's trouble they want to send the kids out. And, and to me that basically strips the teacher. They strip themselves of all the power in the classroom. And I want them to be empowered in the classroom. And, we're, the students know that they're, the teacher is in charge. And we try to support them as much as we can. And we've been very supportive of discipline. It is fair, it's swift and it's fair. As I said before, the referrals, I believe that referrals themselves are down. The kids are, yea you know, its funning the the kids now have a saying. You know, we will, there will be a call to the classroom the teacher will answer the phone. And they'll say, Johnny the assistant principal wants to see you and the term now is "you've been buffed." Meaning that you've got your discipline from the assistant principal. So, uhm, I think we are very supportive in that manner. Uhm, that's all I can think of right now.

Researcher: During an observation you identify any student or students off task. How is the identified student doing in the teacher's class and how does he or she address the student's needs? 
Principal A: So if you're saying, if we are making an observation, we see a student off task. Uhm, in the meeting afterwards we'll sit down with that teacher and ask them "do you realize that John may be off task?"

\section{Researcher: Correct}

Principal A: We will make them aware of the situation sometimes they may not be aware of the situation, but if they are we talk about what's being done for the student. What do you need help with. Is there anything we can do to help you out. Uhm, and we try to offer some suggestions uhm you know, if we see, one of our math teachers. You won't meet her, she's on pregnancy leave. Very good teacher when it comes to instruction. But she's weak on discipline. Uhm, she'll be teaching and she will be working with a group of kids and and she'll have a group of kids over here that are off task and not working. And instead of keeping a watchful eye on all the classroom. She's got her focus here and that allows them to kind of screw around. We give her some suggestions to try to get to help her get all the kids back on task. And, and that could be some instructional strategies, or, you know, it's just making her aware of the situation. Did you know this was going on in the back of the classroom. And we help them out that way.

Researcher: When you brought that to her attention did she know or suggest to you ways that she would work on (Principal A: we offer) not allowing those kids to be off task?

Principal A: yeah, Uhm, and she's a quiet person and she's just one that we have to continually will have to work on and she will be a good teacher and she does some great things instructional wise in the classroom. She was one of the first ones in the building to use the Smart Board with her, in her classroom lessons and she does a lot technology wise but again she's weak in, in discipline and keeping kids on task and so we try to work with her not only us but we also, those are things that we refer back to her mentor or to the department head to say you know can you help them out. They're having some issues you know, with, it could be one child that they're having issues with.

Researcher: is that child then when you have the post conference, uh, with that teacher does the child's academics success or lack of become part of that identification process, uhm, did you know Johnny was over there, uh, doodling, making eyes at so-and-so and then that teacher may say, well Johnny always does that he has a $20 \%$ average there's no way that he's ever going to pass, so I allow him to do that. Are discussions such as that ever real?

Principal A: yea, we discuss you know how, how successful is the kid in the classroom. And no, were you having success with to get him to do to get Johnny to do something and where you having weaknesses at and those are some things that we talked to them about and try to and we may suggest other ways and that's where a lot of time you're Uhm, different teaching styles may come into play to try to give them some ideas and uhm, hopefully that would be something that again I don't require notes from the one teams but that would be something in your team meeting that you meet with the other teachers that you know I'm having a lot of trouble with Johnny, you know, what can I do to. What are you having success with in your classroom? And that could be something you know then it comes out that well I'm having trouble with him to or so-and-so is having trouble. So hopefully it gives us the method to identify Johnny's having trouble in a lot 
of classes and this is maybe something that maybe we need to make a referral to the SAT team, so.

Researcher: how often are students being monitored for comprehension as you go through lesson plans and observations?

Principal A: Uhm, from us as administrators?

Researcher: no this goes back to uhm the teachers testing for comprehension but then your role as, you know, do you see this being done? Your verification of testing for comprehension.

Principal A: Uhm, with acuity we do the quarterly assessments. Uhm, and uhm, I, I look at it as our method on on keeping track, uhm of a student. If you get on the plane and you want to go to Europe or you want to go to England. You get on a plane you start your flight you have a flight plan, and you're constantly looking at the gauges to see how far you've gone or where you're at, and with with staff I've explained to them that your flight plan is your pacing guide and your instruments are the quarterly assessments and that allows you to look and see where you're at and where you're supposed to be. And it gives you a destination. Uh, you don't get on a airplane and point your plane east and start flying you don't open up a textbook and start with chapter 1 and take off and just go. You have to have a plan and we use our pacing guides. Uhm, and that's what we try to give a point across to the staff is you either plan of attack, you use the quarterly assessments, but you also look at your assessments. As I said earlier, if you got a concept, if you're looking at the WESTEST and all your kids did not, we look at the goals and the test question and what it's attached to as far as the CSOs. Why did all your students have trouble with that? Is it something that you had not gotten to in the classroom? is that one that they didn't get it? Is it a concept that you've taught and you may have not done a very good job teaching. Why did they not achieve or why did everybody have so much trouble with this one question on the test? So we look at as I said the WESTEST, we look at the quarterly assessments and then as you're testing in the classroom and teacher A does a real good job with that he looks at his tests and he goes back and if every kid in his classroom in trig misses number 17 then he's not vain enough to think well, you know, the kids are all stupid. I've not done something where they understand it. He'll go back and reteach that and remediate it so they do get that understanding. With the WESTEST, that allows us to look at and see where teachers the previous year may have touched in an area that or didn't touch in an area that I need to touch on before I go too far in the math book. Uh, and we look at all of those as measurements to see how we're doing with the students and see how the students are doing themselves.

Researcher: Is there any, again based upon your five by fives, is there any in, or uhm, formative assessment going on?

Principal A: no. Other then, not anything in particular other then the classroom assessments and the quarterly assessments that they do.

Researcher: how are you involved in providing techniques used for student monitoring? So, from what you said before, let me get a little more specific with that; what has your role been in training the faculty in the use of acuity? 
Principal A: Uhm, we had we talked about acuity was introduced a little bit last year. This year the District it was a part of the things we worked on before students arrived. The in-service, and what we do as a District is, uh, we, I picked four teachers from Orange high school. They went to training over the summertime they were given pay in the summertime and they become instructional leaders. Uhm, those instructional leaders after they are trained or sent back to their schools and they become instructional leaders at the school, teaching or providing them information and the four ladies that we had did a great job on telling us about acuity, about the WESTEST, about the writing assessments and they went back in and worked on, as I said the Ed-Line and uhm, gradequick. So, uhm, we were fortunate enough to be able to use those instructional leaders and they came back very positive and what I tried to do was take not necessarily brand-new teachers but new teachers to the school and pair them up with a veteran teacher one to help build that camaraderie that they have, uhm, but uhm that could be a veteran teacher that may need additional help in technology, and a younger teacher coming in may have some knowledge that they can provide that veteran teacher to help them out a little bit.

Researcher: during an observation it was noted that a low achieving student was asked a question and when he or she did not respond no additional probes were given by the teacher. What's happening to get low achieving students to be actively engaged in in answering questions?

Principal A: last year we asked the staff to do bell ringers, and we have them when they go over those bell ringers to try to get input from students and the biggest thing that I tell the staff that you know in the inquisitive child there's nothing wrong with asking questions. And we had uhm in our observations and are five by fives we see things that the teachers do and will talk with them afterwards and say, now look you may want to rephrase that. We had a math teacher that the assistant was talking about it. He set in the class and uhm, she was beginning starting to do something in the class, I forget what he said it was, but the teacher says we're going to start this in class. There was a kid in the back that said I know I know I can show you, and she said you don't know that yet I haven't taught it to you. So, automatically now she's turned that student off. A lot of times we say and do things that we're not aware of. When we have those five by fives and those observations, again that's feedback that we provide the staff. You know sometimes even the good teachers may say something now and again that may turn a student off that you know you need to rephrase, or you need to put that a different way. You need to know you kind of crushed the kid in the back when he thought he was, he knew the concept already and could help. Instead of using him to try to bring forth a class discussion you know you pretty much crushed him and so that's the use of a 5 x 5 or an observation, it's good feedback to the teachers.

Researcher: you have mentioned the five by fives several times now and I haven't an and it just dawned on me now to ask you this question how often are you doing a 5 x 5 walk-throughs?

Principal A: Uhm, we try to get into five classrooms a week, uhm, sometimes there's more sometimes there's less. Researcher: which is the term $5 \times 5$. Principal A: yea, five minutes Researcher five classrooms a week. Principal A: Yea. Researcher: Okay. 
Researcher: Both of you doing 5 a week, so that's 10 classrooms a week that an administrators in. And then naturally with that you're saying there's the follow-up with the teacher.

Principal A: yes, sometimes there's follow-up sometimes there's not. With us the five by fives, we try to go in and try to be as least obstructive as possible. We want to walk-in walk through the classroom and we don't want the teacher to stop talking, to stop whatever she's doing, we want to be able to walk-in, walk around get the jive of the classroom the feeling of the classroom see what's happening and be able to walk out and not cause a disturbance. Uhm, and that's hard a lot of times cause the kids know you, you know, they may want to ask you something about and you want to be able to go in again that's why we have them turn the lesson plans in at the beginning of the week so we can walk-in and see what's going on in the class see if it matches what's in the lesson plans and that way not disrupt what's going on or disrupt the teacher while she's in the middle of a lesson or disrupt a student while they're doing something, could be at the board or a PowerPoint presentation we want to come in walk around walk-through and back out.

Researcher: What professional development activities are planned for the school year?

Principal A: Uhm that will come from the District. Uhm, we just sent in a item on what we would like to do professional development wise. Uhm, Dr. B I don't know if you know him/her or not, uhm, he/she will develop, uhm, what we need to do, uh, he/she wanted input from us and I would like to have more time or additional time to go over uhm, we'll have our ACT plan and explore results back in February so we will know how our kids did uhm we had a gentleman from the State Department come up and we asked he came in and talked with the kids and told them the importance of the test. Uhm, we've got him scheduled to come back and one, talk to the kids, interpret the data with the students but also we have him set up in the evenings where parents come in and talk about their child's test data. But then we need to look at that data and see how our kids did and I was hoping to use one of those instructional days to be able to look at that data to see how we did. And what we could do or what I did is our staff has I'm trying to improve some of those test results.

Researcher: Okay. Uhm, how is professional development decided? I understand you're saying that the District office is the person responsible for it, but you also said you sent stuff in so is there a local committee? How did you get the ideas from your school to send to the District Office?

Principal A: Uhm, they. We got an e-mail this past fall that asked what we want to do to continue on what we thought would be good. Uh, we have a staff development council that gets together and and comes up with concepts that, or they look at things that they would like to see the direction the District would like to go in. And, uhm, they take referrals from administration on things. They get together vote and then they determine on determine what they want to do in the summertime uh in developing instructional leaders, how they're going to train them, how they're going to get that information back to the schools. So it's something that in the spring they'll get together, uh, the Council will get together and develop concepts that will be used for the next school year.

Researcher: so it's only input from administrators? 
Principal A: Uhm, they it's made up of administrators and teachers, the Council is. And, uh, the majority of those are teachers. They come in and uhm they bring recommendations. It could be from faculty Senate, from LSIC, could be also, uhm. It could be groups, I meant the teacher's allowed to bring anything they want to the table as far as

Researcher: so is the Council these teachers is it evenly dispersed between the three high, between, I guess it would be all the schools in the district correct?

Principal A: actually, uhm, I'm trying to think of how, I know there's about 20 on there. I'm not sure that every, I think every school is represented.

Researcher: Is Orange High School represented?

Principal A: Orange High School is represented, that person would be teacher $\mathbf{J}$

Researcher: Is that your faculty Senate chair?

Principal A: No, she is uhm she is on the staff development Council, she is was president of the LSIC last year. So....

Researcher: Okay. Which professional development activities will you have that best promote teachers having high expectations and I guess again in the district we're not saying necessarily you, what has the Council planned that's going to promote high expectations?

Principal A: Uhm, this is what they have put together and this is. We nicknamed it B's Bible, and he/she calls it his/her little white book. But those are some things that we have discussed and talked about the last few years that each school has, uhm, and we have done. Some uhm. We've had in-service on all those materials that you see there in the book, and each year that book's changed a little bit. But it is uhm, again we call it B's Bible, but it's things that we can use: instructional strategies, it could be a lot of different things that we use. Dr. B is the one that's in charge of curriculum and he/she develops a lot of those and he/she uses the Council to help him/her develop ideas and methods that he/she wants to use the next year. And I'll make you a copy of that or I'll call and see if the assistant has a copy an extra copy.

Researcher: are Uhm, but only you and the assistant have this?

Principal A: no every teacher gets a copy.

Researcher: Oh, every teacher gets a copy of that.

Principal A: Yes.

Researcher: And this is what they, this is overwhelming, lets see. Are they, based upon your $5 \mathrm{x}$ 5 's, lets go back to that, are you looking at if their using any of these? 
Principal A: He/she does not want us to walk into a classroom and say. At one time she wanted us to go through and ask who's doing the fantastic four-which is: vocabulary, content graphic organizers, collaborative pairs or summarizing. She wanted an actual, almost like a tally of how many teachers are using it and how many are not. That caused disruption because we had to interrupt the teacher on our five by fives. What he/she wants from us now is at the end of this nine weeks. The assistant and I will take turns. We will dicuss some of the ideas some of the concepts that are being used in the classroom. We have to document that, not necessarily say a teacher was witnessed doing this on such a such date, but he/she wants us to put down what we've witness what we've seen. We send that into him/her and he/she gets that from every school.

Researcher: Do you know what he/she does with that then?

Principal A: He/she correlates that and he/she gets that back to us. We just had a tally of that Researcher: So he/she tallies it.

Principal A: Yea, and gets that back as far as what we've seen and the different, at different levels and not just our high school but the elementary schools

Researcher: And his/her directive then would be? We need to try to increase differentiated instruction, I mean, I'm just wondering why would he/she take the time to tally all that, for what purpose?

Principal A: You'll have to pardon my mess, uhm he/she wants feedback to see what we taught over the summertime how it's been used in the school setting.

Researcher: Again, would that idea then be if it's not being... twofold: if it's not being used in the school setting either, A we need to offer additional workshops, or B abandon it?

Principal A: Yes. And how is what this is on. And I'm sure he/she uses this along with how each school is doing. Can he/she make a tie between if the school-how well the school is succeeding and what methods they are using in the classroom that they're getting

Researcher: So there's more teeth to this. So what's he/she is going to do is go to a

Principal A: He/she has never stated to us the purpose but I'm sure that's what he/she is using it for, is looking and seeying you know what techniques are they using at their school that's making their test results become that much higher

Researcher: Or vice-versa.

Principal A: Or Vice-versa.

Researcher: Or if it's a struggling school is there a lack of these instructional practices that research has shown to be effective. And you probably don't know anything of that because your 
school isn't in that way so it's an unfair question to ask does he/she then come out and maybe meet with that principal and see.

Principal A: He/she has not and I've not seen him/her here meeting with. He's/She's not been here with me or previous administrators. So, either we're doing something right or you know were lucky I don't know.

Researcher: Okay, okay. When do follow-up activities and discussions occur that reinforce high expectations?

Principal A: uhm, we have monthly I meant

Researcher: In your curriculum meetings.

Principal A: in our curriculum meetings we talk about it but also uhm administrators have their monthly meetings where we will have we have book readings that we have to do and I don't know if I brought my book here my book's at the house. Uhm, each month you're given a chapter and you are to do readings from this book. We get together and talk about that we talk about things in our school. A lot of times Dr. B's there and he's/she's asking how, what's being used in your classroom, how things are going. But, it also allows us to get together and talk to each other and see what's being used. You know, being used at the school, what their having success with and what they're not. And, uhm as I said, principal B at school Z with the math program. I knew about the math program, we sent some teachers over to Warren to try to get that math program here but it was a program that was never going to be we could never use because the way the scheduling is set.

Researcher: When do you then. Okay, we've talked about at the principals' monthly meeting, you do it also at the curriculum meeting and then is it then expected that your department heads that are in the curriculum team will go out and talk about that in their departments?

Principal A: we don't assign it, but I hope that they would discuss it and

Researcher: Because what I'm gathering is you yourself aren't out at like faculty Senate, or uhm, you attend or the assistant attends a department meeting. You for say aren't preaching, uhm, that material you're expecting. As you say it's not an assignment but you're hoping when the department chair goes back they will discuss this area with their folks, okay.

Researcher: How would data, because you talked about the ACT plan and of course in your case both Plan and Explore, and WESTEST data. How will the data be collected to show whether the professional development activity augments high expectations? Now actually I started off on that wrong thing. This would be data, not acuity, but what type of data? Your gauges now what are you looking at that's going to verify high expectations are not within the classroom?

Principal A: Uhm, we have a variety of tests that we look at. And it's not just the Westest and it's not just a PLAN or EXPLORE but we look at and see how our kids do on the SAT and ACT. Uhm, the NAEP test we look at because again it's not a standardized test for West Virginia, it's a 
national test where uhm our kids are compared with other kids across the nation. So it's a good tool for us. To see how we compare with other students. Uhm, we have the, there's a variety of tests that we do and being that we are seven through 12 there is a number of the Golden horseshoe the PSAT. Uhm, we have a variety of tests. But, for the classroom teacher the Westest seems to be the measuring stick and then the quarterly assessments that they do with acuity. Because those are gauges of especially acuity, it's the gauge to let you know how you're proceeding and where you're at in your proceedings. The one thing that I think that's wild is, you have the test questions, the teacher can go on get to test questions and basically you can teach the test. And the same practice test that you can take leading up to the date that you do the acuity they don't change the questions. It's the same questions. So I'm interested in seeing how some of the schools do if they truly if if they've used the pre-test and and actually see how well their kids do, or if they actually teach the test to them to make themselves look good. And that's going to be a question I'm going to have. Uhm, we recommend it's mandatory that our math and English do it, but we also suggest highly that the science and the social studies departments do theirs to. Uhm, but again, we look at all the data and see we're constantly comparing how we do against other schools in the district or other schools in the state, or other counties in the state, and then the tests that are national tests we look to see how we compare to other students across the nation.

Researcher: so if we tie that back to professional development piece and Dr. B. So the reason that you. Well two reasons: you think you may be lucky, but at the same time if your test scores are okay then Dr. B at her seat, and you at your seat are saying then, the Bible your staff must be utilizing something within there. You know, a mixture or one thing that seems to be working, because the students' achievement. Those high expectations are set. So if it ain't broke don't fix it.

Principal A: Right, right. Uhm, and and we're constantly looking at techniques. Dr. B's constantly bringing things in, and just because our scores have been high doesn't mean that we can't make them better with some new techniques. So you know he's/she's constantly striving that if we're good to make us better if we're, you know, if we're poor to make us better, if we're better to make us great so

Researcher: So, he's/she's not happy with just platueing?

Principal A: No

Researcher: There's always improvement to be made.

Principal A: there should always be improvement and when we look at setting goals not only and with the LSIC, but uhm, I trying to think of what we just did. I had to turn in to the District or into the state. We just did something for the state and we're constantly looking at improvement and some times we've taken a step back we've not improved and we have high standards that we've developed, uhm, trying to figure out how much we're going to improve this year and we've set I guess times and and we've set standards that we have to reach and we've not always met those standards and basically education is constantly evolving. Your, we've lost good teachers, we've picked up good teachers and basically you try to have them work together 
see what they're using in their classroom that's working and try to get the other teachers to try to use and just because it's working in teacher B's room may not work in teacher E's room. So we're constantly striving to find methods that we can deliver the lesson that helps the kid achieve the best.

Researcher: okay

Principal A: Achieve the most.

Researcher: Some say National Board Certification for teachers is important to increase student achievement in schools, what is your belief on National Board Certification?

Principal A: Uhm, it's hard, it's a process that the teachers do. Uhm, the teachers that do the national board certification, uhm, are good teachers, I think it makes them better teachers. Uhm, there's techniques and things that they have to do and projects that, uhm, they learn that they have to do to make Board certification that they would not normally use in the regular classroom and from talking to them it's tough and they get a lot out of it uhm, and a lot of times those are the teachers that I go to, uhm, not because they're board-certified but because they have a wealth of knowledge that, uhm, the new teacher or the novice teacher coming in would not have. And so, uhm, it's a resource that you can go to and it's nice having the number that we have had in the past and have now, but again National Board certified teacher's a resource that you can use in the school and that's what we use them for, it's, you know, it's another resource that we can talk to the that can mentors or they just about, not everyone of them, just about every national Board certified teacher was also one time a department chair. So it seems like those teachers are also the go-getters and just because a teacher doesn't go after their national boards doesn't mean that they're not good teachers also. We also have teachers that put in a tremendous amount of work and effort in the classroom, uhm, and they're constantly improving their methods of instruction but also, uhm, they're constantly improving students.

Researcher: Okay. How has having a teacher who is Nationally Board Certified promoted or enhanced high expectations in the school? Because you've talked about using them as a resource, how does that..

Principal A: as far as recognition, uh, in the district at the district level here we have a dinner and those individuals that achieve, uh, are national Board certified car are recognized at this dinner and am the press release is given that indicates that they have passed their boards and then there's the pay raise that goes with that as far as recognition here at the school level, I don't think there's a lot of teachers, the staff here doesn't, the ones that have it don't flaunt it to where, you know, I'm board-certified and you're not. Uhm, but those are the ones that, as I said, if I need a person to go to, those are the ones that in the past have been department chairs they been they have been the instructional leaders here at the school and so

Researcher: so do you think, as the go-getters and the instructional leaders two terms you just used, that helps not that they're flaunting it, but that it helps bring everybody on board to raise and promote high expectations? 
Principal A: I think in their departments yes. I think it, it by having them on board helps you know, if they're in charge of the department, you know, in their departmental meetings I think they bring forth techniques that help the other teachers and make them better also.

Researcher: cause didn't during the faculty Senate meeting one of you two mentioned that there may be a little competition going on, I mean positively in terms of, of, in terms of keeping kids on task or something about academics. I thought that I heard today during today's faculty Senate meeting, and it may have been the assistant that was saying something there I don't necessarily want to say competition but just that you all seem to be working together to raise achievement. I can't remember, all I'm saying is doesn't this go along with those nationally board certified teachers that they're helping lead the pack.

Principal A: Right, right. And you know if you look at our staff, uhm, we have, I haven't looked at the latest ones because we've changed over so many staff members. But, at one time we had more teachers that were at the Masters level than at +15 or +30 so even those teachers, because of them furthering their education, has, has made them better teachers and in turn made our staff stronger. So it's not just Board certification it's also regular certification. I meant, to me you getting your doctorate is going to make your school much better, you'll be a much better instructional leader at your school because of your doctorate.

Researcher: Just closing thoughts on this question: what leadership role does the national Board certified teacher serve and what I'm saying closing thoughts is your stressing again that is your go to person and your instructional leader. Is there anything else in terms of their leadership role, uhm, you know, in terms of helping in helping you? To me that says enough there, that's your go to person that you use.

Principal A: Nothing else I can think of right off hand. Uhm, I mean I told you that you were in for a good faculty Senate meeting and and it was a little bit different and there was not a lot of bickering back and forth,uhm, but you, I hope you saw in that meeting the camaraderie that we have that, you know, we can throw barbs back and forth at each other and not feel offended and not be hurt, uhm, the staff as a whole, it is a great staff to work with and, you know, those individuals that have their masters or are the national board certified people, those are additions that we have on staff that are blessings to me in that they, as I said, they are my go to people if I need something I go to them, uhm, they're a wealth of knowledge, uhm, you know not only we have, I have talked to them and said you know we've got a new English teacher and she needs help and they come on board and they've actually as I've said taken time observed her in the classrooms. We had an English teacher last year that we put on an improvement plan, and she wanted an improvement team to develop her improvement plan, and, uh, we had two English teachers and they were both nationally Board certified. I meant you couldn't ask for better qualified teachers and you know the teacher was upset because we put her on an improvement plan and she picked the team when we could have said I, we don't want that I want someone else, we agreed who is going to be on that team just because of who they were and how good they are. And, I think it made that teacher a better teacher. So you know having again having board certified teachers is a blessing for us but it is also, uh, I think it's a blessing for the staff because they help each other out a lot. 
Researcher: we are at the finish line we talked about the ways principle teachers contribute to high expectations of their other aspects within a school or district that you would like to discuss related to high expectations? And of course this would've been I guess we could of waited here to talk about the scheduling but you've already talked about that.

Principal A: Uhm, this week, I meant we use teams a lot, uhm, for not having a true teams concept here where we have a designated planned time to be able to pull that off we do a lot with teams and, uh, at all levels, I meant as an administrator I'm part of an administration teams that meet. I come back and meet with my department chairs and that's another level, and then department chairs they go back to the department have their departmental meetings. Uhm, I meet with the LSIC team and we do a survey, interest survey, we do the discipline survey that the state has required now, uhm, we do that with parents and we have input from parents. Uhm, I do weekly meetings and Wednesday is let's see, the 28th I have a seventh graders. I meet with, I take the team leaders of each grade level your, class officers, your class representatives, and each week I meet with a different grade level and I'll bring them in and sit them down and this will be the first meeting for the seventh graders so they're going be, it's going to be like pulling teeth with them but I will sit down with them and chat with them and say what's working for you, what's happening with you guys, what are you upset with, what changes would you like to see, what do we need to do and I get feedback from the students on any how we are doing as educators, or as administration, but how's the teacher doing in the classroom and it's amazing some of the teachers that I have identified as being weak teachers and we need to work on improving, we also get that from the kids that they're not getting what they need in the classroom and that's what has amazed me the most is, uhm, the kids want to achieve, they want to do well, they want to improve, they want discipline and we're the tools that provide that and you know meeting with these kids it's amazing what comes out of their mouths. Now here's a chance for them to come in and sit down with me and pretty much, you know, bitch all they want to and the the majority of what I heard last year was: the food in the cafeteria, and the biggest thing I heard was classroom temperature and that was something I could fix automatically and it's amazing you know what you hear from these kids mouths you know they'll tell you that Mrs. so and so, you know there worried about their next year in math, or next year in science, or next year in English because they don't feel like they're getting what they want this year and they'll tell you that. So you know it's a form of communication that were opening not just as I said with between staff members but with administration and students. That's helped I think improve the school a little bit also. So, uhm, I'm trying to think what else. If you would like to sit on, again that's Wednesday, we do that during channel 1. I'll remind the kids on Wednesday. Uh, other than that I'm brain dead (laughter) I may have other if you'll leave me a copy of that, I'll see what other things I can think of in the next couple days we will sit down again and go over some things.

Researcher: Okay, I'll stop it. 


\section{Appendix E}

Teacher Interview Questions 


\section{Teacher Interview Questions \\ - Probes}

1. What do you think the phrase high expectations means?

- How do you communicate classroom expectations?

- If I were to ask students about your class and high expectations, what might they say?

- When the year 2014 comes, do you believe that all students will be at or above mastery?

2. What are some activities or traditions at this school that promote high expectations?

- What is the school slogan or motto:

- Where is this exhibited or displayed?

- Which activity do you feel is most effective and why?

- What kind of things happen at this school that promote high expectations?

3. What are the ways in which your curriculum is aligned with the state assessment tool?

- How is data collected to verify the taught content standard was mastered?

- If I were to ask students what was taught in your class, how would they respond?

- What do you use in determining the content of your lesson?

4. Tell me some of the teaching strategies that you use so delivery of content is varied?

- What strategies are used so that students don't become bored, off-task and want to sleep?

- If I were to ask a group of your students to describe your teaching style, what might they say?

5. How are all students provided the goals and objectives to each lesson or unit?

- If I asked any student to describe what the lesson was about, what would he/she say?

- How would an absent student be able to seek the objectives and goals of the missed lesson?

6. How do you provide meaningful, relevant feedback to students?

- What are some ways you probe low ability students to answer questions?

- How do you structure Q \& A so that all students are provided the opportunity to answer a question?

- What type of comments are provided on written work?

- If I were to ask a student how you provide feedback, what would he/she say? 
7. What are some ways that you recognize and reward student achievement?

- Where is the recognition done?

- Who decides who is recognized?

- How are low ability students recognized for accomplishments?

- If I ask a student to tell me how the school or teachers recognize students, what would he/she say?

8. How visible is the principal in the building during the school day?

- When was the principal in your room?

- Where do you see the principal most often?

- What do students do when the principal comes into class?

- If a student were asked how often he/she sees the principal out of the office, what would the response be?

9. How are teachers assisted in the development of lesson plans that enhance instructional practices?

- How do lesson plans reflect high expectations?

- How does the principal monitor lesson plans?

- When you develop a lesson plan, how do you ensure that the students will be engaged in learning for the full instructional period?

10. How does the school and/or district deliver professional development that is a part of the school/district 5-year strategic plan?

- Who makes the decision on what professional development is provided for the year?

- Where in the calendar is time built-in to address school needs?

- When did professional development occur on writing effective lesson plans?

- How has the professional development enhanced providing high expectations?

11. NBC teacher question. How has the NBC process made a difference to you and your students in the classroom?

- How is data used to meet the instructional needs of all students?

- When is time provided for data analysis or teachers to talk about the instructional needs of students?

- Imagine that every teacher in your school was NBC. How would that change the environment of the school?

\section{Closing}

1. We've talked about how teachers and administrators contribute to high expectations. Are there other aspects within the school or district that you would like to discuss related to high expectations? 


\section{Appendix F}

Teacher Interview 


\section{This is an interview with a mathematics teacher held on October 26, 2009.}

Researcher: what do you think the phrase high expectations means?

Teacher: to me high expectations would be a, uhm, getting students to achieve at their optimum level of learning and above, challenging them to go further than they think they can go.

Researcher: what do you believe would. How do you determine what that child's optimum level is?

Teacher: that's, that's a difficult question to determine that I think that if you can look certainly at test scores and answers and, you know, communications that you have with the student. But I think it's more a reaction that you see in the student, you know are they quickly to get finished and seem to be grasping things much quicker than someone else, and seeing them you know, a little on the board side, or need, uh, seem like they're not being challenged I guess enough to make them think, uh, maybe a higher order a higher-level thinking skills. So it's hard to determine but I guess to me it's more of a judgment call than anything else what I see in students reactions.

Researcher: when you look at a student's reaction to further understand this, you know, working to the optimum. If a student finishes early and that isn't going to alarm you until then you then go and grade that child's work so you're putting the two assessments together so you if see a student kind of like somehow signifying he's done with the test and then when you grade him does poorly then, then you're, then you're going to realize or make a judgment that that child isn't working to their potential or to their optimum.

Teacher: Correct yeah, yeah. I mean it's certainly the level of their, uh, the grading should certainly should also meet what I would consider again they're a higher. What I think they should be able to reach if they're finishing early and doing poorly on the test that are either not taking it seriously or else they're simply not putting forth the effort.

Researcher: and the reason I ask that question is because if a student finishes early and is getting a high A's, then you're not going to be alarmed because you just realize again to their optimum you may use the other end of the spectrum which is you need to maybe give that student something else after that test to meet their challenges because it appears right now to be pretty easy for that child so maybe you as the teacher again to get them to work to their optimum you're saying okay here's something a little more challenging for you to do now while, you can work on this while somebody else is taken the test or the other students are taking the test.

Teacher: you have to differentiate your instruction a little bit if you're going to reach those kinds of kids since there is no leveling of any kind, you know, so you have to make sure they're being challenged but yet at the same time you got to be able to bring along the weaker ones and that's the real challenge in teaching today. You know, how do you do that. You know, without the one kid thinking you are punishing him because he's getting done early and yet you can't. You don't want him to sit there and think this is too easy, or this is boring so. So, uhm, it's a difficult thing to do it's, it's a challenge. 
Researcher: how do you communicate the classroom expectations now that you said what your definition of high expectations are how do the kids know them?

Teacher: the kids know them first of all by I think by the, the way that I present my lessons. Uh, I try to present them in a way that they understand that it's important that I feel it's important and that I feel it is important for them to learn if they don't buy into the fact that I think it's important or that it's something they're going to be needing later on then you're not going to have a lot of success with them especially the higher level kids. They're going to see right through you, you know, busy work and that kind of thing. I try first at the beginning of the class, classes to tell them you know the advantages of being well-versed in mathematics and to go as far as you can in mathematics even if you're not going to go in to a mathematics related field sort of speak. I keep telling them that mathematics is a divider. I really believe it is. You know, it's a division, it's a divider between who gets a job and who doesn't get a job. I don't care whether it's math related or not and I tell them a lot of them have no idea what they want to go into until they go to college and for them to reach whatever they want to get to, they have to expect that it's going to involve taking more then what maybe they think they need. Uhm, we talk about the how they're competing not just against people from Williamstown and Wood District and it's now a global society and of course we have some foreign exchange kids and you know I tell them you're going to be working for some of these people if you don't see that it's important, you know. So, I just try to I'm more of a mot, I guess it's bringing, more the coach in me. It's more of a coaching motivation speech then it is, you know, the nuts and bolts type of speech, you know, sort of speak.

Researcher: okay have I worked as students about your class and high expectations what might they tell me?

Teacher: Uhm, I think that they, they would tell you that the class is, uh, a no-nonsense fun class. Uh, most of the kids enjoy the class but at the same time they tell you it's one where they probably work as hard or harder than any other class. Uh, I think that they would say I expect them to do their best and uhm can't always get that out of him but they. I think that they feel that I want them to do their best, that I'm going to try to make them do their best and I'm not going to let them slack off, you know, so I would hope that's what they would say.

Researcher: how do you get them to work to their best when you say you don't allow them to slack off?

Teacher: okay, ah, ah, just like if someone is done with their assignment for example early, uh, there's always a, a pr, a higher-level thinking problem somewhere in that assignment that maybe wasn't assigned and I'll point to it and say, you know, what do you think about this. See if you can answer that question for me, you know, I might ask you to explain something about that to your classmates. Uhm, or if they, if I know they're interested in something in particular that they're going to go into; if there's anyway I can relate what we're doing to what they're interested in. Uhm, I think that, uh, you know I'm continually walking around the room and while they're doing assignments and I answer their questions they don't have to come to me I come to them because I think that's a little bit of a thing that tells them that Mr. Lathey cares 
whether I get this or not. You know, I think just little things like that let them know that I think they're important and that I expect them to do their best and I keep telling them that I'll always give them my best. You know, I expect the same from them. So again, it's coach, more the coach coming out in me more than anything else.

Researcher: okay. When the year 2014 comes do you believe that all students will be at or above mastery?

Teacher: no, no. I don't think that uh we're going to reach all of them. I think there's too many negative factors in some of their lives that society won't maybe let them get there. Uh, you can't, there's certain things that we have no control over that are sincere factors in their life that affect their performance in school.

Researcher: are those the negative factors that you're alluding to?

Teacher: yes yes, uh, whether they're all capable I'm not saying they're not capable of becoming mastery. But I just think, just in a perfect world yes. But you know we have too many. There's so many things going on that schools, especially public schools, have no control over that, you know, that I think some kids they're just not going to get there for reasons that we can't control.

Researcher: and some of those reasons, I mean do you know what some of those reasons are in your tenure as an educator?

Teacher: oh yeah. You know you see, you see kids that, that live in a home situation that first of all education is not conducive to being successful in education. You know, it's a, you can't become a parent to these kids when they go home to another set of parents and uh that are not really encouraging them and kids today have, have so many distractions with golly you know I guess we don't have gangs around here, but I mean you have gang activity, you've got drugs, you've got you know all those societies ills right now that they're a lot of time coming to school is the least of their worries.

Researcher: what are some activities or traditions at this school that promote high expectations?

Teacher: we have, we have an honors banquet for the seniors where they, they will invite a teacher or someone who's made a impact on their life and that has led them to where they are so they have to you know they have to really relate to who's made a difference in their life, you know, and as to their future. We have academic recognition banquet's for those who have achieved a certain GPA or for those who have improved a certain percentage from one 9 weeks to the next. So we have of, you know, we do extra things for them like we have a ACT workshops, you probably saw the sign in the main hall which is kind of new this year where we put the next test is coming up, how many days you have, you know, hopefully trying to get the kids to realize that it's important. That's an important day coming up, uhm, we, you know, have many scholarships and things that we try to push them towards we have our own faculty Senate scholarship and again just trying to relate to them that, that a it's important that they achieve so you know academics is stressed in most areas so. 
Researcher: now you mentioned the honors banquet for seniors is that for every senior?

Teacher: No, that is for high achieving that is for I think you have to have a 3.5 or above to go to that.

Researcher: and then you mention the academic recognition banquet for those who have improved in addition to that set achievement.

Teacher: Yes, yes, this is every nine weeks.

Researcher: Uhm, uhm, is there uhm a set criteria in terms of improvement so it isn't just gone from a 2.5 to 2.6 .

Teacher: now it's got to be a .5 increase or above I think I believe I'm not sure it's the number but. So we're stressing improvement.

Researcher: in addition to just reaching that goal.

Teacher: Right, exactly, right. We have, let's see, we also have student of the month types of things you know for the.

Researcher: What's the criteria for the student of the month?

Teacher: a basically they're nominated by teachers for and the teacher writes why they nominated uhm, this doesn't have to be just grades it can be, you know, something special that they've done that incorporates not just the grades but also attitude and citizenship and those kind of things, you know.

Researcher: so, so it's up to that teacher then because the teachers nominated them and then they're going to give the reasons why they believe this person deserves student of the month.

Teacher: Right, right. And then those are voted on as to for the student of the month so you know by the teachers.

Researcher: Uhm, is there a school slogan or motto that the students buy into?

Teacher: Ah, probably not necessarily a motto. I don't know of any that we've actually come up with.

Researcher: but there is the fight song and the Alma Mater.

Teacher: Oh yea. There's the fight song and Alma Mater. You know there traditional wise you know that they know there's certain expectations you know we hold at Williamstown, I think. But it's not necessarily written in the slogan, but we do have the fight song and the alma mater. 
Researcher: Now are those. Do students get involved with those when there is assemblies or is that just.

Teacher: they are first of all, they are taught that those by our music teachers. Each seventh grader when they come in are taught both of those and they see them on the walls of the cafeteria and, you know, and that's about the only time is you know pep Assemblies and things like that that we have, but that's about the only time you're going to they're going to come in to play.

Researcher: but they are, but they are, but they are used in a pep assembly.

Teacher: Yes,

Researcher: which is about how often?

Teacher: we have normally just a couple probably for football, a couple for basketball, we don't do a whole out of that because of class time interruptions and things. To be quite honest with you we try to minimize class disruptions as much as possible because, between you and I, you know, the state's disruption us enough with all these blasted tests that we have to give and, you know, it's getting ridiculous and it's really hurt because we have to take out some of those things you know that I think are vital to a school you know and again coming from the athletic background that I come from I know that we used to have more of those and there was a greater excitement around the school that what we have now even though we have a tremendous sports program still but the excitement in the student body is not there anymore. So, you know, I think that's a part of it. But, you know, I think all that comes into play in there.

Researcher: Okay. Of all the activities that you mentioned do you think there's any that is most effective in getting kids to reach or maintain high expectations? Is there a Ah-Ha moment in a student's eyes when they say I am going to really dig in and do this because I've heard of this?

Teacher: I think partly some of that may come toward the end of the year when we have our recognition assemblies and they see kids leaving here that are seniors that are walking off with $\$ 30,000$ education paid for, or a 50,000 or whatever you know I think that has an effect on some kids. I don't know if that may be, you know, maybe in some individual classes perhaps there's if it's stressed enough like I really try to hit that with my older kids. Guys this is money this is important to you and your going to have to take it seriously and you know may be to some extent in classes but uh I don't think there's a lot again that specifically does that and I still think it comes back to the fact that some of the excitement is gone of what it means to be a student, too often we get caught up in just the academic part of it is and, and like I said the testing and all that kind of stuff takes away from what it means to be successful. We have tests, we give kids tests that don't mean anything, they know that and so I think it, it just takes their whole idea of what's important and kind of puts it in to a in disarray as to what is important to them. You know, when is a test important, when is a, you know, and that's what I say I'm really discouraged because the state has gone this direction, you know. Didn't use to be that way and I know I'm old school but you know I mean there is a lot more than school than just testing and an especially when the testing is not always measuring what's out there so I think it just affects all the kids, in a negative manner. 
Researcher: what kind of things happen at this school that promote high expectations, that may be different from what you just been talking about? With the banquets and the end of year recognition, is there. Basically, anything that you may have left out?

Teacher: Uh, nothing, other than maybe the, you know, of course the normal PLAN explore testing that projects their ACT scores and those kind of things. I don't see a whole lot more that's would really give any more motivation to, than what I've already told you there.

Researcher: Uhm, in terms of promoting high expectations, do you feel though that after talking to Mr. Peters where he's asking for more rigor to be in to the curriculum. Do you see the design of your tests with more rigor is, as Mr. Peters is requesting, is increasing the expectations of students?

Teacher: ah, to some extent. Although we're just, just starting to do that here. I don't think we been at it enough to really see the, to be able to compare right now because you're always as a classroom teacher, like I said, you're always trying to balance that you got to make your class, you know, for the low achieving student as well as a high achieving student and, you know, what's rigor for one is, is almost death for another, you know. So, uhm, that's still yet to be seen how much that's going to change. I think it needs to be there, but I think there's a lot more involved it's more than just saying okay teachers put more rigor. I think it's going to have to be a grass roots campaign right down to the parents. Say, folks here's how it is: you've got to have four units of mathematics, we're going to hold him to the standard, you're going to have to see that your kids do their homework, you're going to have to be willing to make them feel that it's important what they're doing and, and again it goes back to community involvement and its almost got to be a wholesale thing to get everybody involved that it needs to be that we yes because the kids need to be able to compete globally as well as, you know, just around around state level or what ever. And average is not good enough anymore but it's hard, it's one of those things that's hard to accomplish too many people involved variables.

Researcher: you keep talking about, uhm, going global is this something that you're using within your classroom to get high expectations and I think I've been hearing you say that when you've told me you tell your students folks we're no longer competing against Williamstown students or the other two high schools in wood District or Wood district or the state of West Virginia, we're dealing with globally. Do you see the students taking a buy-in to that to raise their expectations from what you're saying mediocrity is no longer going to cut it.

Teacher: Right, uh, they keep hearing it from me, now whether it's going to make a difference or not well you know. Some kids obviously it will, but you know it's one of those things that I try to tell them I try to keep preaching at them whenever I have the opportunity. You know, I don't have, I tell them you don't have to look very far. I says, we have Hino motors down here. I said Hino is not a Williamstown name, and I said that came from Japan. I said, your not, you can't go get a job at Fenton's now, Fenton's is closing down, just about. I said, that's were if you couldn't go to college you got a job at Fenton's. I said 50 years ago that's what you did or you went to one of the plants around here. I said, you know, the plant jobs are being taken by 
automation, by computers. Uhm, I said you can't just be average and then think you're going to just get a job like your dad did, you know, for and retire from the place it's not going to happen. It's, everything is going modern and you're going to be left behind. I, I kid them some times but I told one class the other day that I felt was being a little bit lazy. I said what I'm going to do is I'm going to go get a whole stack of McDonald's applications for you. Because I said unless you get better, I said that's the application you're going to have to fill out because that's the only job you're going to get. I said you're, it's nice to have foreign exchange students, I said it's these guys are not over here to just see what America's like. I said, you need to understand that they all are pretty good students and they're the ones that are leading the class average for the most part. I said there is a reason for that and you're going to compete against them. You're going to compete against all these people around the world. So it's just a matter of. I just keep beating it beating it into their heads hopefully maybe it'll stick to some of them. I don't know.

Researcher: What are the ways in which your curriculum is aligned with the state assessment test?

Teacher: Well we, you know we teach basically the standards that the West Virginia state standards that are put out for us there. Uh, we use a prioritized curriculum that where we have gone through and, and uh basically prioritized those standards into the most important and the ones that we feel are essential and you know trying to hit the main things that's being asked for and the kids the skills that they need to be able to do to when they get out of here and when they go on to college.

Researcher: how did you prioritize I mean what

Teacher: we did that as a District. We took the state mandated I guess at that time they were called CSOs I think they've had all those different names for them but they we took those and each grade level and each class of geometry, trig whatever and we went as a group math teachers and we decided okay here's here are the Core you know standards that we have to cover you know you can't these are essential ones that you have to cover then after we got those down then we talked about ones that should be covered and then there's a few of them you know that you look at and you say well, you know, if I had to leave one or two out this would be the ones that would be least missed probably, you know, so we put a prioritized curriculum together and in that format

Researcher: so so the prioritization of that curriculum did not match per se what the westest questions were?

Teacher: not necessarily at that time, that was done before the Westest came about.

Researcher: so the group of teachers just said hey to get ready for geometry. Do you use the backwards approach? Teacher: Yes. Kids in geometry kids in geometry need the following algebra concepts (Teacher: Right, right) that are crucial for success in geometry so those must be covered then if they can get to this that will help them in geometry but these items are fluff they're not fluff they they are the icing on the cake where if you can get to it it would be great but 
it's not essential for them to be successful in geometry, okay, and then so on. Like you say backwards by design okay I follow you.

Researcher: how is data collected that verify the taught content standard was mastered and again we're talking about just your class?

Teacher: uh, basically uh you know the the testing I use not only formal tests but some informal assessments as well. Uh, uh .

Researcher: Could you mentioned some examples of the informal?

Teacher: Uh, things like uh, uh as uh they have different names for them. But, uh, you know I'll just we got two minutes left in class and I'll say, okay right down something that you learned today that you didn't really understand before or right down something that you're still not sure of you know, uh, uh, or uh, uh, tell, you know, I may give them a topic and say explain this to me, what, and to you what does this mean to you. Uh, you know, just different things like that and then I use that as basically to build the next lesson as far as do I go on, do I need to go back and reteach this part, you know and and I use that that a lot. We do problems of the day type things that I'll use if I didn't use a informative assessment. Uh, I'll put a problem of the day on the board that starts what we talked about yesterday, you know. See if they can do that problem before before we start. Uhm, uhm my upper-level classes I use I have ACT tests that I pick questions off of and use as questions of the day you know to get us started. But, you know, there's different assessments that way that don't really count as far as grade level. It helps me know we're their

Researcher: do you use, uhm, any type of spreadsheet or chart within your lesson plans. Not in your lesson plans but within your lesson plan that if you're going to cover this state standard and then somewhere else you have that logged to check

Teacher: actually to check off

Researcher: to show, to show that you covered that and that you know not some people could get as specific as listing every child that as if they had mastery

Teacher: No, I don't do that.

Researcher: or just you as a Okay.

Teacher: basically that's done in general you know uh again on that prioritized curriculum we have each state man, you know, uh, uh, under each concept what objectives that covers and then as we go through that you know we can say you know we cover I can't say they all mastered it, you know, I don't do that. No.

Researcher: Okay. Uh, if I were that ask students what was taught in your class how would they respond? So any student, if I were outside this door and yanked a student out just as the bell would ring what would they tell me was taught for the last 45 minutes. 
Teacher: Uhm, basically I think they would depending on what the concept is for the day obviously but you know it would be uh, uh, one of the concepts or one of the the state mandates somewhere in there there's a piece of that, that they would should be able to tell you what was taught, you know. I don't know, I'm not quite following the exactly what you are asking for there. But, uh.

Researcher: again you are on target I would say, you know, in anybody's class they may not know, students would not know the teachers necessarily jargon of well we covered CSO MA4. (Teacher: right, right). You know, it wasn't that, but they would be able to say coming out today Mr. X, you know, he told us, we learned something about if two parallel lines were cut by a line (Teacher- yea) that that we worked on finding alternate interior angles (Teacher: right, exactly) or or, uh we learned how to find the radius of a circle or we did the quadratic formula that that they can

Teacher: like you, say they can tell you, they can specifically tell you what the focus of the lesson was, let's put it that way.

Researcher: what do you use in determining the content of your lesson and I believe you answered that if I can reiterate that to you you're saying based upon the Wood District schools math prioritization chart, you're using you're using those uh items developed in as a District to plan your lessons.

Teacher: right and also you know student uh, you know, where student progress is on those, you know, as far as sometimes I got a break it down even finer you know or whatever.

Researcher: And, I was going to go back and fill that in. You are correct, like you said with those students. You are, the last two minutes of the class period where you ask them to write down something that they learned today (Teacher: right) for you to give a child or, or the socalled bell ringer (Teacher: right) that you talked about so you know again it goes back previously to the mastery (Teacher: right) you're going to make sure they understand something before you pile it on higher and deeper. Okay

Teacher: again that's in an ideal classroom Okay, I mean, you know (laughter) you've been there.

Researcher: Correct, correct. Tell me some of the teaching strategies that you use so delivery of content is varied. Because you've talked about, uh at least two if not three times since we've been talking about, you know, the low, the low-level and then the high-level students and this differentiated instruction. Can you be a little more specific now how you are trying to reach those extremes?

Teacher: yeah, well you know it has to do with the way it's presented I think I try uhm. I try especially when we're starting a new concept, I try to present it in just about every way, every learning style that you can present it. You know, we will talk about it will put a picture of it on the board, we will practice whatever it is individually. I have individual white boards for 
example that we use a lot with magic marker, with dry erase markers, you know, where each kid has his own whiteboard and, and uhm that way they're, I'll give them something and when they get it answered they will shut their white board up so I can see they're doing the problems and I can see who's right and who's wrong and those kind of things. I teach a lot by question and answer. I lead the students more on. Very seldom do I just come out and tell them something am not a great lecturer on, you know, so they just take notes. But what I do is I try to lead them along as I go through and show them why this happens and why this is true and help them discover on their own.

Researcher: okay discovery learning and then your Q. and a sessions do you have a way to mark to assure that all students are being given all students are given the opportunity to answer a question?

Teacher: I try to. Not as so much a list but I do take a certain group that each day that I'm going to focus on, you know. And say I'm going to ask my questions, I'm going to focus, I'm going to direct them more at this group than I do.

Researcher: and that was actually, I should have gone back and restated that. So you don't asked whole group questions. (Teacher: no) You're going to call out John.

Teacher: well I do both. But it just depends, you know. If I, if I see somebody obviously not paying attention, you know, the next question is going right at them you know but, but also if I see someone who's really got that puzzled look on their eye, in their eyes, you know, I'll direct and say do you understand you look a little puzzled. Uhm, uh, again as I get to know the kids I also know which ones get embarrassed if you ask them questions and I may make sure I give them one that I'm pretty sure they know the answer to. You know, I do a lot of things to try to not embarrass them but include them let them feel comfortable enough to answer questions.

Researcher: so if I'm hearing you correctly on this, through the question and answer session or whole group question but through this process it sounds like you're not only checking for understanding but but taking a child who may not have a good self efficacy in math and as you just said shooting them a question that you're pretty certain they will know so it starts to build up their confidence and again do you feel by doing that that you're then going to help that child raise up to high expectations?

Teacher: Oh,absolutely. I, I, I mean because uh. You know, I'm a firm believer that, you know, you're whether or not you like mathematics is you know that before you leave elementary school. And you know I think part of my job is to get that fear away from them and so that's one of the things we try, I try to do is in that answer period. I do some lecture but not a lot. You know, like I said, it's more, I guess probably more discovery than anything else. Without taking a lot of time I mean cause we can't. I say, you know how it is in the perfect world. I can take and make this wonderful little lab about learning how the angles of a triangle add up to $180^{\circ}$, you know we can do all the paper cutting and all the folding and all that kind of stuff and make a, which is really neat and fun I know but I don't have time to do a lot of that. You know it's much easier for me just to show them with things and let them discover that then it is, you know, so I don't do a lot of lab type activities. 
Researcher: and you talked about uhm if you see a student that may not be engaged that they're going to get shot the next question. My next question is what additional strategies other than questions that you may be using uh, so that students don't become bored, off task or want to sleep. In other words is there anything other than you just saying okay John what's the answer to this question?

Teacher: I talk loud (laughter) Uh, I mean I've done some crazy things as far as that's concerned but I can only do that because I've been here 30 some years, you know. But uh, I will walk back to that student and you know if they've got their head down or something it's it's nothing other than just you know sleep on your own time or something you know I try to keep them awake and at least paying attention to me by not standing in one spot and I will as I talk about it I'll move around and you know just to try to let them know that I am at least focused in seeing what they're doing and again it's still, to me it's still part that I, that I'm relating to them that he cares if I'm really going to learn this stuff or not you know. The easiest thing in the world is to let a kid sleep but that also tells him you don't care you know.

Researcher: if I were to ask a group of your students to describe your teaching style, because you described it so far what do you think students would say is your teaching style?

Teacher: I think I think they would say that it's interesting I think they would say it's varied and I think they would say he asked 1 million questions (laughter)

Researcher: let me go back and ask you of again from what you just said because you use that word very again how if it's possible for you to get into one of your students of mine said how would they describe you in terms of that word varied?

Teacher: varied

Researcher: what would you do that would give them the idea that hey he's in varying what he's doing in there?

Teacher: the fact that that in in some cases uh I'm showing you know I guess I'm showing and lecturing on one part but then shortly I'll be over to change to question and answer or letting them try to figure out what's going on. Then we stop and give them time to do individual work. Uh, then maybe one of them will come to the board and put what they have on the board or we have whiteboards or you know I think that they would say I try to involve them they're always doing something you know in here, that to that goes along with the lesson

Researcher: Okay. How are all students provided the goals and objectives to each lesson or unit? You talked about how you are using wood District schools, uhm ma, district wide system that goes along with the state system now how are the uh students provided these goals and objectives.

Teacher: I try to I don't always write it on the board but I always start a lesson say okay guys when we finish here today this is what I want you to be able to do. And if I don't write 
something, I'll write something, usually something about that on the board. You know, we'll start tomorrow uh, no it will be Wednesday with in geometry we'll be starting congruent triangles. You know, and I'll you know I'll make the statement or I'll put on the board classification of triangles you know then I'll make the statement by the time you finish today I want everybody in here to classify triangles according to their sides and their angles you know.

\section{Researcher: Okay}

Teacher: they will verbally hear what I'm after.

Researcher: if I were to ask a student here we go so take it from a student's perspective to describe what the lesson was about what would he or she be able to say?

Teacher: I think they can tell you what it was I was trying to get them to do. I think they can tell you that.

Researcher: goes back to our earlier question. So from what you just said if Wednesday you are going to be able to classify triangles by angles and sides when they leave here, and again in a perfect world every student should (Teacher: right) be able to. If I'm taking a pole outside this door they should be able to say okay, I learned what a scaling triangle was today (Teacher: right right).

Researcher: how would an absent student be able to state the objectives and goals of the missed lesson?

Teacher: Uhm, uhm, they have the opportunity to anything I do as far as handouts uh, uh, uh, they will be given those of course when they come in. I do tell them it's their responsibility, uh, to come if you're absent you have to come. I not going to come to you. They're sophomores and above basically in here and I they hear me say this statement a lot if all I ever teach you about in this class is a geometry I haven't been a very good teacher you've got to learn lessons in life a little bit somewhere to so I say I'm going to give you an assignment you're going to have to do this this is part of growing up and taking responsibility so they know they have to come to me and then I'll provide them with whatever handouts we had or whatever. I will tell them that I do not have copies of my notes uh you know, they can get that from another student any notes that I put on the board or on the screen or whatever uh and then I'm always available to them after school if they don't understand something or if they need help with anything just about every night after school so they have the opportunity to come in to get what they missed then so that's pretty much. I do not although I'm going to try to start putting them on Ed-Line because of all the illness and things we're having right now. So, I guess I'm going to have to brush up on my technology a little bit forgot how to do that but I've never done that before so I guess that'll be something I'll be doing probably. But those, that pretty much again I put a lot on the students I expect them to accept responsibility for being in here.

Researcher: how do you provide meaningful relevant feedback to the students? 
Teacher: Uhm, again just if I give them a some type of informative type of thing as they go out the door, whatever, I'll tell them the next day it looks like, you know, most of you got this but we're still having some questions here, you know. And, uh, you know I'll let them know we're going to look at this today, you know, and other than that it's just basically tests, quizzes, looking at homework, occasional homework checks, I give them homework quizzes in which I'll pick maybe two or three problems out of their homework that they were supposed to do after we have gone over the answers, after I've explained anything they need explained, I'll say okay you take number 3 and 5 and you do that on a piece of paper real quickly, show all your work turn it into me. Uh, you know, it let's me know if they've done their homework or not and I get their test back to them normally within a day most two day's. You know, if they take tests, and then we go over the tests question by question. Anything they didn't understand, so hopefully they can see what they missed, uh, they then have the opportunity to come in after school to go over the test individually with me and I will let them retake a test if they want to be obviously a different test a little tougher than the one the first one but uh, they have a chance to retake it and hopefully learn from what mistakes they made on the first one so.

Researcher: Okay, so you do allow them to retake individually or the whole class has to.

Teacher: yes, no, individually, individually.

Researcher: is there a, uh, is there a uh. We're going back to your high expectations then. Uhm, so let's go back several questions ago so one way to get them to reach high expectations is allowing them retake that.

Teacher: it's reteaching is what it is.

Researcher: what is the cutoff though I mean, can any student even if they got a 90 on the test retake it?

Teacher: yes

Researcher: how many times?

Teacher: once.

Researcher: okay

Teacher: unless they were absent. I work on them being here on test days. If you're not here on the test day, you've got one shot.

Researcher: if a student doesn't do well on a retest. In other words, I guess my simple question is if a student, if a student retakes a test which grade is going to count?

Teacher: The one on the retake.

Researcher: Regardless 
Teacher: Regardless. And like I said it's. You know, some people say well that's, that's too easy you shouldn't let them do that. But, you know, and they it may sound like it's not going for high expectations but to me it is because like I said there is nothing better than taking a student and seeing what they missed on a test and letting them go through and see where they're missing it. To me that's the reteach part, uh of it. The easiest way to reteach it and then give them a different problem same types of problems but different problems with maybe a little bit more rigor in it because they had a little bit extra time and so forth. I think it helps them learn what they didn't know the first time.

Researcher: do you have a lot of kids to take advantage of that?

Teacher: not as many as I would hope. But, uh, I would say on average maybe $15 \%$.

Researcher: the next question to go with that and then I think I'll be done with that, with that part but excellent excellent material you're given me. Fifteen percent retake it, how many of them then improve?

Teacher: that improve probably 12 .

Researcher: so it's worth retaking it.

Teacher: yes, but they all said no and it discourages someone who made a, made a 90 on it with a B. It discourages them knowing that I know that the test is a little bit; like I tell them I always pick the best problems for this test. Now you are going to get some that aren't quite as easy and maybe they don't come out quite as even, you know, I tell them it's going to be just a little tougher but you're going to take the grade you get on that retake. Now, if you want to do that that's fine but uh, it discourages some of them from, you know, they, you know, that's why not everybody retakes it you know so I would have a nightmare if I did. But, it, it, works. For me it works well, you know. It also gives the the kids an opportunity that like I said we have a lot of kids here that have a lot of baggage when they come to school and there are some days that they're going to come to school and they're not going to be ready to take the test . They couldn't study the night before. I tell them if you didn't get to study, I said, uh, uh, go ahead and take the test and you can take the retake you know. And it gives any of those kids that were sick or didn't get a chance to study or whatever. I got a lot of kids that work, you know, they have that opportunity to do better, you know, so.

Researcher: okay. What are some ways that you probe the low ability students to, to answer questions you talked earlier about and we did about the improving or increasing the student efficacy in their ability to answer math questions. But how are you going to how do you probe the low ability student's to answer the questions or am I. Or basically what I'm saying there is that the same question as what you're saying that you design a question so that they can answer?

Teacher: yeah, that's that's pretty much what I do as far as orally goes, you know. And uh, I try to uh, be very, uh optimistic with them. If I can get them to come in for to go over a test with me 
for example, you know, it's like I see you can do. You know, I mean, it's just a, a it's just one of those things. That's about all I do to reach them.

Researcher: how do you structure your Q. and A. so that all students are provided the opportunity to answer a question? And again earlier we talked about, about that. So just let me, uhm, summarize it in a way. You're not saying necessarily that everybody is going to get that opportunity within that class period. You're going to focus on a particular group or again if you see John startin to dose he, he, he's going to get it so would you say over a 2 to 3 day time frame that everybody within that class (Teacher: more of a week's time) So, within a week a student has been given an opportunity to ask to answer a question?

Teacher: Now, again it depends on the student, uh, uh it takes. Golly I'm just now really getting to know some of the students and it takes a little while for me to get to know them to where, you know, I know that this one's not going to really want to speak out, you know. I want to make sure that she has a question that I'm pretty sure she can answer, you know, and get right and uh, uh, so it's one of those things to that as I the year progresses that becomes more evident just where I'm going to group to group rather than maybe earlier in the year, the first nine weeks, I may do more throwing it out to the whole class till I see who my vocal ones are and who's not going to you know then I'll start zoning in on people that I know are going to be a little less likely to talk.

Researcher: so the bottom line here is even that quiet church mouse, you're going to get to be involved (Teacher: hopefully) in that lesson over time? Not, not within

Teacher: yes, yes

Researcher: what type of comments are provided on, on written tests, if any?

Teacher: Uh, you know, just, I don't do a lot of writing on comments or other than you know, super, great job, much better, uh, you're starting to get, uh, you know just I try nothing but positive. Uh, anything I can do positive wise for them. Uh, the ones that make, you know, good, the A's and stuff. That's comments on those or have finally seen somebody that's really improved or, you know, like I said, they're just positive comments. I don't make a lot of comments on tests, and I do more of that individually in, you know when I meet with them, uhm, on an individual basis more so than verbal more than written comments.

Researcher: if I were to ask a student how you provide feedback would he or she say the same thing? He does more one-on-one verbally than anything written on tests or quizzes.

Teacher: yeah, yeah I'm sure they would.

Researcher: okay. What are some ways that you recognize and reward student achievement within your classroom?

Teacher: Uhm, other than verbal praise, not a lot. I, that's probably one of the areas I don't do do very much, uhm, you know like I said other than just the praise whatever I do write on their test 
if it's something like that or I talk to them individually or whatever, that's, that's more the comments, feedback they get from me on that.

Researcher: as a school, you mentioned the different ways in which students are recognized and awarded for their achievement, where is this recognition done?

Teacher: where? The, uh, academic investment, uh, group of our school that we have provides them a little, uh, not a lunch but you know cookies and things like that in the cafeteria and they give them prizes they have like a prize raffle thing. Researcher: and so it's done in the school. Teacher: in the school day, in the cafeteria. Researcher: cafeteria. Teacher: like one, they'll take like a one period at the end of each nine weeks will we recognize junior high one period and we will recognize Senior high the next period.

Researcher: and then who decides who is recognized? That is that organization they have set up criteria to recognize.

Teacher: yea, that's where we look at the GPA and the improvement you know that they have.

Researcher: and that was set by the school, by the teachers meaning?

Teacher: Uh, I think they run the grades from MIS down in Parkersburg. They get a printout of those who have increased by .5 or more.

Researcher: but what I'm saying though, is this to recognize students who have increased by .5 that was a faculty decision here to recognize those students or is that a District policy.

Teacher: no, that's the Cat lies here, that's this school.

Researcher: how are low ability student's recognized for accomplishments. You've mentioned the improving .5

Teacher: That, that's about it other than the, I mean they can be nominated of course for student of the month you know that's another program that we have. But pretty much that's why the improvement thing was put in there so they would have a chance as well, you know.

Researcher: if I ask a student to tell me how the school or teachers recognize students, what would they say? In other words you're aware of all these do students know what's available?

Teacher: Uhm, probably most of them do. The younger ones maybe a little. Little uh, you know especially seventh graders since we haven't had one yet this year, you know, they probably don't know much about that. But those uh

Researcher: so once they start, word-of-mouth spreads.

Teacher: yeah, yeah 
Researcher: did you hear, you know so-and-so got awarded or won this in the cafeteria today.

Teacher: yea

Researcher: how visible as a principal in the building during the school day?

Teacher: not very, not very that's one, one of the things that I wish, we wish that Pat could change but you know I know how principals you know there are a lot of meetings to go to there's a lot of things they have to handle they don't let them get out much I really wish he could get out more she and Mr. Buffington both and I think it would mean mean more to the kids and everything so.

Researcher: based upon what you said then when was the principal last in your room? And again we are talking about this year. So has he been in this year?

Teacher: the principal no, assistant principal was in about 2-3 weeks ago probably.

Researcher: okay. Where do you see the principle most often?

Teacher: cafeteria. He has cafeteria duty again which is not good. I mean there's just some things it has to do but we have three lunches and and you know that ties up a lot of time so.

Researcher: okay. What do students do when the principal comes into the class. I guess now I'd be asking, you know, with this question to help me if you can remember back to last year when he came in usually how do the students react?

Teacher: not, you know. I don't notice any difference, any change you know. If he comes in I know he'd come in and check lesson plans or come in and listen to, you know do a five by five walk-through or whatever they call them, you know. And, uh, students you know wouldn't really react much differently that I could tell.

Researcher: if a student were asked how often he/she sees the principal out of the office what would their response be?

Teacher: in the cafeteria, that's what they'll tell you.

Researcher: how are teachers assisted in the development of lesson plans that enhance instructional practices? Is there any help?

Teacher: maybe a little District meeting or district in-service type thing once in a great while or something about instructional.

Researcher: there has been nothing done within the building?

Teacher: not school wise, not, other than what was maybe set forth in the District on the opening days of school or whenever students aren't here when we do our meetings and things here at 
school. There's been some things certainly there that, uh, led into to, you know I don't remember all the names the scaffolding, and the different types of things like that that we been over about a 3 to 4 year period talked about in these meetings. But nothing specific school wise.

Researcher: how do lesson plans reflect high expectations? Or probably better said, how do your lesson plans reflect high expectations?

Teacher: Uh, mine are more what I'd turn in as far as for lesson plans for the school are general you can't put into a little block this big you know what you're going to do my lesson plans then are written notes to myself as far as that goes as to how I'm going to do that. I don't necessarily put them on my own lesson plans other than just basically tell the substitute that's going to be here this is what we're doing, covering and uhm, and we don't put the state objectives on the numbers like what we're covering that day that's not part of what we put on their necessarily I guess like I said mine are more notes to myself as far as you know what I want to cover to make sure that I've present it in a certain way or whenever.

Researcher: okay, how does the principal monitor the writing and the implementation of lesson plans?

Teacher: Uh, basically he comes uh, like I mentioned I think the five by five walk-throughs, you know five minutes or so they'll stop in. And, uh, he also checks them we turn them in each week uh, and uh their checked to see if they're done and they'll come in and observations you know if they do observations like I really haven't been observed much but I know they do go and observe and I'm sure they're checking lesson plans and following see what the teachers doing then but uh, I mean. To me lesson plans don't do a lot for me because mine changes daily depending on, you know, where my students are, you know, so.

Researcher: okay, when you develop a lesson plan how do you ensure that the students will be engaged in learning for the full instructional period? Way many minutes ago you mentioned if you had one to two minutes left, you go back and ask the students what did you learn today? Uh, is that always in the back of your mind to fulfill, so I guess what I'm asking here from what we talked about up to this point are you using the full instructional 45 minutes?

Teacher: absolutely, we you know we start with a bell ringer before while they're doing the bell ringer I'm doing the attendance and then you know they we're ready to start as soon as I get, they get the bell ringer we start we go over it and we start in with a lesson and very seldom is there any time left in the class because we do a lot of the homework we get started in class and do a lot of it in class for that matter. I'm you know I believe with eight periods it's really hard to give much homework and expect students to do it. I would much rather be here with them so I can see what they're doing I give fewer homework problems than I used to give, but I try to pick specific ones that do certain things that I want to see if they know how to do that and uh usually I mean very seldom is there any time left if there is that's when we do the informative assessment of some type or you know kind of finish it off. I can't stand to see kids sitting there doing nothing I keep telling them I don't have enough time to teach you the way it is don't expect me to let you have five minutes off or whatever you know so. 
Researcher: okay, how does the school and or district deliver professional development that's part of the five-year strategic plan. So, this is a two-part question you have to know what the strategic plan is and are they doing professional development that meet what's in that plan?

Teacher: I do not know what are specific school strategic plan is, I just know that the District provides as I said you know part of part of what we've done over the last five years has its been a plan set forth by Mr. X, uh you know to kind of take us into this 21 st century learning thing and uh it all, a lot of it started with this prioritize curriculum and it seemed like a different concept differentiated under curriculum you know and so forth it seemed like it was a different focus each beginning of the school year you know, and that focus is carried on throughout the year in our meetings when we have our our meetings days of school you know, so that's pretty much all I know about how that fits into strategic planning that's about all I know about it.

Researcher: so who makes the decision on what PD is provided for the year, you're saying $\mathrm{Mr}$. $\mathrm{X}$ from the central office is.

Teacher: Central office for the last few years have pretty much. There is a Council where a a group that meets, CE group that meets for the District. I don't know whether we have anybody on that now or not. We used to have some from each school that would meet for that and decide what to CE was going to be but I think since we're gone into this five-year stuff that uh lately most of its been pretty well District developed.

Researcher: okay, where in the calendar is time built in to address school needs then?

Teacher: not much, individual school needs. There's some. Uh, we do have some teams here at school that meet on some of those days you know where the morning is basically taken up for a District CE stuff at then a lot of times the afternoon are more school related and school-based. We have academic teams it's kind of hard for us because we're junior high - high school combined and we all teach like some junior high, some high school. It's hard to find you can't do it like a middle school concept you know but but uh, there is some teaming according to grade level some teaming level according to departments and so forth but that's about all we do in that aspect.

Researcher: when did professional development occur on writing effective lesson plans. We talked about that earlier you said what two three years ago at best?

Teacher: well, other than it wasn't exactly writing lesson plans, it was basically the curriculum and standards. Prioritize curriculum and that's from that's were we write our lesson plans but as far as writing I've never had CE on writing lesson plans you know so.

Researcher: how has the professional development enhanced providing high expectations, if any. Again you're saying Mr. X, they District office people are kind of in charge of that now with this five-year stuff have you seen any of this that they're giving you enhancing high expectations? 
Teacher: Yea, I think uh, I think the prioritized curriculum is one of the greatest things we've ever done here. And uh, and then some of the concepts differentiated understanding, and the scaffolding, and the those kind of things some of the informative assessments and those kinds of things have really been helpful in raising standards. We're getting ready to do our the acuity test which are benchmark tests you know those of been help for me to see you know what objectives have been mastered and what ones haven't. It helps us, we didn't have those in the past. So, there's several good things that have come out of this.

Researcher: you've made it to the end. We talked about how teachers and administrators contribute to high expectations. Are there other aspects within the school or district that you would like to discuss related to high expectations your chance to give me your your philosophy after $30+$ years?

Teacher: Uhm, I honestly believe we're missing the boat in elementary school if I had my perfect world and I was the King they would never do anything for the first 3 to 4 grade levels other than mathematics, reading and writing. Ah, you can bring in all the other things in reading and things, but they, if give you can do math and read and write you can do anything and I truly believe that we're missing the boat in elementary schools that we're focusing too much on being so diversified and make sure that everybody gets a little art, a little music, and which are great. I love all those things, but I think that would do more than anything else to enhance what's, you know higher level expectations it has to start at, at the bottom and you know statistics that I read show that the kids make up their minds by third or fourth grade whether they liked math or not, and whether they can do math or not.

Researcher: Or if they're going to drop out or not.

Teacher: Or if they're going to drop out. And so you tell me where should the focus be you know and that and like I said I think we're just testing them too much you know. Too many instructional days lost too much too many tests that don't mean anything to the kids they don't take them seriously. Stats, statistics are good you know but I'd rather have the days in the classroom to teach them so. That would be my two changes right there. 
Appendix G

Principal Interview Question Matrix 
Principal Interview Question Matrix

\begin{tabular}{|c|c|c|c|}
\hline Interview Question & Research Question & Literature Cite & Anticipated Responses \\
\hline $\begin{array}{l}\text { 1. What do you think } \\
\text { the phrase high } \\
\text { expectations means? }\end{array}$ & 2 & $\begin{array}{l}\text { Teddlie and Reynolds } \\
(2000) \\
\text { Lezotte (2001) } \\
\text { Training manual and } \\
\text { handbook for } \\
\text { education } \\
\text { performance audits } \\
(2006)\end{array}$ & $\begin{array}{l}\text { Teachers keep students on } \\
\text { task through relevant, } \\
\text { meaningful instructional } \\
\text { activities. All students will } \\
\text { achieve mastery of the content } \\
\text { being taught. }\end{array}$ \\
\hline $\begin{array}{l}\text { 2. What are some } \\
\text { activities or traditions at } \\
\text { this school that promote } \\
\text { high expectations? }\end{array}$ & $1,2,3$ & $\begin{array}{l}\text { Lezotte (2001), } \\
\text { WVDE Policy 2510, } \\
\text { Bamburg } \\
\text { Bolman, L.G., \& } \\
\text { Deal, T.E. (2003). }\end{array}$ & $\begin{array}{l}\text { Homecoming, semester test } \\
\text { exemption policy, attendance } \\
\text { policy, honors courses, AP } \\
\text { courses, student of the month, } \\
\text { athlete of the month, } \\
\text { achievement/awards } \\
\text { assemblies. }\end{array}$ \\
\hline $\begin{array}{l}3 \text { How are high } \\
\text { expectation courses (i.e., } \\
\text { advanced placement, } \\
\text { college, and honor } \\
\text { courses) chosen to be } \\
\text { offered? }\end{array}$ & 1,3 & $\begin{array}{l}\text { Heinlein (personal } \\
\text { communication), } \\
\text { WVDE Policy } 2510 \\
\text { (2008). }\end{array}$ & $\begin{array}{l}\text { In accordance with Policy } \\
2510 \text {, at least } 4 \text { advanced } \\
\text { placement courses have to be } \\
\text { offered. Student requests for } \\
\text { honor and college bound } \\
\text { courses determine offering. In } \\
\text { addition, Policy } 2510 \text { states } \\
\text { that higher level course } \\
\text { (including college level) must } \\
\text { be offered. }\end{array}$ \\
\hline $\begin{array}{l}\text { 4. How do teachers vary } \\
\text { instructional teaching } \\
\text { strategies? }\end{array}$ & 1,3 & $\begin{array}{l}\text { WVDE Policy 2510, } \\
\text { Good \& Brophy } \\
\text { (2003), Bloom's } \\
\text { Taxonomy, Kennedy, } \\
\text { M.M. (2005). }\end{array}$ & $\begin{array}{l}\text { Project based learning } \\
\text { activities, hands-on activities, } \\
\text { cooperative learning groups, } \\
\text { labs, student powerpoint } \\
\text { presentations. }\end{array}$ \\
\hline $\begin{array}{l}\text { 5. Tell me the ways } \\
\text { students are recognized } \\
\text { and rewarded? }\end{array}$ & $1,2,3$ & $\begin{array}{l}\text { Teddlie \& Reynolds } \\
\text { (2000), Jacobson \& } \\
\text { Rosenthal (1968), } \\
\text { Good \& Brophy } \\
\text { (2003), No Child Left } \\
\text { Behind Act (2002) }\end{array}$ & $\begin{array}{l}\text { Student of the month, National } \\
\text { Honor Society, Honor } \\
\text { Graduate, Principal's list, } \\
\text { Dean's list, student work is } \\
\text { displayed in the room or in a } \\
\text { trophy case in the hallway, }\end{array}$ \\
\hline
\end{tabular}




\begin{tabular}{|c|c|c|c|}
\hline $\begin{array}{l}\text { 6. How is } \\
\text { communication within } \\
\text { the teachers related to } \\
\text { instruction and } \\
\text { instructional activities? }\end{array}$ & $1,2,3$ & $\begin{array}{l}\text { DuFour, R. (2004, } \\
\text { May), DuFour, R., } \\
\text { DuFour, R., Eaker, R., } \\
\text { \& Many, T. (2006), } \\
\text { Ennis, C.D. } \\
\text { (1989),Hord, S. } \\
\text { (1997),. }\end{array}$ & $\begin{array}{l}\text { Teachers are provided a } \\
\text { common planning to enhance } \\
\text { collegiality, professional } \\
\text { learning communities, team } \\
\text { meetings, department } \\
\text { meetings.. }\end{array}$ \\
\hline $\begin{array}{l}\text { 7. Describe how you } \\
\text { assist teachers in } \\
\text { meeting the needs of all } \\
\text { students? }\end{array}$ & $1,2,3$ & $\begin{array}{l}\text { WVDE Policy 2510, } \\
\text { Bamburg (1994) }\end{array}$ & $\begin{array}{l}\text { Work on ways to assure that } \\
\text { instruction is varied every } 20 \\
\text { to } 25 \text { minutes, lesson plan } \\
\text { should include student hands- } \\
\text { on activity during the class } \\
\text { period; provide suggested } \\
\text { activities that can assist in } \\
\text { meeting the planned content } \\
\text { standard. }\end{array}$ \\
\hline $\begin{array}{l}\text { 8. What professional } \\
\text { development activities } \\
\text { are planned for the } \\
\text { school year? }\end{array}$ & 1,3 & $\begin{array}{l}\text { WVDE Policy } 2510, \\
\text { Good \& Brophy } \\
(2003),\end{array}$ & $\begin{array}{l}\text { WESTEST data analysis } \\
\text { determines where instructional } \\
\text { strategies need to focus. In } \\
\text { addition, district wide } \\
\text { initiatives are driven from top } \\
\text { down (i.e., character } \\
\text { education, respect and protect, } \\
\text { RTI, special education paper } \\
\text { work) that need to be } \\
\text { addressed during the PD days. }\end{array}$ \\
\hline $\begin{array}{l}\text { 9. Some say National } \\
\text { Board Certification for } \\
\text { teachers is important to } \\
\text { increase student } \\
\text { achievement in schools, } \\
\text { what is your belief on } \\
\text { National Board } \\
\text { Certification? }\end{array}$ & $1,2,3$ & $\begin{array}{l}\text { National Board for } \\
\text { Professional Teaching } \\
\text { Standards, 2008), } \\
\text { Boyd \& Reese (2006), } \\
\text { Barker \& Robinson } \\
(2001) .\end{array}$ & $\begin{array}{l}\text { The teachers are committed to } \\
\text { students and their learning, } \\
\text { teachers know the subjects } \\
\text { they teach and are highly } \\
\text { qualified, teachers use data to } \\
\text { monitor student learning, } \\
\text { teachers are members of } \\
\text { learning communities. }\end{array}$ \\
\hline
\end{tabular}


Appendix $\mathbf{H}$

Teacher Interview Question Matrix 
Teacher Interview Question Matrix

\begin{tabular}{|c|c|c|c|}
\hline Interview Question & Research Question & Literature Cite & Anticipated Answers \\
\hline $\begin{array}{l}\text { 1. What do you think } \\
\text { the phrase high } \\
\text { expectations means? }\end{array}$ & 1 & $\begin{array}{l}\text { Luyten, Visscher, and } \\
\text { Witziers (2005); Good } \\
\text { and Brophy (2003); } \\
\text { Rosenthal and } \\
\text { Jacobson (1968); } \\
\text { Murnane (1981) }\end{array}$ & $\begin{array}{l}\text { Students are not allowed to } \\
\text { sleep, homework given } \\
\text { daily, students expected to } \\
\text { be responsible and have } \\
\text { assignments completed on- } \\
\text { time (by the due date), and } \\
\text { students stay on task. }\end{array}$ \\
\hline $\begin{array}{l}\text { 2. What are some } \\
\text { activities or traditions at } \\
\text { this school that promote } \\
\text { high expectations? }\end{array}$ & 1,3 & $\begin{array}{l}\text { Lezotte (2001), } \\
\text { WVDE Policy 2510, } \\
\text { Bamburg (1994), } \\
\text { Bolman, L.G., \& } \\
\text { Deal, T.E. (2003). }\end{array}$ & $\begin{array}{l}\text { Homecoming, award } \\
\text { assemblies, student of the } \\
\text { month, coffee with the } \\
\text { principal. }\end{array}$ \\
\hline $\begin{array}{l}\text { 3. What are the ways in } \\
\text { which your curriculum } \\
\text { is aligned with the state } \\
\text { assessment tool? }\end{array}$ & 1 & $\begin{array}{l}\text { Good and Brophy } \\
\text { (2003), WVDE Policy } \\
\text { 2510, English, F.W. } \\
\text { (2010). }\end{array}$ & $\begin{array}{l}\text { Curriculum mapping, access } \\
\text { to ACUITY web site, } \\
\text { professional development } \\
\text { workshops provided by the } \\
\text { WVDE. }\end{array}$ \\
\hline $\begin{array}{l}\text { 4. Tell me some } \\
\text { teaching strategies that } \\
\text { you use so delivery of } \\
\text { content is varied? }\end{array}$ & 1 & $\begin{array}{l}\text { WVDE Policy 2510, } \\
\text { Good \& Brophy } \\
\text { (2003), Bloom's } \\
\text { Taxonomy }\end{array}$ & $\begin{array}{l}\text { Cooperative learning } \\
\text { groups, project based } \\
\text { learning, virtual learning, i- } \\
\text { casting, use of blogs. }\end{array}$ \\
\hline $\begin{array}{l}\text { 5. How are all students } \\
\text { provided the goals and } \\
\text { objectives to each lesson } \\
\text { or unit? }\end{array}$ & 1 & $\begin{array}{l}\text { Good \& Brophy } \\
(2003)\end{array}$ & $\begin{array}{l}\text { Write them on the board, } \\
\text { state them at the start of } \\
\text { each lesson and have them } \\
\text { displayed in the room. }\end{array}$ \\
\hline $\begin{array}{l}\text { 6. How do you provide } \\
\text { meaningful, relevant } \\
\text { feedback to the } \\
\text { students? }\end{array}$ & 1 & $\begin{array}{l}\text { Dusek (1985), Brophy } \\
\text { (1998) and Good \& } \\
\text { Brophy (2003) }\end{array}$ & $\begin{array}{l}\text { Oral probing during Q \& A } \\
\text { time, written responses on } \\
\text { tests and quizzes, body } \\
\text { language such as thumbs up } \\
\text { or high fives. }\end{array}$ \\
\hline $\begin{array}{l}\text { 7. What are some ways } \\
\text { that you recognize and } \\
\text { reward student } \\
\text { achievement? }\end{array}$ & 1 & $\begin{array}{l}\text { Teddlie \& Reynolds } \\
\text { (2000), Jacobson \& } \\
\text { Rosenthal (1968), } \\
\text { Good \& Brophy } \\
\text { (2003), No Child Left } \\
\text { Behind Act (2002) } \\
\end{array}$ & $\begin{array}{l}\text { Student of the day, week or } \\
\text { month, classroom helper, } \\
\text { bumper sticker, stickers, } \\
\text { smiley faces on written } \\
\text { work, bonus points added to } \\
\text { grade, certificates. }\end{array}$ \\
\hline $\begin{array}{l}\text { 8. How visible is the } \\
\text { principal in the building } \\
\text { during the school day? }\end{array}$ & 2,3 & $\begin{array}{l}\text { WVDE Policy 2510, } \\
\text { Teddlie \& Reynolds } \\
\text { (2000), Good \& } \\
\text { Brophy (2003) }\end{array}$ & $\begin{array}{l}\text { Principal is most visible in } \\
\text { the morning, lunch time, and } \\
\text { dismissal. For new teachers } \\
\text { the principal is in the } \\
\text { classroom at least three }\end{array}$ \\
\hline
\end{tabular}




\begin{tabular}{|c|c|c|c|}
\hline & & & $\begin{array}{l}\text { times per semester. } \\
\text { Principal does do a walk } \\
\text { through on occasion. }\end{array}$ \\
\hline $\begin{array}{l}\text { 9. How are teachers } \\
\text { assisted in the } \\
\text { development of lesson } \\
\text { plans that enhance } \\
\text { instructional practices? }\end{array}$ & 3 & $\begin{array}{l}\text { WVDE Policy 2510, } \\
\text { Bamburg (1994) }\end{array}$ & $\begin{array}{l}\text { Principal articulates what is } \\
\text { expected in a lesson plan } \\
\text { prior to completing. When } \\
\text { reviewed, the principal } \\
\text { makes suggestions as to } \\
\text { hands-on activities that } \\
\text { could assist in providing } \\
\text { instruction and gives } \\
\text { additional assistance in how } \\
\text { technology could have been } \\
\text { used in the lesson. Principal } \\
\text { expects the suggestions to be } \\
\text { followed in hopes that the } \\
\text { following set of lessons } \\
\text { incorporates them. }\end{array}$ \\
\hline $\begin{array}{l}\text { 10. How does the } \\
\text { school and/or district } \\
\text { deliver professional } \\
\text { development that is a } \\
\text { part of the 5-year } \\
\text { strategic plan? }\end{array}$ & 1,3 & $\begin{array}{l}\text { WVDE Policy 2510, } \\
\text { Good \& Brophy } \\
(2003)\end{array}$ & $\begin{array}{l}\text { Training on the use of } \\
\text { ACUITY and other state } \\
\text { provide technology support } \\
\text { and enhancement tools, } \\
\text { provides training on } 21^{\text {st }} \\
\text { Century teaching skills. }\end{array}$ \\
\hline $\begin{array}{l}\text { 11.) NBC teacher } \\
\text { question. How has the } \\
\text { NBC process made a } \\
\text { difference to you and } \\
\text { your students in the } \\
\text { classroom? }\end{array}$ & 1 & $\begin{array}{l}\text { National Board for } \\
\text { Professional Teaching } \\
\text { Standards, 2008), } \\
\text { Boyd \& Reese (2006), } \\
\text { Barker \& Robinson } \\
\text { (2001). }\end{array}$ & $\begin{array}{l}\text { Commitment to students } \\
\text { learning and doing whatever } \\
\text { it takes to get them to } \\
\text { succeed, knowledge of } \\
\text { subject matter, belonging to } \\
\text { learning communities both } \\
\text { in and out of school, using } \\
\text { assessment in order to } \\
\text { monitor student progress } \\
\text { and mastery of content (use } \\
\text { of charts and/or } \\
\text { spreadsheets). }\end{array}$ \\
\hline
\end{tabular}


Appendix I

Classroom Observation Form 


\section{Classroom Observation Form}

Y N Description of item, date and time

Varied instructional strategies used

Classroom rules and/or expectations posted

School vision posted

School mission statement posted

Students engaged in hands-on activities

Student time on task maximized

Students actively engaged in the lesson

Student reward and/or recognition system in place

Student work posted in the classroom.

Display of newspaper or other written articles showing student accomplishments or awards.

Teacher articulated the goals and objectives of the lesson

Teacher instruction structured and organized

Teacher has the materials for the lesson

Teacher monitors student progress

Teacher provides feedback

Teacher uses probing to assist students in answering questions

Teacher began class on time

Teacher provided a summary

Teacher accommodates individual learning differences

Teacher has a prepared lesson plan and implemented it

Teacher uses bell ringer or sponge activity

Teacher is at the door or in the classroom greeting students upon arrival to class

\section{NOTES}

This section will be used to provide date and time of the observation. Elaboration of specific details will be completed in anecdotal form. 